



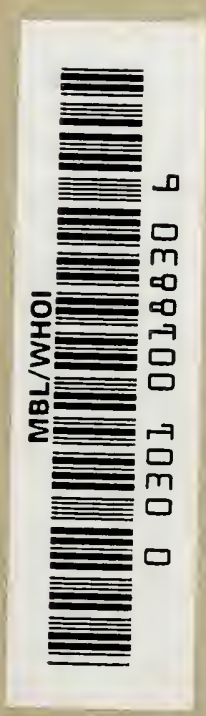





\title{
EINLLITUNG
}

IN DIE

\section{VERGLEICHENDE GEHIRNPHYSIOLOGIE}

\author{
UND
}

\section{VERGLLICHENDE PSYCHOLOGIE.}

MIT BESONDERER BERÜCKSICHTIGUNG

DER WIRBELLOSEN THIERE.

TON

\section{JICQUES LOEB,}

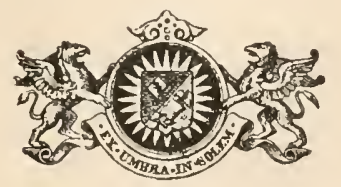

LEIPZIG,

VERLAG VON JOHANN AMBROSIUS BARTH. 1899. 
Von demselben Verfasser:

Der Heliotropismus der Thiere und seine Uebereinstimmung mit dem Heliotropismus der Pflanzen.

- Würzburg 1890. G. Hertz.

Tntersuchungen zur physiologischen Morphologie der Thiere. I. Theil. Heteromorphose.

Würzburg 1891. G. Hertz.

Tntersuchungen zur physiologischen Morphologie der Thiere. II. Theil. Organbildung und Wachsthum.

Würzburg 1892. G. Hertz.

Physiological Archives. I. 1896. II. 1898.

- Chicago. The University Press.

Alle Rechte vorbehalten. 


\section{SEINEN LEIIRERN, DEN HERREN}

\section{PROFESSOR F. GOLTZ UND PROFESSOR N. ZUNTZ}

ZU STRASSBURG I. E.

ZU BERLIN

IN TREUER VEREHRUNG GEWIDMET. 



\section{Vol'wort.}

Die Veranlassung zur Abfassung des vorliegenden kleinen Buches waren meine Untersuchungen über die Tropismen der Thiere. Ich konnte zeigen, dass Heliotropismus, Geotropismus und Stereotropismus nicht nur bei Thieren allgemein vorkommen, sondern dass sie auch hier in all ihren Einzelheiten mit den entsprechenden Tropismen der Pflanzen übereinstimmen. Die Tropismen der Thiere ordnen sich dem Reflexbegriff unter, auf dem ja die ganze Physiologie des Centralnervensystems beruht. Es wird nun im Allgemeinen stillschweigend angenommen, dass alle Reflexe durch specifische Einrichtungen der Ganglien bestimmt sind. Der Nachweis der Identität der thierischen und pflanzlichen Tropismen musste die Berechtigung dieser Annahme in Frage stellen. Es war deshalb nothwendig zu untersuchen, ob nicht die Ganglientheorie der Reflexe eine willkiirliche und unnöthige oder gar falsche Annahme sei. Ich glaube, dass die Thatsachen der vergleichenden Hirnphysiologie die aufgeworfene Frage unzweideutig beantworten.

Die Tropismen der Thiere bilden ferner einen erheblichen Theil in Complex jener Erscheinungen, welche Gegenstand der vergleichenden Psychologie sind. Die Identität der thierischen und pflanzlichen Tropismen zwingt nun dazu, entweder auch bei den Pflanzen Bewusstsein anzunehmen, oder nach einem Kriterium für die Möglichkeit von Bewusstsein bei niederen Thieren zu suchen. In der Litteratur fand ich nichts über den Gegenstand, das mir practisch brauchbar erschien. Seit 5 Jahren habe ich in verschiedenen Abhandlungen den Nachweis zu führen rersucht, dass das assoziative Gedächtniss die Grundlage aller Bewusstseinsthätigkeit sei und dass nur bei solchen Thieren Bewusstscin möglich sei, bei denen sich assoziative Gedächtnissthätigkeit nachweisen lasse. Ich beliaupte nicht, dass ïberall, wo assoziatives Gedächtniss vorhanden ist, auch Bewusstsein vorhanden sein müsse. Dagegen behaupte ich, dass wo der Nachweis von assoziativem Gedächtniss nicht zu führen ist, die Annahme ron Bewusstsein wissenschaftlich unberechtigt und eine reine Gefühlsangelegenheit ist. 
Der Wunsch, meine Arbeiten über die Tropismen nach der Seite der Gehimplyysiologie und rergleichenden Psychologie abzusehliessen, war nicht der einzige Umstand, der mich zur Abfassung dieses Buches reranlasst hat. Ich bin ïberzengt, dass die heutige Schulphysiologie, welche nur ein paar Wirbelthiere beriicksichtigt, durch eine vergleichende Physiologie ersetzt werden muss. In den verschiedenen Thierklassen mit ihrer verschiedenen Organisation hat die Natur ebensoviele Versuche in grossen Maasstab für uns angestellt, welche an Sicherheit und Vollkommenheit Alles übertreffen, was wir mit unseren relativ wenigen Virisectionen leisten können. Wenn die letzteren zur Ergänzung oder Interpretation des Materials dienen, das die vergleichende Physiologie uns liefert, so sind sie werthroll. Wenn man aber glaubt, dass die nothwendig spärlichen, oft unverständlichen oder zweideutigen Vivisectionsversuche an ein paar Wirbelthieren allein die ausreichende Basis für die Physiologie zu bilden im Stande sind, so ist das ein Irrthum.

Der Inhalt des Buches ist schon seit mehreren Jahren von mir in meinen Vorlesungen benutzt worden. Das Manuscript wurde im April 1898 abgesehlossen und im September an die Verlagsbuchlıandlung abgeschickt. Die Litteratur der letzten 6 Monate konnte nicht mehr beriieksichtigt werden. Da keine zusammenbängende Bearbeitung des Gebietes rorlag, und da ich ron neuen Gesichtspunkten ausging, so musste ich mich vielfach auf meine eigenen Versuche oder die meiner Schüler stiitzen.

Der Verlagsbuchhandlung spreche ich für ihr freundliches Entgegenkommen meinen ergebensten Dank aus.

The University of Chicago, Januar 1899.

Jacques Loeb. 


\section{Inhaltsverzeichniss.}

I. Ueber einige Grundbegriffe und Grundthatsachen der vergleichenden Gehimphysiologie . . . . . . . . . . . . . . . . . 1

II. Ueber das Nervensystem der Medusen und über Antomatie und Coordinatıon 10

III. Das Centralnervensystem der Ascidien und die Bedeutung desselben für Reflexe . . . . . . . . . . . . . . 22

IV. Versuche an Aktinien . . . . . . . . . . . . . . 30

V. Versuche an Echinodermen . . . . . . . . . . . . . . 39

VI. Versuche über die Gehirnphysiologie der Wïrmer . . . . . . . . 48

VII. Versuche ïber die Gehirnphysiologie der Arthropoden . . . . . . . 6S

VIII. Versuche an Mollusken . . . . . . . . . . . . . . . 85

IX. Die Segmentaltheorie bei Wirbelthieren . . . . . . . . . . . . $\$ 9$

X. Halbkreuzungen, associirts Stellungsänderungen der Extremitäten und Zwangsbewegungen . . . . . . . . . . . . . . . . . . 101

XI. Bezielnungen zwischen der Orientırung und Function gewisser Elemente der segmentalen Ganglien . . . . . . . . . . . . . 108

XlI. Versuche an Kleinhirn . . . . . . . . . . . . . 115

XIII. Zur Theorie der thierischen Instincte . . . . . . . . . . . . 119

XIV. Centralnervensystem und Vererbung . . . . . . . . . . 132

XV. Kriterien für die Constatirung von Bewusstsein bei niederen Thieren . . 139

XVI. Gehirn und Bewusstsein . . . . . . . . . . . . . . 152

XVII. Centrentheorie (Functionslocalisation) und Segmentaltheorie im Grosshirn 168

XVIII. Theilseelentheorie und Localisation einzelner Erinnerungsbilder . . . . 184

XIX. Ueber einige Angriffspunkte für eine künftige Mechanik der Gehirnthätigkeit 193

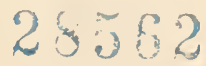





\section{Ueber einige Grundbegriffe und Grundthatsachen der vergleichenden Gehirnphysiologie.}

1) Die Analyse complicirter Erscheinungen besteht in der Zerlegung derselben in einfachere Bestandtheile. Fragen wir, was die einfacheren Bestandtheile in der Physiologie des Centralnervensystems sind, so werden wir auf eine Klasse ron Vorgängen verwiesen, die wir als Reflexe bezeichnen. Unter einem Reflex rersteht man bekanntlich eine Reaction, welche durch einen äusseren Reiz auf das Thier reranlasst ist, und welche in einer geordneten Bewegung endet. Als Beispiel eines einfachen Reflex-Torganges dient das Schliessen des Augenlides auf Berührung der Conjunctiva oder das Verengern der Pupille auf Lichteinfall u. s. f. Die Berührung oder das Licht bringen in den Nerrenendigungen der Conjunctiva oder der Netzhaut chemische Aenderungen herror; die chemische Aenderung (die Erregung) reranlasst eine Zustandsänderung in den Nerven, welche sich im allgemeinen bis in das Centralnervensystem fortpflanzt, von dort auf motorische Nerven übergeht, in den Muskelfasern endet und hier Contractionen reranlasst. Die Gehirnphysiologen haben sich mehr und mehr bemüht, die Analyse der Gehirnfunctionen so durchzuführen, dass die Reflexe die Elemente derselben bilden.

In den Reflexen sieht man im allgemeinen die Ganglienzellen als die wesentlichen Umstände an, welche die Natur der Reaction auf den äusseren Reiz bestimmen. Der Name Reflex weist auf einen Vergleich mit der Lichtreflexion hin. Das Rückenmark ist gewissermaassen der Spiegel, ron dem die ron clen sensibeln Nerren ausstrahlende Erregung auf die Muskeln reflectirt wird. Zerstörung des Rückenmarks macht diese Reflexion unmöglich, wie Zerstörung des Spiegels die Reflexion des Lichtes aufhebt. Der Vergleich des Reflexvorganges im Centralnerrensystem mit der Reflexion des Lichtes ist freilich längst gegenstandslos geworden, und nur Wenige, die den Ausdruck Reflex heute 
in der Physiologie gebrauchen, denken dabei an seine ursprüngliche Bedeutung. Statt dessen ist aber ein anderer Umstand im Reflexbegriff ron Bedeutung geworden, nämlich der zweckmässige Character vieler Reflexbewegungen. Das Schliessen der Augenlider auf Berührung der Cornea ist ron grosser Bedentung für den Schutz der Hornhaut gegen Verletzıng durch Fremdkörper, das Schliessen der Pupille auf Lichtreiz schüitzt die Netzhaut gegen die zerstörende Wirkung grellen Lichtes. Wenn ein decapitirter Frosch einen auf seine Haut gebrachten Tropfen Essigsäure mit der Pfote abwischt, so ist dieser Reflex zweckmässig. Noch ein anderer Umstand fällt bei diesen Reflexen anf: Die ausgeführten Bewegungen sind so wohl berechnet in ihrem Effect und geordnet in ihrer Ausführung, dass ein Stück Intelligenz scheinbar bei ihrer Entstehung oder gar bei ihrer Ausführung im Spiele ist. Ein hervorragender Psychologe hat behauptet, dass die Reflexe als die mechanischen Folgen der Willenshandlungen vergangener Generationen aufzufassen seien, so erkläre sich der zweckmässige Character derselben. Kein Wunder, dass als der wesentliche Umstand im Reflexmechanismus die Ganglienzelle angesehen wird, denn wo sonst könnten solche mechanischen Folgen der Willenshandlungen aufgespeichert werden? Die Nervenfasem sieht man (und wohl mit Recht) als indifferente Leiter an. Aber auch diejenigen, die im Reflexrorgang nur einen rein maschinenmässigen Vorgang sehen und die Zweckmässigkeit desselben vernachlässigen, haben stets die Ganglienzelle als den wesentlichen Träger der complicirten geordneten Bewegungen beim Reflex angesehen.

Ich würde ebensowenig wie irgend ein anderer Physiologe an der Richtigkeit dieser Auffassung gezweifelt haben, wonach die Ganglienzelle ein specifisches und wichtiges Glied in der Mechanik des Reflexvorganges bildet, wenn nicht der ron mir geführte Nachweis der Identität des thierischen mit dem pflanzlichen Heliotropismus die Haltlosigkeit dieser Ansicht bewiesen und gleichzeitig eine andere Auffassung der Reflexe geliefert hätte. Das Fliegen der Motte ins Licht ist ein typischer Reflexvorgang. Das Licht reizt periphere Sinnesorgane oder Hautelemente der Motte, der Erregungsvorgang geht zum Centralnervensystem und von hier zu den Muskeln der Flügel, und das Thier gelangt in die Flamme. Allein dieser Reflexvorgang stimmt Punkt für Punkt überein mit den heliotropischen Wirkungen des Lichtes auf die Pflanzenorgane, die gar keine Nerven besitzen. Die nothwendige Consequenz dieses Nachweises des thierischen Heliotropismus und seiner Identität mit dem pflanzlichen war der Schluss, dass diese Wirkungen nur auf Umständen beruhen können, welche den Thieren und Pflanzen gemeinsam sind. (1.) Ich gab dem am Ende einer Schrift ïber Heliotropis- 
mus in folgenden Worten Ausdruck: "Wir haben gesehen, dass bei Thieren, welche Nerren besitzen, die Orientirungsbewegungen gegen Licht in allen Stiicken durch dieselben äusseren Umstände bestimmt sind und in derselben Weise von der äusseren Körperform abhängen, wie bei Pflanzen, welche keine Nerven besitzen. Folglich können diese heliotropischen Erscheinungen nicht auf specifischen Eigenschaften des Centralnervensystems beruhen." Man hat dagegen eingewendet, dass Zerstörung der Ganglienzellen den Reflexvorgang unterbricht. Aber dieser Einwand ist nicht stichhaltig, da ja der nerröse Reflexbogen bei höheren Thieren die einzige Protoplasmabrücke zwisehen den sensibeln Organen der Körperoberfläche und den contractilen Elementen bildet. Zerstören wir also die Ganglienzellen resp. das Centralnervensystem, so unterbrechen wir im allgemeinen die Continnität der protoplasmatischen Reizleitung zwischen Körperoberfläche und Muskeln, und ohne diese Continuität ist keine Reizleitung zu den Muskeln und kein Reflex mehr möglich. Die Axencylinder des Nerren sind ja in erster Linie nichts als Protoplasmafäden, und die Ganglienzellen sind eben auch protoplasmatische Gebilde. Wir haben erst dann ein Recht und eine Veranlassung, in ihnen mehr als die allgemeinen Protoplasmaeigenschaften zu suchen, wenn wir finden, dass mit den letzteren allein die Erscheinungen nicht zu erklären sind.

2) Man hat nun weiter den Einwand erhoben, dass allerdings diese Reflexe bei Pflanzen obne Nervensystem zu Stande kommen, dass aber bei Thieren Ganglienzellen nun einmal vorhanden sind, und dass sie folglich besondere Reflexmechanismen enthalten. Es war deshalb nöthig zu prïfen, ob es nicht Thierformen giebt, bei denen geordnete Reflexe auch dann noch weiter bestehen, nachdem man ihnen das Centralnerrensystem zerstört hat. Ein solches Resultat war nur bei Formen zu erwarten, bei denen ausser durch das Centralnerrensystem auch noch eine directe Leitung von der Oberfläche zu den Muskeln möglich ist. Das ist beispielsweise der Fall bei Ascidien. Es gelang, den Nachweis zu führen, dass nach Exstirpation des Centralnervensystems bei Ciona intestinalis dennoch die complicirten Reflexe erhalten bleiben (2). Aehnliches stellte sich bei Würmern heraus. Wrr brauchen deshalb auch nicht mehr überrascht zu sein, dass die Blutgefässe der höheren Thiere, auch wenn alle Verbindungen mit dem Centralnervensystem abgeschnitten sind, dennoch ihre sogenannten 'Regulationseinrichtungen, d. h. ihre Reflexe bewahren.

Es ist also ein Ergebniss der vergleichenden Physiologie, dass für Reflexe nur Erregbarkeit und Reizleitung nöthig und dass beide Umständle allgemeine Eigenschaften alles Protoplasmas sind. Die specifische 
Bedentung des Centralnerrensystems, resp. der Ganglienzellen als Träger ron Reflexmechanismen muss fallen. Dagegen tritt eine wichtige Eigenthümlichkeit der Nerven mehr in den Vordergrund, nämlich ihre leichtere Erregbarkeit und ihr besseres und schnelleres Leitungsvermögen. Hierdurch wird ein Thier in die Lage gesetzt, sich besser wechselnden Bedingungen anzupassen, als es ohne Nerven möglich wäre. Für bewegliche Thiere ist ein solches Anpassungsvermögen unumgänglich nöthig.

3) Während einzelne Autoren soweit gehen und bei allen Reflexen auf Grund ihrer Zweckmässigkeit ein psychisches Element voraussetzen, finden wir, dass die Mehrzahl der Forscher das nur bei einer gewissen Gruppe von Reflexen thun, nämlich den sogenamuten Instinkten. Die Instinkte werden verschieden definirt. Aber allgemein handelt es sich um ererbte Reflexe, die nur so merkwürdig zweckmässig und complicirt sind, dass man schwer rerstehen kann, wie etwas Anderes als Intelligenz und Erfahrung zu denselben geführt haben könne. Dahin gehört beispielsweise die Thatsache, dass gewisse Insecten ihre Eier auf solches Material legen, welches die Larven als ihr Futter nöthig liaben. Wenn man bedenkt, dass die weibliche Fliege, nachdem sie ihre Eier gelegt hat, sich nicht mehr weiter um dieselben kümmert, so kann man sich nicht genug über die scheinbare Fürsorge der Natur für die Erhaltung der Arten wundern. Wie kann die Handlung eines solchen Insectes bestimmt sein, wenn das nicht durch geheimnissvolle Strukturen geschieht, die nur in Ganglienzellen möglich sind? Wie können wir uns die Vererbung solcher Instinkte vorstellen, wenn wir es als eine Thatsache ansehen, dass die Ganglienzelle für den Reflexvorgang nur als reizleitendes Element in Betracht kommt? Während der alte Standpunkt nun thatsächlich weder im Stande gewesen ist, eine Mechanik der Instinkte zu entwickeln noch die Vererbung derselben auf ungezwungene Weise zu erklären, wird das gerade durch unsere Auffassung möglich. Unter den Elementen, aus denen diese complicirten Instinkte sich zusammensetzen, spielen die Tropismen (Heliotropismus, Chemotropismus, Geotropismus, Stereotropismus etc.) eine Hauptrolle. Diese Tropismen aber sind identisch für Thiere und Pflanzen. Die Umstände, aus denen sich die Tropismen erklären lassen, sind erstens die specifische Erregbarkeit bestimmter Elemente der Oberfläche und zweitens die Symmetrieverhältnisse des Körpers. Symmetrische Elemente der Körperoberfläche haben gleiche Reizbarkeit, unsymmetrische Elemente haben verschiedene Reizbarkeit. Die dem oralen Pole näheren Elemente haben höhere oder entgegengesetzte Reizbarkeit wie die aboralen. Diese Umstände zwingen die Thiere sich gegen eine Lichtquelle oder Diffusionsquelle chemischer Stoffe etc. so zu orientiren, dass symmetrische Punkte der Körperober- 
fläche gleich intensive Reize crhalten. Dadurch werden die Thiere entweder zur Reizursache hin oder von ihr fort geführt. Für die geheimnissrollen Mechanismen der Ganglienzellen bleibt dabei nichts $7 u$ thun übrig als etwa den Reiz zu leiten, was ja jedes Protoplasma zu leisten rermag. Für die Vererbung der Instinlte braucht das Ei niehts weiter zu enthalten als besondere Stoffe, (welche die verschiedenen Tropismen bedingen) und die Vorbedingungen für die Hauptseitlichkeiten des Embryo. Dic Ganglienzellenmystik hat nicht nur nicht zu bestimmten Einsichten in diese Vorgänge geführt, sondern sich nur als Hemmniss für die Gewinnung weiterer Einsichten erwiesen.

4) Wenn so die Mechanik einer Zahl ron Instinkten auf die Tropismen zurïckgeführt wird, wclche Thieren und Pflanzen gemeinsam sind, und wenn die Bedeutung der Ganglienzellen bei diesen wie bei allen Reflexvorgängen auf rlie Reizleitung beschränkt ist, so müssen wir die Frage aufwerfen, welche Umstände denn die geordneten Muskelbewegungen bei den Reflexen, namentlich den complicirteren, bedingen. Die Annahme complicirter aber unbekannter und vielleicht unergründlicher Structuren in den Ganglienzellen hatte bisher als bequemes Ruhekissen für alles Nachdenken in dieser Richtung dienen können. Mit dem Aufgeben dieser Annahme sind wir gezwungen die Umstände nachzuweisen, welche den geordneten Character der Reflexbewegungen zu bestimmen im Stande sind. Versuche ïber den Galvanotropismus der Thiere haben zu dem Ergebniss geführt, dass eine einfache Bezielıng bestehen muss zwischen der Orientirung nervöser Elemente im Centralnerrensystem (in Bezug auf die Hauptaxen des Körpers) und der Richtung der Bewegung des Körpers, welche durch die Thätigkeit dieser Elemente hervorgerufen wird. Hiermit wird eine rationelle Basis für die weitere Erforschung der Coordination unserer Bewegung geschaffen, wobei der Ganglienzelle keine anderen Leistungen zugemuthet werden als solche, welche jedes einfache protoplasmatische Gebilde auszuführen im Stande ist.

5) Wie wir den Ganglienzellen jede specifische Bedeutung bei den einfachen Reflexen und den Instinkten absprechen müssen (es sei denn, dass sie als protoplasmatische Leiter von Erregungsrorgängen in Betracht kommen), so müssen wir das Gleiche auch für die spontanen Bewegungen thun. Unter spontanen Bewegungen verstehen wir solche Bewegungen, welche anscheinend durch innere Umstände des lebenden Systems bedingt sind. In aller Strenge giebt es aber keine ausschliesslich durch innere Umstände bestimmten Bewegungsvorgïnge lebender Gebilde, da ja Sanerstoffzufuhr von aussen und eine bestimmte Temperatur oder bestimmte Temperaturgrenzen stets nöthig sind, um die Thätigkieit 
ïber kleine Zeiträume hinaus zu erlualten. Davon abgesehen bedarf es aber für die spontanen Vorgänge keiner auffallenden äusseren Reizursachen.

Wir unterscheiden nun zwischen schlechthin spontanen Vorgängen und bewusster Spontanëität. Wir wollen zunächst die ersteren ins Auge fassen. Auch damn haben wir wieder zwei Arten von Vorgängen zu unterscheiden: Einfach spontane und rythmisch spontane, oder automatische. Die letzteren sind die wichtigeren für uns. Athmung und Herzschlag gehören in diese Kategorie. Es ist kein Zweifel möglich, dass automatische Thätigkeit in Ganglien entstehen kann, die Athembervegungen beweisen das. Man hat nun weiterhin daraus geschlossen, dass alle automatischen Bewegungen durch 'Ganglienzellen bestimmt sind, so dass wir hier wieder ein Stïck jener mystischen Einrichtungen dieser Zellen vor uns haben. So soll auch die Herzbewegung durch die letzteren bestimmt sein. Gaskell (3), Engelmann (4) und Andere haben aber zu beweisen versucht, dass die antomatische Thätigkeit des Herzens nicht durch Ganglienzellen bestimmt ist, sondern dass die Bedingungen der Automatie in den Muskelelementen selbst enthalten sind. Die Thatsachen der vergleichenden Hirnphysiologie sind dieser Ansicht nicht ungünstig. Den coordinirten Character der automatischen Bewegungen hat man oft durch die Annahme eines „Coordinationscentrums" erklärt, das eine Art Polizeiaufsicht über die einzelnen automatisch thätigen Elemente fülıren und darauf achten solle, dass sie sich in der richtigen Folge bewegen. Dem gegenüber zeigen die Beobachtungen an niederen Thieren, dass die Coordination automatischer Bewegungen hier einfach dadurch hergestellt wird, dass das am raschesten thätige Element die übrigen zwingt in seiner Periode thätig zu sein.

Noch weniger als die rythmische ist die einfache Spontanëität eine specifische Leistung von Ganglienzellen. Die Schwärmsporen von Algen also pflanzliche Organe, welche keine Ganglienzellen besitzen, zeigen ebensoviel Spontanëität wie die mit Ganglienzellen ausgerïsteten Thiere.

Es fragt sich, wie wir die erwähnten Formen der Spontanëität dem Reflexbegriff subsumiren können. Das ist insofern möglich, als auch bei spontanen Vorgängen eine Veränderung die Ursache der Bewegung ist, und als anch bei diesen Vorgängen im Allgemeinen eine Fortleitung der Erregung stattfindet. Nur ist die Reizursache eine innere.

6) Wir haben bisher die Frage, die am allerwichtigsten ist, nämlich nach den psychischen Eigenschaften der Thiere, noch nicht berührt Wir nennen eine Erscheinung psychisch, wenn sie eine Function des Bewusstseins ist. Aber wie sollen wir entscheiden, ob ein Thier Bewusstsein besitzt oder nicht? Einige Physiologen und Psychologen helfen sich einfach damit, dass sie die Zweckmässigkeit der Handlung 
als Maassstab benutzen. Wenn ein Thier so reagirt wie ein rernunftbegabter Mensch im gleichen Falle thun würde, so erklären diese Autoren, dass es Bewusstsein besitzt. Auf diese Weise werden riele Reflexe, besonders Instinkte, als psychische Leistungen angesehen und selbst dem Rückenmark wird Bewusstsein zugeschrieben, weil manche seiner Leistungen zwcckmässig sind. Wir werden in den folgenden Vorlesungen sehen, dass viele dieser Reactionen nichts als Tropismen sind und genau ebenso bei Pflanzen vorkommen. Dann müssten wir also auch den Pflanzen psychisches Leben zuschreiben. Nan müsste es aber dann auch Maschinen zuschreiben, da die Tropismen ja nur auf einfachen maschinellen Vorrichtungen beruhen. Man gelangt so schliesslich bis zu rlen beseelten Molekïlen und Atomen.

Auf der anderen Seite haben Physiologen, die den metaphysischen und haltlosen Character derartiger Speculationen empfanden, den einzigen Ausweg darin gesehen, die Frage nach der Beseeltheit oder dem Bewusstsein in der Physiologie ganz aus dem Spiele zu lassen und sich einfach auf das Studium der Folgen vou Gehinnoperationen zu beschränken. Das aber heisst das Kind mit dem Bade ausschïtten. Der Felıler der Metaphysiker liegt nicht darin, dass sie sich mit fundamentalen Fragen beschäftigen, sondern darin, dass sie sich einer falschen Forschungsmethode bedienen und Wortspielereien an die Stelle von Sacherklärungen setzen. Wenn die Gehirnphysiologie ihr fundamentales Problem, nämlich die Entwickelung einer Theorie des Bewusstseins, aufgiebt, so schneidet sie sich damit die Quelle ab, aus der ihre besten Früchte stammen. Dagegen ist es nöthig, den Irrweg der Metaphysik zu rermeiden und Methoden zu wählen, welche zu Sacherklärungen und nicht zn Wortspielereien führen. Diese Methode ist für die Thierpsychologie dieselbe wie für die Gehirnphysiologie und sie besteht in der richtigen Erkenntniss des Grundvorganges, der in allen psychischen Vorgängen als elementarer Bestandtheil wiederkehrt und lier dieselbe Rolle spielt, wie der Reflex im Thatsachengebiet der Gehimphysiologie. Dieser Vorgang ist meiner Ansicht nach die associative Gedächtnissthätigkeit. Was wir als Bewusstsein bezeichnen, ist nur eine Function associativer Gedächtnissthätigkeit. „Dabei verstehe ich unter associativem Gedächtniss diejenige Einrichtung, durch welche eine Reizursache nicht nur die ihrer Natur und der specifischen Structur des reizbaren Gebildes entsprechenden Wirkungen herrorbringt, sondern ausserdem auch noch solche Reizwirkungen anderer Ursachen, welche früher einmal nahezu oder völlig gleichzeitig mit jenem Reiz an dem Organismus angriffen." (6). Wenn ein Thier dressirt werden, wenn es lernen kann, so ist associatives Gedächtniss rorhanden, und dann kann es Bewusstsein besitzen. Mit Hülfe 
dieses Kriteriums lässt sich zeigen, dass bei Infusorien, Cölenteraten und Würmern keine Spur eines associativen Gedächtnisses, und deshalb auch kein Bewusstsein vorhanden ist. Bei Insecten und Mollusken ist die Frage im Einzelnen noch nicht entschieden. Fest steht nur, dass zahlreiche Wirbelthiere Bewusstsein besitzen können. Dieses Kriterium dürfte sich von grossem Nutzen für die Entwickelung der vergleichenden Psychologie erweisen, da jetzt die fruchtbare und leicht lösbare Aufgabe gestellt ist, zu untersuchen, welche Repräsentanten der einzelnen Thierklassen associatires Gedächtniss besitzen und welche nicht. Die Ausführung dieser Áufgabe wird den Inbalt einer künftigen vergleichenden Psychologie bilden.

7) Unserom Kriterium gegenüber fällt die metaphysische Theorie der Allbeseeltheit der Materie oder der ganzen Thierwelt, ebenso wie die Beseeltheit des Rückenmarks vor ihr keinen Bestand hat. Auch die Annahme, dass die zweckmässigen Reflexe und Instinkte ein psychisches Element enthalten, wird ihr gegenüber unhaltbar. Wenn Zweckmässigkeit ein Kriterium für Bewusstsein wäre, so müsste ja auch die Organbildung als ein bewusster Akt aufgefasst werden, da ja hier bekanntlich die Zweckmässigkeit womöglich noch schlagender ist als bei den Instinkten und Reflexen. An die Stelle der Allbeseeltheit der Thierformen nuss also die Theorie treten, dass nur bestimmte Thierarten Bewusstsein besitzen, und dass bei ihneu das Bewusstsein auch nur dann auftritt, sobald sie ein bestimmtes embryologisches Entwickelungsstadium erreicht haben. Das erklärt sich daraus, dass das associative Gedächtniss an bestimmte maschinelle Vorrichtungen geknüpft ist, die nur bei bestimm. ten Thieren und bei diesen auch nur von einem bestimmten Stadium ihrer embryologischen Entwickelung an vorhanden sind. Mit diesen Ansichten stimut die Thatsache, dass es bei Wirbelthieren ein Organ giebt, dessen Zerstörung das associative Gedächtniss und nothwendig nur dieses beseitigt, nämlich das Grosshirn. Wir finden ferner, dass solche Wirbelthiere, bei welchen das associative Gedächtniss gar nicht oder nur schwach entwickelt ist (wie z. B. beim Haifisch oder Frosch) nach Verlust ihres Grosshirns sich in ihren Reactionen vom normalen Thier gar nicht, resp. wenig unterscheiden. Der Umstand, dass nur bestimmte Thiere die für das associative Gedächtniss (und damit das Bewusstsein) nöthigen maschinellen Vorrichtungen besitzen, ist nicht befremdender als der Umstand, dass nur bestimmte Thiere die maschinellen Vorrichtungen besitzen, um die von einem leuchtenden Punkte des Raumes ausgehenden Strahlen in einem Punkt ihrer Iichtempfindlichen Organe zu rereinigen. Im Vorgange der Verflüssigung der Gase lehrt uns die Physik die Möglichkeit sprungweiser Zustandsänderungen bei stetiger 
Aenderung einer Variabeln kemnen. Es wäre widersinnig, wenn wir die Möglichkeit sprungweiser Aenderungen in der belebten Natur leugnen wollten.

Nicht alle, aber vicle Reflexe sind zweckmässig. Diese Zweckmässigkeit ist ein fundamentales physiologisches Problem. Aber ich bin der Heinung, dass weder die Anthropomorphismen der ,natürlichen Zuchtwahl" noch die meist metaphysischen Speculationen der Lamarckianel uns hier weiter helfen. Ich glaube, dass besonders die physikalische Chemie berufen ist, uns die einstweilen noch fehlenden Einsichten zu gewähren.

Als höchstes und wesentliches Ziel der Gehirnphysiologie dürfen wir wohl eine Mechanik der Hirnthätigkeit und ganz besonders der associativen Gedächtnissthätigkeit hinstellen, da ja das Bewusstsein nur eine Function des letzteren ist. Die heute herrschenden Anschauungen über die Localisation der Functionen in der Grosshirnrinde behandeln das Erinnerungsbild wie einen Stoff, welcher in einer Zelle oder in einer Gruppe ron Zellen deponirt wird. In einer künftigen Jechanik der Gehirnthätgkeit wird wohl eine dynamische Theorie des Erinnerungsbildes an die Stelle der gegenwärtigen stofflich-histologischen Theorie desselben treten müssen.

\section{Litteratur zu I.}

1) Loeb, J. Der Heliotropismus der Thiere und seine Uebereinstimmung mit dem Heliotropismus der Pflanzen. Würzburg 1890.

2) Loeb, J. Untersuchungen zur physiologischen Morphologie der Thiere II. Würzburg 1892.

3) Gaskell, W. H. On the innervation of the heart. Journal of Physiology Vol. 4. 1883.

4) Engelmann, Th. W. Beobachtungen und Versuche am suspendirten Herzen. Pflügers Archiv, Band 56, 1894. 1869.

5) Engelmann, Th. W. Zur Physiologie des Ureters. Pflügers Archiv, Band 2,

6) Loeb, J. Beiträge zur Gehirnphysiologie der Würmer. Pflügers Archiv Band 56, 1894. 
II.

\section{Ueber das Nervensystem der Medusen und über Automatie und Coordination.}

1) In einem kleinen Buche „Jelly-fish Star-fish and Sea-Urchins" hat Romanes eine Reihe schöner Versuche ïber die Functionen des Nerrensystems dieser Thiere mitgetheilt, von denen wir einige über Medusen hier wiedergeben wollen. Der Schirm der Medusen besitzt an der convexen Innenseite eine sehr dünne Lage von Muskelfasern, die sich ryth-

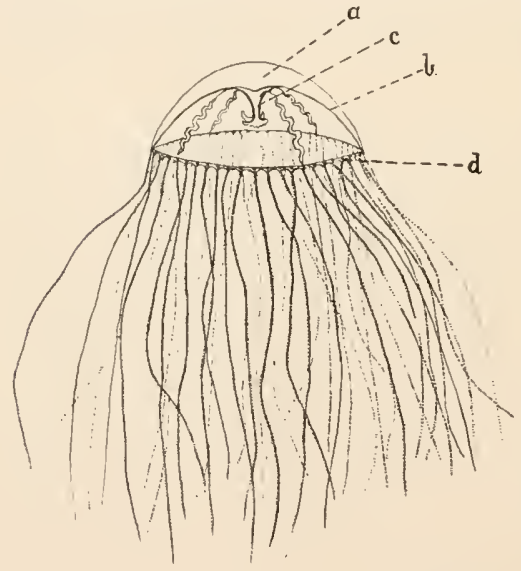

Fig. 1. Hydromeduse.

(Gonionemus vertens,) misch contrahiren. Bei dieser Contraction wird der Hohlraum des Schirmes rerkleinert und Wasser aus demselben herausgepresst. I) urch den Riickstoss, den das Thier dabei erleidet, bewegt es sich vorwärts. In Bezug auf das Nerrensystem müssen wir die Medusen in 2 Klassen theilen, die auch systematisch ron einander getrennt sind: Erstens die freischwimmenden Medusen der $\mathrm{Hy}_{y}$ droidpolypen (Hydroidea) (Fig. 1.) und zweitens die Acalephen, deren einer Vertreter, die Ohrenqualle (Aurelia aurita) (Fig. 2.), auch dem zoologischen Laien bekannt ist. Das Nera Schirm, b Subumbrella mit IIuskeln, c Manubrium, d Rand der Schwimmglocke mit dem Nervenring. rensystem der Hydroidea besteht aus einem am Rande des Schirmes ( $d$ Fig. 1.) angebrachten doppelten Nervenring. Der obere Nervenring bildet meist eine flache Schicht im Ectoderm und besteht aus feinen Fasern mit spärlichen Ganglienzellen. Der untere Nervenring hat dickere Fasern und melır Ganglienzellen als der obere Ring. Beide Nervenringe sind durch Nervenfasern verbunden. Ausser diesem Ring, der als Centralnervensystem bezeichnet wird, existirt noch ein sogenanntes 
peripheres Nervensystem, das als Plexus (bestehend aus Fasern und Ganglienzellen) sich in der ganzen Subumbrella (b Fig. 1) rerbreitet. Es liegt zwischen dem Epithel und Muskellager. Die convexe Oberfläche des Schirmes besteht aus nicht contractiler gelatinöser Masse und hier sind auch keine nerrösen Elemente zu entdecken.

Bei den Acalephen (Fig. 2) haben wir keinen geschlossenen Nervenring, der den ganzen Schirmrand umzieht, sondern eine Reihe getrennter Centren ( $S$ Fig. 2), die unter einander nicht durch Commissuren in Verbindung stehen. Die Zahl der Centren entspricht (bei Aurelia aurita wenigstens) der Zahl der Sinnesorgane S. Diese Nerrencentren liegen ebenfalls am Rande des Schirmes und zwar im Ectoderm ron Stiel und Basis der Randkörper (Sinnesorgane). Die-

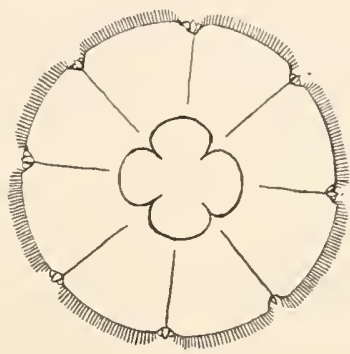

Fig. 2. Diagramm des Schirmes von A urelia a urita mit 8 Sinnesorganen S. Nach Claus. ses Nervensystem enthält keine Ganglienzellen, sondern nur besondere Epithelzellen, von denen Fortsätze ausgehen, die als Nervenfasern bezeichnet werden. Auch soll ein peripheres Nerrengeflecht in der Muskulatur der muteren Schirnwand rorhanden sein.

Romanes hat num gefunden, dass wenn man bei einer Qualle der $\mathrm{Hy}_{-}$ droidpolypen (Hydroidea) den Rand der Glocke ( $b$ Figur 3) abschneidet, die rhythmischen Contractionen der Glocke (a Fig. 3) aufhören, wälırend der Rand $b$, welcher den Nervemring enthält, ungestört fortfährt, rhythmische Contractionen auszuführen. Die Verwundung bringt nicht einmal eine Verminderung in der Zahl und der Energie der Contractionen des Randes hervor. Der Versuch ist von anderen Autoren mit dem gleichen Erfolg wiederholt worden, und ich habe mich ebenfalls von der Richtigkeit der Angabe

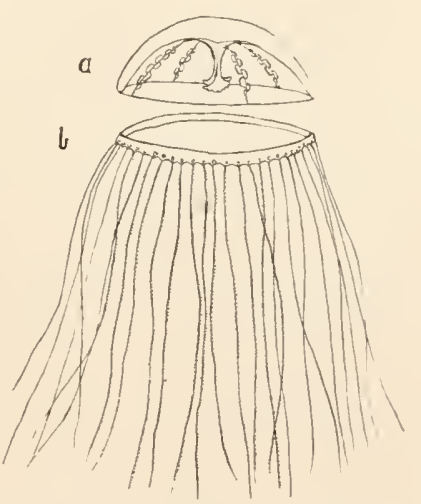

Fig. 3. Durchschneidungsversuch bei einer Hydromeduse.

Der abgeschnittene Rand $\mathrm{b}$ der Meduse fährt fort, sich rhythmisch zu contrahiren, wälırend die Glocke a sich nicht mehr contrahirt. ron Romanes ïberzengt. Man kann den Schirm einer solchen Qualle beliebig verwunden. So lange der Schirmrand, d. Ir. der Nerrenring, intact bleibt, gehen die rhythmiselıen Contractionen ungestört ror sich. 
Es scheint also, dass der den Nerrenring enthaltende Rand der Qualle der Sitz der rhythmischen Thätigkeit ist. Ich finde aber, dass das Gesagte nur für die ersten 48 Stunden nach der Operation gilt. Nach dieser Zeit kann die rhythmische Thätigkeit wieder beginnen.

Weiterhin suchte Romanes sich davon zu überzengen, wie viel vom Rande erhalten bleiben muss, um die rhythmischen Bewegungen des Schirmes zu erhalten. Er fand, dass wenn nur ein einziges Stiickchen des Randes übrig ist, dasselbe geniigt, um die spontane, automatische Thätigkeit der Qualle zu unterhalten. Es scheint also, dass jedes Element des Randes als ein Centrum für dic rlyythmischen Contractionen der ganzen Meduse angesehen werden kann.

Die Versuche an Acalephen, z. B. Aurelia aurita, aber ergaben das Resultat, dass nach Abschneiden des Schirmrandes die rhythmischen Bewegungen beider Theilstiicke ununterbrochen weitergehen. Nur ganz vorübergehend (d. h. einige Secunden oder Minuten) mag nach der Abtrennung des Schirmrandes die Meduse ruhig liegen, dann aber beginnen die rhythmischen Contractionen wieder. Man kann die Abtrennung des Randes hier mit der Stannius'schen Abtremnung des Sinus venosus beim Froschherzen vergleichen, welche ja auch nur einen vorïbergehenden Stillstand der rhythmischen Thätigkeit bedingt. Diese vorübergehende Shockwirkung nach Abschneiden des Randes ist nach Romanes allein bedingt durch das Abtrennen der Theile des Randes, in denen die sogenannten Tervencentren gelegen sind, nämlich der Sinnesorgane (S Fig. 2). Wir sehen also hier, dass bei denjenigen Formen der Medusen welche das höher entwickelte Nervensystem enthalten, nämlich den $\mathrm{Hy}$ droidea, die rhythmische Spontanëität ausschliesslich in dem Theil localisirt ist, der den Nervenring enthält, nämlich im Rand, während bei den Acalephen mit dem weniger entwickelten Nervensystem jedes Element des Schirmes Sitz automatischer Erregung ist.

2) Der zweite Umstand, der bei dieser automatischen Thätigkeit ron Interesse ist, ist die Coordination der automatischen Thätigkeit. Darunter verstehen wir die Erscheinung, dass der ganze Schirm sich gleichzeitig zusammenzieht, dass also nicht beispielsweise ein Theil des Randes sich in Systole befindet, während gleichzeitig ein anderes Element in Diastole ist. Diese Coordination ist keineswegs selbstverständlich. Romanes hat anch darauf hingewiesen, dass diese Coordination nur bei gesunden Individuen rorkommt. Bei rerletzten oder geschwächten Individuen bemerkt man in der That einen Mangel an synchronischer Thätigkeit der Eleniente. Die Frage nach dem Mechanismus der Coordination ist aber deshalb für uns von besonderer Bedeutung, weil ja die Erscheinung der coordinirten Bewegungen bei höheren 
Thieren noch ein vollkommenes Räthsel ist. Die Lösung dieses Rüthsels liegt für Vielo in der Annahme eines mysteriösen, nervösen Centrums, das diese Coordination besorgen soll. Wir werden gleich in der Lage sein zu entscheiden, ob die Coordination bei niederen Thieren durch ein besonderes "Coordinationscentrum" besorgt wird oder ob sie nicht vielmehr die Folge von einfachen Gesetzen der Erregung und Reizleitung ist.

Romanes fand, dass wenn man durch radiale Einschnitte in den Rand einer Acalephe jede directe Verbindung zwischen den nerrösen Centren unterbricht, auch die Coordination aufhört. In dem Falle contrahiren sich die einzelnen Sectoren nicht mehr synchron. Dasselbe geschieht durch ähnliche Einschnitte bei den Hydromedusen, wobei also die Leitung durch den Nervenring unterbrochen wird. Nur muss in allen Fällen der radiale Einschnitt weit genug hinauf reichen. Macht man aber derartige Einschnitte in den Schirm der Hydromedusen, ohne den Rand und den Nervenring zu rerletzen, so findet keine Coordinationsstörung statt. Die Continuität der im Randtheil des Schirmes gelegenen Gebilde ist also für die coordinirte Thätigkeit eine Bediingung. Wie kommt es nun, dass, so lange diese Continuität gewährt ist, alle Elemente synchron thätig sind, während die Synchronie nach Unterbrechung der Continuität verloren geht? Um diese Frage zu beantworten, müssen wir uns an ein Organ wenden, das die Erscheinungen der coordinirten ryhthmischen Thaitigkeit in der wunderbarsten Weise zeigt, nämlich das Herz. Es ist bekannt, dass wenn man das Her'z eines Frosches in verschiedene Stiicke schneidet, dieselben alle rhythmisch thätig sein können, dass jedoch die Zahl der Contractionen in den verschiedenen Stiicken ungleich ist. Die grösste Zahl hat der abgeschnittene sinus venosus, und zwar ist die Zahl seiner Contractionen diejenige, mit der das Herz vor der Durchtrennung schlug. Man sieht also, dass das ganze Herz mit dem Rhythmus desjenigen seiner Theile schlägt, welcher die maximale Zahl der Contractionen in der Minute besitzt. Es liegt also nahe anzunehmen, dass die Coordination der Herzthätgkeit dadurch zu Stande kommt, dass der Theil, welcher sich am häufigsten contrahirt, die anderen Theile zwingt, in gleichem Rhythmus thätig zu sein. Hierzu ist es nur nöthig, dass die Erregung des sinus venosus auch jedesmal erregend auf die übrigen Herztheile wirkt, wodurch dieselben sich nothwendigerweise im gleichen Rhythmus contrahiren müssen. Ein Coordinationscentrum ist deshalb ganz überflïssig. Bei den Medusen findet also sy̌nchrone Contraction aller Theile statt, wenn der Reiz ron dem zuerst erregten oder thätigen Theile des Randes sich rasch genug auf den Rest 
des Randes fortpflanzen kann. Das ist nur möglich, wenn der Rand unverletzt ist. Dabei aber handelt es sich offenbar nicht um den Nervenring allein, sondern auch um das benachbarte Gewebe, weil ja der radiale Einschnitt recht weit gegen das Centrum geführt werden muss, wenn die Coordination auflıören soll. Muss aber die Erregungswelle sich im Zickzack un die eingeschnittenen Stellen herum fortpflanzen, so hat jede Stelle zwischen zwei Einschnitten Zeit, sich selbstständig zu contrahiren. Daher der Mangel an Synchronie. Auch bei verletzten oder absterbenden Medusen, wo die Zellen in weniger engem Anschluss an einander stehen, kommt es zu uncoordinirter rhythmischer Thätigkeit.

Um diese Ansicht weiter zu prüfen, schlug ich Dr. Hargitt, der in meinem Laboratorium arbeitete, vor, den Versuch zu machen, zwei Hydromedusen zusammenzuheilen, und zuzusehen, ob sie nach der Zusammenheilung synchron oder unabhängig zu schlagen fortfahren. Zu diesem Zwecke war es nöthig, den Rand abzuschneiden, um sie zu immobilisiren und eine Wundfläche zu gewinnen. Die beiden so verstïmmelten Medusen wurden dann mit den Schnitträndern an einander gelegt und künstlich zusammen gehalten. Solche Thiere heilten in kurzer Zeit zusammen. Fig. 4 zeigt zwei so zusammengeheilte Gonionemus. Die Verwachsung erfolgt bei diesen zwei Thieren am ganzen Schnittrand mit Ausnahme eines kleinen Stückes bei 0. Hier würden sich wohl mit der Zeit neue Tentakel gebildet haben, wenn wir das Thier nicht (um es zu conserviren) getötet hätten. Bei anderen Formen erfolgte die Verwachsung nicht in so ansgedehnter Weise. Es ergab sich nun, dass die Thiere, die in grosser Ausdehnung zusammen rerwachsen waren, wie das in Fig. 4 gezeichnete, jedesmal wie ein einziges Thier sich synchron contrahirten, und zwar bereits zwei Tage nach der Operation. Die Thiere dagegen, die nicht so ausgedehnt zusammengeheilt waren, contrahirten sich nicht synchron. Ich glaube, dass, wenn es gelänge zwei Herzen völlig zusammenzuheilen, sie auch synchronisch schlagen würden.

Die Erklärung der Coordination, die wir hier versucht liaben, weicht von der von Romanes gegebenen ab. Romanes ninmt an, dass alle oder die meisten Ganglia dieselbe Zeit für ihre Ernährung brauchen und dass sie gleich sind in Bezug auf die Widerstände, die das benachbarte Gewebe ihnen entgegensetzt. Sie müssen so alle gleichzeitig schlagen. Er giebt aber selbst zu, dass es an positiven Beweisen für diese Ansicht fehlt, und dass der erwähnte Versuch mit den radialen Einschnitten nicht für seine Auffassung spricht. Mr. Hargitt's Versuch spricht ebenfalls gegen die Ansicht von Romanes. 
Wir wollen aber hier noch eine Bemerkung über die Coordination der Herzthätigkeit hinzufügen, die unsere Auffassung bestärkt, dass das Organ, welches die meisten Contractionen in der Zeiteinheit ausführt, die Zahl der Contractionen des Ganzen bestimmen muss, rorausgesetzt, dass die Leitungsverhältnisse in allen Richtungen die gleichen sind. Denken wir uns das Froschherz in einen langen Schlauch ausgezogen, so dass es dem embryonalen Herzen vergleichbar ist, so folgen sich in diesem Schlauche die Hauptbestancltheile in folgender Ordnung: Sinus venosus, Vorhof, Ventrikel, Bulbus aortae. Da aber die Zahl der automatischen Contractionen im Sinus venosus grösser ist als im Bulbus aortae, so müssen sich die

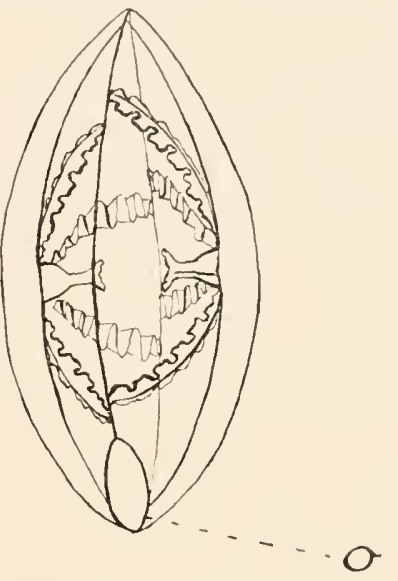
Contractionswellen stets in derselben Richtung über das Herz hin ausbreiten, näm- 2 Gonionemus, deren Pänder ablich rom Sinus zum Bulbus. Denken wir gesthnitten waren, werden mit uns aber die antomatische Thätigkeit des ihren Schnittllächen an einander Bulbus wachsen, bis sie die des Sinus er- gelegt und zusammengeheilt. Nur reicht, so müssen wir, wenn meine Voraussetzungen richtig sind und die Leitungsfähigkeit des Her'zschlanches in beiden Rich- synchron, wie ein einziges Thier. tungen die gleiche ist, ein Organ ron der

Eigenschaft des Ascidienherzens (Fig. 5) erlangen. Das letztere ist bekanntlich dadurch ansgezeichnet, dass sich die Contractionswellen nicht wie im Herzen der iibrigen Thiere stets in einer Richtung hin ausbreiten, sondern dass ahwechselnd bald peristaltische, bald antiperistaltische Contractionswellen an ihm ablaufen. Wenn es sich beispielsweise 500 Mal hinter einander von links nach rechts contrahirt und sein

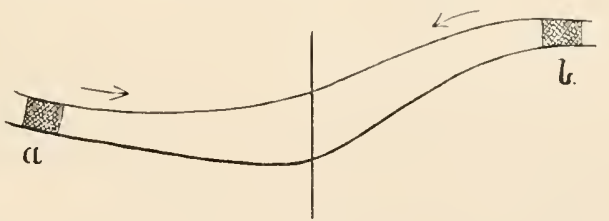

c.

Fig. 5. Diagramm tles Ascidienherzens. Im Ascidienherzen erfolgen eine Zeit lang Contractionen in der Richtung von a nach $b$ und dann von b nach a. Durchschneidet man es aber in der Mitte bei c, so contrahirt sich die linke Hälfte nur in der Richtung von a nach $c$, die rechte Hälfte nur in der Richtung von $b$ nach $c$. Blut nach rechts schickt, so folgen dieser Thätigkeit sagen wir 300 Pulsationen ron rechts nach links, wobei das Blut also in umgekehrter Richtung wie 
rorhin durch das Gefässsystem fliesst. Dann folgen wieder eine grössere Zahl ron Pulsationen von links nach rechts u. s. f. Dr. Lingle hat nun vor sechs Jahren in Woods Holl die folgenden Versuche am Ascidienherzen angestellt. Ist $a b$ (Fig. 5) das Ascidienherz und schneidet man es bei $\mathrm{c}$ durch, so contrahiren sich beide Stïcke a c und b c ununterbrochen in constanter Richtung, jenes in der Richtung ron a nach c, dieses in der Richtung ron $b$ nach $c$. Ferner hat Dr. Lingle noch festgestellt, dass die Quelle der automatischen Thätigkeit anf zwei kleine Regionen bei a und bei b beschränkt ist, die etwa dem sinus renosus und dem bulbus aortae des Froschherzens entsprechen. Schnitt er diese beiden Stiicke aus dem Herzen herans, so schlugen sie ununterbrochen weiter, während das dazwischen liegende lange Mittelstück nicht mehr pulsirte. Diese Versuche lassen, wie mir scheint, keinen Zweifel daran, dass der Wechsel der Contractionsrichtung im Ascidienherzen dadurch bedingt ist, dass abwechselnd das cine der beiden Herzenden die Oberhand gewinnt und dann das andere Centrum für eine Zeit lang zwingt, in seinem Rhythmus mit thätig zu sein. Dieses , die Oberhand gewinnen“ dürfte aber möglicher Weise in nichts Anderem bestehen, als dass es Zeit gewinnt, eine Erregung oder resp. Contractionswelle abzusenden, ehe das andere Ende mit der Contraction beginnt. Dazu ist es nur nöthig, dass einmal ein einzelner Herzschlag bei dem gerade führenden Ende des Herzens sich etwas verzögert oder ganz ausfällt, was ja auch bei menschlichen Hejzen gelegentlich beobachtet wird. Alsdann wird das andere Herzende Zeit gewinnen, eine Contractionswelle auszusenden, und seine automatische Erregung wird so lange die Reizursache für die Erregung des anderen Endes werden, bis eine Verspätung oder ein Ausfall einer Contraction eintritt, wodurch das andere wieder Zeit gewinnt, automatisch thätig zu werden u. s. f.

3) Die Versuche ron Romanes erwecken den Eindruck, als ob die automatische Thätigkeit bei den Medusen von den Ganglien des Randes ausyinge. Ein zwingender Grund für diese Annahme ist bei den Acalephen aber sicher nicht rorhanden, da ja jeder Theil des Schirmes hier antomatisch thätig sein kann. Wir wissen, dass das embryonale Herz antomatisch thätig ist, lange ehe es Ganglienzellen enthält. Engelmann hat eine Reihe rou Thatsachen angeführt, die darauf hinweisen, dass selhst im Herzen des Erwachsenen die Muskelelemente Sitz automatischer Thätigkeit sind. Bei Infusorien haben wir automatische Contractionen der Vacuole, ohne dass hier Nervenelemente rorhanden wären. Tom Standpunkt der vergleichenden Physiologie hat also der Gedanke, dass automatische Thätigkeit nicht nothwendig an Ganglienzellen gebunden zu sein brancht (selbst wenn solche rorhanden sind), nichts Befremden- 
des. Anderseits dagegen kennen wir Fälle, in denen die automatische Thätigkeit sicher von nervösen Elementen ausgeht, nämlich bei den Athemcentren.

Was nun die Ursache der rhythmischen Thätigkeit betrifft, so hat meines Wissens zuerst J. Rosenthal darauf hingewiesen, dass es kcineswegs nöthig ist, dass eine rhythmische Erseheinung anch eine rhythmische Ursache hat, sondern dass constante Umstände sehr wohl zu rhythmisehen Wirkungen führen können. Wenn in eine Pipette Wasser

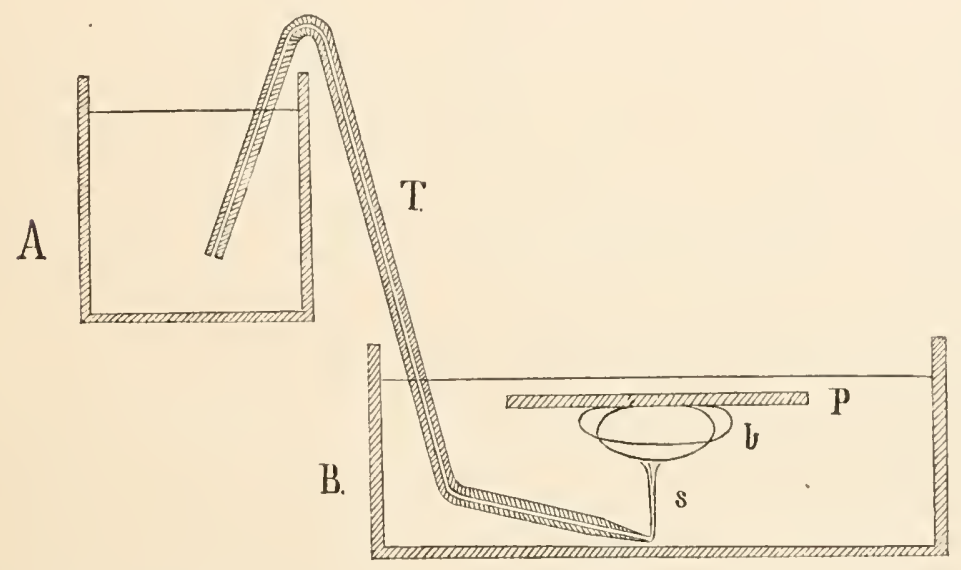

Fig. 6. Vorrichtung zur Herstellung antomatisch pulsirender Luftblasen.

Siehe Text.

constant in einem sehr schwachen Strom einfliesst, so wird der Ausfluss rhythmisch (in Tropfen) erfolgen. Das Gewicht des Tropfens muss grösser sein als die Oberflïchenspannung in der Peripherie der Ausflussüfnnung, ehe der Tropfen abreissen kann. So lange die Quantität Wasser, lie in der Zeiteinheit einfliesst, unter einer gewissen Grenze bleibt, wird es immer eine Zeit lang dauern, ehe der Tropfen schwer genug ist, um abzureissen. Quincke hat eine einfache und elegante Methode angegeben durch die es sehr leicht ist, Luftblasen zu rhythmischen Contractionen zu veranlassen. Ich will den Versuch so mittheilen, wie ich ihn in der Vorlesung zeige. In einem mit Wasser gefüllten Gefässe B (Fig. 6) befindet sich eine Glasplatte P und unter derselben eine Luftblase b von etwa $5 \mathrm{~mm}$. grösstem Durchmesser. Unter der Blase, im Centrum derselben, mündet die (in eine enge Oeffnung ausgezogene) Thermometerröhre $\mathrm{T}$, deren oberes Ende in das mit 95procentigem $\Lambda$ lcohol gefüllte Gefüss A taucht. Der Alcohol steigt in einem dünnen Strahle $\mathrm{S}$ gegen 
18 Ueber das Nervensystem der Medusen und über Automatie und Coordination.

das Centrum ler Blase. Sobald der Alcohol mit der Luftblase in Berührung kommt, breitet er sich an der Grenze zwischen Luft und Wasser aus, weil die Summe der Oberflächenspannungen zwischen Luft und Alcohol und Alcohol und Wasser kleiner ist als die Oberflächenspannung zwischen Luft und Wasser. Durch diese Abnahme der Oberflächenspannung wird die Luftblase niedriger und breiter. Infolge der mit der Ausbreitung rerbundenen Wirbelbewegungen im Wasser wird der Zufluss des Alcohols zur Luftblase unterbrochen. Die die Luftblase umgebende Alcoholschicht diffundirt rasch ins umgebende Wasser und die Luftblase wird wieder höher, entsprechend der grösseren Oberflächenspannung zwischen Wasser und Luft. Der Zufluss des Alcohols zur Luftblase wird, da die Wirbelbewegungen nunmehr aufgehört haben, wieder möglich und von Nenem findet das Flachwerden der Luftblase statt u. s. f. Unter den angegebenen Bedingungen erhielt ich bei Zimmertemperatur etwa 80 Pulsationen der Luftblasen in der Minute, also ungefähr die Periodicität des Herzens (4).

Was num die Entstehung der rlıythmischen Thätigkeit der Medusen des Herzens und der Athemthätigkeit betrifft, so kann man sich leicht vorstellen, dass dem constanten Zufluss des Alcohols im Quincke'schen Versuche eine stetige fermentative Erzengung von Stoffwechselproducten durch Wärmezufuhr von aussen in den automatisch thätigen Zellen entspricht. Diese Stoffe können recht gut von der Art sein, dass sie Ausbreitungserscheinungen in den Zellen herbeiführen wie im Quincke'schen Versuch. Aber es muss erst eine gewisse Quantität dieser Stoffe vorhanden sein, ehe es zu einer Ausbreitungserscheinung kommt. Daher die Periodicität. Es ist unmöglich einzusehen, warum solche Erscheinungen ausschliesslich in Ganglienzellen erfolgen sollten, wie es die alte Meinung in der Physiologie verlangt und warum nicht ebenso gut Ausbreitungserscheinungen in Muskelzellen oder andern Zellen von Statten gehen sollten. Freilich ist es nur eine Vermuthung, dass geradeAusbreitungserscheinungen den Anstoss zur rhythmischen Thätigkeit geben.

4) Der Leser weiss wohl aus eigener Anschauung, was geschieht, wenn man eine Stelle des Rückens eines Frosches mit einem Tropfen verdünnter Essigsäure betupft: der Frosch bringt den Fuss zur gereizten Stelle und wischt die Säure ab. Bindet man ein Bein fest, so benutzt er ein anderes zu dem Zweck. Aehnlich benimmt sich die Schildkröte, wenn man die Essigsäure auf den Rückenpanzer tupft. Sie kann den gereizten Punkt nicht erreichen, aber die Beine bewegen sich unter dem Panzer so weit als möglich dorsal gegen den gereizten Punkt. Die Physiologie begnïgt sich diesen Erscheinungen gegenüber mit dem Hin- 
weis auf die unnachahmliche Complicirtheit und die unergründlichen Strukturgeheimnisse des Centralnervensystems. Und doch haben wir dieselben Reactionen bei einer Hydroidmeduse, bei der der Ausdruck Centralnervensystem nur eine conventionelle Bedeutung hat. Reizt man bei Tiaropsis indicans mit einer Nadel einen Punkt a (Fig. 7) der concaren Seite des Schirmes, so wird das Manubrium an die berührte Stelle gebracht (Fig. 7 ), als wollte das 'Thier den irritirenden Körper entfernen. Diese Bewegung kommt so zu Stande, dass in demjenigen Meridian des Schirmes $a b$, welcher durch den gereizten Punkt $a$ geht, eine Krümmung des Manubrium sowolıl wie der Glocke erfolgt. Es ist so, als ob alle Muskelfasern zusammen wirkten, um das Manubrium an die gereizte Stelle zu bringen. Das Central-

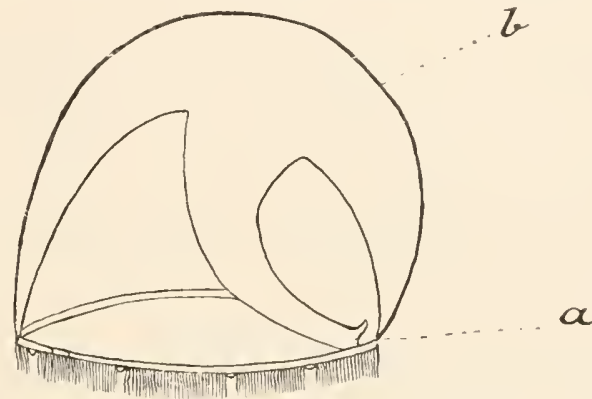

Fig. 7. Localisirungsreflex bei Tiarnpsis indicans. Reizt man eine Stelle a des Randes, so wird das Manubrium an die gereizte Stelle gebracht; ähnlich wie der decapitirte Frosch einen Tropfen Essigsäure mit der Pfote abzuwischen versueht.

Sehematisirt nach Romanes.

nervensystem hat nichts mit der Reaction zu thun, denn Romanes fand, dass nach dem Abschneiden des ganzen Randes mit den Ringnerven die Reaction erhalten bleibt. Hacht man dagegen einen Einschnitt in den Schirm parallel zum Rande und reizt man einen unterhalb der Mitte der Schnittlinie gelegenen Punkt, so zeigen sich zwar unbestimmte Bewegungen des Manubriums gegen den Quadranten, wo der gereizte Punkt liegt, aber eine genaue Localisation ist unmöglich. Romanes schliesst daraus, dass alle Theile der Glocke von radialen Linien differenzirten Gewebes durchzogen werden, deren Function die Uebertragung von Eindrücken zum Manubrium ist. Er nimmt an, dass dieses Gewebe nervösen Characters ist. Ich glaube, die ganze Erscheinung erklärt sich ohne jede Annahme eines, besonders in radialen Richtungen, differenzirten nerrösen Gewebes. Das blosse Vorhandensein der Muskelfasern auf der Unterseite des Schirmes und der Oberfläche des Manubriums genügt zur Erklärung. Ich stelle mir vor; dass jeder punktförmige Reiz etwa bei a Fig. 8 zu einer allseitigen Spannungszunahme der Muskeln führt. die am intensirsten in der Nähe des gereizten Punktes ist und um so mehr an Intensität abnimmt, je weiter man sich vom gereizten Punkt entfernt. Denkt man sich nun die vom gereizten Punct ausstrahlenden Linien der Spannungszunahme 
$u \iota^{1}, a b^{1}, u{ }^{1} a d^{1}, a e^{1}$ (Fig. 8) alle in je eine mericlionale $a a^{1}, d d^{1}, b b^{1}$ ete. und ciue darauf senkrechte äruatoriale Componente ab, ac etc. zerlegt, so ist es klar, dass die letzteren auf das Manubrium keinen Einfluss haben können. Nur die radialen Componenten können einen Einfluss haben, und zwar muss diejenige radiale Componente ein Maximum sein, wolche rlurch den gereizten Punkt geht. Das muss nothwendig zu einer

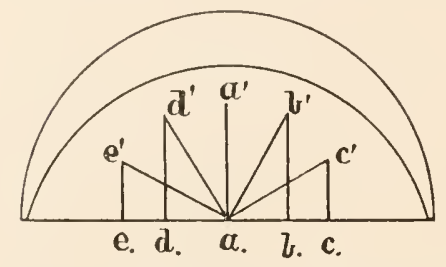

Fig. 8. Diagramm zur Erklärung des Localisirungsreflexes bei Medusen. Krümmung des Manubriums zum gereizten Punkt hinführen. Das zeigt auch olıne Weiteres, warum ein lem Rande des Sehirmes paralleler Schnitt das genauere Localisationsvermögen aufhebt und nur unbestimmte Bewegungen gegen den gereizten Quadranten hin zulässt. Ich glaube auch kaum, dass die Einrichtungen für den analogen Reflex beim Frosch oder der Schildkröte von einer höheren Ordnung der Complieation sind. Denken wir uns einen Frosch mit derjenigen Einfachheit des Baues, wie er sieh im frühen Embryonalstadium findet, so sieht man ohme Weiteres, dass dieselben Annahmen für den Froseh ausreichen, wie für die Medusen. Ich halte es aber für denkbar, dass trotz der Verschiebungen, welche die Muskeln bei der Entwickelung erleiden, dennoch das einfache Schema protoplasmatischer Verknüpfungen erhalten bleibt, das zur Zeit der Urwirbel existirte. Die Complieirtheit der Einrichtungen für den Localisirungsreflex ist alsdann nur seheinbar. Die Natur arbeitet immer nur mit sehr einfachen Mitteln. Dieses Mittel ist beim Localisirungsreflex die Reizkrümmung, z. B. Contactkrümmung, die uns in der einfachsten Form bei Pflanzen gegenübertritt, bei denen die mit einem festen Körper berührte Seite coneav wird. Bei den Pflanzen ist sicher kein Centralnervensystem mit geheimnissvollen Reflexstructuren im Spiele. Reizbarkeit und Reizleitung ist alles was zur Erklärung hier nöthig ist. Bei der Meduse ist die Sache nur insofern etwas complicirter, als das contractile Gewebe hier richtiges Muskelgewebe ist. Beim Frosch tritt als einzige weitere Complication der Umstand hinzu, dass die Reizleitung durch eine besondere Art von Gewebe erfolgt, nämlich Nervengewebe.

Es lassen sieh also alle erwähnten Erseheinungen an Medusen dureh die einfachsten Thatsachen der Erregung und Reizleitung erklären, ohme Jass wir nöthig haben, den Ganglienzellen andere geheimnissvolle Structuren und Funetionen beizulegen, als wie sie in allem reizleitenden Protoplasma vorkommen. 


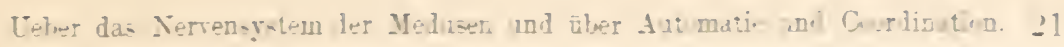

\section{Litteratur zu II.}

1) Romanes. G. J. Jelly-tish. Star-tish and Sea-[rehins. The Iuternational seientific Series 15,5 .

Vergleiche fermer

Eimer, Die Melusen. fhrsiologisch unl in rhol-gisch auf ihr Nerrensystem untersacht. Täbingę $15 \overline{i s .}$

- Das rellstāadigste and be:ae Werk über Anat mie uud Histolugie de- Nerven-ratems der Madnen ist Hatwig. O. und P.. Das Marten-ratem and die singezortane der Meilusen.

3 Engelmant. bobachingen unt Terache am suspendirten Herzen. PAuger :

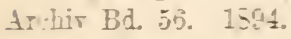

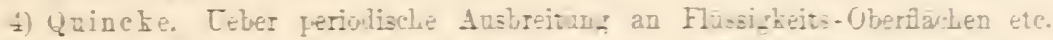

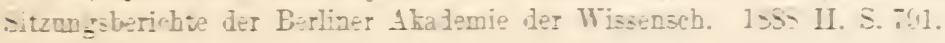


III.

\section{Das Centralnervensystem der Ascidien und die Bedeutung desselben für Reflexe.}

1) Wenn wir die Reihenfolge des natürlichen Systems unserer Darstellung zu Grunde legen wollten, so hätten wir kein Recht auf die Merlusen die Ascidien folgen zu lassen. Allein wir halten es für vortheilhafter, die Reihenfolge der Untersuchungsobjecte so zu wählen, dass dic einfachsten Untersuchungsobjecte den complicirteren voraufgelıen. Nachdem wir am Ende des vorigen Abschnittes zu der Ueberlegung geführt worden waren, dass bei den Medusen die spontanen Leistungen und die Reflexe den einfachen Gesetzen der Erregung in protoplasmatischen Gebilden folgen, müssen wir die Consequenzen einer solchen Anschaumng bei einer Thierklasse prüfen, deren Centralnervensystem aus einem einzigen Ganglion besteht, welches sich sehr leicht entfernen lässt, nämlich den Ascidien. Am günstigsten ist für operative Zwecke lie durchsichtige und sehr grosse Ascidie, Ciona intestinalis (Fig. 9), bei der das Ganglion bei d (Fig. 9) zwischen der oralen Oeffnung a und der aboralen Oeffnung b liegt.

Ciona (sowie die anderen mir bekannten Ascidien) besitzt einen sehr characteristischen Reflex. Berührt man die orale oder aborale Oeffnung ( $a$ oder b Fig. 9) des Thieres, so schliessen sich diese beiden Oeffnungen, und ras ganze Thier zieht sich zusammen, so dass es klein und kugelig wird. Dieser Reflex ist, wie mir scheint, durch zwei Gruppen von Muskeln bestimmt, crstens Ringmuskeln an der oralen und aboralen Oeffnung, zweitens Längsmuskeln, welche die ganze Oberfläche des Thieres durchziehen. Durch die Contraction dieser Muskeln ist das Thier gegen das Eindringen ungebetener Gäste in seinen Körper geschützt. Diese Reaction ist ein typischer Reflexakt, dem auch das Characteristicum der Zweckmässigkeit nicht fehlt. Nach den herr- 
schenden Vorstellungen iiber die entseheidende Rolle der Ganglien fiir diə Reflexe verläuft der Vorgang folgendermaassen.

Die Erregung wird durch die peripheren Nerven zum Ganglion geleitet, hier wird der mysteriöse Reflexmechanismus in's Spiel gresetzt und den Muskein der Befehl ertheilt, sich in der zweckentsprechenden Weiso zu contrahiren. Ferrier beispielsweise führt in seinem Lehrbuch gerade die Ascidien mit ihrem Ganglion als typisches Beispiel für die Bedentung des letztern für die Reflexe an.

Ich entfernte bei einer Reihe von Cionen das Ganglion. Unmittelbar nach der Operation, gewöhnlich etwa 24 Stunden lang, blieben die Thiere maximal contrahirt. Dann streckten sie sich wieder aus. Zu meiner grossen Ueberraschung aber fand ich, dass der typische Reflex der Thiere auch nach der Enthirnung weiter besteht: Lässt man nämlich einen Tropfen Wasser auf ein solches Thier fallen, so löst dieser Reiz wieder den typischen Reflexakt aus, wie beim normalen 'Thier' (1). Der Reflex kann also nicht durch einen Reflexmechanismus in Ganglion selbst bestimmt sein. Wodurch aber ist er bestimmt und was ist die Rolle des

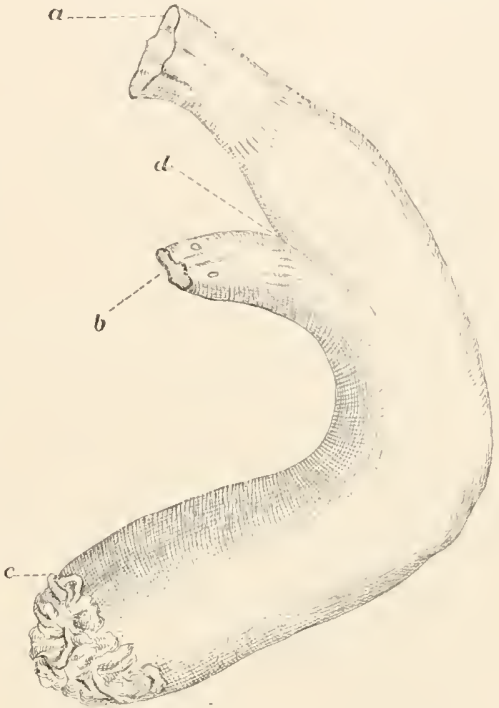

Fig. 9. Ciona intestinalis. a orale, b aborale Oeffnung, c Fuss. d Lage des Ganglions. Ganglions?

Hier geben Versuche über die Reizschwelle Auskunft: Die Reizschwelle für die Auslösung des Reflexaktes ist höher bei den operirten als bei den nichtoperirten Thieren. Als Reizquelle benutzte ich die kinetische Energie ron Wassertropfen, die aus einer Röhre mit enger Oeffnung (Pipette) auf das Thier fielen. Da das Giewicht des fallenden Tropfens für dieselbe Pipette stets das gleiche ist, so ist das Jinimum der Fallhöhe, von der aus der 'Tropfen eine Contraetion auszulösen rermag, ein bequemes Maass der Reizbarkeit (die letztere ist natiurlieh gleich dem reciproken Werth der Reizschwelle). In einem Falle befanden sich in einem Aquarium (gleich nahe der Oberfläehe) eine frisch operirte und eine normale Ciona. Beide waren gleich tief unter dem Wasserspiegel. Die minimale Fallhölie, ron der noch eine Contraction ausgelöst werden konnte, war für die normale (a) und die operirte (b) wie folgt: 
24 Das Centralnervensystem der Ascidien und die Bedeutıng desselben für Reflexe.

$\begin{array}{cc}\text { a (normal) } & \text { b (enthirnt) } \\ 8 \mathrm{~mm} & 65 \mathrm{~mm} \\ 4 " & 75 \quad \\ 10 " & 80 " \\ & 80,\end{array}$

Bei zwei anderen Versuchsthieren erhielt ich folgende Werthe:

$\begin{array}{lc}\text { a (normal) } & \text { b (enthirnt) } \\ 6 \mathrm{~mm} & 22 \mathrm{~mm} \\ 8 \% & 20,\end{array}$

Dieser Unterschied der Reizbarkeit rührt meiner Ansicht nach daher, dass in der normalen Ascidie die Erregung durch die Nerven und das Ganglion fortgeleitet wird, wozu eine geringere Energie des auslösenden Reizes nöthig ist, während bei der operirten Ascidie die Muskeln direct erregt werden und vielleicht die Fortleitung der Erregung von Muskelzelle zu Muskelzelle statffindet, wie im Herzen. Wir wissen ja übrigens, dass die directe Erregbarkeit von Muskelfasern geringer ist als die der Nerven. Das Wesentliche aber, das der Versuch lehrt, ist der Umstand, dass der "Reflex" der Ascidie nicht durch geheimnissvolle Mechanismen im Ganglion bestimmt ist, sondern lediglich durch die Anordnung der peripheren Muskeln des Thieres; und dass das Ganglion wie überhaupt das Centralnervensystem nur die Rolle einer empfindlicheren und besseren Reizleitung spielt (1).

2) Man könnte nun geneigt sein, sich vorzustellen, dass diese Fällc keine Schlïsse erlauben auf die "Reflexcentren" höherer Thiere, dass bei höheren Thieren die Ganglien Functionen übernommen haben, welche hei niederen Thieren durch periphere Organe besorgt werden kömnen. Es ist ja eine beliebte Behauptung, dass ein „Wandern" der Functionen um so höher hinauf im Centralnervensystem stattfindet, je höher ein Thier im System stehe. Wie man sich aber ein „Höherhinaufwandern“ von „Functionen" vorstellen solle, setzt leider keiner dieser Autoren auseinander. Es lässt sich indessen leicht zeigen, dass die Dinge bei höheren Thieren nicht anders liegen als bei niederen Thieren, nur muss man zum Vergleich mit dem niedern Thiere nicht das gesammte höhere Thier, sondern einzelne Segmente resp. Organe desselben auswählen. Wenn die Intensität des Lichtes plötzlich vermehrt wird, so verengert sich bekanntlich die Pupille. Der Sphineter Iridis contrahirt sich, und die Lichtstrahlen werden in ähnlicher Weise abgehalton, wie die ungebetenen Gäste durch Schliessen der Sphinctern bei der Ascidie. Im Auge haben wir es, wie bei der Ascidie, mit einem typischen Reflexact zu thun. Die Zunahme der Lichtintensität reizt die Retina. Die Erregung pflanzt sich durch den Sehnerv auf dessen Centren fort und 
wird ron hier vermittelst des Oculomotorius auf den Sphineter Iridis übertragen, der sich contrahirt. Gleichwohl wäre es falsch, anzunehmen, dass das „Centrum" für den Pupillarreflex irgend eine andere Rolle bei diesem Vorgange spiele, als etwa die einer protoplasmatischen Verbindung zwischen Retina und Iris. Es ist nämlich von Arnold und später von Brown-Séquard und Budge gezeigt worden, dass selbst in der ausgeschnittenen Iris auf Lichteinfall noch die Verengerung der Pupille stattfindet. Ich selbst habe oft die Beobachtung gemacht, dass bei Haifischen, deren Gehirn ich entfernt hatte, die Verengerung der Pupille auf Lichteinfall noch mehrere Stunden nach dem Tode stattand, als schon Zeichen von beginnender Fäulniss in der Schädelhöhle sich zeigten. Steinach hat in einer sehr gründlichen Arbeit den wichtigen Nachweis geführt, dass es sich hierbei um directe Erregung der pigmentirten Muskelelemente in der Iris handelt (3). Dieser Reflex ist also bestimmt durch die Muskulatur der Iris, und die nervösen Verbindungen dienen nur zur rascheren und bequemeren Reizleitung. Es benimmt sich also der Augapfel dem Licht gegenüber genau wie die Ascidie mechanischen Reizen gegenüber.

Einige Physiologen scheinen die Möglichkeit zu bezweifeln, dass Muskeln direct ohne Vermittelung von Ganglienzellen, durch Jicht erregbar sind. Wir finden aber, dass Contractionserscheinungen auch bei Pflanzen und Protozoen durch das Licht ausgelöst werden, die doch sicher keine Ganglienzellen enthalten. Es zweifelt fermer Niemand daran, dass auch Muskeln ohne Ganglienzellen chemisch oder mechanisch erregt werden können. Warum soll es nicht auch Muskelfasern geben. welche durch Licht direct erregbar sind? Es ist doch kein Grund zu der Annahme vorhanden, dass alle Muskeln sich genau wie die Muskeln des Froschschenkels verhalten müssen, bloss weil an ihnen zufällig die gegenwärtig herrschenden Anschaumngen über die Eigenschaften der Iuskeln gewonnen worden sind.

Wir können ein anderes Beispiel wählen. Die Entleerungen des Mastdarms und der Blase höherer. Thiere sind Reflexerscheinungen, ausgelöst in Rückenmark. Der Druck der Faeces oder des Urins wirkt als Reiz, der die Centren für die Entlesrungen dieser Organe erregt und diese Erregung soll die Erschlaffung des sonst contrahirten Sphincters zur Folge haben. Goltz und Ewald haben aber gefunden, dass auch nach Entfernung des ganzen Rückenmarks bis auf's Halsmark die Entleerumg der Blase und des Mastdarms ganz normal vor sich geht (4). Nur eine gewisse Zeit nach der Operation sind die erwähnten Sphincteren erschlafft, in Folge der Shockwirkung der Operation, später aber wird alles wieder normal. Del Fall ist wohl derselbe wie bei der Ascidie. 
Die Vorgänge bei der normalen Entleerung der Blase und des Mastdarms sind nicht durch geheimnissvolle Strukturen im sogenannten Reflexcentrum, sondern in peripheren Apparat der Blase und des Mastlarms, speciell der Muskeln bestimmt. Das Rückenmark dient nur für die bequemere Reizleitung. Goltz und Ewald sind allerdings geneigt anzunelımen, dass hier dennoch Ganglienzellen oder unbekannte nervöse Verbältnisse bestimmend wirken. Vom Standpunkt der vergleichenden Physiologie ans scheint mir diese Annahme nicht nothwendig zu sein. Die Actinia mesembryanthemum der Ostsee und des mittelländischen Meeres sind morphologisch vielleicht weniger verschieden als der Sphincter ani und der Gestrocnemius. Und doch zeigt die Actinia mesembryanthemum des Mittelmeeres eine Form der Reizbarkeit, welche die gleichnamige Actinie der Ostsee nicht zeigt: nümlich negativen Geotropismus, Ich erwähne dieses Beispiel (dem ich viele ähnliche anreihen könnte) um zu zeigen, dass Strukturgebilde, die morphologisch gleich sind, dennoch nicht in allen ihren Reactionen gleich zu sein brauchen. Eine kleine stereochemische Verschiedenheit eines Kohlehydrates odcr eines Eiweisskörpers kann, wie die Versuche über Gährung zeigen, ganz verschiedenes physiologisches Verhalten bedingen, ohne dass das morphologische Verhalten beeinflusst zu sein brancht.

Es bleibt natürlich die Möglichkeit bestehen, dass auch bei Ascidien nervöse Plexus unter der Epidermis bestehen, wie bei den Medusen; Herr Hunter, der sich im hiesigen zoologischen Institnt eingehend mit dem Nervensystem der Ascidien beschäftigt hat, findet, dass er an bestimmten Stellen unter der Epidermis der Ascidien Zellen gefunden habe, die er als Ganglienzellen deutet. Es ist möglich, dass die Leitung der Frregung bei den enthirnten Ascidien zum Theil wenigstens durch diese Plexus stattfindet. Das ändert freilich nichts an der Thatsache, dass die characteristischen Reflexe der Ascidien anch nach Exstirpation des Centralnervensystems fortbestehen.

Nenerdings hat Schaper eine Beobachtung gemacht, welche dafiir spricht, dass bei den jungen Larven der Amphibien ähnliche Bedingungen vorhanden sein mögen, wie bei den Ascidien. Lr amputirte einer Froschlarve in den ersten Tagen das Gehirn und sah das Thier dennoch in den nächsten sieben Tagen sich spontan bewegen. Das Merkwürdige ist, dass bei der Zerlegung des Thieres in Serienschnitte gefunden wurle, dass auch das Rückenmark zu Grunde gegangen war (2). Diese Beobachtung sollte erweitert werden. Es ist selır wohl denkbar, dass auch bei den Froschlarven in den ersten Tagen der Entwickelung eine directe Fortpflanzung der Erregungswellen von der Haut auf die Mfuskeln stattfinden kann, ohme dass das Nervensystem in Thätigkeit treten muss. 
3) Man köunte nun den Einwand erheben, dass es sich in Falle der Blase oder des Mastdarms um kleine unwesentliche Organe des Körpers handele. Das Gesagte gilt aber für grössere Organgruppen ebenso: z. B. für die Blutgefässe. Wie wunderbar sind die Einrichtungen, welche die Weite unserer Blutgefïsse den äusseren Bedingungen anpassen und es ermöglichen, dass die Hautgefässe weit werden, wenn Wärmeverlust wünschenswerth ist, dass sie eng werden in der Kälte, wenn der Wärmeverlust beschränkt werden soll. Auch hier nimmt man an, dass diese wunderbar zwecknässigen Einrichtungen durch geheimnissvolle Strukturverhältnisse im Centralnervensystem bestimmt sind. Goltz und Ewald (4) haben aber gefunden, dass Hunde, die das Riickenmark bis nahe an die Medulla oblongata verloren hatten, Jahre lang am Leben bleiben. Das allein beweist, dass die Blutgefässe sich unabhängig vom Centralnerrensystem reflectorisch der Aussentemperatur anpassen können. Goltz hatte früher schon bewiesen, dass wenn man alle Nerven einer Gliedmasse durehschneidet und und die Gliedmasse nur mittelst der Blutgefässe mit dem Thier im Zusammenhang lässt, die anfänglich crschlafften Gefässmuskeln resp. contractilen Gefässelemente ihre Spannung (Tonus) wiedergewinnen. Dasselbe findet auch nach Zerstörung des Rïckenmarks statt. Die Temperatur der Hinterpfoten bei Thieren, deren Rückenmark vom Brusttheil an zerstört war, wurde einige Zeit nach der Operation wieder gleich der Temperatur der Vorderpfoten, die nervös noch mit den Centralnervensystem zusammenhingen. Es ist bekaunt, dass wenn eine Hand eine Zeit lang im Schnee steckt, nachher eine locale Nachwirkung des Kältereizes auftritt, die sich in einer Erschlaffung der Gefässmuskulatur und Temperaturerhöhung des betreffenden Theiles geltend macht. Goltz und Ewald konnten zeigen, dass dieselbe Erscheinung anch beobachtet wird, wenn man die Hinterpfoten von Hunden mit zerstörtem Rückenmark eine Zeit lang in Schnee einpackt.

Vom Standpunkt der menschlichen Physiologie sind diese Resultate befremdend, rom Standpunkt der vergleichenden Physiologie sind sic leicht verständlich. Wir sehen ja, wie sehr die Reactionen der Pflanzon gegen äussere Reize mit denen von Thieren übereinstimmen. Warum sollte es nicht denkbar sein, dass einzelne Organe und Gewebe hölierer Thiere anch ohne Centralnervensystem zweckmässig auf äussere Reize reagiren?

Während so die Ascidien uns helfen können, falsche Anschauungen über die Bedeutung der Ganglien des Centralnervensystems höherer Thiere los zn werden, helfen sie uns auch weiterhin die wirkliche Rolle des Nervensystems höherer Thiere festzustellen. Obwohl nämlich die 
rückenmarkslosen Hunde von Goltz und Ewald noch im Stande waren, die Weite ihrer Blutgefüsse den Temperaturverhältnissen anzupassen, war es doch nöthig, sie vor raschen Temperaturwechsehn viel sorgfältiger zu schiitzen, als das bei normalen Thieren nöthig ist. Wie bei den Aseidien nach Verlust des Ganglions die Reizschwelle erhöht (und vermuthlich die Geschwindigkeit der Leitung verringert war), so war dasselbe wohl auch in Bezug auf die Temperaturregulirung bei den rückenmarkslosen Thieren von Goltz und Ewald der Fall. Zum Leben im Freien taugten diese Hunde deshalb nicht mehr, die Temperaturregulirung war bei ihnen zu langsam und die Reizseliwelle wohl zu hoch. Wie cin Betrunkener würden sie rascher in der Kälte zu Grunde gegangen sein, als ein normales Thier. Die Rolle des Nervensystems besteht also nicht darin, dass es Regulationsmechanismen enthält, sondern, dass die Leitung durch dasselbe rascher stattfindet und dass es deshalb den peripheren Organen erlaubt, mit grösserer Präcision zu arbeiten.

4) Bethe hat neuerdings einen schwierigen Versuch an einem Krebs (Carcinus maenas) angestellt, welcher allerdings nur in zwei Fällen gelang. Wenn dieser Versuch richtig ist, so beweist er, dass bei der Leitung eines Reflexes im Centralnervensystem der Leitungsvorgang gar nicht einmal durch die Ganglienzellen zu gehen braucht (5). Eine anatomische Betrachtung veranlasste Bethe zur Ausführung dieser Operation. „Fast alle Ganglienzellen von Carcinus sind unipolar und oft läuft der Axenfortsatz der Zelle weite Strecken dahin, ehe er die ersten Dendriten ahgiebt und die periphere Faser entsendet. Es schien mir nun recht sonderbar, dass der durch die sensibeln Nerven in das Centralorgan tretende Reiz durch die Dendriten zu der weitentfernten motorischen Ganglienzelle einen grossen Theil desselben Wegs rückwärts und dann erst in die periphere motorische Faser gehen sollte, anstatt direct von den Dendriten auf dem viel näheren Wege anf die motorisehe Faser überzugehen. Diese Frage war leicht dadurch zu entscheiden, dass man die Ganglienzellen mit dem Axenfortsatz unter Schonung des Neuropils von motorischen Neuronen abtrennte. Wäre dic Ganglienzelle zum Functioniren absolut nöthig, so müsste gleich nach der Operation eine Lähmung der betreffenden Muskeln eintreten; im andern Falle, wonn der Reizstrom direct von Dendriten zur peripheren Faser, olme die Ganglienzello passiren zu müssen, übergehon könnte, so müsste die Lähmung ausbleiben, wenigstens für einige Zeit." Die Operation liess sich bei Carcinus ausführen und zwar für die Ganglienzellen, welche die Muskeln der 2. Antenne innerviren. Durchschneidung des peripheren Nerven (Antennarius secundus), welcher zu diesen Ganglienzellen geht, ruft sofort vollkommene Lähmung der Antenne hervor, ein Beweis, dass 
die Fasern dieses Nerven die einzigen Leiter der Erregung sind, wclche reflectorisehe Bewegung dieser Antennen hervorrufen kann. Entfernte Bethe aber diese Ganglienzellen, olme die Neuropile der zweiten Antenne zu verletzen (so dass der Nerv der zweiten Antenne nur noeh mit seinen der Ganglienzellen total entbehrenden Endstïtten zusammenhing), "lamn behält die zweite Antenne ihren Tonus und ihre Reflexerregbarkeit. Sie hängt nicht schlaff herab, sondern wird steif in der normalen Lage 'gehalten. Auf Reiz wird sie eingeklappt und nachher wioder beim Aufhören des Reizes vorgestreckt. Es gelit daraus hervor das die Ganglienzellen zum Zustandekommen von Reflexen nicht nothwendig sind, dass entweder der Reflexbogen ïberhaupt nicht dureh die Ganglienzellen geht oder wenigstens nicht hindurchzugehen braucht. Ferner geht daraus hervol, dass die Ganglienzelle mit dem Tonus der Muskeln nichts zu thun hat, dass der dauernde Einfluss, den das Centralnervensystem auf die Muskulatur ausübt, indem er sie in Spannung erhält, nieht in den Ganglienzellen erzeugt wird." (6)

Die Neuronentheorie, welche zu manchen Seltsamkeiten geführt hat (man denke nur an Ramon y Cajal's Hypothese der Aufmerksamkeit), wird durch die Arbeiten von Bethe und die voransgehenden Arbeiten Apathy's erheblich modificirt.

\section{Litteratur zu III.}

1) Loeb. J. Untersuchungen zur Physiologischen Morphologie iler Thiere. Il. Würzburg 1892. S. 37.

2) Schaper, A. Experimentelle Studien an Amphibienlarven. Archiv für Entwicklungsmechanik. Bd. VI. 1895.

3) Steinaeh, E. Untersuchnngen zur vergleiehenden Physiologie der Iris Pflüger's Archiv Bd. 52. 1892.

4) Goltz und Ewald. Der Hund mit verkürztem Rückenmark. Pflüger's Arch. Bil. 63. 1896 .

5) Bethe, A. Das Centralnervensystem von Carcinus maenas. I. Theil. II. Mittheilung. Archiv f. unikroskop. Anatomie und Entwicklungsgeschichte. Bd. 50. 1897.

6) Bethe, A. Das Centralnervensystem von Careinus maenas. II. Therl. Arch. f. mikroskop. Anatomie und Entwieklungsgeschiehte. Bı. 51. 1S!18. 
IV.

\section{Versuche an Aktinien.}

1) Wir gehen nach der Disenssion der Ascidien weit in die Thierreihe zuruick zu den Aktinien. Von einem Centralnervensystem, wie es bei den Aseidien vorhanden ist, kann bei den Aktinien nicht die Rerle sein. Unter dem Eetoderm befinden sich bei Aktinien Elemente, welche als Ganglienzellen und Nervenfasern gedentet werden. Wie wenig bestimmt eine solche Deutung ist, geht daraus hervor, dass beispielsweise Claus dieselbe als unsicher betrachtet, und dass von ihm unter den Umständen, welehe sich für diese Deutung anführen lassen, die Möglichkeit der Reizleitung erwähnt wird. Aber Reizleitung findet doch auch bei Pflanzen statt!

Ich habe über die Reactionen von Aktinien im Jahre 1888 in Kiel und 1889 und 90 in Neapel Versuche angestellt, ïber die ich sehon frïher berichtet habe, (1) die ich aber hier wieder erwähnen will, weil sie zeigen, wie wenig Veranlassung wir haben, von complieirten Reactionen auf Reflexcentren von ähnlicher Complication zu schliessen. Es ist vielmehr die Struktur und Reizbarkeit der peripheren Gebilde, welche die complieirten Reactionen bestimmt. Wir beginnen mit der Schilderung von Versuchen an der Actinia equina (mesembryanthemum) der Ostsee. Wenn man auf den Mund einer solchen Aktinie ein Papierkügelchen legt, das lange in Seewasser aufgeweicht wurde, so nimmt der Mund dieses Stück nicht an, während er ein Stück Krebsfleisch, das für unsern Gesehmack bei blosser Berührung der Zunge sich von dem Papierkiigelchen nicht unterseheidet, meist sofort nimmt. Ich band das eine Ende eines ganz kurzen Fadens um ein Papierkügelchen, das andere Ende um ein Stuick Fleiseh, und warf das Ganze auf die ausgestreckten Tentakel eines hungrigen Thieres. Die Tentakel, die rom Fleischstiick (a Fig. 10) berührt wurden, reagirten sofort mit Krümmungen, welche das Fleischstïck an den Mund brachten; die rom Pa- 
pier b berïlnten Tentakel reagirten nicht. Ich zog den Faden wierler weg und legte ihn umgekehrt auf die Mundscheibe, so dass die vorhin rom Papier beriulnten Tentakel jetzt vom Fleisch berïhrt wurlen. Dic

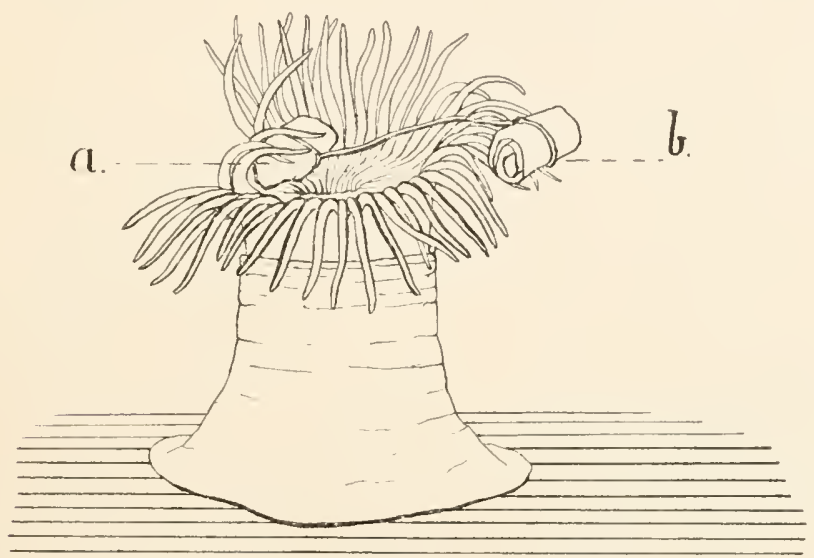

Fig. 10. Unterscheidungsvermäigen bei Aktinien.

Die Tentakel pressen das Fleisehstiick a in den Mund ter Aktimie, währemd sie das in Seewasser aufgeweiehte Papierstück b herunterfallen lassen.

vom Fleisch berührten Tentakel führten das Fleischstück zum Munde, wïh'end die rom Papier berührten Tentakel dasselbe herunterfallen liessen. Das Fleischstïck wurde dann in den Mund gewürgt, der Faden wurde mit lineingezogen, aber das Papierstïck und ein Stïck Farlen blieb vor der Mundöffunng liegen (Fig. 11). In den nächsten 24 Stunden änderte sich hieran nichts; dann aber wurde der Faden ausgespieen, aber obne rlas Fleisch. Dasselbe war wahrscheinlich verdaut. Ich habe den Versuch oft mit dem gleichen Erfolg wiederholt; nur wurde gelegentlich der Farlen rascher erbrochen und

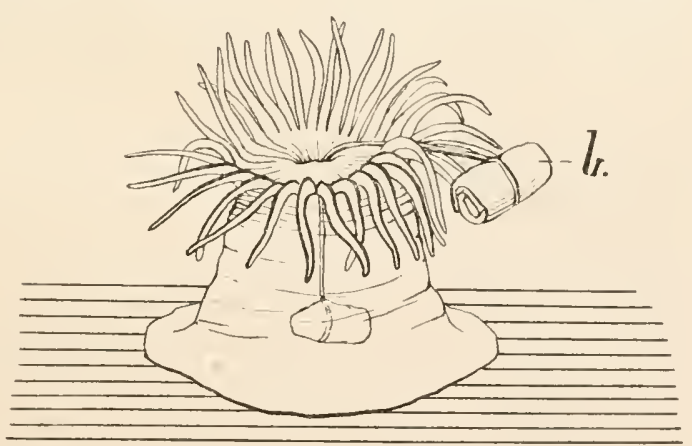

Fig. 11. Fortsetzung des Versuches in Fig. 10. dlumn ling das Fleischstück theilweise oder ganz unverlaut am Faden. Für die Erklärung dieser Erscheinungen kann die Annahme mysteriöser Reflex- 
mechanismen in Ganglienzellen ebenso aus dem Spiel bleiben, wie für die Erklärıng des Verhaltens insektenfressender Pflanzen. Die vom Fleisch diffundirenden chomischen Stoffe, zusammen mit den tactilen Reizen des Fleisches verursachon eine Krümmung der berührten Tentakeln in dem Simne, dass dieselben gegen das Fleisch concar werden und dass sie sich mit dem Fleisch gegen die Mundöffnung krümmen. Der Contact des Fleisches mit rler Mundscheibe verursacht eine Erschlaffung des Sphincters der Mundöffnung, und der Druck der Tentakel und die Thätigkeit der Mundscheibe befördern das Fleisch ins Innere der Verdauungsröhre. Fehlen aber diese specifischen chemischen Reize, giebt man dem Thiere beispielsweise in Seewasser aufgewcichtes Filtrirpapier, so werden die Contractionen derjenigen Muskeln, welche die Tentakel zum Munde führen, nicht ausgelöst. Die Tentakel bleiben schlaff oder erschlaffen unter dem Reiz noch mehr und dieser Umstand, sowie eine Flimmerbewegung führen zum Abfallen des Papierkügelchens.

2) Es wird angegeben, dass in der Nähe der Mundscheibe die Nervenelemente in grösserer Dichte angehäuft seien. Man kömnte denken, dass diese Anhäufung den Reflexmechanismus für die erwähnten Rcactionen bestimme. Ich machte deshalb Gebrauch von Ergebnissen, zu welchen ich im Verlauf von Untersuchungen über Heteromorphose gekommen war. Ich hatte gefunden, dass bei einer Aktinie des Mittelmeeres, Cerianthus membranaceus, durch einen seitlichen Einschnitt in den Körper des Thieres neue Tentakel und eine neue Mundscheibe hervorgebracht werden können. Die Mundöffunng aber fehlt in manchen dieser Fälle. Fig. 12 stellt ein solches Thier vor. a ist der alte normale, b der neue Kopf. War der Einschnitt sehr klein, so wurden nur einzelne Tentakel ohne Mundscheibe gebildet. Diese neuen Tentakcl verhalten sich nun den Nahrungsstoffen gegenüber genau so, wie die Tentakel des alten Mundes. Bietet man einem solchen neuen Kopf ein Stiick Fleisch an; so ergreifen die Tentakel es und pressen es gegen das Centrum der Mundscheibe, wo der Mund sich befinden sollte, wo aber keine Oeffnung ist. Nach einigen Minuten vergeblichen Pressens crschlaffen die Tentakel und das Fleisch fällt ab. Diese Reaction bcstand Monate lang, so lange ich das Thier beobachtete. In anderen Fällen war der zweite Kopf dem alten so nahe, dass es ein Leichtes war, durch dasselbe Fleischstück die Tentakel des alten und des neuen Kopfes gleichzeitig zu reizen. In dem Falle entstand ein förmlicher Kampf zwischen den beiden Tentakelsystemen, indem jedes das Fleischstïck zu seiner Mundscheibe zu ziehen suchte. Parker hat neuerdings gezeigt, dass selbst eine einzelne abgesclinittene Tentakel ein Stück Fleisch ergreift und an die Stelle führt, wo sich der Mund befinden sollte (3). 
Steht man diesen 'Thatsachen unbefangen gegenüber, so kommt man zu der Ueberzengung, dass die Reaction der Tentaliel nur bestimmt ist durch die Reizbarkeit der Tentakelelemente selbst und durch die Anordnung der contractilen Elemente in denselben. In demselben Sinne dürfen auch wohl die folgenden weiteren Beobachtungen angesehen werden.

3) Durchschneidet man cine Actinia equina der Quere nach, so hat das orale Stück, welches wir das Kopfstück nennen wollen, an seinem oralen Ende den alten, normalen Mund; an seinem anderen aboralen Ende ist die Leibeshöhle ebenfalls often und ron lier aus wird ebenfalls Nahrung aufgenommen; aber Tentakel sind hier nicht rorhanden. Der alte Mund eines Kíopfstïckes war mach der Durchschneidung ebenso wählerisch wie früher. Der aborale Mund des Kopfstïckes nahm dagegen Papierstïckchen und verschlang sie. Ich sah jedoch auch, dass er Papicrstückchen verschmähte, während er Krebsfleisch gierig nahm. Während der alte Mund eines solchen Stückes oft auch die Annahme eines Fleischstückes rerschmähte, war der aborale Mund fast stets zur Nahrungsaufnalıme bereit.

Ich legte ein solches Bruchstück, welches an beiden Enden Nahrung aufnahm, auf die Seite und rersuchte, ob beide Mäuler gleichzeitig Nahrung aufnehmen wïrden. Ich brachte ein Fleischstïck zuerst an

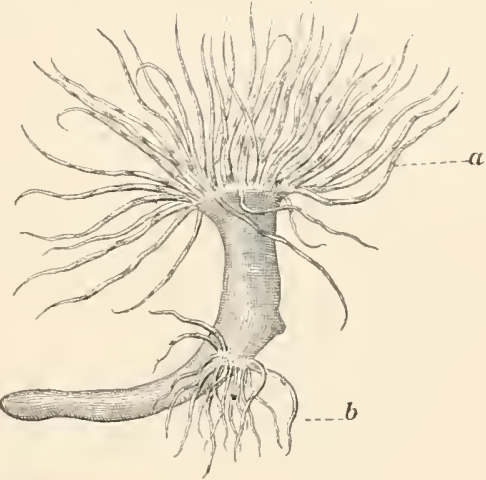

Fig. 12. Aktinie (Cerianthus) mit einem uormalen Kopfe a und einem künstlich erzeugten partiellen Kopf $b$. Obwohl der letztere keine Mundöffuung hat, so betördern die Tentakel Fleischstücke an die Stelle, wo der neue Mund sich befinden sollte. den aboralen Mund, um ihn zu veranlassen, sich zu öffnen. Sobald das geschehen war und das Fleischstück anfing, in den Mund gezogen zu werden, bot ich auch dem oralen Mund ein Fleischstiick an, das ron diesem ebenfalls genommen wurde. In demselben Augenblick wurde der Schluckakt am anderen Mund dadurch sofort unterbrochen, dass die Ringmuskulatur sich fest contrahirte. Nach einigen Augenblicken aber, als das Fleischstïck am oralen Munde hineingewürgt war, erschlaffte die Muskulatur am aboralen Ende und das Fleischstïck fiel wieder zum Munde heraus. Fütterte ich beide Mäuler nach einander so gab der Mund, der vorher gefressen hatte, seine Nahrung wieder ron sich, wenn der andere seine Nahrung aufzunehmen begann. 
Wir haben bisher nur das Kopfstïck einer der Quere nach getheilten Aktinie berückisichtigt. Wenden wir ums nunmehr dem Fussstïck zu, so finden wir, dass hier am oralen Ende sich alsbald eine newe Mundscheibe mit Tentakeln zu bilden beginnt. Aber schon ehe es so weit gekommen ist, nimmt der Mund Fleischstïcke auf und rerschluckt sie. Es machte mir den Eindruck, als ob dieser nene Mund schon ror der Bildung der Mundscheibe und der Tentakel mehr dem alten normalen Mund gleiche, insofern er keine Papierkïgelchen und Sandkörner annalım, wälırend er Fleisch gewandt rerschluckte.

4) Wesentlicher ist aber beim Fuss die Contactreizbarkeit. Der Fuss einer normalen Actinia erquina heftet sich an der Oberfläche fester Körper an. Für die Auslösung dieser Anleftungsrorgänge ist die Oberflächenbeschaffenheit des festen Körpers ron grosser Bedeutung. Die Aktinie heftet sich, wenn sie keinen anderen Körper findet, an die Glaswand des Aquariums fest und gleitet auf derselben umher. Brachte ich aber die Schale einer Miesmuschel in das Aquarium und kam das Thier bei seinen Bewegungen an die Miesmuschel, so heftete es sich sofort an diese fest und blieb an derselben sitzen, gleichviel ob die Miesmuschel leer oder bewohnt war. Ebenso wirkte die Oberfläche eines Blattes von Ulven, die ich im Aquarium hielt. Während jederzeit, wenn das Thier an der Glasplatte sass, der Contact mit einem Ulvenblatt zur Folge hatte, dass das Thier sich an die Ulva festheftete und die Glasplatte verliess, trat das Umgekehrte nicht leicht ein. Diese Contactreizbarkeit des Fusses ändert sich nicht, wenn man dem Thier den Kopf oder die grössere orale Partie abschneidet. Die Mechanismen zur Auslösung dieser Reactionen müssen also im Fuss der Aktinie vorhanden sein.

5) Bei den höheren Thieren kennen wir ein Bestreben, ihren Körper in bestimmter, Weise in Raum zu orientiren. Wir nennen die betreffende Orientirung bei höheren Thieren gewöhnlich die Gleichgewichtsstellung des Thieres. Auch gewisse Aktinien zeigen solche Erscheinungen. Setzt man einen Cerianthus in ein mit Seewasser gefülltes Reagenzglas so, dass der Kopf des Thieres unten, der Fuss oben sich befindet, die Längsaxe des Thieres aber in die Verticale fällt, so beginnt nach einigen Minuten die Spitze des Fusses sich vertikal abwärts zu krümmen. In Fig. 13 ist der Verlauf eines solchen Versuches nach dem Leben abgebildet. Einige Minuten vor 12 Uhr war das Thier in der angegebenen Weise in das Reagenzglas gestellt worden. Um 12 Uhr hatte der Fuss seine Abwärtskrümmung begonnen (Fig. 13 a), in den nächsten 13 Minuten war die Krümmung gegen den Kopf hin fortgeschritten (b), 5 Minuten später hatte der Fuss die Basis des Reagenz- 
glases erreicht (Fig. 13 c). Die Krümmung ergriff inmer neue, dem Kopf näher gelegene Elemente; da der Fuss auf den Borlen des Rea-

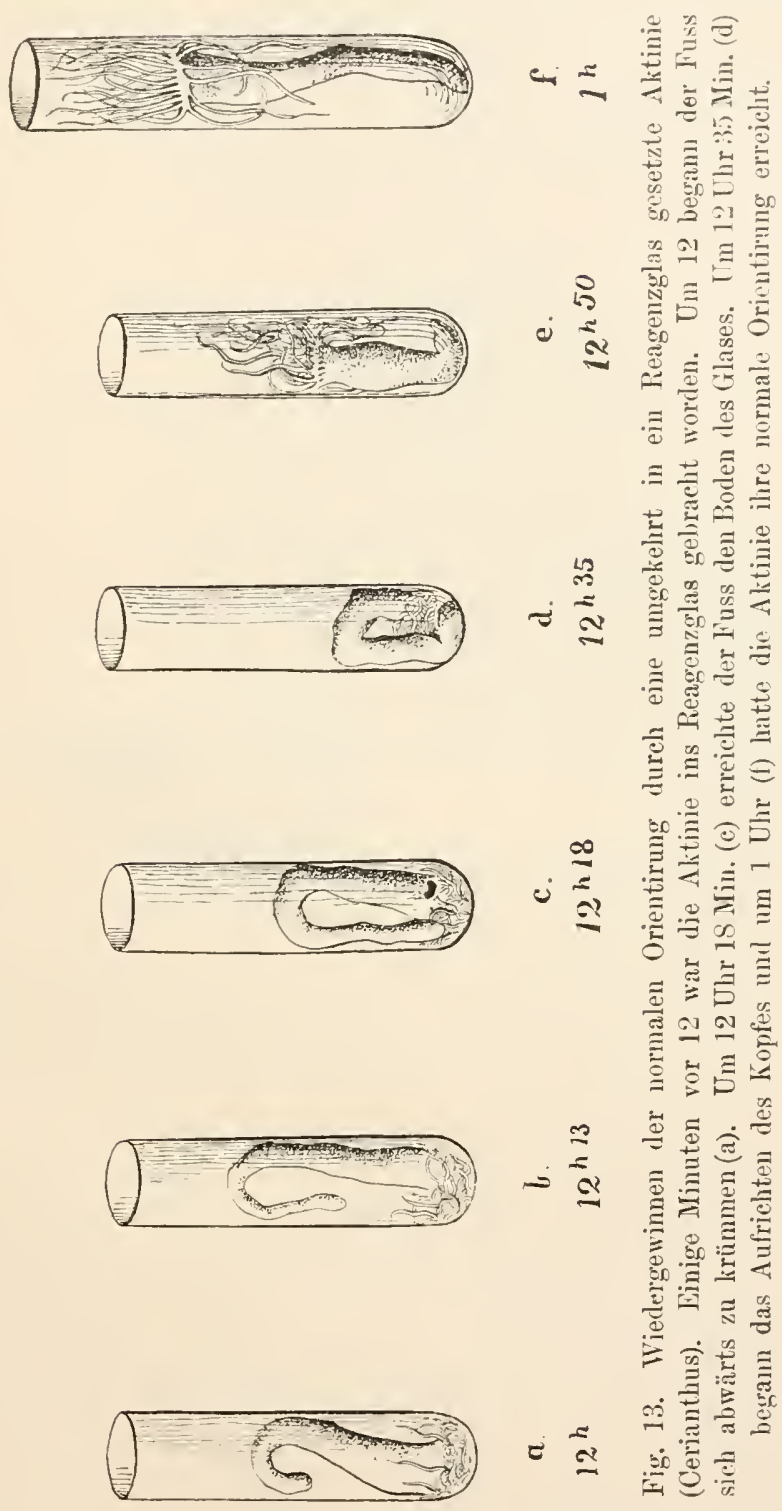

genzglases stiess, so hatte das weitere Fortschreiten der Krïmmung gegen den Kopf die Hebung des letzteren zur Folge (Fig. 13 d und e) und dann richtete sich das Thier ganz auf und hatte um $1 \mathrm{Uhr}$ die 
Stellung (f). In einer Stunde war also der Orientirungsvorgang abgelaufen. Nunmehr blieb das Thier 2 Tage lang in dieser Stellung, und dann kroch es aus dem Reagenzglas.

Wenn wir die Bedingungen analysiren, die das Aufrichten des Cerianthus in diesem Falle bestimmen, so kommen zwei Umstände in Betracht: Die Sehwerkraft und die Berührungsreize. Es lässt sich nun leicht zeigen, dass die Schwerkraft allein im Stande ist, die geschilderte

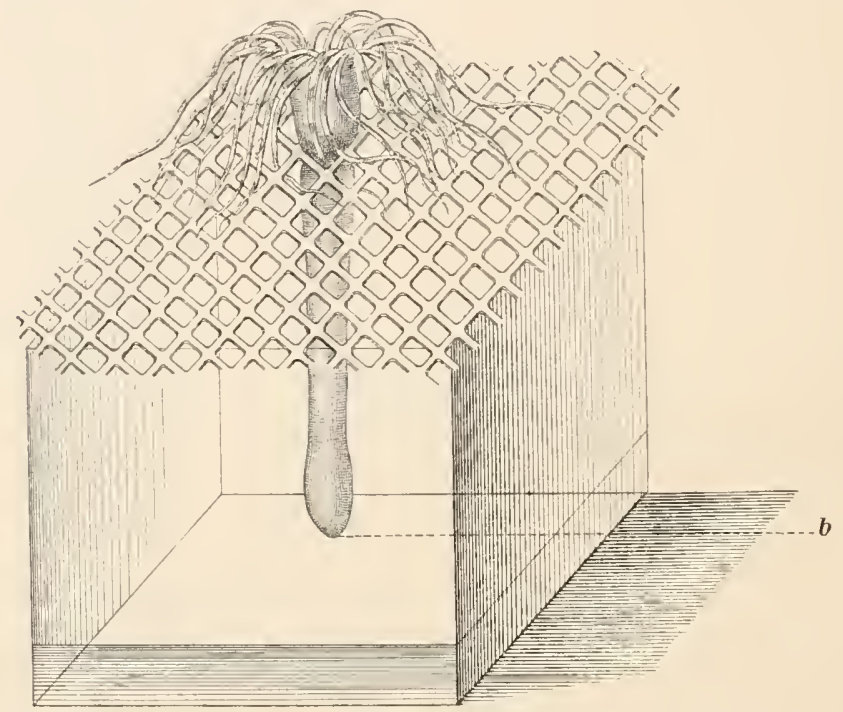

Fig. 14. Wiedergewinnen der normalen Orientirung durch einen Cerianthus. Das Thier war horizontal auf das Drahtnetz gelegt worden, zwängte sich durch die Maschen und erreichte im Laufe einer halben Stunde seine normale rertikale Stellung.

Reaction der Cerianthen herbeizuführen. Ein Drahtnetz, dessen Maschen so eng sind, dass es nur mit Anwendung von Gewalt möglich ist, den Körper eines Cerianthus durch dieselben durehzuziehen, wird horizontal auf ein im Aquarium stehendes Glas gelegt (Fig. 14). Auf das Drahtnetz wird ein Ceriantluus gelegt. Nach wenigen Minuten beginnt der Fuss des Thieres sich nach abwärts zu krümmen und sich durch eine Masche des Drahtnetzes durchzubohren. Am oralen Pol tritt dabei keine andere Veränderung ein, ausser dass die Tentakel sich dicht zusammenlegen, so dass sie aussehen wie ein Pinsel, dessen Stiel von dem Körper des Thieres gebildet wird. Das Thier zwängt seinen Körper immer weiter durch die Maschen, bis es endlich in verticaler Stellung sich halten kann, so wie es in Fig. 14 dargestellt ist. Diese Orientirung 
kann im Laufe einer haben Stunde erreicht werden. Kehrt man, sobald das Thier die in Fig. 14 abgebildete Stellung erreicht hat, das Drahtnetz um, so dass der Fuss nach oben gerichtet ist, so zieht es sich nicht etwa wieder aus dem Drahtnetz heraus, sondern der Fuss beginnt wieder sich abwïrts zu krümmen wie in Fig. 13; die Krümmung schreitet dann ron Element zu Element des Körpers, ron dem Fuss gegen den Kopf hin, fort; sobald die Spitze des Fusses wieder das Drahtnetz berührt, zwängt sie sich wieder durch und zwar so weit als möglich. Kehrt man dann das Drahtnetz noch einmal um, so wiedorholt sich der Torgang ron Neuem. Man kann so bloss mit Hilfe der Schwerkraft das Thier zwingen, sich mehrfach durch die Maschen des Drahtnetzes durchzuwinden. Fig. 15 zeigt einen Cerianthus, welcher auf diese Weise drei Mal durch die Maschen durehgezogen ist bei $a, b$ und c. Die Zeichnung ist nach dem Leben angefertigt. Es handelt sich also in diesen Versuchen um eine geotropische Reizbarkeit, um positiren Geotropismus. Da diese Art Reizbarkeit bei Wurzeln ron Pflanzen sehr häufig ist, so folgt hieraus schon, dass für den Mechanismns dieser Reizwirkungen keinerlei specifische Eigenschaften der Ganglienzellen nöthig sind. Macht man in der Mitte des Cerianthus einen queren Einschnitt, der die beiden Hälften nahezu, aber nicht völlig ron einander trennt, und legt man dann

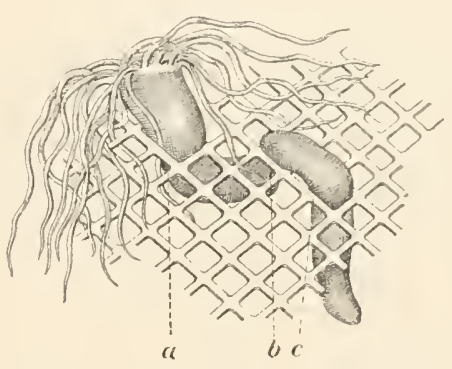

Fig. 15. Aktinie, die mit Hülfe der Schwerkraft gezwungen wurde, sich dreimal (bei a, b und c) durch die Mascheu des Drahtnetzes durchzuwinden. (Siehe Text.)

ein solches Thier unmittelbar nach der Operation anf das Drahtnetz so bohrt sich der Fuss bis zur. Stelle des Einschnittes durch die Nasche und stellt sich in die Verticale. Das orale Stück dagegen, von der Einschnittstelle bis zum Kiopf, bleibt gewöhnlich horizontal auf dem Drabtnetz liegen. Das zeigt, dass der Fuss geotropische Reizbarkeit besitzt. Durchschneidet man die Aktinie aber vollständig der Quere nach, so sieht man nicht nur das Schwanzstïck sich durch die Maschen durchbohren, sondern auch, wenngleich nicht so hänfig, das Kopfstïck.

Während nun eine Alitinie, die rertical in einem Reagenzglas oder in der Masche eines Drahtnetzes schwebt, in dieser Lage selten länger als zwei Tage bleibt, bleibt sie dauernd im Sande stecken, wenn sie ihren Fuss einmal in denselben eingebohrt hat. Neben der Schwerkraft muss noch ein anderer Reiz sie hier festhalten. Ich glaube, dass das der Contactreiz des Sandes ist. Eine derartige Reizbarkeit bezeichnete 
ich als positiven Stereotropismus und ich habe gezeigt, dass der Stereotropismus bei einer Reihe von Thieren für ihre Lebensgewohnheiten bestimmend ist. Der positive Geotropismus und der positive Stereotropismus veranlassen die Cerianthen, sich rertical in den Sand einzubohren, und der positive Stereotropismus hält sie dauernd im Bohrloch fest.

Wir sehen also, dass bei diesen Thieren, welche noch kein eigentliches Centralnervensystem im Sinne der höheren Thiere besitzen, dennoch recht complicirte Reactionen rorhanden sind. Wenn wir denselben Reactionen bei höheren Thieren begegneten, würden wir sicher a priori geneigt sein, dieselben auf die complicirte Struktur des Centralnervensystems zurückzuführen. Die Versuche an Aktinien werden vielleicht uns davor bewahren, einen solchen Schluss zu ziehen, ehe wir zwingende Grïnde dafür haben. Ein hoher Grad der Complication in den Reactionen eines Thieres kann erreicht werden, olne dass das Centralnerrensystem mehr dabei zu thun braucht, als die blosse protoplasniatische Verbindung zu vermitteln. Die Ursache der complicirten Reactionen liegt alsdann in morphologischen und namentlich chemischen Strukturverhältnissen der peripheren Organe. Das ist beispielsweise bei den Aktinien der Fall. Die folgenden Kapitel werden uns aber zeigen, dass das in Princip ebenso bei höheren Thieren zutrifft.

\section{Litteratur zu IV.}

1) Loeb, J. Untersuchungen zur Physiologischen Morphologie der Thiere. I. 1891. Würzburg. G. Hertz.

2) Loeb, J. Zur Physiologie und Psychologie der Aktinien. Pflüger's Archiv Bd. 59. 1895.

3) Parker, G. H. The Reactions of Metridium to Food and other Substances. Bullet. of the Inseum of comparative Zoology at Harvard College. Vol. XXIX. 1896.

4) Pollock. W. H. On Indications of the Sense of Smell in Actiniae. Journ. Linnean Soc. London. Zoology. Vol. 16. 1882.

5) Nagel, teraten. Pflüger's Archiv Bd. 57. 1894. 


\section{Versuche an Echinodermen.}

1) Das Nervensystem der Seesterne besteht 1. aus einem centralen Nervenring, der den Hund umgiebt (Fig. 16) und 2. aus den peripheren Nerven, die ron diesem Ring in jeden der Arme ausstrahlen. Durch diesen Complex ron Fasern ist eine protoplasmatische leitende Verbindung zwischen allen contractilen und sensibeln Theilen des Thieres hergestellt. Bei Thieren von der Art der Aktinien oder gar der Hydroidpolypen wird eine solche Verbindung dadurch herbeigeführt, dass eine Uebertragung der Erregung von Element auf Element ohne Vermittelung ron Nerven möglich ist.

Es ist eine Erfahrung, die wohl so alt ist, wie die Kenntniss der Seesterne selbst, dass wenn man ein solches Thier auf den Rücken legt, es sich alsbald wieder in die Bauchlage zurückdreht. Diese Umdrehung wird bei gewissen Arten, wie die in Fig. 17 abgebildeten, dadurch herbeigeführt, dass die Ambulacral-

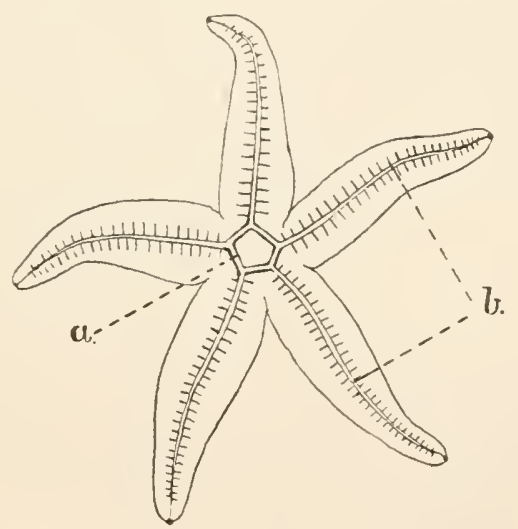

Fig. 16. Nervensystem eines Seesterns. a centraler Nerrenring, der den Mund umgiebt, b periphere Nerven der Arme. füsschen, welche in grosser Zahl die ventrale Oberfläche eines Seesternes bedecken, das Thier in die Bauchlage zurückziehen. Diese Füsschen sind muskulöse Schläuche, die in eine Platte enden. Mit dieser Platte kann sich das Füsschen ähnlich wie der Blutegel an harten Gegenständen festheften.

Legt man einen Seestern auf den Rücken, so sieht man zunächst, dass die Füsschen aller Arme ausgestreckt und wie tastend hin- und 
herbewegt werden, wälırend alsbald die Spitzen eines oder mehrerer Arme sich umdrehen und mit ihrer ventralen Seite den Boden berühren (Fig. 17). Die Füsschen dieser Arme heften sich am Boden fest, bis das Thier einen Purzelbaum schlägt und damit in die Banchlage zurück kommt. Dabei ist aber eine Bedingung nöthig, nämlich, dass nicht alle fünf Arme gleichzeitig rersuchen, das Thier in die Bauchlage

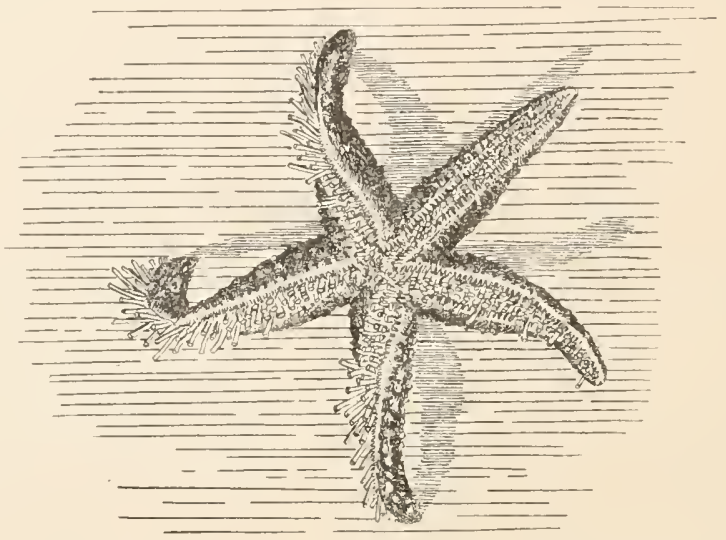

Fig. 17. Jechauismus des Aufrichtens bei einem auf den Rücken gelegten Seestern. Die Ambulacralfüsschen der 3 nach links gelegenen Arme ziehen am Boden des Aquariums, währeud die 2 anderen Arme in Ruhe bleiben. Das ganze Thier schlägt in Folge dessen einen Purzelbaum nach links und kommt in die Bauchlage zürück.

zurückzubringen. Würden die Füsschen der Spitzen aller fünf oder auch nur von vier Armen gleichzeitig ziehen, so wäre es unmöglich, dass das Thier je in die Bauchlage zurück käme. Thatsächlich sehen wir nun, dass bei normalen fünfarmigen Seesternen nur je drei der Arme die Undrehungsthätigkeit begimnen, während die beiden übrigen ruhen. Heben wir aber die nersöse Verbindung zwischen den Armen auf, etwa durch zwei Einschnitte bei a und b Fig. 1S, so hört auch diese Cooperation der Arme auf, wenn das Thier auf den Rücken gelegt wird. Las in Fig. 18 gezeichnete Thier lag den ganzen Nachmittag auf dem Rücken, obwohl seine Arme beständig daran arbeiteten, es in die Bauchlage zurück zu bringen. Der normale Seestern drehte sich in wenigen Minuten in die Banchlage zurück. Wir müssen aus diesen Versuchen schliessen, dass wenn zwei oder drei Arme ein normales Thier in eine Ricbtung ziehen, dieser Reiz hemmend auf die anderen Arme wirkt. 
Diese Hemmung fällt fort, wenn man die nerröse Terbindung zwischen den einzelnen Armen aufhebt, beispielsweise durch Durchschneidung des centralen Nervenrings wic in Fig. 18. Romanes hat gefunden, dass ein einzelner Arm, der nur den peripheren Armmers enthält, sich noch in die Bauchlage zuriick drelıt, wenn man ilın auf den Rücken legt (1). Der

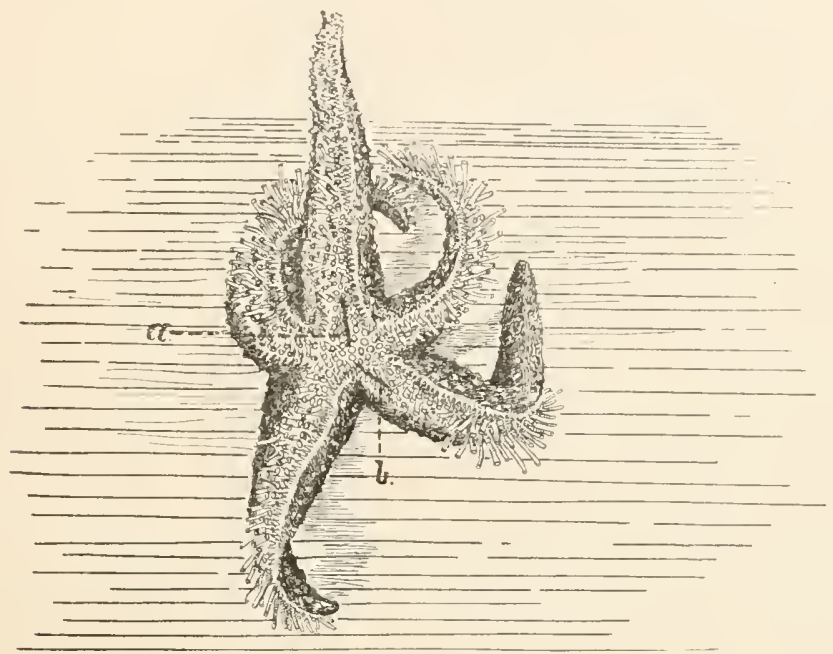

Fig. 1S. Derselbe Verstch bei einem Seestern, dessen centraler Nervenring an 2 Stellen bei a und b durchtrennt worden ist. In Folge dessen sind die rechts und links gelegenen Arme nicht länger in nervösem Zusammenhang. Wird ein solches Thier auf den Rücken gelegt, so arbeiten meist die Ambulacralfüsschen von 4 oder sogar von allen Armen und das Thier kommt alsdann nicht in clie Bauchlage zurück.

centrale Nervenring kommt also nur als Reizleiter und nicht als "Centrum" für dliese Reaction in Betraclit.

2) Wenn wir diesen Umdrehreflex der Seesterne analysiren, so haben wir an zwei Möglichkeiten zu denken. Entweder ist es die Schwerkraft, welche die Seesterne zwingt, die ventrale Seite dem Schwerpunkt der Erde zuzudrehen, oder es handelt sich un Contactreizbarkeit insofern, als das Thier gezwungen ist, die ventrale Fläche seines Körpers mit festen Körpern in Berührung zu bringen, während die dorsale Seite vielleicht die entgegengesetzte Reizbarkeit besitzt.

Dass die Schwerkraft nicht die Ursache ist, geht daraus hervor, dass die Thiere den horizontalen Boden eines Aquariums rerlassen und sich an den verticalen Wänden festheften. Es kamn also nnmöglich bei 
diesen Thieren ein Zwang bestehen, ihre ventrale Seite dem Schwerpunkt der Erde zuzuwenden.

Preyer hat einen Versuch gemacht, aus dem er schliesst, dass die Wendung der Seesterne darauf beruhe, dass sie die Bauchseite nach unten kehren müssen (2). Er suspendirte einen Seestern in der Mitte eines Aquariums in der Weise, dass er je einen Arm desselben mit einem Faden an einen Kork befestigte, der an der Oberfläche des Aquariums schwamm. War nun der Seestern mit dem Rücken nach unten aufgehängt worden, so beobachtete Preyer, dass er sich in die umgekehrte Lage, mit dem Batche nach unten, umdrehte. Das könnte allerdings die Vermuthung veranlassen, dass es sich bei der Selbstwendung der Seesterne doch um eine geotropische Erscheinung handelt. Ich habe nun den Versuch Preyer's wiederholt und seine Beobachtung bestätigt gefunden; aber gleichzeitig stellte ich einen Controllversuch an, den Preyer unterlassen hat. Ich befestigte den Seestern von vornherein so an die Korkplatte, dass die Bauchseite dem Boden zugekehrt war. Allein auch in diesem Falle drehte sich der Seestern un, und zwar in die Rückenlage. Es handelt sich also bei diesem Versuch nicht darum, dass das Thier eine bestimmte Orientirung aufsucht, sondern nur darum, dass die Suspension es in Unruhe versetzt und dass es allerlei windende Bewegungen ausführt, wobei es natürlich gelegentlich auch Wendungen ausführt. Ich glaube vielmehr, dass auch dieser letzte Versuch dafür spricht, dass die ventrale Seite des Seesterns stereotropisch ist, oder dass m. a. W. der Seestern unruhig wird, wenn seine Ambalacralfüsschen nirgends feste Körper berïhren.

3) Preyer hat den Seesternen auch „Intelligenz" zugeschrieben (2). Er steckte bei Ophiuriden einen Arm in ein Stück Gummischlauch, um zu sehen, ob das Thier gescheit genug sei, sich von diesem Hinderniss bei seinen Bewegungen zu befreien. Er fand, dass nach einiger Zeit der Arm aus dem Schlauch befreit wurde. Ich habe den Versuch bei diesen Thieren wiederholt und gefunden, dass die Ophiuriden sich in dem Fall um den Gummischlauch nicht kümmern. Allerdings verliert das Thier den Gummischlauch nach einiger Zeit, falls er nicht zu eng ist. Aber das ist stets der reine Zufall und es ist dabei nicht mehr Intelligenz im Spiele, wie bei der Leine, wenn der Wind die daran aufgehängte Wäsche herunterwirft. Romanes hat gefunden, dass wenn man bei Seesternen einen Arm reizt, der Seestern sich in der Richtung vom gereizten Arm fort entfernt (1). Auch das sieht wie ein intelligenter Akt aus, das Thier scheint im Stande zu sein, sich aus der Verlegenheit zu befreien. Prof. W. W. Norman aber machte mich darauf aufmerksam, dass wenn man bei einem Seestern einen Arm reizt, die Füsschen dieses 
Armes alle eingezogen werden und der Arm unbeweglich wird. Das ist jedoch nur für den gereizten Arm der Fall, während die ïbrigen Arme thätig bleiben. Es muss also in diesem Fall nach dem Parallelogramm der Kräfte eine Bewegung ron der Reizstelle fort erfolgen. Es ist dabei nicht mehr Intelligenz bei dem Seestern im Spiele wie bei dem Segelboot, welches ebenfalls dem Parallelogramm der Trrifte folgt.

4) Bei vielen Echinodermen ist eine Reaction in sehr ausgesprochener Weise rorhanden, die auch sonst in der Thierreihe häufig ist, nämlich ein Bestreben, an vertikalen Flächen in die Höhe zu kriechen. Yan findet ein solches Bestreben bei pflanzlichen Organismen, z. B. Plasmodien von Myxomyceten, wo Sachs es auf negativen Geotropismus zurückgefïhrt hat. Es findet sich bei Aktinien, z. B. Actinia mesembryanthemum des Nittelmeers. Unter den Insecten zeigen die Coccinellen es in dieser Weise.

Bei Echinodermen ist diese Erscheinung sehr weit verbreitet, Ich will die Schilderung dieser Erscheinung, die ich in einer früheren Arbeit gegeben habe (3), hier wiederholen.

Jedem, der bei ruhiger See die an Felsen orler an Pfählen nahe der Meeresoberfläche sitzenden Thiere betrachtet, wird die relatir grosse Zahl von Stachelhäutern auffallen. Hanche dieser Echinodermen, z. B. die im Golf von Neapel sehr häufig vorkommende Cucumaria cucumis, leben nur nahe der Oberfläche bis zu einer Tiefe ron etwa $30 \mathrm{~m}$. Bei Cucumaria encumis lässt sich zeigen, dass sie wie die Plasmodien oder die Coccinellen an vertikalen Flächen emporkriechen muss und dass keine andere Ursache als die Schwerkraft dieses Verhalten bestimmen kann. Cucumaria cucumis hat einen langgestreckten 5kantigen Körper von etwa $10 \mathrm{~cm}$ Länge oder darüber, der an seinem oralen Ende radiär gestellte baumartig verzweigte Fühler trägt. An jeder der 5 Kanten stehen 2 Längsreihen kleiner Füsse, mit denen das Thier im Stande ist, selbst an glatten Glaswänden emporzukriechen. Bringt man diese Thiere in ein Aquarium, so kriechen sie auf dem Boden desselben so lange umher, bis sie an eine vertikale Wand gelangen; sie klettern alsdann an derselben empor und bleiben an der höchsten Spitze derselben, wenn möglich dicht unter dem Wasserspiegel sitzen. Diese Orientirung bleibt dann gewöhnlich dauernd und das Thier ist ron nun an ein festsitzendes.

Lässt man eine solche Cucumaria sich an einer vertikalen Glaswand festsetzen, die man beliebig im Aquarium um eine horizontale Axe drehen kann, so ist das Thier unermüdlich. immer wieder nach oben zu kriechen, so oft man die Scheibe um $90^{\circ}$ gedreht hat. Um eine compensatorische, durch die Centrifugalkraft ausgelöste Bewegung handelt 
es sich dabei nicht; wälnend der Drehung der Scheibe bleibt das Thier in Ruhe und lange nachher, rielleicht $1 / 4-1 / 2$ Stunde nach der Drehung, beginnt es erst seine Wanderung nach oben. Es handelt sich hierbei anch nicht um eine Wirkung des ron oben einfallenden Himmelslichtes. Bringt man die Thiere in ein Aquarium, in welches man mit Hülfe passender Vorrichtungen nur Licht ron aussen und unten her einfallen lässt, so kriechen die Thiere dennoch an den rertikalen Flächen in die

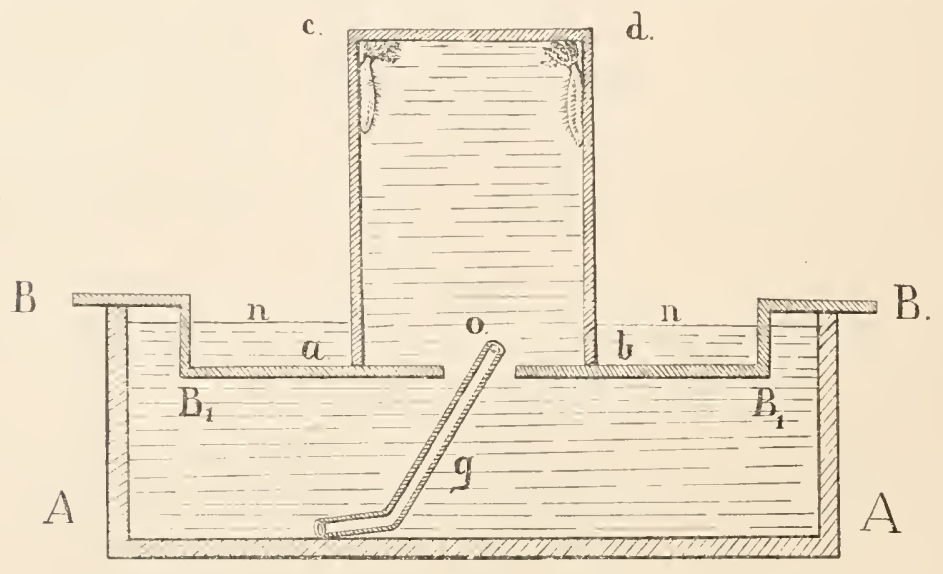

Fig. 19. Geotropische Reaction von Cucumaria cucumis.

Die Thiere befinden sich in einem Batterieglase a b c d. Dasselbe ist mit Wasser gefüllt und ruht auf der Brïcke BB im Aquarium AA. Frisches Seewasser wird den Thieren durch das Rohr $\mathrm{g}$ bei o zugeführt. Die Thiere sammeln sich an der höchsten Stelle c d des Gefässes.

Höhe, ohne sich im Uebrigen in der Richtung ihrer Bewegung durch das Licht irgendwie beeinflussen zu lassen. Genau so wie im Licht verhalten sie sich auch im Dunkelzimmer.

Man könnte denken, dass das Bedürfniss nach Sauerstoff die Aufwärtsbewegung der Cheumarien zur Oberfläche des Wassers bestimmt. Allein es lässt sich zeigen, dass anch das nicht der Fall ist. Stellt man ein sehr grosses Becherglas, nachdem man alle Luft in demselben durch Wasser verdrängt hat, verkehrt, d. h. mit dem Boden nach oben ins Aquarium, so beginnen die unter dem Becherglas befindlichen Cucumarien dennoch bis zum Boden des Glases in die Höhe zu steigen. Sie thun dasselbe auch dann, wenn man den Versuch in der f'orm anstellt, die in der untenstehenden Figur 19 veranschaulicht ist. In das Aquarium AA Fig. 19 ist eine Brüicke BB gelegt, deren horizontaler Theil $\mathrm{B}_{1} \mathrm{~B}_{1}$ sich unter dem Wasserspiegel $\mathrm{n}$ des Aquariums befindet; derselbe hat einen kreisförmigen Ausschnitt o, über welchem das Becherglas abcd, 
in dem wieder die Luft durch Wasser verlrängt ist, rerkehrt aufgestellt wird. Durch eine passend gebogene Glasröhre $g$ wird frisches Wasser unter geringem Druck bei o zugeführt. Gleichwohl gehen die Cucumarien ron o fort und setzen sich an der Fläche ed oder an den rertikalen Wänden nahe bei cd fest. (Fig. 19.)

Es handelt sich aber auch nicht darum, dass der hydrostatische Druck die Thiere zwingt, zum Niveau emporzukriechen. Denn bringt man die Thiere in eine ganz flache Schale, in der die Wasserhöhe nur 1 -2 cm beträgt, so dass die Thiere nur eben unter dem Wasserspiegel sich befinden, so gehen sie gleichwohl an die vertikale Wand und heften sich an dieser fest, obwohl sie damit dem Niveau nicht näher kommen, als sie schon ohnedies sind. - Rleotropisnus und Hydrotropismus sind bei der Natur der Tersuchsberlingungen ausgeschlossen.

Versuche auf der Centrifugalmaschine luatten kein Ergebniss, da die Thiere überhaupt wäbrend der Drehung keine Bewegungen ausfülırten. Der einzige Umstand, der die Thiere zwingt, vertikale Flächen anfzusuchen und an denselben in die Höhe zu kriechen, kann nur die Schwerkraft sein, und zwar wïrle ich mir den Zwang, den die Schwerkraft ausübt, in ähnlicher Weise vorstellen, wie bei den Insecten, z. B. dem aus der Puppenhülle auskriechenden Schmetterlinge. Die Flügel desselben sind unmittelbar nach dem Auskriechen noch nicht entfaltet und das Thier läuft in stetiger Unruhe auf dem horizontalen Boden hin und her, bis es an eine rertikale Fläche geräth; an dieser krjecht es hoch, um dann an derselben mit dem Kopf nach oben relativ lange Zeit stetig sitzen zu bleiben, bis nach Entfaltung der Flügel andere Umstände ron Neuem das Thier in Unruhe bringen.

Diese Abhängigkeit der Cucumarien von der Schwerkraft muss die Thiere zu Bewohnern der Oberflächenregionen des Meeres machen. Würde auch eine Larve in grössere Tiefen verschlagen, sie wäre durch ihren negativen Geotropisnus gezwungen, rastlos aufwärts zu kriechen, bis der höchste Punkt erreicht wäre oder der Tod dem Emporstreben ein Ende setzte.

Wie Cucumaria verhalten sich gewisse Seesterne, wie Asterina gibbosa. Alle Versuche, welche ich an Cucumaria angestellt habe, gelingen auch bei Asterina gibbosa, nur mit dem Unterschied, dass die ausserordentlich gefrässige Asterina, wenn sie den höchsten Punkt einer vertikalen Ebene erreicht hat, und keine Nahrung dort findet, an demselben nicht dauernd sitzen bleibt wie Cucumaria, sondern nach 2 Tagen etwa oder noch früher sich wieder in Bewegung setzt oder auch herunterfallen lässt. Auch Asterina gibbosa lebt nur nahe der Oberfläche des Meeres. 
Wie der negative Geotropismus, so wirkt natürlich auch der positice Heliotropismus. Asterina tenuispina lebt wie Asterina gibbosa an der Oberfläche des Meeres. Sie ist aber geotropisch nicht reizbar; dagegen ist sie positiv heliotropisch. Ich brachte eine grössere Zahl von Exemplaren beider Species zusammen auf einen Haufen in ein Aquarium, in welches nur von einer Seite her nahezu horizontale Lichtstrahlen einfielen. In kurzer Zeit vollzog sich rollständige räumliche Trennung beider Thiere. Die Tenuispinae krochen auf dem Boden zur Lichtquelle hin, die Asterinae gibbosae vertheilten sich auf dem Boden allseitig und krochen an den rertikalen Wänden in die Höhe, ohne durch das Licht in der Richtung ihrer Bewegung beeinflusst zu werden. Im Meere, wo nur wesentlich die rertikal einfallenden Strahlen des Himmelslichtes für die räumliche Orientirung der Thiere in Betracht liommen, muss der positive Heliotropismus Asterina tenuispina ebenso an die Oberfläche des Meeres treiben, wie es in Folge des negativen Geotropismus bei A. gibbosa geschieht.

Preyer erwähnt kurz in seiner umfangreichen Arbeit ïber „die Bewegungen der Seesterne" die "Tendenz dieser Thiere nach oben", welche ihm bei seinen Versuchen über das Klettern der Seesterne aufgefallen ist. Die betreffende Stelle im Aufsatze Preyer's lautet: „Die aus all diesen Beobachtungen hervorgehende starke Tendenz der Seesterne und Schlangensterne nach oben kann nicht auf Luftmangel, Nahrungsmangel, Temperatur- oder Strömungsänderungen, auch nicht auf Lichtsucht zurückgeführt werden, denn das Emporklettern geschieht ebenso, wo diese Gründe fortfallen. Wahrscheinlich reranlasst irgend eine Eigenthümlichkeit des Bodens oder gerade der Stelle desselben, wo das Thier sich befindet, und welche zum Ansaugen oder zum längeren Verweilen ungeeignet geworden, zum Hinaufsteigen. Doch können auch Parasiten, welche ich oft in den Ambulacralfurchen bei Luidia u. a. fand, zur Flucht nach oben reranlassen, indem die durch diese bedingten Reize als von unten kommende dem horizontalen Boden zugehörig erscheinen könnten" (2).

Der erste Satz ist in dieser Allgemeinheit unrichtig, das Licht ist thatsächlich die Ursache, welche Asterina tenuispina nach oben treibt. Was zweitens die Annahme betrifft, dass die Beschaffenheit des Bodens die Thiere nach oben treibe, so lässt sich dieselbe durch folgenden Versuch widerlegen. Bringt man Asterina gibbosa in einen würfelförmigen Kasten mit gläsernen Wänden, so verlassen die Thiere die basale horizontale Wand, und klettern an den vertikalen Wänden in die Höhe. Dreht man mun den Kasten um $90^{\circ}$ um eine horizontale Axe, so wird die jetzt basale Wand ron den Thieren verlassen, während diese an der 
Wand, die sie vorher verlassen hatten, weil sie horizontal lag, jetzt emporkriechen und sitzen bleiben. Die Beschaffenheit der Wand war also nicht die Ursache für das Aufwärtskriechen der Seesterne. Wenn endlich Preyer glaubt, dass Parasiten die Thiere zwingen, nach oben zu kriechen, so ist nicht abzusehen, warum die Parasiten nicht die an der vertikalen Wand sitzenden Thiere wieder heruntertreiben sollten, da diesen doch die ron den Parasiten herribrenden Reize nunmehr als von der vertikalen Wand ausgehend erscheinen müssten. Thatsächlich aber bleibt Asterina gibbosa (und noch vielmehr Cucumaria cucumis) an der höchsten Stelle der vertikalen Wand sitzen. Ich glaube, es liegt doch wohl näher, bei den vertikalen Aufwärtsbewegungen gewisser Seesterne an einen Einfluss der in vertikaler Richtung wirkenden Schwerkraft zu denken.

\section{Litteratur zu $\Gamma^{\top}$.}

1) Ronianes. G. J. Jelly-Fish, Star-Fish anı Sea-Urchins. New York 1893.

2) Preyer, W. Ueber die Bewegungen der Seesterne. Mittheilungen aus der zoologischen Station zu Neapel. Bd. VII. S. 96. (Hier die ältere Litteratur.)

3) Loeb, Jacques. Ueber Geotropismus bei Thieren. Pflüger's Archir Bd. 49. 1891. 


\section{Versuche über die Gehirnphysiologie der Würmer.}

1) Für die Zwecke der Gehirnphysiologie dürfen wir die Würmer in zwei Hauptklassen theilen: Solche, bei denen die Ganglien am Kopfende zusammengedrängt sind, während der übrige Körper keine segmentalen Ganglien enthält (z. B. Planarien) und zweitens Würmer mit einer Reihe segmentaler Ganglien (Amneliden). Wir werden hier nur die

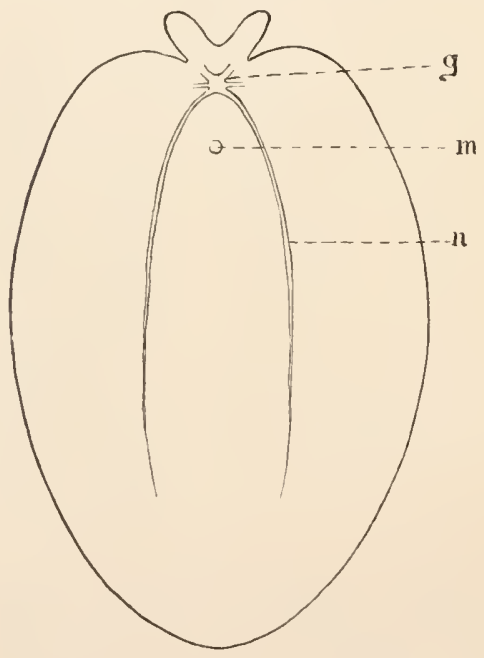

Fig. 20. Thysanozoon Brocchii, eine marine Planarie.

g Gehirn, m Mund, n Längsnerv.

Schematisch nach Lang.
Planarien und Anneliden besprechen. Wir unterscheiden See- und Süsswasserplanarien. Es ist auffallend, class bei wenig verschiedenem Bau beide Formen auf den Verlust des oralen Ganglions in verschiedener Weise reagiren.

Thysanozoon (Brocchii), Fig. 20, ist eine marine Planarie, die im Golf von Neapel häufig ist und etwa 1 bis $3 \mathrm{~cm}$ lang und nahezu ebenso breit wird. Am rorderen Körperende, das durch zwei Tentakel ohne Weiteres kenntlich ist, befindet sich das Gehirn des Thieres (g Fig. 20). Dasselbe besteht aus zwei mit einander verbundenen Ganglien, von denen eine Reihe von Nerven ausgehen. Unter diesen ragen die beiden grossen Längsnerren (n Fig. 20) hervor, die das ganze Thier nach hinten der Länge nach durchlaufen. Die Nerven enthalten einzelne Ganglienzellen, eine Eigenthümlichkeit, die sich ja bekanntlich auch 
bei einzelnen peripheren Nerven höherer Thiere findet. An der Peripherie bilden die Nerven Plexus. (1) Das eigentliche Centralnervensystem dieser Thiere besteht also aus dem am vorderen Lnde des Thieres gelegenen Doppelganglion. Wie alle Planarien kriecht Thysanozoon an den Wänden des Aquariums oder an Wasserspiegel. Allein es unterscheidet sich ron den Süsswasserplanarien in seinen Locomotionen dadurch, dass es im Stande ist, auch wirkliche Schwimmbewegungen auszuführen. Es führt dabei mit den seitlichen Theilen seines Körpers ähnliche Schwingungen aus wle ein Schmetterling mit seinen Flügeln.

Schneidet man ein Thysanozoon, während es am Wasserspiegel des Aquariums gleitet, mit einer Scheere der Quere nach in zwei Hälften, so fällt die hintere aborale Hälfte, b Fig. 21, sofort wie eine todte Masse za Boden, während das orale Stück, a Fig. 21, welches das Gehirn enthält, ruhig weiter kriecht. Ist der Schnitt rasch erfolgt und war die Scheere scharf, so deutet nichts im Verhalten des oralen Stückes auf eine Erregung von der Art hin, wie wir sie als Begleiterscheinung des Schmerzes bei höheren Thieren finden. Schneidet man das Thier mit einem scharfen Messer durch, wäh-
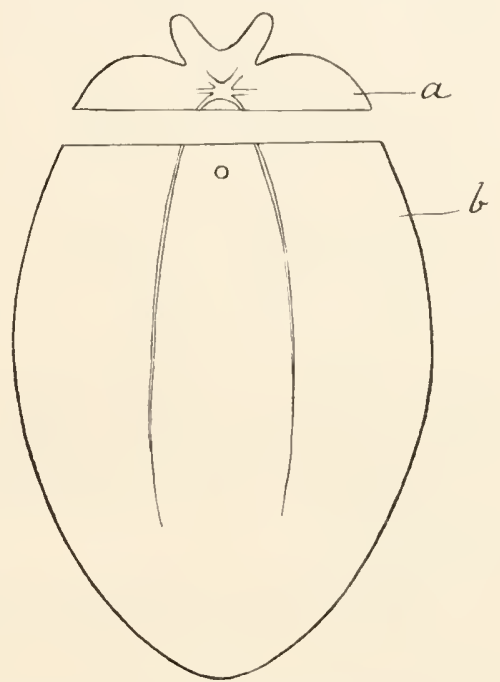

Fig. 21. Quere Durchsehneirhng eines Thysanozoon. Das vordere Stück a, welches das Gehiru enthält, zeigrt Spontanëität, das bintere gehirnlose Stück besitzt keine Spontanëität. rend es auf einer Glasplatte kriecht, so haben wir dieselbe Thatsache: das orale Stück kriecht unbeeinflusst weiter, während die Progressivbewegung des hinteren Stïckes sofort aufhört. Dass in der That bei diesem Thier die Progressirbewegungen eine Function des vorderen Stiickes sind, welches das Gehirn enthält wird besonders klar, wenn man bei einem sehr grossen (ca. $2 \mathrm{~cm}$ langen) Thysanozoon nur das kleine Stück, a Fig. 21, abschneidet, welches das Gehirn enthält. Dann kriecht oder schwimmt dieses winzige vordere Stiuck weiter, während der im Vergleich mit ihm colossal erscheinende Rumpf b keine Progressivbewegung mehr ausführt. Die Spontanëität der Progressivbewegung ist also bei Thysanozoon eine Function des das Gehirn enthaltenden Körpertheils (2).

2) Beide Stücke eines durchschnittenen Thysanozoon bleiben am LeL oeb, Vergleichende Gehirnphysiologie. 
ben und regeneriren die ihnen fehtenden Theile. Allein das orale Stïck regenerirt rascher als das aborale, welches einen Kopf zu bilden hat. $\mathrm{Ob}$ der letztere auch ein neues Gehirn bildet, habe ich nicht untersucht. Ich hielt solche Stücke 4 Monate an Leben. Die Spotanëität des aboralen Stückes kehrte nie zurück, die Spontanëität des oralen Stückes blieb dauernd erhalten.

Wir haben bei dem Fuss des Cerianthus, der physiologisch radiär gebant ist, einen allseitigen positiven Stereotropismus kennen gelernt. Bei den dorsorentralen Planarien haben wir positiven Stereotropismus auf der ventralen Seite, negativen Stereotropismus auf der dorsalen Seite; d. h. das Thier ist gezwungen, seine ventrale Seite mit festen Körpern und seinen Rücken mit Wasser in Berührung zu bringen. Bringt man den Rücken des Thieres in Berührung mit dem Boden des Aquariums und die Banchseite mit Wasser, so dreht sich das Thier in die Bauchlage zurück. Nan könnte nun auch denken, es handele sich hier um eine Wirkung der Schwerkraft, derart, dass dieselbe das Thier zwinge die Bauchseite gegen den Schwerpunkt der Erde zu wenden. Dass das nicht der Fall ist, wird dadurch bewiesen, dass Planarien lange an der Oberfläche des Wasserspiegels kriechen, wobei ihr Rücken nach unten gekehrt ist. Die Schwerkraft beeinflusst die Orientirung dieser Thiere nicht.

Es fragt sich nun, ob diese stereotropischen Orientirungserscheinungen bei Thysanozoon eine Function des Gehirns sind, wie die spontane Progressivbewegung. Das ist nun überraschender Weise nicht der Fall. Das enthirnte Thysanozoon dreht sich, wenn man es auf den Rücken legt, in die Bauchlage zurück, nur erfolgt die Reaction langsamer als beim normalen Thier oder überhaupt den hirnbegabten Stïck eines solchen Thieres. Wir sehen hier wieder, dass das Nervensystem nur der rascheren Reaction dient. - Reactionen gegen Licht lassen sich bei Thysanozoon nicht nachweisen.

Wenn man, anstatt die quere Durchschneidung ganz vollständig zu machen, die beiden Stücke noch durch eine sehr dünne Substanzbrücke an einer Seite in Verbindung lässt (Fig. 22), so kann das aborale Stück keine directen Innervationen durch die Längsnerven vom Gehirn erhalten. Eine Fortleitung der Erregung durch die seitlichen Nervenplexus wäre aber immerhin möglich.

Als ich unnittelbar nach der Operation ein solches Thier auf den Boden des Aquariums legte, setzte sich das orale Stück sofort in Bewegung, während das aborale Stiick sich am Boden festzuheften versuchte. Es folgte aber dem Zuge, welchen das orale Stïck ausübte und nahm num in völlig coordinirter Weise an der Progressivbewegung theil, 
als ob keine Durchschneidung stattgefunden hätte. Nach einiger Zeit machte las orale Stück Kehrt, kroch über den Rücken des aboralen Stückes hinweg, wobei dieses passir nachgezogen und auf den Rücken gelegt wurde. Es drehte sich aber sofort in die Bauchlage zurïck und bewegte sich dann actir in derselben Richtung wie das orale Stïck. Aenderungen der Bewegung gingen also nur vom oralen Stück aus, welches das Gehirn enthält und theilten sich dem aboralen Stïck niemals direct mit. Wenn aber das orale Stiick eine Zeit lang in derselben Richtung und mit derselben Geschwindigkeit sich bewegte. so trat die gleiche Bewegung alsbald auch in aboralen Stück ein. Es verhielt sich also das aborale Stück nicht ganz wie ein enthirntes Stück, da es überhaupt noch Progressirbewegungen ausführte, aber auch nicht wie ein normales Thysanozoon, da es seime Spontanëität verloren hatte. Das wird noch deutlicher aus folgender Beobachtung. Ich warf das Thier in ein Bassin mit Wasser. Beide Stücke machten energisch synchronische Schwimmbewegungen. Das orale Stïck erreichte nun im Schwimmen alsbald die vertikale Glaswand des Aquariums. In Folge einer Aenderung der Richtung der Bewegung des vorderen Stücks, wurde das Verbindungsstïck zwischen

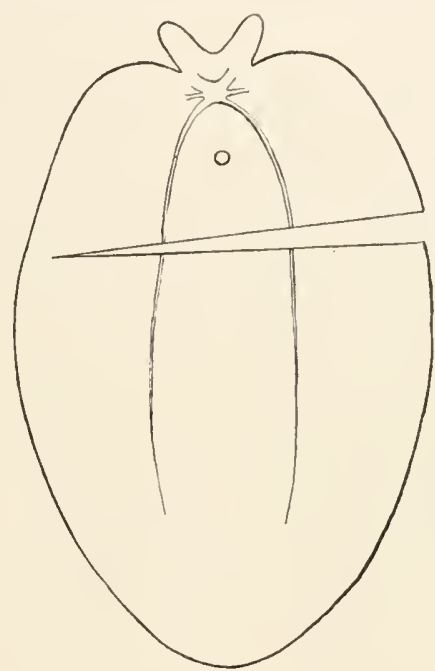

Fig. 22.

Partielle Querdurchschneidung von Thysanozoon. beiden Theilstücken des Thieres torquirt und das aborale Stück kam mit dem Rücken gegen die Glaswand, während die ventrale Seite desselben dem Wasser zugekehrt war. Jetzt führte es Schwimmbewegungen aus und folgte so den Kriechbewegungen des oralen Theilstückes. - Dass bei constanter Bewegung das hintere Stück activ an der Progressirbewegung theil nimmt und nicht bloss passiv nachgeschleppt wird, wird auch ferner daraus ersichtlich, dass es oft mit seinem freien Rand auf den Rüicken des oralen Thieres kroch, namentlich wenn das letztere plötzlich sich langsamer bewegte.

Diese Versuche zeigen, dass ein gehirnloses Stiick ron Thysanozoon sich nicht mehr spontan, d. h. ohne wahrnehmbare änssere Reizursache bewegt. Allein es gelingt auch nicht, durch irgend welche äussere Reizursache eine Progressivbewegung eines enthirnten Thysanozoon auszulösen. Berührt man es, so erfolgen locale Contractionen an der Be- 
rührungsstelle, aber keine Progressivbewegungen. - Schneilet man ein seitliches Stück parallel zur Medianebene eines Thieres ab, so erfolgt eine Contraction des Schnittrandes, die so stark sein kann, dass das Stiuck sich spiralig zusammenrollt. (Diese Contraction des Wundrandes erfolgt übrigens bei jeder Lage des trennenden Schnittes.) Das laterale Stück, welches kein Gehirn enthält, führt keine

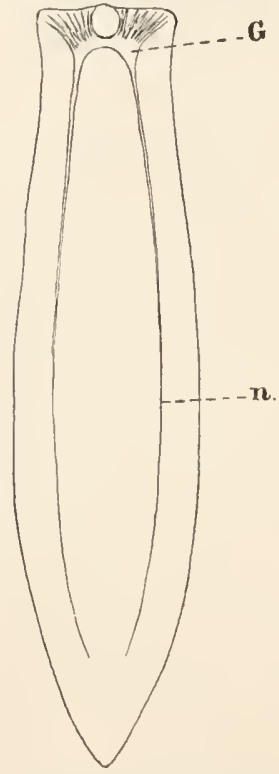

Fig. 23. Süsswasserplanarie (Planaria torva). g Gehirn, n Längsuerv.

Nach Jijima.

Progressivbewegung aus. Tritt aber auch bei dem anderen Stück eine so starke Contraction des Wundrandes ein, dass eine spiralige Einrollung des Stückes stattfindet, so erfolgen die Progressivbewegungen desselben nicht mehr geradlinig, sondern im Kreise. Dagegen gelingt es nicht, Kreisbewegungen durch einseitige Zerstörung des Gehirns bei Thysanozoon hervorzurufen.

2) Das Gehirn und Nervensystem der Süsswasserplanarien (Fig. 23) ist dem der Seewasserplanarien so analog, dass es für unsere Zwecke unnöthig ist, eine besondere Schilderung desselben zu geben. Der wesentliche Unterschied dürfte der sein, dass die beiden Längsnerven grössere, fast segmentale Ansammlungen von Ganglienzellen enthalten. Man sollte nun denken, dass auch die Gehirnfunctionen der Süsswasserplanarien denen der Polycladen analog seien. Das ist aber durchaus nicht der Fall. Wir machen vielmelır hier wieder eine Erfahrung, auf die ich wiederholt in früheren Arbeiten über niedere Thiere hingewiesen habe, nämlich, dass morphologisch einander sehr nahestehende Thiere in ihren physiologischen Reactionen die grössten Verschiedenheiten aufweisen können. Schneidet man eine Süsswasserplanarie, z. B. Planaria torva, der Quere nach durch, so kriecht die aborale Hälfte, die kein Gehirn besitzt, ebenso munter weiter, wie die orale Hälfte. Die Spontanëität der Progressivbewegungen ist also bei Planaria torva keineswegs eine Function des Gehirns. Jedes nicht zn kleine Stück des Thieres besitzt Spontanëität. Die decapitirten Thiere kriechen mit dem oralen Ende voran, wie die normalen Thiere (2).

Das Verhalten von Planaria torva gegen Licht ist ron besonderem Interesse. Die Thiere sind im Wesentlichen unterschiedsempfindlich, d. h. Acnderungen der Lichtintensität ändern ihre Bewegungen. Bringt man die Thiere plötzlich aus dem Dunkeln ins Helle, so setzen sie sich 
in Bewegung. Im ersten Augenblick wirl hierbei anch die Richtung der Bewegungen rom Licht beeinflusst, die Thiere gehen wie negativ heliotropische Thiere zur Zimmerseite des Gefässes, aber sie sammeln sich hier nicht (wie die negativ heliotropischen Thiere), sondern sie zerstremen sich in allen Richtungen und bewegen sich nummehr in jerler Richtung, um endlich an einer Stelle des Gefässes, welche schwächer belenehtet ist als ihre Umgebnng, zur Ruhe zu kommen. Es macht danach den Eindruek, als ob Zunahme ler Lichtintensität sie zu Bewegungen veranlasst, während Abnahme der Lichtintensität sie veranlasst, zur Ruhe zu kommen. Daher findet man sie bei T'age immer an relativ dunkeln Stellen des Gefässes, oder an der Unterseite von Steinen. Ich vermuthe, dass die Thiere in (ler Nacht - vielleicht von "Hunger" aufgeweckt - von Nenem sich in Bewegung setzen und dann, wenn es 'Tag wird, sich wieder an relativ dunkeln Stellen sammeln. Ich bedeckte wiederholt am Morgen dïe eine seitliche Hälfte des gläsernen Behälters mit sehwarzem Papier. Während des Tages änderte sich nichts. Am näclisten Morgen aber fanden sich dann alle Thiere unter den bedeckten Theil des Aquariums. Das war nur so verständlich, dass sie in der Nacht im Glase umberkrochen und am Morgen an der dunkelsten Stelle zur Ruhe kamen. Diese Thiere besitzen am oralen Pol nicht nur ein Gehirn, sondern auch relativ hoch entwickelte Angen. Ich beschloss zu prüfen, ob eine decapitirte Planarie, trotz des Verlustes von Gehirn und Auge, noch dieselben Reactionen gegen Licht zeigt, wie die normale Planarie. Das ist in ganz ïberraschender Weise der Fall. Am Abend wurden ca. 60 Exemplare von Planaria torva der Quere nach hinter dem Gehirn und den Augen, aber nahe am vorderen Ende durchschnitten. Alle Stücke wurden in ein Gefäss mit geraden Wänden gethan, das zur Hälfte mit schwarzem Papier bedeckt wurde. Am nächsten Morgen befanden sich fast alle Hinterstïcke sowohl wie oralen Stïcke in dem bedeckten Theil des Aquariums. Sie waren hier ziemlich gleichmässig zerstreut. In dem unbedeckten Theil des Gefässes fand ich einige wenige, unter diesen aber ebenfalls sowohl Kopfstücke wie aborale Stiicke, in einer Ecke der Zimmerseite zusammengedrängt. In rlieser Ecke war die Lichtintensität ebenfalls ein relatives Minimum. Bei genaner Wiederholung dieses Versuches mit normalen Thieren ergab sich dasselbe Resultat wie mit den decapitirten Thieren. Hatten die decapitirten Thiere sich in dem bedeckten Theile des Behälters gesammelt und waren sie in völliger Ruhe, so wurde die Ruhe sehr bald gestört, wenn man plötzlich das dunkle Papier, ohne las Gefïss zu erschüittern, wegnahm. Sie geriethen in Bewegung, krochen umher, zunächst zur Zimmerseite, und sammelten sich schliesslich wierler in einem relativen Minimum der 
Lichtintensität. Auch diese Reaction verlief wie bei normalen Thieren, nur mit dem Unterschied, dass die Reactionszeit der enthirnten Thiere auf Aenderung der Lichtintensität grösser war als bei den normalen. Bei den mit Gebirn und Augen versehenen Stücken begann die Reaction etwa 1 Minute nach dem Lichteinfall, bei den gehirnlosen Stücken nach etwa 5 Minuten. Hierbei wurde nur diffuses Tageslicht als Reizursache benutzt. Bringt man unversehrte Planarien in ein Gefäss mit kreiscylindrischem Querschnitt, so sammeln die Planarien sich nicht (wie rein heliotropische Thiere) an der Fensterseite oder Zimmerseite des Gefässes, sondern an der rechten und linken Seite desselben. Ganz dasselbe Verhalten zeigen auch diejenigen Planarien, denen der Kopf sammt Gehirn und Augen abgetrennt ist. Alle diese Versuche gelingen schon am Tago nach der Operation. Man darf nur ganz frisches Material zu denselben verwenden. - Bei warmem Wetter bilden die Hinterstücke schon nach einer Woche einen neuen Kopf mit Augen und wahrscheinlich auch mit Gehirn.

Es war früher allgemein Sitte, wenn ein Thier auf Licht reagirte, zul schliessen, dass es Augen besitzen müsse; und da man ferner nicht zweifelte, dass die Reflexbewegungen in Centralnerrensystem bestimmt seien, so nahm man dann auch ohne Weiteres an, dass solche Thiere auch ein Centralnervensystem besitzen müssen. Als ich dann fand, dass die Orientirung der Thiere gegen das Licht durch dieselben einzelnen Umstände bedingt ist, wie die Orientirung pflanzlicher Organe gegen dieselbe Reizursache, zog ich den selbstverständlichen Schluss, dass die Orientirung der Thiere gegen das Licht unmöglich auf Eigenschaften beruhen könne, welche nur dem Auge und nur dem Gehirn zukommen, da Pflanzen ja derartige Organe gar nicht besitzen. Vielmehr müsse die Lichtempfindlichkeit der Augen darauf beruhen, dass die Augen einen Umstand mit den heliotropischen Pflanzen gemeinsam haben, nämlich Elemente, die unter dem Einfluss des Lichtes eine Veränderung erleiden. Im Uebrigen aber brauchen diese Elemente bei den verschiedenen Organismen weder morphologisch noch chemisch identisch zu sein. Ganz Analoges lässt sich über das Gehirn sagen. Wenn ein Thier mit Gehirn dieselbe Reaction zeigt wie eine Pflanze, die doch kein Gehirn besitzt, so folgt daraus, dass die Reaction gegen Licht nicht Folge einer "specifischen Energie" des Gehirns sein kann, sondern dass das Gehirn in dem Falle nur eine Leistung ausführt, die bei den Pflanzen ohne Nerven möglich ist. Diese Leistung braucht nichts Anderes zu sein als die Fortleitung der Reizwirkung des Lichtes, die ja bekanntlich auch bei Pflanzen stattfindet, hier aber durch andere Einriclitungen besorgt wird. Es war eine weitere Consequenz dieser Auffassung, dass 
bei Thieren, welche Augen besitzen, die lichtempfindlichen Elemente keineswegs auf die Augen allein beschränkt zu sein brauchen. Sie können sich auch an anderen Stellen der Körperoberfläche finden. In der That hat schon Graber (3) über Versuche an Tritonen und Regenwürmern berichtet, die er in ähnlichem Sinne dentete. Fs war ferner vorauszusehen, dass möglicher Weise auch ohne den eigentlichen Reflexbogen im Centralnervensystem bei manchen Thieren noch eine Reaction auf Licht möglich sei, da ja auch bei Ciona intestinalis nach Zerstörung des Centralnervensystems eine typische Reflexerscheinung weiter besteht. Es war endlich auch die Möglichkeit vorhanden, dass beide Umstände sich bei demselben Thiere vereint finden könnten. Dieser letztere extreme Fall ist bei Planaria torva verwirklicht.

Es ist nach alledem kaum noch nöthig bervorzuheben, dass gehirnlose Stücke von Planaria torva sich die Rüickenlage ebensowenig gefallen lassen, wie das intacte Thier. - Alle Versuche, bei diesem Thiere durch einseitige Verletzung des Gehirns Zwangsbewegungen herrorzurufen, blieben ebenso erfolglos wie bei Thysanozoon.

Bei Seesternen haben wir nach der Ansicht einiger Autoren eine Colonie ron ebensoviel Individuen, als Arme vorhanden sind. Wir sahen, dass diese Arme, so lange sie nervös (durch den centralen Nervenring) verbunden sind, harmonisch

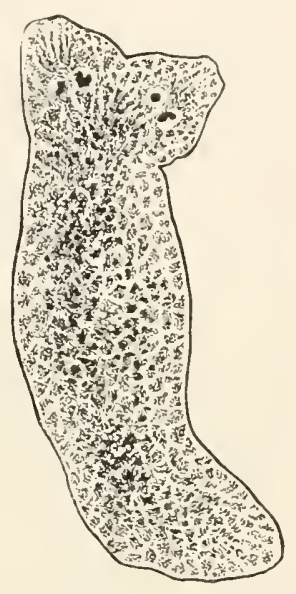

Fig. 24. Künstlich zweiköpfig gemachte Planarie. Nach van Duyne. reagiren. Bei Aktinien, die künstlich mehrköptig gemacht waren, war eine solche Harnonie z. B. in Bezug auf das Ergreifen von Nahrung nicht nachweisbar, beide Köpfe machten sich die Nahrung streitig. Ich veranlasste nun Herrn Dr. van Duyne in meinem Laboratorium Versuche anzustellen, künstlich mehrköpfige Planarien zu produciren. Fig. 24 ist ein Beispiel einer künstlich 2köpfig gemachten Planarie. Es liessen sich Planarien mit 4-6 Köpfen erzielen. Waren die beiden Köpfe genügend weit ron einander getrennt, wie in Fig. 25, so bewegten sie sich nicht länger harmonisch in derselben Richtung, sondern nach entgegengesetzten Richtungen (Fig. 25). Der Zug war oft so stark, dass das Thier völlig entzwei riss (6).

Wir müssen nun die Frage aufwerfen, wie es kommt, dass bei Thysanozoon die Spontanëität der Bewegung aufhört, wenn man den Kopf wegschneidet, während das bei den Süsswasserplanarien nicht der Fall ist? Man wird rersucht sein, den Unterschied darauf zu schieben, dass 
die Süsswasserplanarien mehr Ganglien im Verlauf der Längsnerven besitzen als Thysanozoon. Mit Hülfe der vergleichenden Physiologie sind wir in der Lage, die Unhaltbarkeit einer solehen Ansicht nachzuweisen. Bein Flusskrebs repräsentirt das Unterschlundganglion mit der ventralen Ganglienkette ein viel höher entwickeltes Gangliensystem als die Längsnerven bei Planaria torva. Nichtsdestoweniger werden wir sehen, dass ein Krebs, der diese Ganglien besitzt, aber das Oberschlundganglion verloren hat, keine spontanen Progressivbewegungen mehr ausführt. Wir werden ferner sehen, dass ein Frosch, dem das Grosshirn und der Tha-

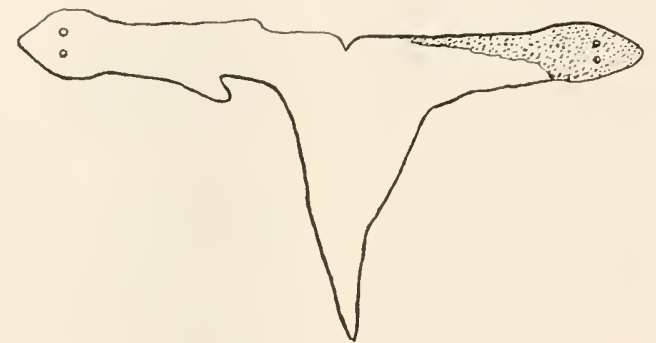

Fig. 25. Planarie mit 2 Köpfen, die sich in entgegengesetzten Richtungen fortzubewegen sucben und dabei ihren gemeinsamen Körper zerreissen. Nach ran Dilyne. lamus opticus entfernt sind, keine spontanen Progressivbewegungen mehr ausführt, obgleich er doch viel mehr Ganglien im Rückenmark besitzt als die Planaria torva. Derselbe Frosch bewegt sich aber wieder spontan, wenn man ihm noch etwas mehr vom Gehirn entfernt, nämlich den Lobus opticus und die Pars commissuralis der Medulla oblongata.

Die Ausführung von spontanen Progressivbewegungen ist so wenig eine specifische Function einzelner Ganglien oder ron Ganglienzellen überhaupt, dass wir sie sogar bei den Schwärmsporen von Algen und bei Bacterien beobachten. Worauf es beruht, dass das decapitirte Thysanozoon keine Progressirbewegungen mehr ansführt, während eine decapitirte Süsswasserplanarie sich noch spontan bewegt, vermögen wir einstweilen nicht anzugeben. Sicherlich aber haben wir kein Recht zu sagen, dass die grössere Zahl ron Ganglienzellen in den Längsnerven der Süsswasserplanarien den Unterschied bedingt.

3) Mit den Anneliden beginnt nunmehr für uns die Reihe der Thiere mit segmentaler Anordnung des Centralnervensystems. Wir finden diesen Typus des Baues weiterhin bei den Arthropoden und Wirbelthieren. Es ist vielleicht am einfachsten, wenn wir ein segmentirtes Thier als eine Colonie von so viel Individuen oder Thieren auffassen, als Körpersegmente resp. Ganglien rorhanden sind. Jedes einzelne derartige Segment für sich allein ist alsdann der Ascidie vergleichbar, bei der das Centralnervensystem ja aus einem einzigen Ganglion bestelt. Die Fasern und Zellen jedes Ganglions bilden die protoplasmatische Brücke zwischen der Haut und den Muskeln für das betreffendle Segment. Aber ein Er- 
regungsvorgang, der sich in einem Segment abspielt, bleibt nicht auf dieses beschränkt: Die einzelnen Ganglien der verschiedenen Segmente sind durch Nervenfasern mit einander verbunden, den sogenannten Längscommissuren, und so pflanzt sich ein Erregungsvorgang, der in einem Segment entsteht, auch auf die benachbarten Ganglien fort, bis schliesslich der Erregungsrorgang das Ende les Thieres erreicht.

Das Centralnervensystem der Anneliden besteht aus einer rentralen Ganglienkette, die dem Rückenmark der Wirbelthiere entspricht. Als Gehirn können wir das Oberschlundganglion bezeichnen, obwohl eine derartige Bezeichnung bei der geringen Analogie zwischen Wirbelthieren und Würmern eine willkürliche ist. Das Oberschlundganglion ist mit dem Unterschlundganglion durch zwei Commissuren, eine auf jeder Seite, verbunden. Fig. 26 stellt das Gehirn ron Nereis dar, das in anatomischer Hinsicht einen hohen Grad von Entwickelung zeigt. Die wesentliche Frage, die uns nun hier interessirt, ist die folgende: Ist das Gehirn nichts Anderes als ein segmentales Ganglion, oder hat es die Rolle eines Organes höherer Ordnung, das die Thätigkeit der übrigen Ganglien regulirt oder leitet?

Wir beginnen mit der Analyse der Nervenfunctionen des Regenwurms und wählen hier zunïchst die Pro-

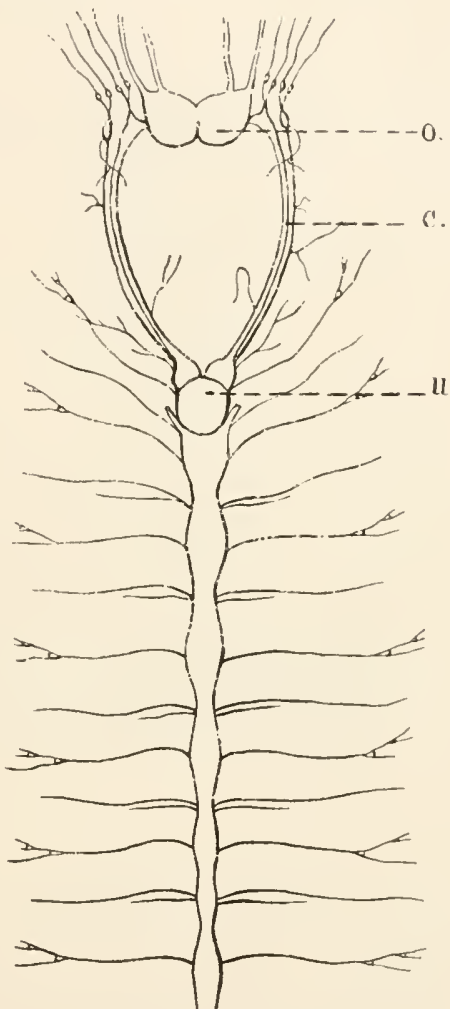

Fig. 26. Gehirn und eine Reihe segmentaler ranglien einer Annelide (Nereis). o Oberschlundganglion oder Gehirn, c Längscommissur (Schlundring), u Unterschlundganglion. Nach Claparède. gressivbewegung aus. Ist die coordinirte Progressivbewegung, an der alle Segmente des Körpers theilnehmen, an das Gehirn (o Fig. 27 und 28) geknüpft? Die Locomotion der Anneliden, z. B. der Regenwürmer, ist ein sehr einfacher Vorgang. Dabei spielen die Seitenborsten, die beim Regenwurm mit blossem Auge unsichtbar sind, eine wichtige Rolle, insofern sie wie Extremitäten wirken, die dem Thiere einen Halt am Borlen gewähren. Die eigentlichen 
Locomotionsmuskeln sind in Hautmuskelschlauch enthalten. Derselbe besteht ans Ringfasern und Längsfasern. Setzt sich der Wurm in Bewegung, so contrahiren sich zunächst die Ringfasern. Dadurch wird der

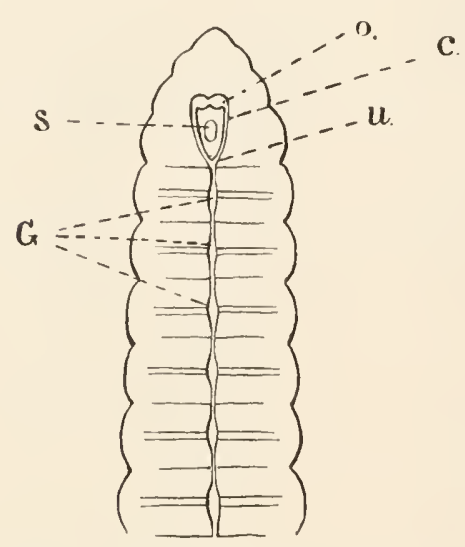

Fig. 27. Dorsale Ansicht des Centralnerveusystems eines Regenwurms. o Oberschlundganglion, c Commissur, u Unterschlundganglion, S Schlund, G Ganglien des Bauchstranges.

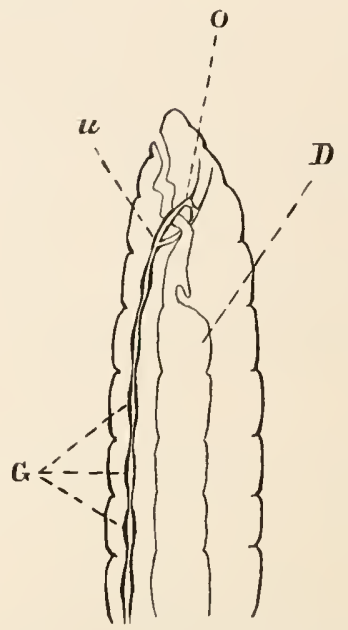

Fig. 28. Seitennasicht des Centralnervensystems əines Regenwurms,

o Oberschlundganglion oder Gebirn, u Unterschlundganglion, D Darm, G Gang-

lion des Bauchstranges.

Wurm dünner und länger. Die Borsten sind nach hinten gerichtet und gestatten in Folge des Widerstandes des Bodens nur eine Verschiebung des Thieres nach vorne. So wird der Kopf vorgeschoben. Sobald das Maximum der Verlängerung erreicht ist, contrahiren sich die Längsmuskeln und das Thier verkürzt sich. Da aber die Borsten nach hinten gerichtet sind, so kann die Verkürzung nur so zu Stande kommen, dass sich das hintere Ende dem Kopf nähert, aber nicht umgekehrt. Was geschieht wun, wenn wir die Ganglienkette des Thieres in der Mitte des Körpers durchschneiden oder einige Ganglien entfernen? Wird sich das vor dem Schnitt gelegene Stïck des Wurmes unabhängig von dem hinter dem Schnitt gelegenen Stücke bewegen? B. Friedländer hat diese Versuche ausgeführt und gefunden, dass trotz der Trennung des Centralnervensystems die Coordination weiter besteht (4). Setzt sich das vordere Stiick in Bewegung, so nimmt auch das hintere Stiick in gleicher Richtung und gleichem Tempo an der Bewegung vollständigen Antheil. Das widerlegt die Idee, dass die Coordination bei diesen Thieren durch 
ein besonderes, im Gehirn gelegenes Coordinationscentrum bestimmt sei, Wie geht aber die Coordination vor sich? Wenn sich das Vorderthier ausstreckt und dann durch Contraction der Längsmuskulatur zu verkürzen strebt, so wird ein Zug auf die Hant des Hinterstïckes ausgeübt und dieser Zng wirkt wahrscheinlich als Reiz, der auch die Längsmuskulatur des Hinterthieres reflectorisch oder vielleicht auch direct zur Contraction veranlasst. In dieser Weise ist anch eine Coordination zwischen Hinter- und Vorderthier trotz der Unterbrechung der nervösen Verbindung möglich. Friedländer hat das dann ferner noch dadurch bewiesen, dass er Würmer vollkommen durchschnitten und die beiden Hälften durch Bindfaden verbunden hat. Selbst dann noch konnte er gelegentlich beobachten, dass das Hinterstiick activ und in coordinirter Weise an den Berregungen des Vorderstuickes theilnahm.

Welche Rolle spielt das Centralnervensystem bei der Coordination? Es dient eben nur als bequemer Reizleiter. Aber wenn auch diese Leitung unterbrochen ist, sind die Einrichtungen an der Peripherie ausreichend, um die coordinirte Bewegung zu ermöglichen. Das Gehirn spielt keine führende Rolle bei den Progressirbewegungen des Regenwurmes.

Man könnte glauben, dass die Coordination der Progressivbewegung: höherer Thiere principiell von der bei den Würmern verschieden sei. Es existirt aber eine Beobachtung von Goltz, die zeigt, dass das bei Hunden wenigstens nicht der Fall ist. Wenn man einen Hund mit durchschnittenem Rückenmark unter den Vorderbeinen aufhebt, so dass der Hinterkörper senkrecht herabhängt, so beobachtet man eine merkwürdige Erscheinung. Die Hinterbeine gerathen in pendelartige Bewegungen, welche Gehbewegungen ähnlich sind. Diese Bewegungen sind vermuthlich ausgelöst durch die passive Dehnung, welche die Haut an der ventralen Seite der Hüftgelenke durch das Gewicht der Beine erfährt. Sie sind durchaus vergleichbar der reflectorischen Contraction der Längsmuskulatur des Regenwurms bei Dehnung der Haut der Thiere. Dieser Reflex würde genügen, um auch beim Hunde mit durchschnittenen Rückenmark coordinirte Gehbewegungen zu ermöglichen, wenn dieser Hund nur im Stande wäre, sich auf seinen Hinterbeinen stehend zu erhalten. Die Gehbewegungen der Vorderbeine nämlich würden die zur Auslösung der Gehbewegung der Hinterbeine nöthige Dehnung der Haut periodisch herbeiführen. Der Unterschied im Verhalten eines Hundes mit durchschnittenem Rückenmark und eines Regenwurmes mit durchschnittenem Banchmark in Bezug anf coordinirte Progressivbewegungen ist also nicht so sehr bedingt durch Unterschiede in den Functionen der Centralorgane als durch Unterschiede in der Ent- 
wickelung der peripheren Organe, der Haut und der Locomotionsorgane. Hätte der Hund statt seiner hohen, mehrgelenkigen Beine kurze Stummel, so hätten wir nach der Rückenmarksdurchschneidung dasselbe Schauspiel des Fortbestehens der coordinirten Progressivbewegungen wie beim Regenwurm. Die Reizbarkeitsverhältnisse der peripheren Organe und dic einfache segmentale Anordnung der nervösen Elemente sinl ausreichend, die Gangbewegung zu unterhalten, wenn sie einnal in den Gang gesetzt ist. Die Richtigkeit dieser Schlussfolgerung wird durch Versuche an einer marinen Annelide, nämlich Nereis, bestätigt, welche Dr. S. S. Maxwell in meinem Laboratorium angestellt hat. (5) Bei diesen Thieren ist die Coordination der Bewegungen zwischen Vorderstiick und Hinterstiick nach Durchschneidung der Ganglienkette so gut wie erloschen. Aber hier bestehen zwischen den einzelnen Segmenten tiefe Einschnitte, welche verhindern, dass der gesammte Hautmuskelschlanch gleichmässig gedehnt wird. Jedenfalls ist die Struktur des Bauchstranges bei Nereis und Lumbricus so sehr gleich, dass man hier die Bedingungen für den Unterschied im Verhalten nicht wird suchen dürfen. (Vergl. Fig. 26 und 28.) Beim Regenwurm gelang es Maxwell, Friedländer's Beobachtung zu bestätigen. Ich erhielt ähnliche, wenn auch weniger deutliche Resultate an Blutegeln. (2)

Schneidet man einen Regenwurm entzwei, so führt auch das hintere gehirnlose Stiick noch Progressivbewegungen aus. Auch diese Thatsache bestätigt, dass für die Progressivbewegungen das Gehirn keine führende Rolle besitzt.

Es fragt sich nun, ob die übrigen characteristischen Functionen des Regenwurns Gehirnfunctionen oder segmentale Functionen sind. Bringt man Lumbricus foetidus in einen durchsichtigen, geschlossenen Belälter, so stellt sich zunïchst heraus, dass die Thiere vor allem positiv stereotropisch sind. Sobald sie die concave Seite einer Kante oder eine Rinne erreichen, kriechen sie an derselben entlang und verlassen sie nicht mehr. Zweitens lässt sich zeigen, dass sie dem Licht gegenüber unterschiedsempfindlich sind. Sie kommen an den Stellen, die schwächer beleuchtet sind als die benachbarten Stellen, zur Ruhe. Die Richtung der Lichtstrahlen ist dabei von geringer Bedeutung. Es scheint auch, dass, wenn ein oder mehrere Thiere irgendwo zur Ruhe gekommen sind, die anderen an derselben Stelle ebenfalls leichter zur Ruhe kommen. Das ist ein Beispiel von "Geselligkeit" bei niederen Thieren. Es handelt sich hier wohl um eine chemotropische Reizbarkeit. Die Riechstoffe, welche von einem derartigen Wurm ausgehen, haben einen beruhigenden Einfluss aul andere Würmer derselben Art und sie kommen daher in Berührung mit einem Wurm insbesondere derselben Species leichter zur 
Ruhe. Diese chemischen Reize wirken also wie eine Falle, ganz chenso wie das relative Minimum der Lichtintensitü bei Planarien und auch beim Regenwurm. Es ist nun bemerkenswerth, dass für die unterschiedsempfindlichen Thiere, zu denen der Regenwurm gehört, die durch rothes Glas gehenden, weniger brechbaren Strahlen weniger wirksam sind, als die durch blaues Glas gehenden stärker brechbaren Strahlen. Dic Regenwürmer kommen unter rothem Glas eher zur Ruhe als unter blauom.

Wie verhalten sich decapitirte Regenw ïrmer? Decapitirte Lumbrici foetidi zeigen alle denselben Stereotropismus wie die normalen Thiere. Wenn sie an die concave Seite der Kante eines Gefässes gelangen, so verlassen sie die Kante so leicht nicht wieder. Die decapitirten Thiere kommen ferner an den Stellen relativ geringer Lichtintensität zur Ruhe, während Zunahme der Lichtintensität Bewegungen bei ihnen anregt. Es lässt sich auch zeigen, dass das durch blaues Glas gehende Licht in dieser Hinsicht wie Licht stärkerer Intensität, das durch rothes Glas gehende wie Licht schwächerer Intensität wirkt.

In all diesen Versuchen kriechen die decapitirten Stücke sowohl mit dem Schwanzende wie mit dem oralen Ende voran.

Merkwürdiger Weise ist die Reactionszeit für Lichtreize bei decapitirten Regenwürmern nicht merklich grösser als bei normalen Thieren. Die Versuchsthiere befanden sich in einem dunkeln Kasten, in dem sie ohne Erschütterung plötzlich dem diffusen Tageslicht ausgesetzt werden konnten. 3-18 Secunden nach dem Einfall des Lichtes erfolgten bei den decapitirten Regenwürmern die ersten Bewegungen. Ungefähr ebenso lange dauerte es bei normalen Würmern.

Lumbricus foetidus lebt in der faulen Spreu und dem Dünger von Ställen und es liegt nahe anzunehmen, dass die chemische Natur gewisser hier enthaltener Substanzen die Thiere festhält. Man kann leicht feststellen, dass wenn in einem Kasten die Hälfte des Bodens mit weissem, feuchtem Fliesspapier und die andere Hälfte mit einer dünnen Lage von faulem Stroh bedeckt ist, die normalen Würmer, die auf das Fliesspapier gelegt werden, alsbald sich alle auf dem Dünger sammeln. Genau ebenso aber verhalten sich auch die Hinterstücke durchschnittener Würmer. Werden sie auf das Fliesspapier gelegt, so werden sie zwar nicht direct von den Riechstoffen des Düngers angelockt. Aber sobald sie bei ihren Progressivbewegungen in Berührung mit dem Dünger kommen, kriechen sie auf denselben und wenn sie einmal auf ihm sind, verlassen sie ihn nicht melır. In kurzer Zeit befinden sich so die gehirnlosen Würmer stets ausnahmslos in dem Dünger. Legt man sie auf einen Haufen fauler Spreu, so kriechen sie meist sehr bald in denselben hinein. Das ist nicht bloss Wirkung des Lichts, da die Reaction auch im Dunkeln stattfindet (2). 
Wir sehen also, dass bei decapitirten Regenwürmern alle Reactionen, welche der normale Regenwurm zeigt, erhalten bleiben. Das Oberschlundganglion besitzt also hier keine übergeordnete, führende Rolle.

Mit Schlüssen auf die führende Rolle eines Ganglions kann man iiberhaupt nicht vorsichtig genug sein. Eine viel höher entwickelte Annelide, Nereis, gräbt sich in den Sand ein. Decapitirt man sie, so hört diese Function auf. Man könnte nun vermuthen, dass das durch den Verlust des Gehirns bedingt sei. Das wäre aber grundfalseh. Frühere Versuche hatten mich zu der Vermuthung geführt, dass das "spontane" oder ,instinctive“ Sicheingraben nur ein Reflex sei, ausgelöst durch die Contactreize des Sandes. Ich versuchte num, ob es nicht unter besonderen Umständen möglich sei, denselben Reflex anch noch bei gehirnlosen Stücken nachzuweisen. Ich legte ein solches enthirntes Stiick auf den Sand; wie gewöhnlich blieb es ruhig liegen. Nun bedeckte ich langsam das vordere Ende dieses Stückes mit Sand. Alsbald fing der Rest des Thieres an die typisehen Bewegungen auszuführen, welche das Eindringen des Thieres in den Sand zur Folge haben. Zu gleieher Zeit begannen die Drüsen der Fussstummel die klebrige Substanz zu seeerniren, welehe die Sandkörnchen zusammenkittet und die Wand des Bohriloches solide macht. Diese Secretion ist eine regelmässige Begleiterseheinung des Einbohrens der Thiere. Es ist dieselbe Seeretion, die bei anderen Würmern zur Bildung eines Gehäuses führt.

Warum aber gräbt sich das enthirnte Thier nicht ein? Einfach deshalb, weil es zum Eingraben sich der Mundorgane bedient, die bei der Deeapitation abgesehnitten werden. Es ist also der Verlust eines peripheren Kopforgans, welcher das Eingraben deeapitirter Nereiden verhindert und nicht der Verlust des Gehirns. Das letztere wirkt dabei nur als das segmentale Ganglion der zugehörigen peripheren Organe.

4) Wir wollen nun zur Sehilderung von Nereis übergehen, bei der wir anscheinend characteristische Gehirnfunctionen finden werden. Im Ansehluss daran wollen wir uns dann die Frage vorlegen, wie es konmt, dass beim Regenwurm das Oberschlundganglion nur als segmentales Ganglion wirkt, während bei Nereis dasselbe Ganglion eine grössere Rolle spielt.

Wenn eine Nereis sich einmal in den Sand eingegraben hat, so bewohnt sie lange dieselbe Röhre. Entfernt man aber bei einer Nereis das Oberschlundganglion ( 0 Fig. 26 s. 57), so hört das Thier auf, sesshaft zu sein. Es wird, wie S. S. Maxwell gefunden hat, ein rastloses Thier. Es kriecht fortwährend auf dem Sand umher, ohne einen Versuch zu machen, sich einzubohren. Dagegen ist die Rastlosigkeit dureh einen Zug ausgezeichnet, dem wir auch bei höheren Thieren nach gewissen Gehirnver- 
letzungen begegnen, nämlich, dass sie vor keinem Hinrlerniss zurückweichen, sondern gewissermaassen durch dasselbe durchzudringen versuchen, selbst wo es sinnlos ist (5).

Hat man die Thiere in einem viereekigen Aquarium, dessen Boden mit Sand bedeckt ist, so kriecht eine normale Nereis, wenn man sie

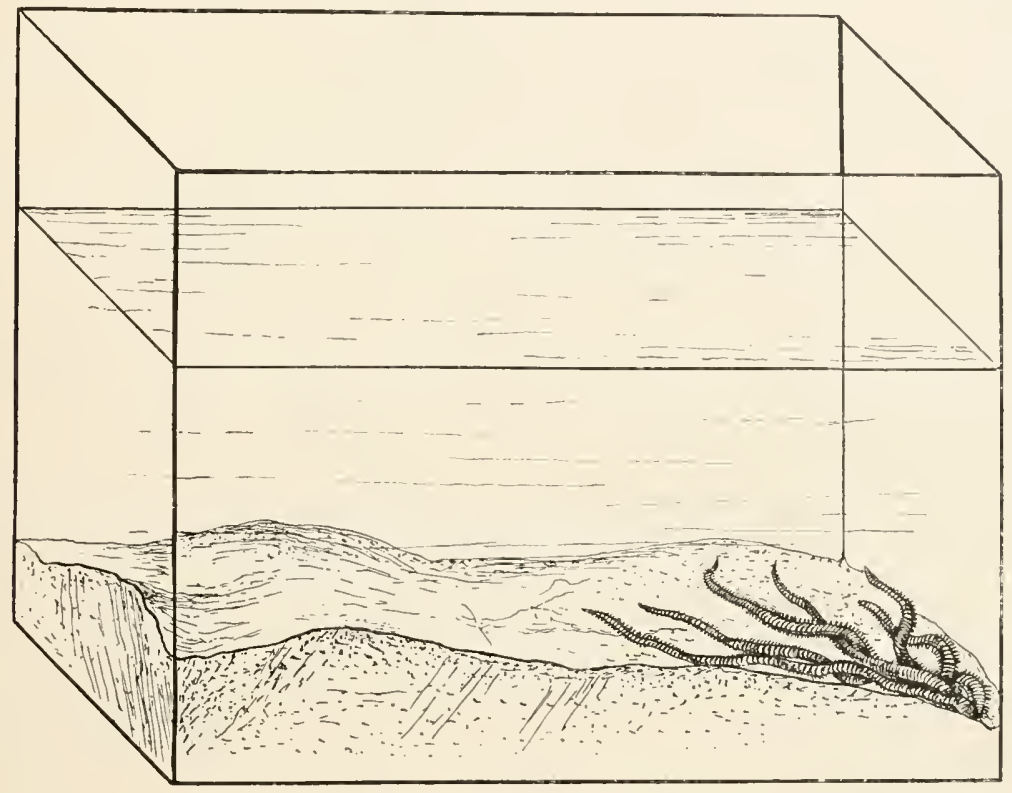

Fig. 29. Enthirnte Nereis in einem Aquarium. Sie gerathen schliesslich in eine Ecke und gehen hier in ihrem Bestreben, durch die Wand des Aquariums zu rennen, zu Grunde. Nach Maxwell.

stört, an den Wänden entlang. Das ist Folge des Stereotropismus. Eine Nereis ohme Obersehlundganglion thut dasselbe nur mit dem einen Untersehied, dass, sobald sie die Ecke erreicht, sie nicht ausbiegt, sondern gewissermaassen versucht, durch die Wand zu rennen. Hat man mehrere so operirte Würmer in einem Gefäss zusammen, so kann man ein Schauspiel, wie das in Fig. 29, beobachten. Sie gerathen in eine Ecke und suchen hier durch die Wand zu rennen. Die Würmer blieben viele Stunden so und gingen schliesslich in Folge ihres unsinnigen Strebens vorwärts zu kommen, zu Grunde. Es fehlen eben jene Reactionen, welehe in normalen Thiere auf Druckreize an vorderen Körperende erfolgen. Diesen Beispielen liessen sich noch andere ähnliche anreihen. Der mit der Gehimphysiologie rertraute Leser wird schon er- 
kannt haben, dass diese Nereiden sehr an die Hunde erinnern, denen Goltz die vorderen Hälften des Grosshirns entfernt hatte. Man kann sagen, dass enthirnte Nereiden sich so verhalten, als ob das Oberschlundganglion hemmende Wirkungen möglich macht.

Hält man normale Nereiden in einem Gefässe ohne Sand, in das man aber $20 \mathrm{~cm}$ lange Glasröhren legt, deren Lumen ein wenig weiter ist als der Umfang des Wurmes, so kriechen die Nereiden, sobald sie an eine solche Röhre gerathen, in dieselbe und bleiben in derselben dauernd liegen. Das ist eine Folge des Stereotropisnus. Hat man beispielsweise 6 solche Glasröhren in der Schüssel und thut man 6 normale Nereiden in die Schüissel, so darf man sicher sein, dass nach wenigen Stunden jede Nereis sich in einer Röhre häuslich niedergelassen hat. Es kommt nun leicht vor, dass eine Nereis in eine Röhre hineingeht, die schon einen Bewohner enthält. In dem Fall zuckt der neue Eindringling zurïck, sobald er den alten Bewohner berührt und solange der neue Eindringling im vollen Besitz seines Gehirns ist, verlässt er unter solchen Unständen die Röhre. Hat er aber sein Oberschlundganglion verloren, so hat die Anwesenheit des anderen Wurmes in der Röhre keinen liemmenden Einfluss auf seinen Versuch, in die Röhre hineinzukriechen. Er versucht sich in die Röhre einzuzwängen, auch wenn er darüber zu Grunde geht. Haben nämlich beide Würmer, der alte und der nene Insasse, das Oberschlundganglion verloren, so reiben sie sich die Köpfe wund. Will man die Thiere am Leben erhalten, so muss man die Glasröhre durchbrechen und so die Thiere trennen. Vergleichen wir die Handlungsweise einer derartigen enthirnten Nereis mit der einer normalen, so erscheint uns der Unterschied von derselben Art, wie der zwischen einem Verrückten und einem vernünftigen Menschen. Es wäre aber falsch, aus dieser Analogie zu schliessen, dass die hirnbegabte Nereis Vernunft oder Intellect besitzt. Die Dinge liegen hier viel einfacher. Die eigenthïnliche Reizbarkeit, vermöge deren die Nereis ihren Kopf zurüickzieht und rückwärts wandert, beruht auf Strukturverhältnissen, die am vorderen Körperende gelegen sind und deren sensibele Nerven zum Oberschlundganglion gehen und von hier aus mit dem Rest der Ganglienkette communiciren. Exstirpirt man daher das Oberschlundganglion, so wird diese Verbindung unterbrochen und die am vorderen Körperende angreifenden Reize können keine Rückwärtsbewegung in hinteren Thier mehr auslösen.

Aber damit ist die Characteränderung, die Rastlosigkeit des enthirnten Thieres noch nicht erklärt. Man sagt, dass, wenn nach Ausfall eines Hirntheiles die spontane Thätigkeit des Thieres oder die Reflexerregbarkeit erhöht ist, dass der betreffende Hirntheil ein Henmungs- 
organ sci. Wir werden dieser Auffassung weiterhin noch begegnen. Aber mit einer solchen Behauptung ist natürlich nichts gewonnen. Wir wollen wissen, wie das Oberschlundganglion Bewegungen hemmen kann und wie sein Fortfall entfesselnd auf die Reflexerregbarkeit wirken kann. In dieser Beziehung möchte ich an zwei Möglichkeiten erinnern, die allerdings nur den Weg andeuten, auf dem weitere Einsichten möglicher Weise gefunden werden können. Das Oberschlundganglion der Anneliden ist mit den Eingeweiden nervös verknüpft. Die Vorgänge, die sich im Darmkanal abspielen, also die chemischen Vorgänge der Secretion und Verdauung, können das Gesammtthier nur so lange auf nervösem Wege afficiren, als das Oberschlundganglion intact ist. Entfernt man es, so fällt der ganze Einfluss dieses sogenannten sympathischen Nervensystems auf das Gesammtthier fort. Es ist möglich, dass die vom Sympathicus ins Nervensystem einströmenden Erregungsvorgänge die Abwechselung ron Ruhe und Thätigkeit bedingen, welche das normale Thier characterisirt und dass der Ausfall dieser Erregungsquelle den Anlass zur Ruhe aufhebt. Eine andere Möglichkeit könnte in dem Einfluss liegen, den der Ausfall des Oberschlundganglions auf die Spannung gewisser Muskeln ausübt. Darauf kommen wir später bei der Besprechung der Versuche an Krebsen zurück.

Eine Nereis, welche das Unterschlundganglion verloren hat, wird, wie Maxwell gefunden hat, abnorm ruhig. Derartige Thiere kriechen viel weniger umher, als die normalen Thiere und machen keinen Versuch, sich in die Erde einzubohren. Der Grund für das letztere Verhalten liegt darin, dass die motorischen Nerven der Schlundmuskeln vom Unterschlundganglion entspringen und dass demnach Entfernung dieses Ganglions zur Parese oder Lähmung dieser Muskeln führt. Der Pharynx spielt aber eine grosse Rolle bei dem Bohren des Loches. Dieselbe Lähmung oder Parese der Schlundmuskeln ist auch der Grund, warum eine Nereis nacl Verlust des Unterschlundganglions nicht mehr frisst.

Wir wollen aber gleich bemerken, dass Entfernung des Unterschlundganglions nicht bei allen Anneliden Fressstörungen liervorruft. Der Blutegel ist nach Verlust dieses Ganglions, wie Maxwell fand, noch im Stande, sich voll Blut zu saugen. Beim Blutegel entspringen die motorischen Nerven des Saugapparats vom Oberschlundganglion, wie Mr. Mc Caskill gefunden hat. Das Unterschlundganglion verhält sich beim Blutegel wie das erste Glied in der Ganglienkette, während es beim Nereis mit solchen peripheren Organen der Kopfsegmente zusammenhängt, die den Lebensgewohnheiten des Thieres einen specifischen Character aufdrängen: z. B. den Organen des Pharynx, die fül das Eingraben nöthig sind.

L oeb, Vergleichende Gehiruphysiologie. 
Was die Ruhelosigkeit von Nereis nach Entfernung des Oberschlundganglions und die Ruhe nach Entfernung des Unterschlundganglions betrifft, so müssen wir noch hervorheben, dass sie mit der Wunde nichts zul thun haben. Haxwell's Beobachtungen sind an geheilten Thieren angestellt. Macht man die Wunde wie bei der Entfernung ler betreffenden Ganglien, nur mit dem Unterschied, dass die Ganglien nicht entfernt werden, so tritt keine der beschriebenen Störungen ein. Unmittelbar nach der Operation gräbt sich der Wurm trotz der Wunde wieder cin.

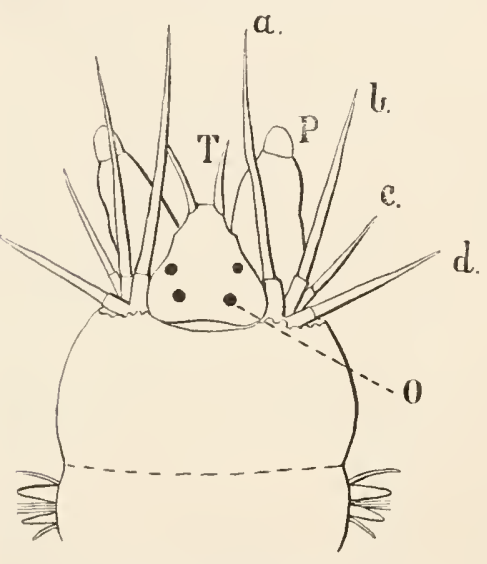

Fig. 30. Kopf von Neress. Nach Quatrefages.

Derartige Unterschiede im Verhalten des Thieres wie bei Nereis werden bei Regenwürmern nach Entfernung des Gehirns nicht beobachtet. Was bedingt diesen Unterschied? Ist das Obersehlundganglion beim Regenwurm ein segmentales Ganglion, während es bei Nereis ein "führendes Ganglion", ein Gehirn im Sinne der anthropomorphen Nervenphysiologie, ist? Ich glaube nicht, dass die Dinge so liegen. Wir finden vielmehr bei Nereis einen viel höheren Grad der Differenzirung der Kopforgane als beim Regenwurm. Wir haben aber schon in den früheren Vorlesungen gesehen, dass die scheinbaren Functionen des Gehirns oder der Ganglien wesentlich durch die peripheren Organe bestimmt sind. Bei Nereis unterscheidet sich die Differenzirung der Kopfsegmente sehr stark von der der übrigen Segmente, beim Regenwurm viel weniger. Man vergleiche nur den Kopf ron Nereis Fig. 30 mit dem Kopf des Regenwurms Fig. 27. Entsprechend sehen wir, dass der enthirnte Regenwurm fast genau dasselbe Thier ist, wie der normale Regenwurm, während die enthirnte Nereis ein total abnormes Thier ist. Natürlich muss das Nerrensystem in seiner Entwickelung bis zu einem gewissen Grad der grösseren Differenzirung der peripheren Organe folgen, da es ja aus den protoplasmatischen Verbindungsfäden zwischen allen verschiedenen Organen besteht.

Auch bei Wirbelthieren ist der Kopf durch Reizbarkeiten und Organe (Sinnesorgane, Mundorgane, Kehlkopf etc.) ausgezeichnet, welche den iibrigen Segmenten fehlen. Bei der Beurtheilung der Stellung der Gehirnganglien zu den übrigen segmentalen Ganglien des Körpers darf dieser Umstand nicht ansser Acht gelassen werden. Was die Nerven- 
physiologen zur Annahme des „führenden“ Characters eines Ganglions veranlasst, ist in vielen Fällen nur bestimmt dureh die grössere Differenzirung resp. besonderen Reizbarkeiten der periph eren Organe des entsprechenden Segments und nicht durch die grössere Differenzirung des Gehirns.

Wir wollen schlicsslich noch kurz das Verhalten der Muskelı nach Exstirpation der Ganglien berühren, da das Verhalten der Muskeln nach Gehirnoperationen uns noch wiederbolt beschäftigen wird.

Bei Verlust oder congenitalem Mangel eines Stückes des Rückenmarks atrophiren bekanntlich die zu dem betreffenden Rückenmarkssegment gelörenden Skeletmuskeln. Nichts dergleichen findet bei Blutegeln oder Regenwürmern statt, denen man ein Stück der Bauchganglienkette entfernt. Ich glaube der Unterschied ist dadurch bedingt, dass den ihres Ganglions beraubten Muskeln bei Würmern noch directe Impulse von den benachbarten Muskeln zufliessen, während bei den Wirbelthieren, sobald das Rückennark zerstïrt ist, keine zur Zuführung ron Reizen ausreichende protoplasmatische Verbindung der Skeletmuskeln mit dem Rest des Körpers mehr existirt. In den Muskeln der Blutgefässe der Wirbelthiere ist dagegen eine Leitung der Erregung von Element zu Element möglich und daher bleiben die Gefässmuskeln aıch selbst bei höheren Thieren nach Zerstörung des betreffenden Segments des Rückenmarks intact. Dagegen beobachtet man bei Nereis nach Durchschneidung der Ganglienkette eine Erscheinung, die an das Brondgeest'sche Phänomen erinnert. Der hintere Theil des Körpers wird flacher, während der mit den Gehirn verbundene rund bleibt. Das deutet auf eine Erschlaffung der Ringmuskulatur des hinter der Durchschneidungsstelle gelegenen Theils des Thieres (5).

\section{Litteratur zu VI.}

1) Lang, A. Untersuchungen zur vergleichenden Anatomie und Histologie des Nervensystems der Plathelminthen. Mittheil. ans der Zoolog. Station zn Neapel. Bd. I.

2) Loeb, J. Beiträge zur Gehirnphysiologie der Würmer. Pflüger's Archiv. Bd. 56. 1894. Sowie ferner

Loeb, J. Ueber künstliche Umwandlung positiv heliotropischer Thiere in negativ heliotropische und umgekehrt. Pflüger's Archiv. Bd. 54. 1893.

3) Graber. Grundlinien zur Erforschung des Helligkeits- und Farbensinus der Thiere. Prag und Leipzig 1884. Verlag ron Tempsky \& Freitag.

4) Friedländer, Benedict, Ueber das Kriechen der Regenwiirmer. Biologisches Centralblatt, Bd. 8, sowie ferner: Zur Beurtheilung und Erforschung der thierischen Bewegungen. Biolog. Centralblatt, Bd. 11.

Friedländer. Beiträge zur Physiologie des Centralnervensystems und des Bewegungsmechanismus der Regenwürmer. Pflüger's Archiv, Bd. 55.

5) Maxwell, S. S. Beitrïge zur Gehirnphysiologie der Anneliden. Pflüger's Archiv, Bd. 67. 1897.

б) van Duyne, John. Ueber Heteromorphose bei Planarien. Pflïg. Arch. B. 64. 1896. 
VII.

\section{Versuche über die Gehirnphysiologie der Arthropoden.}

1) Die Versuche an den niedersten Thierformen haben uns gelehrt, dass die eigenthümlichen Reactionen der Thiere bestimmt sind erstens durch die verschiedenen Formen der Reizbarkeit der Elemente und deren Anordnung an der Oberfläche der Thiere und zweitens durch die Anordnung der Muskelfasern. Das Centralnervensystem spielt keine andere Rolle als die eines rascheren und leichter erregbaren Leiters. Bei den Anneliden mit segmentaler Anordnung des Körpers und des Centralnervensystems ist jedes Ganglion die Durchgangsstation für die sensibeln und motorischen Nerven seiner entsprechenden Segmente. Wenn der Kopf mehr Einfluss auf das Verbalten des Thieres übt als irgend ein anderes Segnient (wie z. B. bei Nereis), so liegt das unseres Erachtens daran, dass am oralen Ende mehr Reizbarkeiten vorhanden sind und auch öfters mehr periphere Organe differenzirt sind (Sinnesorgane, Mund) als in den anderen Segmenten. Auch der Umstand, dass das sympathische Nervensystem hier vom Oberschlundganglion seinen Ausgang nimmt, wirkt im selben Sinne. Es ist also nicht die Anwesenheit des Oberschlundganglions, welches die grössere Zahl von Reactionen und die grössere Complicirtheit derselben in den Kopfsegmenten einiger Anneliden bedingt, sondern die grössere Zahl der Reizbarkeiten und die grössere Zahl der specifischen Organe, welche am vorderen Körperende zusammengedrängt sind.

Wir werden nun sehen, dass diese rein segmentale Auffassung des Centralnervensystems auch für die Artbropoden zu Recht besteht. Wir beginnen die Analyse der Gehirnfunctionen bei diesen Formen mit Limulus Polyphemus (Fig. 31).

Limulus ist, nach Ansicht der Zoologen, eine sehr alte Form. Wenn die Lebenszähigkeit das Alter der Arten ebenso begünstigt wie das Alter der Individuen, so erscheint die Behauptung der Zoologen begreiflich, dlenn man kann sich kaum ein zäheres Thicr vorsteflen. Ich ver- 
anlasste Miss Ida Hyde Versuche über die Functionen der einzelnen Theile des Centralnervensystems bei Limulus Polyphemus anzustellen, wobei die Athemcentren besonders berücksichtigt werden sollten (1). Ueber diese hatte nänlich Faivre Behauptungen aufgestellt, welche mit

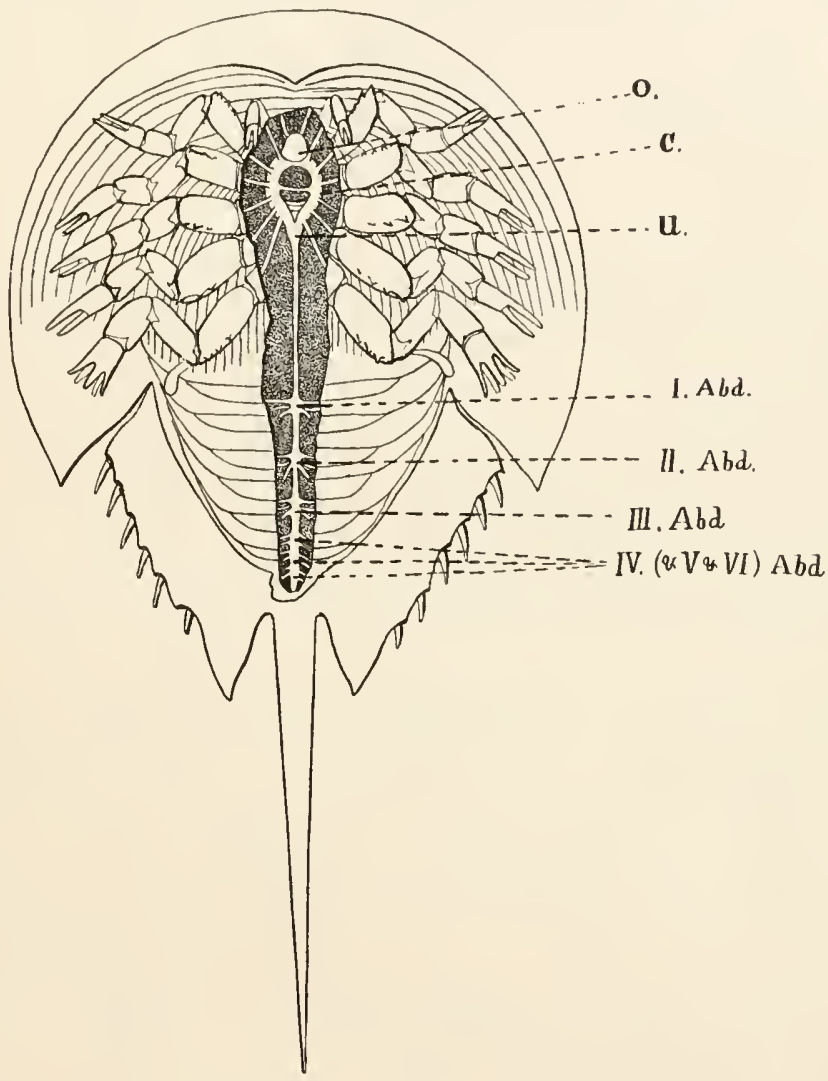

Fig. 31. Limulus Polyphemus mit freigelegtem Centralnervensystem. O Oberschlundganglion, C Commissur, U Unterschlundganglion, I Abd.-IV (u. V u. VI) Abdominalganglien der Athemsegmente.

der offenbaren segmentalen Anordnung des Centralnervensystems nicht harmoniren. Während bei solchen Formen, bei denen die Athemorgane (Kiemen) an Abdomen liegen, naturgemäss auch die Athemnerven aus der Bauchganglienkette entspringen müssen, nimmt Faivre an, dass das an Kopf gelegene Unterschlundganglion einen „coordinirenden" Einfluss auf die Athembewegungen habe. Ja bei Dytiscus soll noch ein drittes Athemcentrum im metathorakalen Ganglion existiren. Die Idee eines am Kopf gelegenen coordinirenden Ganglions war offenbar durch die 
Verhältnisse an Wirbelthieren beeinflusst. Aber bei Wirbelthieren befindet sich ja die erste Anlage des wesentlichen Athmungsmuskels, nämlich des Zwerchfells, in der Nähe des Kopfes und nur durch die Verschiebung des Z/werchfells während der weiteren Entwickelung wird es ron seinem nerrösen Segnıent getrennt. Derartige Wachsthumsverschiebungen finden aber bei den Arthropoden nicht in dem Maasse statt. Faivre war ïberhaupt ganz unter dem Einflusse der Wirbelthierphysiologie und insbesondere der doctrinären Anschauungen von Flourens' und das verleitete ihn zu Irrthümern in der Physiologie der Wirbellosen.

Das Centralnervensystem von Limulus besteht aus folgenden Theilen (Fig. 31): einem Oberschlundganglion O, das gewöhnlich als Gehirn bezeichnet wird, einem den Oesophagus umschliessenden Oesophagusring (Schlundring C Fig. 31), der aus Fasern und Ganglien besteht, einem Unterschlundganglion $\mathrm{U}$ und dem Bauchstrang mit 6 abdominalen Ganlien. Von diesen Theilen gehen eine Reihe peripherer Nerven ab. Bei Limulus nun ist die segmentale Natur der Nervencentren geradezu ideal entwickelt: Jedes periphere Organ hat sein Nervencentrum in dem Theil des Nervensystems, der zu seinem Segment gehört. Am klarsten geht das vielleicht aus dem folgenden Versuche von Miss Hyde hervor. Einem Limulus wurde das ganze Centralnervensystem entfernt mit Ausnahme eines kileinen Stuickes des Schlundringes (C Fig. 31) auf der linken Seite und der Bauchganglien (I-VI Abd. Fig. 31). Beide übrig gelassenen Stiicke besassen natïrlich keinen Zusammenhang. Das im Thier gebliebene Stiuck des Schlundrings lag in gleicher Höhe mit den drei Kieferanhängen, die zum Einführen der Nahrung benutzt werden. Diese drei Kieferanhänge behielten ihre Function, und Fressbewegungen wurden reflectorisch ausgelöst, wenn Fleisch auf die Anhänge gelegt wurde. Der Rest der Anhänge war völlig gelähmt mit Ausnahme der Kiemen am Bauche. Dieses Thier, das wirklich nur eine Fress- und Athenmaschine war, wurde künstlich gefüttert und am Leben gehalten.

Es ist ferner durch Patten gezeigt worden, dass jedes einzelne Fressbein noch normal Nahrung aufnimmt und zum Munde befördert, wenn dasjenige Stiickchen des Schlundrings erhalten ist, aus dem seine Nerven entspringen. Diese Fressbeine „unterscheiden" die chemische und tactile Natur der ihnen angebotenen Nahrung in derselben Weise wie die Tentakel der Aktinien und sie verweigern die Annahme, wenn die ¡hnen angebotenen Stoffe gewisse chemische und mechanische Bedingungen unerfüllt lassen. In Bezug auf die Auffassung dieser Erscheinungen und ihre Mechanik besteht natiirlich kein anderer Unterschied zwischen dem Verhalten der Tentakel der Aktinien und dem Verhalten 
der Mundanhänge eines Limulus als der durch die Skeletverhältnisse bestimmte.

Entfernt man bei Limulus eine Hälfte (sagen wir die rechte) des Obersehlundganglions ( $\mathrm{F}$ Fig. 31), so geht das Thier meist nicht mehr gerade aus, sondern bewegt sich in einem Kreise mit mehr oder wenig grosser Krümmung nach der unverletzten (linken) Seite. Es handelt sich um die bekannten Drehbewegungen (Circusbewegungen). Auf die Mechanik derartiger Bewegungen werden wir in einem späteren Kapitel zurückkommen.

Entfernt man das ganze Ober'schlundganglion, so ist das Thier noch im Stande Nahrung aufzunehmen, welehe man ihm auf die Mundorgane legt. Dagegen scheint es, dass solche Thiere ihre Spontanëität verlieren, soweit dieselbe in Progressivbewegungen zum Ausdruek komnt. Sie behalten auch abnorme Stellungen bei, die man ihnen künstlich giebt. Die Operationen warden zur Zeit der Brunst ausgefübrt. Männliche Limuli ofne Grosshirn kümmerten sich nicht mehr um die sie umgebenden weiblichen Thiere. Dagegen suchen die Beine einen irritirenden Gegenstand von der Körperobertlïche zu entfernen. Das thun ja auch decapitirte Frösche. Alle diese Angaben beziehen sich auf Thiere, deren Wunden völlig geheilt waren, und welche die Operation gut ïberstanden (1).

Durchschneidet man den Schlundring (C Fig. 31) auf einer Seite, so treten zunächst auch Reitbahnbewegungen auf, aber nach der verletzten Seite. Sie dauern jedoch nur so lange, bis die Wunde geheilt ist. Auch die Reitbahnbewegungen nach Exstirpation einer Gehirnhälfte verschwinden wieder nach einiger Zeit. Nimmt man einige Ganglien des Schlundrings heraus, so werden die den entfernten Ganglien entsprechenden Anhänge dauernd gelähmt.

Nach Exstirpation des Untersehlundganglions (U Fig. 31) ist das Thier sehr ruhig und bleibt oft Tage lang an derselben Stelle liegen. Aber seine Athmung geht in völlig normaler Weise weiter, womit die entgegengesetzte Behauptung Faivre's für diese Klasse von Thieren widerlegt ist. Abgesehen von der Ruhe des Thieres und dem Umstand, dass in Folge ron Nervenverletzungen die Streckmuskeln im Thorakoabdominalgelenk gelähmt sind, erscheint es nomal.

Die vier (resp. sechs) Ganglien des Abdomens (Fig. 31) versorgen die am Abdomen gelegenen fünf Kiemen des Thieres. Entfernt man den ganzen Rest des Centrahnervensystems mit Ausnahme dieser Ganglien, so geht die rhythmische Athemthätigkeit doch unverändert weiter.

Unmittelbar nach der Operation, die mit grossem Blutverlust verbunden ist, kann die Athmung eine Stunde lang oder länger stocken. 
Berührt man während dieser Zeit die Kiemenplatten, so verursacht der Reiz eine Reihe rhythmischer Athembewegungen, die aber bald wieder aufhören. Aber nach einiger Zeit beginnen die Kiemen spontan ihre Athemthätigkeit wieder, die nur dann und wann durch einen Krampf unterbrochen wird. Uebrigens ist diese Unterbrechung der Athembewegung eine Erscheinung, die sich auch beim normalen Limulus findet. Liegt ein solches Thier ruhig, so können die Athembewegungen eine Stunde oder länger unterbrochen werden. Auf gewisse Einzelheiten wie z. B. krampfartige Exspiration, die gelegentlich bein normalen Limulus, häufiger aber bei operirten Thieren vorkommt, wollen wir hier nicht eingehen.

Die abdominalen Ganglien sind also Centren für die automatischen Bewegungen der abdominalen Kiemenplatten. Alle Kiemen athmen gleichzeitig und in derselben Phase. Es ist möglich, dass die Inspiration mit der ersten Kieme beginnt und sich dann der Reihe nach auf die folgenden Kiemen erstreckt, aber rasch genug, um das ganze als gleichzeitig erscheinen zu lassen. Nach den herrschenden Vorstellungen müssten wir danach annehmen, dass entweder nur ein einziges, etwa das erste der vier abdominalen Ganglien, automatisch thätig ist und dass die übrigen von diesen aus erregt werden, oder dass, wenn jedes der vier Ganglien rhythmisch thätig ist, ein allgemeines Coordinationscentrum irgendwo in den vier Ganglien existirt. Durchschneidet man nun den Bauchstrang zwischen zwei Ganglien, etwa dem zweiten und dritten, so findet man, dass nichtsdestoweniger alle Kiemen fortfahren zu athmen. Man kann auch irgend ein Ganglion isoliren, d. h. die Commissuren vor und hinter demselben durchschneiden und man wird finden, dass die zugehörige Kieme dennoch fortfährt zı athmen. Das beweist also, dass jedes Ganglion Sitz einer automatischen periodischen Thätigkeit ist. Wie kommt es aber, dass alle die Ganglien, solange sie verbunden sind, nach Zahl und Phase gleichmässig athmen? Was die Zahl der ausgelösten Athemzüge betrifft, so ist dieselbe übrigens auch in den durch einen Schnitt von einander getrennten Ganglien dieselbe. Das liegt wohl daran, dass die Zahl der Athemzüge durch die Temperatur und die chemische Natur des Blutes bestimmt ist. Kohlensäuregehalt und gewisse andere, besonders in den Muskeln gebildete Stoffe (Zuntz und Geppert) bestimmen die Zahl der Athemzüge. Die Phase dagegen ist in den getrennten Ganglien ungleich. Die vor der Schnittfläche gelegenen Kiemen können in Inspiration sein, während die hinter der Schnittstelle gelegenen sich in Exspiration befinden. Im normalen Thier findet man aber nie einen derartigen Unterschied. Ich glaube die Coordination ist in diesem Falle in ganz ähnlicher Weise regulirt wie bei 
der Herzthätigkeit und bei den Medusen. Das zuerst resp. das am schnellsten thätige Ganglion erregt die mit ihm nervös verbundenen, und das bestimmt die Phasengleichheit. Diese Auffassung wird dadurch gestiitzt, dass, gleichviel wie man die Ganglien von einander trennt, die nervös in Verbindung gebliebenen auch stets ihre Kiemen in gleicher Phase thätig erhalten. Gäbe es ein Coordinationscentrum in irgend eineni der Ganglien, so müsste die von ihm getrennte Gangliengruppe in uncoordinirter Weise thätig sein, was aber nie der Fall ist.

2) Bei höheren Thieren liegen die Verhältnisse in Bezug auf die Athmung in Wirklichkeit kaum anders als bei Limulus. Wir haben eine Reihe segmentaler Ganglien im Thorakaltheil des Rückenmarks, welche Nerven zu den thorakalen Athemmuskeln ihrer Segmente schicken Diese Ganglien reichen bis in den Cervicaltheil des Rückenmarks und aus dem 4. (3. und 5.) Spinalnervenpaar treten die Fasern des Phrenicus aus, welche zu dem Zwerchfell gehen, das in Wirklichkeit zu den betreffenden. Segmenten des Halstheiles gehört und nur durch Wachsthumsverschiebungen so weit nach unten hin gerathen ist. Man sollte erwarten, dass die Lehrbücher der Physiologie die Sache so darstellen, dass die unter dem Einfluss der Wärme (Körpertemperatur) beständig stattfindenden chemischen Umsetzungen im Körper oder diesen segmentalen Ganglien eine periodische Thätigkeit in diesen Ganglien und entsprechend in den Athemmuskeln auslösen, deren Coordination in ähnlicher Weise aufzufassen sei wie etwa im Falle von Limulus. Aber eine solche Darstellung wird man in der Mehrzahl der Lehrbücher vergeblich suchen. Statt dessen findet man folgende Angaben: Die antomatische Thätigkeit der Athemmuskeln wird viel höher oben, nämlich an einem bestimmten Punkte der Medulla oblongata, ausgelöst in der Nähe der Einmündungsstelle des Nervus vagus, an derjenigen Stelle, welcher Flourens den Namen noeud vital gegeben hat. Diese Stelle wird als das Athemcentrum bezeichnet. Die Berechtigung für diese Auffassung leitet man aus zwei Thatsachen ab: Erstens daraus, dass Zerstörung dieser kleinen Stelle (des noend vital) Athemstillstand macht, und zweitens, dass Durchschneidung des Rückenmarks zwischen noeud vital und dem Phrenicusursprung ebenfalls Athemstillstand bedingt. Diese Thatsachen berechtigen aber durchans nicht zu dem Schluss, den Le Gallois, Flourens und mit ihm die Mehrzahl der modernen Physiologen daraus ziehen, dass die automatische Thätigkeit der Athmung nicht in den Segmentalganglien der Athemmuskeln, sondern höler oben im noeud vital gelegen sei. Denn man müsste ja sonst mit eben so viel Recht schliessen, dass auch bei Limulus die rhythmische Athemthätigkeit viel höher oben, etwa im Unterschlundganglion, ausgelöst werde, da ja auch 
bei Limulus die Athmung unmittelbar nach der Entfernung des Unterschlundganglions eine Zeit lang still steht. Aber hier sehen wir, dass der Stillstand nur ein vorübergehender, eine Shockwirkung ist, da die Thätigkeit der Athmung selbst dann im Stande ist, wieder weiter zu gehen, wenn das ganze Centralnervensystem mit Ausnahme der Abdominalganglien entfernt ist. Aber auch bei Wirbelthieren ist der Athemstillstand nach Zerstörung des noend vital oder nach einer Durehschneidung des Rïckenmarks zwischen noeud vital und 3. Halswirbel kein dauernder. Langendorff hat die wiehtige Entdeckung gemacht, dass decapitirte Wirbelthiere (denen der noend vital entfernt ist) noch selbständige Athembewegungen zu machen im Stande sind. (2) Es war nöthig, diese Versuche an jungen resp. neugeborenen Wirbelthieren anzustellen, bei denen die Shockwirkungen nicht so intensiv sind. Gelingt es durch Linleitung künstlicher Athmung, diese Thiere nur so lange am Leben zu erhalten, bis die Shockwirkung der Operation geringer geworden ist, so tritt auch wieder spontane Athmung ein. Ich bin überzeugt, dass es möglich ist, ein Wirbelthier ohne noeud vital dauernd am Leben zu erlalten, trotz aller entgegenstehenden Theorieen von Flourens. Es bleibt dann aber noch übrig zu erklären, wie es kommt, dass gerade Zerstörung des noeud vital so schwere Shockwirkungen auf die segmentalen Ganglien der Athemorgane hat. Das liegt, wie ich glaube, einfach daran, dass an dieser Stelle die Verbindungsfasern von beiden Vaguskernen zu den segmentalen Athemcentren verlaufen. Der Vagus ist der sensible Nerv der Lungen und eine Zerstörung dieser Verbindungsfasern zwisehen Vaguskern und segmentalen Ganglien der Athmungsnerven muss begreiflicher Weise explosionsartige Wirkungen hervorbringen, die eine temporäre Unterbrechung der automatischen Thätigkeit dieser segmentalen Ganglien zur Folge haben. Diese Unterbrechung der Athemthätigkeit ist fataler für einen Warmblüter mit seinem starken Stoffwechsel als für einen Kaltblüter mit geringerem Stoffwechsel. Aus demselben Grunde sind auch wohl die Shockwirkungen bei einem Kaltblüter viel geringer als bei einem Warmblüter. Wir sehen an diesem Beispiel schon deutlich, in welche falschen Bahnen die Nervenphysiologie geräth, wenn sie den sicheren Boden der segmentalen Auffassung des Centralnervensystems verlässt. Die Warnungen von Goltz, Brown-Séquard und Langendorff sind nicht genügend beachtet worden. Auf Grundlage der vergleichenden Physiologie wird es hoffentlich möglich werden, der richtigen Auffassung des Centralnervensystems auch der lıöheren Thiere daucrnden Eingang zu verschaffen.

Von jedem Ganglion der Bauchkette entspringt bei Limulus ein vorderer und hinterer Nerv. Es war von Interesse festzustellen, ob 
diesen beiden Nerven ähnliche Functionsunterschiede zukommen wie den vorderen und hinteren Wurzcln des Rückenmarks der Wirhelthiere. Man hat von den Arthropoden behauptet, dass sie auf dem Riucken laufende Wirbelthiere sind und es hat dann auch Fairre angegeben. dass nicht nur eine dem Bell'schen Gesetz entsprechende Trennung der motorischen und sensibeln Wurzeln bei den Arthropoden sich finde, sondern, dass auch bei den Arthropoden im Gegensatz zu Wirbelthieren die ventrale Seite der Ganglien sensibel, die dorsale motorisch sei. Das ist sicher nicht zutreffend für Nervenwurzeln, die von den Ganglien bei Limulus ausgehen. Schneidet man den hinteren Nerv durch und reizt man den peripheren Stumpf desselben, so erhält man Inspirationsbewegungen derjenigen Kiemenhälfte, zu welcher dieser Nerv geht. Alle anderen Kiemen bleiben in Ruhe. Dieser Nerv enthält also motorische Fasern. Reizt man den ventralen Stumpf, so geräth das gesammte Thier in die höchste Erregung. Der hintere Nerv entbält also auch sensible Fasern. Durchschneidet man den vorderen Nerven, so erhält man bei Reizung des peripheren Stumpfes keine Wirkung, bei Reizung des centralen Stumpfes geräth das ganze Thier in Erregung. Der vordere Nerr ist also rein sensibel. Limulus eignet sich besser zur Entscheidung dieser Frage als die kleineren Arthropoden. Aber auch bei den letzteren liegen die Dinge so, dass Vulpian (3) und neuerdings Bethe (4) die Idee energisch zurückweisen, dass die Ganglienkette der Arthropoden in dorsoventraler Hinsicht das Umgekehrte des Wirbelthierrückenmarks sei.

3) Als nächsten Vertreter der Arthropoden, dessen Gehirnphysiologie gut untersucht ist, wählen wir den Flusskrebs. Fig. 32 giebt eine schematische Uebersicht über das Centralnervensystem des Hummers, das mit dem des Flusskrebses fast identisch ist. Bei $O$ haben wir das Oberschlundganglion mit Nerven für die Augen und Antennen. Ferner zweigt sich von ihnen das sympathische Nervensystem ab, das zu den Eingeweiden geht. Dann gehen nach hinten die beiden Schluudconmissuren $\mathrm{C}$ zum Unterschlundganglion $\mathrm{U}$ ab. Das letztere ist scheinbar ein einziges Ganglion, es versorgt aber 6 . Paare von Segmentalorganen, nämlich die Mundanhänge. Die mikroskopische Untersuchnng zeigt, dass dieses Unterschlundganglion in der That ans 6 einzelnen Ganglien besteht. Diese Verschmelzung von Ganglien und damit Verwischung der segmentalen Anordnung findet man sehr häufig. In der Physiologie der Wirbelthiere ist sie fatal geworden, weil sie dazu geführt hat, die segmentale Anordnung des Centralnervensystems unberücksichtigt zu lassen. A uf das Unterschlundganglion folgen 5 thorakale Ganglien ( I - V 'T Fig. 32) für die Segmente der Scheeren und die 4 Paare der Locomotionsanhänge. Dann folgen die 5 Ganglien des Abdomens ( $\mathrm{I}-\mathrm{V}$ Abd. Fig. 32), welche 


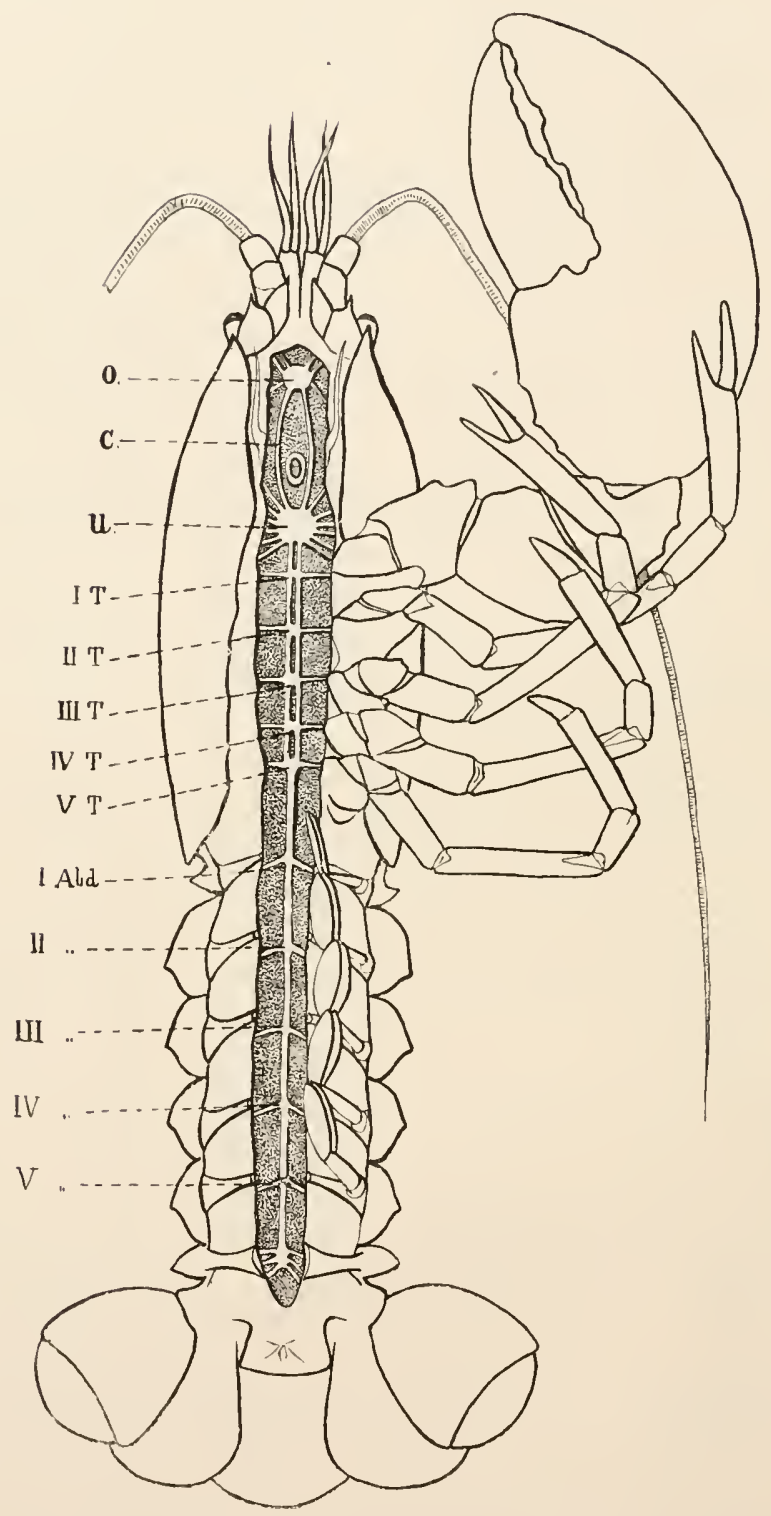

Fig. 32. Hummer mit freigelegtem Centralnervensystem.

O Oberschlundganglion (Gehirn), C Längscommissur, U Unterschlundganglion I-V T', 5 Thorakalganglien $\mathrm{I}-\mathrm{V}$ Abd, 1.-5. Abdominalganglion. 
die Schwimmanhänge und den als Ruderorgan dienenden Schwanz mit Nerven versorgen. Die besten Versuche über das Centralnervensystem dieser Thiere hat unstreitig Bethe angestellt und seiner Darstellung werden wir im Wesentlichen folgen. Viele der Thatsachen, welche Bethe an seinen Versuchsthieren beschreibt, waren mir aus eigener Anschanung bekannt, so dass ich überzeugt bin, dass das von ihm entworfene Bild richtig ist.

Durchschneidet man bei einem Flusskrebs die beiden Commissuren C Fig. 32, welche das Oberschlundganglion 0 mit den Rest des Gehirns verbinden, so erhalten wir ein Thier, desseu Verhalten dem Einfluss des Gehirns $\mathrm{O}$ entzogen ist. Ein solcher Krebs führt keine spontanen Progressirbewegungen mehr aus. Auf einen Reiz setzt er sich in Bewegung, aber er kommt dann, nacbdem er etwa $20 \mathrm{~cm}$ weit gegangen ist, wieder zur Ruhe. Er entspricht also in seinem Mangel an spontanen Progressivbewegungen dem Bild, das Flourens fälschlich für das entgrosshirnte Wirbelthier entworfen hatte. Allein wir wissen jetzt, dass ein entgrosshirnter Hund nur zu viel Spontanëität in seinen Progressivbewegungen zeigt und dass die Schematisirungen von Flourens falsch waren.

Anneliden und Arthropoden stehen in Bezug auf das Centralnervensystem einander sehr nahe. Nereis zeigt nun nach Ausfall des Oberschlundganglions ein Uebermaass der Progressivbewegungen, während Astacus sich nicht mehr spontan bewegt. Wie konmint es, dass ein so fundamentaler Unterschied hier besteht? Ich glaube, der Unterschied ist nur scheinbar, oder vielleicht richtiger, beruht nur auf einem Nebenumstand. Ward hat nämlich schon gefunden und Bethe bestätigt, dass die Beine dieser enthirnten Flusskrebse rastlos thätig sind, inclem sie entweder einander putzen oder pendelnde Gelbbewegungen ausführen. Nur zu Progressirbewegungen kommt es dabei nicht. Das aber liegt, wie ich glaube, möglicher Weise an einem anderen Nebeneinfluss der Ausschaltung des Oberschlundganglions. Die Beine eines solchen Thieres haben eine abnorme Stellung. Sie sind im Hüftgelenke stärker flectirt als normal. Es muss also die Spannung der Extensoren in Folge der Operation verhältnissmässig stark gelitten haben. Derartige mechanische Unstände können es nun recht wohl mit sich bringen, dass die Locomotion erschwert ist, während die einfachen Pendelbewegungen der Beine, wobei keine nennenswerthe Arbeit zu leisten ist, noch möglich sind. Nur wenn ein Reizimpuls von aussen her in das Centralnervensystem bricht, kann für wenige Augenblicke die Innervationswelle zur Ueberwindung der Widerstände bei der Locomotion ausreichen. Der Umstand, dass nach Verlust des Gehirns bei Krebsen die Spannung der 
Flexoren in gewissen Gelenken überwiegt, ist von Interesse, da wir derselben Thatsache bei Hunden nach Verlust der vorderen Region des Grosshirns begegnen und da sic auch bei Menschen nach Apoplexieen wenigstens für die Arme zur Beobachtung kommt.

Bethe schliesst aus den Pendelbewegungen, dass das Gehirn ein Hemmungsorgan sei. Es lassen sich hierüber dieselben Bemerkungen machen, die wir schon in dieser Beziehung bei Anneliden vorgebracht haben.

Die Abschwächung der Muskulatur bei enthirnten Flusskrebsen zeigt sich beispielsweise auch darin, dass das Kneifen der Scheeren nicht mehr so schmerzhaft ist wie bei normalen Thieren.

Nach dem, was wir über den segmentalen Character des Centralnervensystems gesagt haben, lässt sich erwarten, dass beim Ausfall des Oberschlundganglions die Fressbewegungen des Flusskrebses noch richtig ablaufen, da ja die segmentalen Ganglien der Fresswerkzeuge im Unterschlundganglion liegen. Ich gebe die Schilderung in Bethe's Worten wieder: „Das Thier (ohne Oberschlundganglion) ist im Stande zu fressen und trifft dabei eine Auswahl. Zwar werden häufig Steinchen, Holzstiicke oder dergleichen mit den Scheeren der Gangbeine erfasst und zum Munde befördert, aber wenn sie in die Nähe des Mundes gelangt sind, werden sie fortgeworfen. Ein Stück Fleisch wird aber immer in den Mund geschafft und gekaut. Das Schlucken ist hier wie bei Carcinus erschwert. Häufig bleibt der Bissen lange zwischen den Pedes maxillares, ohne verschluckt zu werden, und fällt schliesslich zu Boden. Papierstückchen, die mit Fleischsaft getränkt sind, werden ebenso verarbeitet. Auch Steine, die mit Fleischsaft bestrichen sind, werden bis zum Munde befördert, werden aber nicht gekaut, sondern meist gleich nachdem sie die Pedes maxillares berührt haben, fallen gelassen." Die Natur der Reize bestimmt also wie bei Aktinien den Erfolg. Das Centralnervensystem der Krebse kommt hierbei nur als reizleitendes Organ in Betracht, eine Function, die ebenso gut durch pflanzliches Protoplasma oder durch Muskelgewebe von der Natur des Herzmuskels und der Ureteren ausgeübt werden könnte, wie durch Nervenprotoplasma. Bein Flusskrebs ist die ursprünglich segmentale Anordnung der nervösen Elemente so gut erhalten, dass Ausschaltung des Gehirns den protoplasmatisch-nervösen Zusammenhang zwischen der Oberfläche der Mundund Thorakalsegmente und den Muskeln der Anhänge jedes dieser Segmente nicht unterbricht.

Wenn man diese enthirnten Thiere auf den Rücken legt, so drehen sie sich wieder in die Bauchlage um. Wenn ein auf den Rücken gelegtes Thier sich wierler in seine normale Orientirung umdreht, so können, 
wie wir gesehen haben, zwei Reize mitwirken: Erstens Schwerkraft (Cieotropismus) und zweitens tactile oder richtiger stereotropische Reize. Ein Krebs. dessen Gehirn nicht mehr mit dem Rest des Centralnervensystems zusammenhängt, richtet sich noch in die Bauchlage auf, wenn er auf den Riicken gelegt wird. Da alle geotropischen Reactionen in Organen ausgelöst werden, deren Nerven durch das Oberschlundganglion gehen, so handelt es sich un tactile Reizwirkungen. Die Fühigkeit, sich aufzurichten, fällt aber bei Astacus fort, wenn ihm das Unterschlundganglion entfernt ist.

Interessant sind die Beobachtungen, welche Bethe an Krebsen gemacht hat, denen er die Schlundcommissuren nur auf einer Seite durchschnitten hat. Die Durchschneidung war rechts vorgenommen. Berührte er nun bei einem solchen Thiere die linke Kopfseite, so griff zunächst die Scheere der gereizten Seite, sodann aber die der anderen Seite ganz genau nach der gereizten Stelle. Zugleich trat Flucht nach rückwärts ein. Brachte er aber denselben Reiz rechts am Kopfe an, so erfolgte kcine Reaction der Scheeren. Selbst bei starken Reizen trat kein Greifen der Scheeren nach dem Reizort ein. Der Reiz, der den geordneten Reflex auslöst, kann sich also nur durch die Längscommissur derselben Seite vom Oberschlundganglion aus fortpflanzen. Das scheint allgemein gültig für die Arthropoden zu sein, da Bethe es auch bei Carcinus, Squilla und Hydrophylus feststellen konnte Es scheint nicht nur für die Leitung durci die Schlundcommissuren, sondern durch alle Längscommissuren zu gelten. Nach Durchschneidung einer Schlundcommissur tritt häufig, aber nicht ausnahmslos, Reitbahnbewegung nach der gesunden Seite ein. Ein solches Thier kann aber auch gerale aus gehen, nur mit etwas Anstrengung.

Ist die rechte Schlundcommissur durchschnitten, so ist der Tonus der Muskeln auf der rechten Seite des Abdomens herabgesetzt. In Folge dessen ist das Abdomen concav nach links gekrümmt.

Spaltung des Gehirns in der Mittellinie, also Aufhebung des Zusammenhangs zwischen beiden Hirnhälften, vernichtet die compensatorischen Bewegungen der Augenstiele. Noch merkwürdiger ist, dass solche Thiere nicht mehr wie normale den Aufenthalt im Dunkeln berorzugen.

Durchtrennt man die Längscommissuren zwischen den Mundganglien (Unterschlundganglion) und den Scheerenganglien, so werden alle Gehbewegungen unmöglich, obwohl die Beine nicht gelähmt sind. Das ist auffallend, da doch das Unterschlundganglion die segmentalen Nervenelemente der Mundgliedmassen, aber nicht die der Gangbeine enthält. Bei den anderen Krebsen hat indessen Entfernung des Unterschlundganglions keinen derartigen lïhmenden Einfluss auf die fang- 
bewegungen. Das ausnahmsweise Verhalten von Astacus in dieser Beziehung dürfte meiner Ansicht nach vielleicht darauf beruhen, dass die Entfernung des Unterschlundganglions dauernd in die Thätigkeit gewisser Muskelgruppen eingreift, die für den Gang nöthig sind. Ich glaube nicht, dass wir annehmen müssen, dass hier eine Abweichung rom Gesetz der segmentalen Anordnung der nervösen Elemente (Centren) der Gliedmassen vorliegt. Das folgt schon daraus, dass die Beine eines solchen Thieres nicht gelähmt sind, sondern vielmehr unaufhörlich damit beschäftigt sind, das Abdomen oder die pedes spurii oder sich gegenseitig putzen. Ja mehr als das: ,giebt man einer Zange eines Gangbeins ein Stück Fleisch oder Papier, so kommen sofort andere Beine heraus, fássen es gut und befördern das Stück zum Munde," obwohl jeder nervöse Zusammenhang zwischen den Nerven der Mundorgane und der Beine unterbrochen ist. Freilich verweigern die Mundgliedmassen oft die Annahme und Weiterbeförderung der Fleischstiicke, welche ihnen so von den Beinen übermittelt werden. Wir sehen hier wieder die Versuchung an uns herantreten, die segmentale Auffassung des Centralnervensystems auf Grund von Vivisectionsversuchen aufzugeben und Functionen zu hoch zu localisiren. Wir dürfen aber nicht rergessen, dass die Vivisectionen im Centralnervensysten von Nebenwirkungen begleitet sind, und es ist Sache der wissenschaftlichen Kritik, derartige Schwächen der vivisectorischen Methode zu berücksichtigen. Es handelt sich hier wohl nur um Störung der Gehbewegungen auf Grund von Störung der Spannung einzelner Muskeln.

Was nun die weitere Isolirung der caudalwärts rom Unterschlundganglion gelegenen Ganglien betrifft, so lässt sich im Allgemeinen das sagen, was wir schon bei Limulus constatirt haben. So lange das Ganglion eines Segments mit den segmentalen Organen verbunden bleibt, sind auch die Leistungen des betreffenden Segments erhalten. Freilich sind hierbei von Bethe einzelne Ausnahmen gefunden worden. Aber es ist denkbar, dass diese Ausnahmen Hemmungswirkungen der Operation sind.

Wir wollen nun etwas kürzer iiber die Versuche Bethe's an einigen anderen Arthropoden berichten.

4) Squilla schwinmt nach Isolirung des Oberschlundganglions d. h. nach Trennung der Längscommissuren zwischen dem Oberschlundganglion und den Mundganglien) nicht mehr spontan. Die spontanen Progressirbewegungen scheinen im Allgemeinen erloschen zu sein. Aber auf Reiz geht das Thier normal. Der nervöse Mechanismus für die Gangreflexe ist in den drei Ganglien der Gangbeine localisirt, d. h. sie gehen noch normal, wenn auch die Verbindung mit den davor gelegenen 
Ganglien unterbrochen ist. Bei Heuschrecken (Pachytylus cinerascens) führt Isolirung dles Oberschlundganglions zum Fortfall der spontanen Progressivbewegungen. Diese Thiere putzen ihre Antennen noch mit den Vorderbeinen wie ein normales Thier, dem man die Antennen gereizt hat. Nach Bethe werden diese localisirten Reflexe der Beine durch den Reiz der Durchschneidung ausgelöst. Wie bei Astacus und Squilla finden sich auch abnorme Stellungen der Beine in Folge der Operation.

Entfernt man das Ober- und Unterschlundganglion, indem man die Thiere decapitirt, so sind die Thiere noch im Stande, auf Reiz einige Gehbewegungen und vor allem Sprungbewegungen auszuführen. Das entspricht der Vorstellung der rein segmentalen Anordnung der nervösen Verbindungsfäden. Sehr bedeutungsvoll sind in dieser Hinsicht Versuche von Yersin an Grillen, welche ich Bethe's Arbeit entnehme, da mir Yersin's Abhandlung nicht zugänglich ist. Es handelt sich um Thiere, denen die beiden Längscommissuren zwischen dem Unterschlundganglion und dem ersten Thoracalganglion durchschnitten waren und die dieser Forscher Wochen lang am Leben erhielt. „Die Thiere vermochten sich, auf den Rücken gelegt, gut umzudrehen. Auf Reiz gingen sie einige Schritte je nach der Stelle des Reizes gerade oder nach der Seite. Dabei fielen sie bisweilen um. Auf Reiz machten sie noch Fliegerersuche, ohne sich in die Luft erheben zu können." Yersin beobachtete sogar, dass ein so operirtes Männchen, ,das schon eine Spermatophore von sich gegeben hatte, in richtiger Weise die Begattung mit einem in derselben Weise operirten Weibchen rornehmen konnte, nachdem er es auf das Weibchen heraufgesetzt hatte."

Bienen überstanden die Exstirpation des Oberschlundganglions nur kurze Zeit. Die ausserordentliche Ruhelosigkeit der Biene nach dieser Operation ist auffallend wie bei Astacus.

Bienen, denen das Gehirn längsweise in symmetrische Hälften gespalten war, zeigten eine merkliche Functionsstörung nur im Verhalten zu ilırem Stock. „Setzt man sie zu demselben zurück, so bekümmern sie sich um ihre Genossen nicht mehr. Sie kriechen auf dem Flugbrett umher, streben aber weder dem Eingang zu, noch gehen sie mit Sicherheit, vor den Eingang gesetzt, hinein."

Schneidet man Bienen den Kopf ab und entfernt so Ober- und Unterschlundganglion, so sind sie noch im Stande zu gehen, freilich in ungeschickter Weise. Legt man sie auf den Rücken, so drehen sie sich mit Hilfe der Beine um. „Reizt man sie am Bauch, so umklammern sie den Gegenstand (Bleistift) mit den Beinen, ziehen ihn an sich, krümmen das Abdomen und rersuchen hineinzustechen." Aber nicht alle Thiere geben so günstige Resultate. Es ist natïrlich, dass hier 
wie immer in der Gehirnphysiologie diejenigen Versuchsthiere maassgebend sein müssen, welche am wenigsten Störungen zeigen, da ja Erschöpfung und Shockwirkung der Operation den Rest des Centralnervensystems pathologisch machen können.

Wie a priori auf Grund der Segmentaltheorie zu erwarten ist, ist der Stechreflex noch möglich, so lange das Abdominalganglion erhalten ist. Bethe zeigte, dass das vom Körper abgeschnittene Abdomen auf Reiz auf der Bauchseite sich noch total krümmt und mit dem austretenden Stachel local den Reizort erreicht. Dabei wird Gift ausgetrieben. Der Reflex besteht auch weiter, wenn man alle Abdominalsegmente bis auf das letzte abschneidet.

Entfernt man bei einem Wasserkäfer (Hydrophilus) das Oberschlundganglion, so sind die progressiven Gangbewegungen nicht nur nicht unterbrochen, sondern das Thier geht fast ununterbrochen umher, jedoch mit Modificationen, welche darauf hindeuten, dass das Verlältniss in der Spannung der Antagonisten seiner Beine geändert ist. Das Thier weicht Hindernissen aus. Wirft man einen Käfer obne Oberschlundganglion ins Wasser, so schwimmt er mit Anziehung des ersten Beinpaares gut von dannen. Der normale Wasserkäfer kommt unter dunkeln Gegenständen zur Ruhe. Der Wasserkäfer, dem man das Oberschlundganglion durch einen Längsschnitt gespalten hat, zeigt diese Reactionen nicht mehr; obwohl Licht noch im stande ist, andere Wirkungen auf das Thier auszuïben. Ist das Thier nämlich in Gehen begriffen, so steht es bei plötzlicher Belichtung oder Beschattung still.

Ein Thier, dem die rechte Schlundcommissur durchschnitten wird, stemmt die Beine auf der rechten Seite schwächer gegen Hindernisse als die der linken Seite. Das dentet, wie mir scheint, darauf hin, dass die Strecker der rechten Seite geschwächt sind, da sie die Arbeit des Stemmens zu leisten haben. Ferner werden die rechten Beine fortwährend bewegt. Es wäre möglich, dass beide Umstände zusammenhängen. Der geringere Widerstand der Strecker erleichtert die Pendelbewegungen der Beine. Aehnlich auch bei Astacus und Bienen etc. Exstirpirt man das Ober- und Unterschlundganglion, so macht das Thier nur auf Reiz Progressivbewegungen. Aber die Fähigkeit zur geordneten Progressivbewegung ist nicht beseitigt. Legt man das Thier auf den Rücken, so sucht es sich noch in die Bauchlage zurückzudrehen, aber die Anstrengung der Beine ist erfolglos. Versenkt man das Thier unter Wasser, so treten noch Schwimmbewegungen ein, die das Thier aber nicht vorwärts bringen.

Was die Versuche an den übrigen Ganglien des Thieres betrifft, so liegen dieselben nicht im Rahmen dieser Schrift. Wir wollen jerloch 
das für uns wichtigste Ergebniss Bethe's hier citiren: „Es ist weder das Unterschlundgauglion noch das Prothoracalganglion der Sitz des Umdrelireflexes, der Gang- und der Schwimmeoordination, wie Faivre behauptet. Diese Reflexe sind vielmehr, wie es den Anschein hat, in jedem Thoracalganglion für das entsprechende Segment localisirt."

Dieser letztere Satz drückt die wesentliche Walırheit für alle complicirten Centralnerrensysteme aus. Das einzelne Segment eines segmentirten Thieres kann angesehen werden als ein einfaches Reflexthier, der Ascidie vergleichbar, und die Analyse der Reflexe beruht auf denselben Principien und führt zu denselben Ergebnissen in beiden Fällen. Die Complication, die bei segmentirten Thieren hinzutritt, besteht darin, dass, wenn sich in einem Segment ein Erregungsvorgang abspielt, derselbe sich auf die nächsten Ganglien fortpflanzt und hier Vorgänge der gleichen Art auslöst. Hierbei ist es möglich, dass der zeitliche Verlauf oder die Form des Vorgangs für die Art der Reflexbewegung mit bestimmend ist. Jedenfalls löst die Thätigkeit, die in einem Ganglion sich abspielt, einen Vorgang ähnlicher Art auch im nächsten Ganglion aus. Für die gegenseitige Beeinflussung der Vorgänge in den verschiedenen Ganglien kommen dann nur dieselben Unstände in Betracht, die auch für die Coordination der Thätigkeit der verschiedenen Herzabschnitte zu berücksichtigen sind. Die Annahme besonderer Coordiuationscentren ist überflüssig. Bei Exstirpations- und Durchschneidungsversuchen ist noch ein Umstand maassgebend, nämlich dass die Durchschneidung in denjenigen Theilen, welche mit der Operationsstelle protoplasmatisch verbunden sind, auch eine, manchmal vorïbergehende, manchmal dauernde Veränderung hervorruft. Diese Hemmungs- oder Shockwirkungen fasse ich als chemische Veränderungen auf. Der höchste Grad dieser Veränderungen wird erreicht in den Falle der Degeneration. Es ist eine merkwürdige Thatsache, dass bei einer Operation in Centralnervensystem die Shockwirkung viel grösser ist in dem caudal von der Operationsstelle gelegenen Theil als in dem kopfwärts gelegenen. Diese Shockwirkungen sind bei kaltblïtigen Thieren ungleich viel geringer als bei Warmblütern.

\section{Litteratur zu VII.}

1) Hyde, Ida $\mathrm{H}$. The nervous mechanism of the respiratory movements of Limulus Polyphemus. Journal of MIorphology. Vol. IX. 1894.

2) Langendorff, O. Studien über die Innervation der Athembewegungen, I. Mittheilung, Archiv für Physiologie. 1850. 
3) Vulpian. Leçons sur la Physiologie générale et comparée du Système Nerveux. Paris. 1866.

4) Bethe, A. Vergleichende Untersuchungen über die Functionen des Centralnervensystems der Arthropoden. Pflüger's Archiv, Bd. 68. 1897.

5) Bethe, A. Das Centralnervensystem von Carcinus maenas. Archiv f. mikroskopische Anatomie und Entwickelungsgeschichte, Bd. 501897 und Bd. 511898. 


\section{Versuche an Mollusken.}

Die bisherigen Angaben in der Litteratur über die Functionen des Centralnervensystems der Mollusken sind sehr spärlich. Allein sie sind nichts desto weniger werthvoll als weitere Belege für die Anschauung, dass die einfache und rhythmische Spontanëität, sowie die Reflexvorgänge nicht auf specifischen Eigenthümlichkeiten der Ganglien beruhen. Bei den Krebsen liegen die Schlundganglien ziemlich nahe den Ganglien der Gangbeine, so dass die Gefahr einer Shockwirkung auf die letzteren bei der Exstirpation der Schlundganglien nahe liegt. Es ist nicht unmöglich, dass der Ausfall der spontanen Locomotion nach Exstirpation der Schlundganglien bei Astacus z. B. auf eine derartige Shockwirkung zurückzufübren ist. Bei den Gastropoden liegt das Pedalganglion (P Fig. 33), welches die leitende Brücke zwischen den motorischen

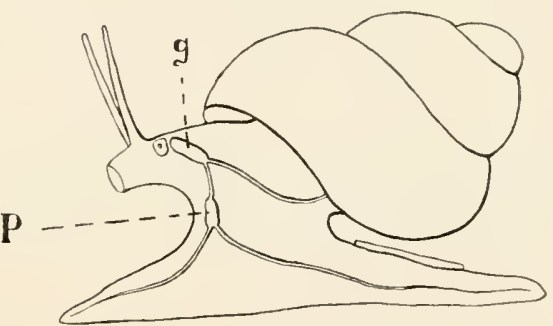

Fig. 33. Schenatische Darstellung des Centralnervensystems bei einer Schnecke (Paludina vivipara), modificirt nach Leydig. g Gehirn, P Pedalganglion.

und den sensibeln Nervenfasern der Locomotionsorgane bildet, meist relativ weit von dem Gehirn (g Fig. 33) entfernt. Wir sehen jedenfalls, dass eine enthirnte Gastropode fortfährt sich spontan zu bewegen. Steiner hat das an einer $10 \mathrm{~cm}$ langen, sehr durchsichtigen pelagischen Schneckenart, nämlich Pterotrachea, beobachtet. (1) Bei derselben ist der Fuss in ein Schwimmorgan umgewandelt. Weder einseitige, noch doppelseitige Zerstörung des Unterschlundganglions hat den geringsten Einfluss auf den Character und die Quantität der spontanen Progressivbewegung. Steiner giebt an, dass gelegentlich Pterotracheen, die ihren Kopf verloren haben, gefangen werden und dass die spontane Beweglichkeit solcher Thiere nicht verringert ist. Zerstörung des Pedalgan- 
glions dagegen hebt alle Locomotion auf. Steiner schliesst: „Also das Pedalganglion allein hat die Herrschaft über die gesammte Locomotion des Thieres." Ein derartiger anthropomorpher Schluss geht allerdings riel zu weit. Wir haben nur das Recht aus dieser Beobachtung zu schliessen, dass die protoplasmatischen Verbindungsfasern zwischen Haut und Fussmuskel des Thieres durch das Ganglion ziehen. Ferner versuchte Steiner, ob er durch einseitige Durchschneidung der Schlundcommissur bei anderen Mollusken, Pleurobranchaea und Aplysia, Kreisbewegungen re1-

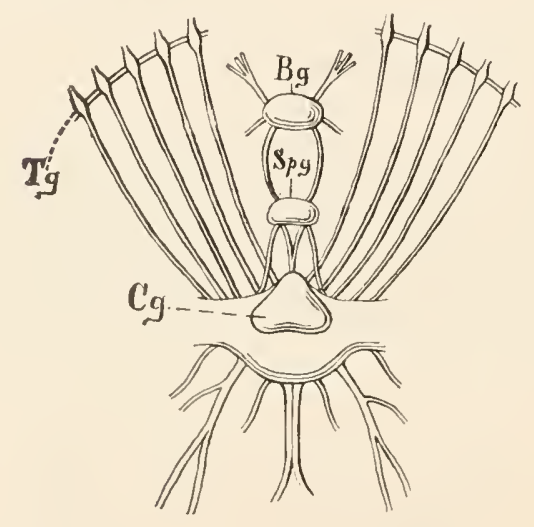

Fig. 34. Gehirn von Sepia (nach Claus). $\mathrm{Cg}$ Cerebralganglion, Spg Suprapharyngealganglion, $\mathrm{Bg}$ Buccalganglion, $\mathrm{Tg}$ Ganglia der Tentakel. anlassen könne. Das gelang ihm aber ebensowenig wie bei Pterotrachea. Einseitige Zerstörung des Pedalganglions verursachte Lähmung der einen Hälfte des Locomotionsorgans bei Cymbulia, ebenfalls einer plagischen Schnecke. Natïrlich bewegte sich das Thier, da nur ein Flügel als Ruder wirkte, im Kreise.

Die Cephalopoden hesitzen ein sehr complicirtes Gehirn (Fig. 34). Dasselbe besteht aus einer rorsalen und einer ventralen Masse und jede dieser beiden Massen ist aus mehreren Ganglien zusammengesetzt. Die dorsalen und ventralen Ganglien hängen durch Commissuren zusammen. Ausserdem besitzen diese Thiere eine Reihe von peripheren Ganglien z. B. die Tentakelganglia (Tg Fig. 34). Es ist für die Segmentaltheorie von Bedelltung, dass diese Tentakelganglia ausreichen, um Tentakehreflexe auszulösen. wie r. Uexkïll für Eledone nachgewiesen hat. Jan hat auf Grund von Wirbelthierversuchen sich oft vorgestellt, dass periphere Ganglien nicht der Reflexvermittelung dienen können.

Was nun die Versuche über das Gehirn der Cepbalopoden hetrifft, so berichtet Steiner über folgende Versuchsergebnisse an Octopus rulgaris. „Trägt man das Dorsalganglion einseitig ab orler durchschneidet die beiden Commissuren der einen Seite, so wird in den Lebensäusserungen des Thieres auch nicht die geringste Veränderung erzeugt, denn es bewegt sich spontan wie vorher, überfällt mit grossem Geschick seine Beute (Carcinus maenas) und rerzehrt sie. Anders aber wird das Bild, wenn man das dorsale Ganglion ganz abträgt. Zwar ist die Beweglichkeit des Thieres in ihrer doppelten Form erhalten, denn es kriecht mit 
Hiilfe seiner Arme oder schiesst pfeilschnell durch die Fluthen, wenn der Trichter sich rhythmisch entleert, aber diese Bewegungen erfolgen nicht melır spontan, sondern nur auf Reiz und ebensowenig nimmt es spontan seine Nahrung. Wälıend der Krake, mit hervorragenden Geisteskräften (?) unter Seinesgleichen ausgerüstet, sonst mit grosser Aufmerksamkeit seine Ungebung beobachtet, sitzt er jetzt theilnahmslos, wie blödsinnig da, und nur die regelmässigen Athemzïge zengen von erhaltenem Leben. Auch sein Gesicht ist erhalten, denn er weicht zurück, wenn man mit einem Stab auf sein Auge zugeht." Eingehender als die Versuche von Steiner ist die Abhandlung ron J. von Uoxküll an Eledone (2). Erwähnenswerth ist besonders eine Beohachtung dreses Autors, wonach ein Thier, dessen Cerebralganglion entfernt war, ungemein aufgeregt ersehien. "Alle Reflexe sehienen gesteigert. Sowie man sich dem Bassin näherte, schwamm das Thier fort, während die gesunden Thiere ruhig sitzen blieben. Das Farbenspiel war fortdauernd in Thätigkeit. In der zweiten Nacht entkam es trotz des Schutznetzes dem Bassin und verendete elend auf dem Fussboden des Instituts." v. Uexkïll sehliesst daraus, dass in den Cerebralganglien Hemmungscentren vor-, handen seien; wir sahen, dass Bethe zu einem ähmlichen Sehluss in Bezug auf das Oberschlundganglion der Arthropoden gekoumen ist. Man könnte auch aus Maxwell's Versuehen dasselbe für Nereis sehliessen.

Die Armmerven entspringen aus dem Brachialganglion. Allein das letztere steht mit dem Obersehlundganglion direct dureh die vorderen Commissuren in Verbindung, und indirect auch durch die linteren. Es ist nun von Interesse, dass der Einfluss, den die vordere Partie des Oberschlundganglions bei Reizung auf die Armbewegungen ausübt, genau der entgegengesetzte ron dem ist, den die hintere Partie auf dieselben ausiibt. Trennt man nämlich rlie ganze Obersehlundmasse zwischen den beiden Commissurenpaaren durch einen frontalen Schnitt und reizt man dann die beiden Stimpfe in der Tiefe, wo die Centralganglien liegen, so erhält man nach Uexküll die folgenden Resultate: Reizıng des rolderen Stumpfes bewirkt heftiges Anfassen der Saugnäpfe, Reizung des hinteren Stumpfes Loslassen der Saugnäpfe und Zurickiehen ler Arme. Es sind also antagonistische Thätigkeiten der Arme an die Integrität räumlich getrennter Theile des Centralnervensystems gebunden. „Ein Thier, dem man in der Gegend des ersten Centralganglions die Oberschlundmasse durchschnitten hat, verluält sieh als typisches Greifthier. Es fasst jede Unterlage fest an und kann sieh nur mit Mühe wieder lösen, meist sitzt es ganz fest mit lang ausgestreekten Armen da oder es kriecht äusserst mühsam vorwärts. Setzt man ein so behandeltes Thier einer 'Torpedo auf den Rücken, so umfasst es dieselbe rundum fest mit 
den Armen und kein Schlagen der elektrischen Organe nutzt dem Fisch, er wird seinen unbequemen Reiter nicht mehr los. Dass anderer seits auch die Eledone nur widerwillig den Ritt mitmacht, ersieht man daraus, dass sie tiefbraun wird und Tinte wirft. Nie wird ein normaler Octopode, wenn er sich ïberhaupt an Torpedo vergreift, was ich nur bei Octopus, nie bei Eledone beobachtet habe, länger als ein paar Secunden in so gefährlicher Nachbarschaft bleiben." Mir scheint, dass aus diesen Thatsachen der Schluss zu ziehen ist, dass die vordere und hintere Partie des Oberschlundganglions mit antagonistischen Muskelgruppen in Verbindung stehen. Diese Beziehung ist von Interesse im Hinblick auf die galranotropischen Versuche, die wir 'später besprechen werden.

Weiter wird es durch die Versuche von Uexküll wahrscheinlich, dass der Fressakt an die Integrität des ersten Centralganglions geknüpft ist, während das zweite und dritte Centralganglion für alle iubrigen Functionen der Arme, wie Schreiten, Steuern, Tasten, nöthig ist.

Sehr wichtig ist ferner für unsere Theorie der segmentalen Natur der Innervationslocalisation die von Uexküll gefundene Thatsache, dass wenn man die Bucca herausschneidet, so dass sie nicht mehr mit dem Centralnerrensystem zusammenhängt, dieselbe dennoch auf Reiz coordinirte Kaubewegungen hervorruft. Haut und Muskeln stehen bier durch Nerrenfasern in Verbindung, die nicht durch das Centralnervensystem gehen, sondem nur durch ein peripheres Ganglion, das ヶ. Uexkïll als Bucco-intestinales Ganglion bezeichnet. Das ist wiederum eine Thatsache, die dafür spricht, dass die Ganglien für die Reflexe nur als Leitungsorgane, d. h. als protoplasmatische Verbindungsfäden in Betracht kommen und nicht als Träger geheimnissvoller Reflexmechanismen.

\section{Litteratur zu VIII.}

1) Steiner, J. Die Functionen des Centralnervensystems der wirbellosen Thiere Sitzungsbericht der Berliner Akademie der Wissenschaften. 1890. I. S. 39.

2) v. Uexkiill. Physiologische Untersuchungen an Eledone moschata. Zeitschr. f. Biologie, Bd. 31. 1895 . 
IX.

\section{Die Segmentaltheorie bei Wirbelthieren.}

1) Die segmentale Anordnung des Centralnervensystems der Wirbelthiere ist durch die Anordnung der Rückenmarksnerven deutlich gemacht. Aus physiologischen Gründen bin ich geneigt, die Frage aufzuwerfen, ob die Rïckenmarkswurzeln der Ausdruck der rollen Zahl der segmentalen Ganglien sind oder ob die Zahl der letzteren nicht grösser ist als die Zahl der Rückenmarksnerven. Für den Kopf ist die Zahl der ursprünglichen Segmente sicher grösser als die der Hirnnerven. Nerven wie der Hörnerv und der Vagus sind die peripheren Ausläufer ron mehr als je einem Segment. In der That haben auch Dohrn, Locy u. A. eine grössere Zahl von Segmenten sicher nachgewiesen. Im Kopfe des Haifischembryo nimmt Locy ursprïnglich 14 Segmente an. Da der einzige morphologische Anhaltspunkt für die Segmentation in Einschnitten besteht, so ist es klar, dass die wirkliche Segmentation viel weiter gehen kann und ich glaube auch, dass die höchsten bis jetzt gegebenen Zahlen für die Segmente noch hinter der Wirklichkeit zurückbleiben. Die Physiologie hat noch mehr Interesse an der Entscheidung dieser Frage als die Morphologie, da die Theorie der coordinirten Bewegungen davon abhängt. Möglicher Weise ist auch die Segmentationsfrage für das Grosshirn indirect von Bedeutung, insofern als die sogenannten Centren der Grosshirnrinde eben nur gesonderte Einmïndungsstellen der Fasern von den einzelnen Segmenten des Centralnerrensystems sind.

Ueber die segmentale Anordnung des Rückemmarks ist folgendes zu sagen. Der Segmentalcharacter ist äusserlich angedeutet durch die Rückenmarksnerven, die je mit einer ventralen motorischen Wurzel und einer dorsalen sensibeln aus dem Rückenmark entspringen. Es mag daran erinnert werden, dass die hintere dorsale Wurzel ein Ganglion durchsetzt. Durchschneidet man die vordere Wurzel, so treten Lähmungserscheinungen der Muskeln des entsprechenden Segmentes auf. Durchschneidet man die hintere Wurzel, so werden die betreffenden Segmente empfindungslos, oder richtiger die Leitung ron Erregungswellen, 
die von der Peripherie ausgehen, zu den Muskeln des Segments und den übrigen Segmenten wird unmöglich. Allein die Operation selbst hat noch einen anderen Einfluss auf die Spannung der Muskeln desselben Segments (rielleicht auch anderer Segmente). Der Betrag der Muskelspannung unter gewöhnlichen Umständen variirt (vermuthlich mit den chemischen Zuständen des Muskels). Dehnen wir einen Muskel mit einem bestimmten Gewicht, so erreicht er eine bestimmte Länge. Durchschneiden wir aber, während er noch mit seinem Segment nervös verbunden ist, die hinteren Wurzeln, so vertängert er sich (E. v. Cyon); ein Beweis, dass seine Spannung abgenommen hat in Folge der Durchschneidung der hinteren Wurzeln. Die Durchschneidung hat also eine Shockwirkung, d. h. rermutblich eine uns einstweilen unbekannte chemische Veränderung im Nuskel, zur Folge gehabt. Dieser Einfluss der hinteren Wurzeln auf die Muskeln zeigt sich auch beispielsweise in den Bewegungen eines Thieres, dem man die hinteren Wurzeln der Hinterbeine durchschnitten hat. Die Bewegungen der Beine sind gestört. Es ist bekannt, dass dieses segmentale Verhältniss des Ursprungs der Nerven auch für die Gehirnnerven gilt, nur dass hier die Ungleichheiten des Wachsthums die segmentalen Verhältnisse äusserlich verwischen. Der Trigeminus oder gewisse Zweige desselben diurfen als die hinteren Wurzeln des Facialis angesehen werden und Bell hat bekanntlich erst ans dem Unstand, dass der wesentlich sensible Trigeminus ein peripheres Ganglion (Ganglion Gasseri) besitzt, während der wesentlich motorische Facialis kein peripheres Ganglion hat, geschlossen, dass auch die hinteren Wurzeh des Rückenmarks, welche periphere Ganglien besitzen sensibel sincl, die vorderen ganglienfreien Wurzehn dagegen motorisch Bell fand schon (auf vivisectorischem Wege), dass Durchschneidung des Trigeminus Fressstörungen bei solchen Thieren hervorruft, die ihr Futter mit den Lippen aufnehmen müssen. Diese Fressstörungen sind natïrlich durch Schwäche der betreffenden Muskeln bestimmt.

Es mag hier noch ein Wort über die Bedeutung der Ganglienzellen für die Frhaltung des Axencylinders hinzugefügt werten. Der Axencylinder kann als l'rotoplasmafortsatz einer Ganglienzelle angesehen werden, der nur so lange am Leben bleibt, als er mit der Ganglienzelle in Continnität steht. Vielleicht ist es berechtigt, dabei an die Bedeutung des Kerns zu denken: Kernlose Zelltheile gehen ja zu Grunde. Nun liegen die Ganglienzellen der hinteren Wurzeln im Spinalganglion, die der vorderen Wurzeln in den Vorderhörnern. Durchschneidet man die hinteren Wurzeln, so degenerirt der mit dem Rückenmark zusammenhängende Theil der Fasern, während der mit dem Spinalganglion verbundene erhalten bleibt und wächst oder regenerirt. Durchschneitet 
man die vorderen Wurzeln, so degenerirt der periphere Stumpf, während der mit dem Rückenmark verbundene erhalten bleibt und wächst. Es mag anch hier kurz erwähnt werden, dass die Nervenfasern der hinteren Wurzeln nach der Golgi'schen Schule mit den Ganglienzellen der Hinterhörner nicht verwachsen sind, sondern dass sie nur in Berührung sind. 1) Für die Leitung der Erregung ist dieser Umstand gleichgültig. Ob electrochemische Umstïnde oder Aenderungen der Oberflächenspannung die Leitung der Erregung bedingen: es ist in beiden Fällen nicht nöthig, dass lintere Wurzeln und die sensibeln Nervenfasern rerwachsen sind, sie müssen nur in hinreichend enger Berührung sein. Engelmann hat ja auf diese Verhältnisse schon vor langer Zeit in seiner ansgezeichneten Arbeit über die Leitung im Ureter aufmerksam gemacht.

2) Was nun die segmentale Localisirung der Reflexe im Rückenmark betrifft, so ist genügendes Material zum Nachweis dieser Thatsache vorhanden. Bei einem Hund, bei dem das Rückenmark etwa im Brusttheil durchschnitten ist, ist das hintere Stiick des Thieres in Bezug auf motorische und sensible Functionen völlig getrennt von dem vorderen Thier. Anfangs nach der Operation machen sich schwere Shockwirkungen bemerkbar, die aber später vergehen und ron denen weiter unten die Rede sein wird. Aber da im Centrahnervensystem der höheren Thiere nur eine Zusammenheilung der Schnittllächen durch Bindegewebe beobachtet ist, aber keine Regeneration, so ist die Continuitätstrennung nach einer Durchschneidung dauernd. Bei einem solchen Thier zeigt der hinter der Schnittstelle gelegene Theil alle die Reactionen, welche in den betreffenden Segmenten möglich sind. Das hat Goltz für Hunde festgestellt. Reiben der Haut bringt Kratzbewegungen der Hinterbeine derselben Seite hervor. Erection des Penis kann durch Reizung der Torhaut desselben ausgelöst werden, ebenso das Uriniren. Mastdarm und Blasenreflexc sind erhalten, wie schon früher erwähnt, ebenso die vasomotorischen Reactionen. Dass die Athembewegungen segmentale Vorgänge sind, ist schon früher erwähnt worden. Dass diejenigen Reflexe, bei welchen die Armmuskeln thätig sind, ebenfalls segmental sind, ist durch Goltz gezeigt worden. (2) Während der Brunstzeit hält das Froschmännchen das Weibchen umklammert. Schneidet man einem solchen Froschmännchen den Kopf ab und den Hinterkörper, so dass nur ein Stück, bestehend aus den Armen und dem zugehörigen segmentalen Stïck des Rückenmarks, übrig bleibt, so genügt sanftes Methode,

1) Die Arbeiten Apathy's erwecken Bedenken gegen die Resultate der Golgi'schen 
Reiben der Haut an der ventralen Seite dieses Stückes, um den Umarmungsreflex auszulösen.

3) Wenn wir zum Gehirn der Wirbelthiere übergehen, so sind wir im Wesentlichen auf das Gehirn der Kaltblüter angewiesen, wenn wir die Berechtigung der Segmentaltheorie nachweisen wollen, aus dem einfachen Grunde, weil man bei Warmblütern nicht gut in der Nähe der

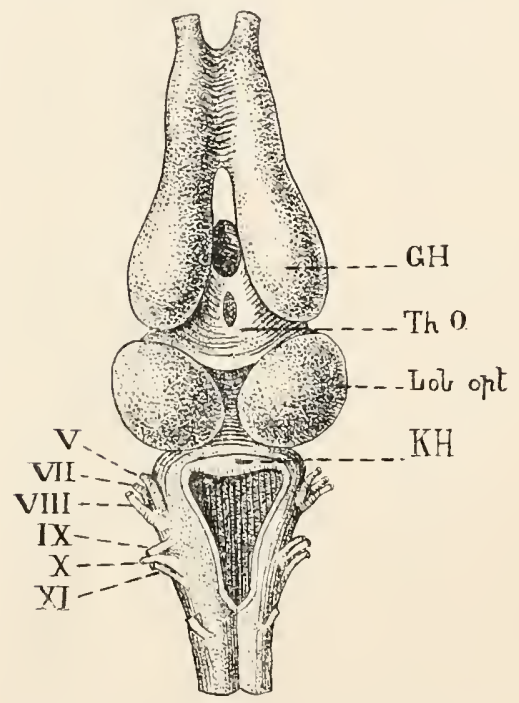

Fig. 35. Das Gehirn des Frosches. Nach Wiedersheim.

GH Grosshirn, Th. O. Thalamus opticus. Lob. opt. Lobi optici, KH Kleinhirn, V-XI Ursprungsstelle der betreffenden Hirnnerven.

Medulla Gehirnoperationen ausfüluren kann, ohne dass es zum Athemstillstand kommt. Bei Kaltblütern sind die Shockwirkungen geringer. Wir wählen als Typus das Froschgehirn, weil dasselbe am sorgfältigsten bearbeitet worden ist. Das Froschgehirn (Fig. 35) besteht im Wesentlichen aus dem Grosshirn (GH lig. 35), Thalamus opticus (Th. O), lobus opticus, Kleinhirnleiste $(\mathrm{KH})$ und Medulla oblongata. Das Diagramm (Fig. 35) giebt auch den Ursprung der Hirnnerren ( $\mathrm{V}$ bis XI). Wir wollen num zeigen, dass die einzelnen Leistungen des Frosches an die segmentalen Ganglien gebunden sind und dass wir kein Recht haben, ron .Centren“ für die einzelnen Leistungen zu sprechen, es sei denn, dass das Wort Centrum mit dem Ausdruck segmentales Ganglion gleichbedeutend wird.

Wir betrachten zuerst die geordneten Gehbewegungen. Es war lange ein Dogma, dass spontane Gangbewegungen nur von solchen Fröschen ausgeführt werden können, welche noch im Besitz des Grosshirns seien. Diese Angabe rührt von Flourens her. Er beobachtete, dass Frösche ohne Grosshirn sich nicht mehr spontan bewegen. (3) Schrader zeigte später, dass diese Beobachtung nicht richtig ist, dass vielmehr dieser Mangel an Spontanëität nu dann eintritt, wenn die Thalami optici rerletzt werden. (4) Sollen wir nun daraus schliessen, dass das spontane Gehrermögen in den Thalami optici localisirt ist? Das wäre falsch, denn wenn man Fröschen das ganze Gehirn inclusive der Pars commissuralis der Medulla oblongata entfernt, sind sie 
„wie beseelt von einem unwiderstehlichen Bewegungstrieb; unermüdlich kriechen sie vollkommen coordinirt umher und gelangen erst zur Ruhe, wenn sie sich in einem Winkel ihres Behälters festgerannt haben." (Schrader.) Sie benehmen sich also genau so wie die enthirnten Nereis in den Versuchen ron Maxwell. Die Localisation von Flourens war also zu hoch oben erfolgt. Es sei auch noch ausdrücklich hinzugefügt, dass die Frösche Schrader's, welche das ganze Gehirn inclusive der Pars commissuralis verloren hatten, sich nicht nur bewegten, sondern dass sie sogar noch geschickt zu klettern im Stande waren. Die Ruhe, welche nach Thalamusverletzung eintritt, ist also eine Hẹmungserscheinung. Ein anderer Versuch, die Locomotion in einem "Centrum" zu localisiren, rührt von Steiner her. Er fand, dass Frösche nach Verlust dor Pars commissuralis der Medulla keine Locomotion mehr ausführten und schloss daraus, dass dieser Stelle die alleinige und ungetheilte Herrschaft über alle Locomotionen des Körpers zukommt. (5 und 6.) Die entgegengesetzten Resultate Schrader's (4) widerlegen die Schlüsse Steiner's. Der letztere Autor beobachtete offenbar nur moribunde Thiere, seine Frösche überlebten die Operation höchstens eine Woche, wäbrend Schrader's Thiere viele Monate lebten und sich von der Operation völlig erholten. Nebenbei möchte ich hier auf den anthropomorphen Character der Centrentheorie hinweisen. Die Beschreibung, die Steiner von dem „Locomotionscentrum" giebt, dass ihm die, ungetheilte Herrschaft etc. zukomme", entspricht ganz dem Bilde eines regierenden Fürsten.

Nach der Segmentaltheorie dagegen ist zu erwarten, dass nur diejenigen Theile des Centralnervensystems für die Locomotion nöthig sind, welche den Segmenten der Arm- und Beinmuskeln entsprechen. Es muss also möglich sein, so lange coordinirte Locomotion zu erhalten, als die segmentalen Ganglien der Arm- und Beinmuskeln intact sind. Damit stimmt der erwähnte Fund Schrader's, dass auch nach Entfernung des gesammten Gehirns einschliesslich der Pars commissuralis noch coordinirte Gangbewegungen erfolgen. Ja mehr als das, „man kann die ganze Medulla bis zur Spitze des Calamus scriptorius entfernen und erhält doch noch völlig coordinirte Locomotion." „Störung der Coordination der Bewegungen beginnt erst mit der augenfälligen Beeinträchtigung der Leistungsfähigkeit der Vorderbeine, welche inmer deutlicher wird, je mehr sich der Schnitt von der Spitze des Calamus scriptorius aus dem Ursprung des Plexus brachialis nähert. Jetzt sinkt das Thier ganz auf den Bauch. Die Vorderbeine vermögen den Rumpf nicht mehr zu tragen. Reizt man in der Mittellinie, etwa am After, so schleudern die Hinterbeine durch kräftigen Stoss den Körper vorwärts. Die vorderen Extremitäten betheiligen sich noch durch "alternirende" aber un- 
zulängliche und eigenthünliche zitternde Bewegungen. Dem Erfolg nach kommt eine coordinirte Fortbewegung also nicht mehr zu Stande." Man sieht anch hierin wieder die strenge Gültigkeit der Segnentaltheorie. Verletzungen des Rückenmarks in der Nähe des Brachialplexus beeinträchtigen die Gangbewegungen nur insofern, als die Mitwirkung der Vorderbeine in Betracht kommst. Die Hinterbeine dagegen functioniren normal weiter. Was für die Frösche gilt, gilt auch für die Fische. Auch hier tritt Ruhe ein, wenn man das Gehirn, bis zur Medulla entfernt. Es wäre aber völlig falsch, daraus zu schliessen, dass in der Medulla oblongata das "Locomotionscentrum" gelegen sei. Schneidet man einem Haifisch den Kopf ab, so schwimmt der Rumpf spontan umher: Steiner hat diesen Versuch angestellt. Nach der Segmentaltheorie war dieses Resultat zu erwarten. Das Bewegungsorgan des schwimmenden Hais ist der Schwanz und zur Thätigkeit desselben sind nur die entsprechenden segmentalen Ganglien des Rückenmarks nöthig. - Schneidet man bei einem jungen Salamander das Rückenmark durch, so werden die Schwimmbewegungen des Vordertheils und Hintertheils dennoch soweit coordinirt ausgeführt, dass man kaum glauben sollte, dass hier eine Operation erfolgt war. Ebenso beim Aal. (1) Die Dinge liegen ähnlich wie beim Regenwurm. - Reibung des Rückens veranlasst den Frosch zum Quaken und bei einem Frosch, der das Gehirn bis zur Medulla verloren hat, lässt sich diese Stimmäusserung mit maschinenmässiger Regelmässigkeit bervorrufen, wie Goltz gefunden hat. (2) Nach der Segmentaltheorie ist dieser Reflex natürlich an die Integrität der Medulla geknüpft, da hier die motorischen Nerven für die Erregung der Stimme ihren Ursprung nehmen. Die Centrentheorie hatte angeblich ein "Centrum" für diesen Reflex höher oben im Gehirn gefunden. Schrader hat dagegen gezeigt, dass ein Frosch, der alles Gehirn bis auf die Medulla verloren hat, noch reflectorisch quakt.

4) Der „Nahrungs- und Selbsterhaltungstrieb" wurde, wie alle Instincte, ins Grosshirn verlegt. Eine Analyse dieses Instincts zeigt, dass derselbe sich aus mehreren Reflexen zusammensetzt, die nach einander ausgelöst werden. Zunächst ein Opticusreflex. Der Frosch fängt nur Objecte (z. B. Fliegen), die in Bewegung sind. Der Opticus endigt im Thalamus opticus und demgemäss ist zı erwarten, dass der Verlust des Grosshirns den Frosch nicht verhindern sollte, Fliegen zu fangen. Das hat auch Schrader gefunden. Wenn frühere Autoren zum Resultat kamen, dass das Grosshirn zum Sehen nöthig sei, so sind sie eben durch die Shockwirkungen der Operation zu einer zu hohen Localisation verleitet worden. Goltz hatte übrigens schon bewiesen, dass der grosshirnlose Frosch noch Hindernisse vermeidet. Für iden grosshirnlosen Fisch 
gilt das Gleiche. Der erste Akt der Nahrungsaufnahme besteht also in einem optischen Reflex. Sobald die Nahrung mit dem Gaumen in Berührung kommt, löst sie Schluckreflexe aus. Diese Reflexe spielen sich in der Vagusgruppe ab. Nach der Segmenttheorie sollten diese Reflexe noch möglich sein, wenn selbst alle vor den Vaguskernen gelegenen Gehirntheile entfernt sind. Das ist auch der Fall. So lange nur noch die Medulla oblongata erhalten ist, verschluckt der Frosch Nahrung, die in seinen Mund gethan wird.

Die Athmung der Frösche ist wesentlich Mund- und Halsathmung. Die entsprechenden nervösen Segmente für diese Körpertheile liegen in der Medulla oblongata und dem Anfang des Ruickenmarks. Durchschneidet man das letztere hinter dem noeud vital (Calamus scriptorius), so fahren, wie Schrader gefunden hat, gleichwohl alle Muskeln fort, coordinirt an der Athmung Theil zu nehmen, sowohl diejenigen, deren Nerven vor der Schuittstelle entspringen, wie diejenigen, deren Nerven binter rler Schnittstelle entspringen.

Man nahm frïher an, dass die compensatorischen Bewegungen der Frösche an Organe des Mittelhirns gebunden seien. Schrader fand aber, dass Frösche, deren Gehirn bis zur Medulla oblongata (der Ursprungsstelle des Acusticus) entfernt war, dennoch compensatorische Bewegungen zeigten. Die früheren Physiologen waren eben durch Shockwirkungen oder sonstige Nebenwirkungen getäuscht worden. Der Vollständigkeit halber sei noch daran erinnert, dass die Abwisch- und Abwehrreflexe des Frosches ebenfalls rein segmentaler Natur sind.

Wir haben damit einen Ueberblick über die Hauptreactionen des Frosches gegeben und gefunden, dass im Gehirn wie im Rückenmark dieses Thieres keine Functionslocalisation existirt, sondern dass wir hier, wie bei den Anneliden und Arthropoden, nur segmentaleReflexe haben. Diese Auffassung war nach den Versuchen an niederen Thieren natürlich. Dass sie bereits von Schrader vorausgesehen war, ehe die hier mitgetheilten Versuche an Anneliden und Arthropoden bekannt waren, beweist folgender Schlusssatz seiner Abhandlung über das Froschgehirn: ,Die mitgetheilte Versuchsreihe lehrt, dass man das Centralnervensystem des Frosches theilen kann in eine Reihe von Abschnitten, welche einer selbstständigen Function fähig sind. Sie nähert das morphologisch geschlossene Centralorgan in physiologischer Auffassung dem centralen Nẻrvensystem jener niederen Thiere, bei denen die functionelle Selbstständigkeit darin ihren morphologischen Ausdruck findet, dass die Nerven gesonderten Ganglienknoten entspringen, welche nur durch Commissuren verbunden sind. Sie spricht nicht für die Alleinherrschaft eines einheitlichen centralen Apparates, auch nicht für einen Bauplan mit einer Rang- 
ordnung verschiedenartiger Centren, sondern fordert auf, die Centralisation zu suchen in eirer vielseitigen Verkoppelung relativ selbstständiger Stationen."

Man könnte Zweifel hegen, ob die in Betracht gezogenen Leistungen des Frosches alle Reactionen dieses Thieres umschliessen. Das ist, glaube ich, wenigstens der Hauptsache nach, der Fall. Die complicirteren Instincte sind meistens nur Reihen von segmentalen Reflexen, - ich bin geneigt, dafür das Wort Kettenreflexe hier vorzuschlagen -, wobei die Einwirkung des einen Reflexes zugleich die Reizursache für die Entfesselung eines zweiten Reflexes wird. Als Beispiel eines solchen Kettenreflexes kann uns die Nahrungsaufnahme dienen. Der optische Reiz der sich bewegenden Fliege löst den Schnappreflex aus, die Berührung der Mundschleimhaut durch die Fliege den Schluckreflex. Jeder einzelne dieser Reflexe ist rein segmental. Auch die complicirten Leistungen bei der Fortpflanzung lassen sich in wenige segmentale Reflexe auflösen. Ein zweiter Umstand, der in Betracht gezogen werden muss, wenn wir die Reactionen eines Frosches auf segmentale Reflexe zurückführen wollen, ist der Umstand, dass die Reizbarkeit der Organe seines Körpers wechselt. Im Kapitel über Instincte werden wir finden, wie namentlich chemische Umstände die Form der Reizbarkeit eines Thieres beeinflussen und wie alle Umstände, welche chemische Veränderungen im Körper hervorrufen (Temperatur, Nahrung, Sexualstoffe) auch die Reizbarkeit des Thieres modificiren. Wir werden es dann auch verstehen lernen, dass beim Beginn des kalten Wetters im Herbst der Frosch sich eingräbt, während er beim Erwachen des Frühlings oder richtiger dem Beginn des warmen Wetters wieder zum Vorschein kommt. Wie bei den niederen Thieren aber ist auch beim Frosch der segmentale Reflex durch die Reizbarkeit der peripheren Organe und die Anordnung der Muskeln bedingt. Das segmentale Ganglion ist wesentlich nur die protoplasmatische Verbindung zwischen der Körperoberfläche und den Muskeln.

Was für die Frösche bewiesen wurde, ist atich für die Fische gültig. Die Versuche von Goltz resp. Goltz und Ewald am Rückenmark von Hunden beweisen ferner, dass auch hier das Gesetz der segmentalen Reflexe richtig ist. Dagegen ist bei Warmblütern jeder Eingriff in der Nähe der Medulla oblongata mit so heftigen Shockwirkungen auf die segmentalen Athemganglien verbunden, dass für die Ganglien der Medulla der höheren Wirbelthiere der experimentelle Beweis noch zu erbringen ist. Man hat sich durch elektrische Reizversuche zu belfen gesucht. Derartige Reizversuche beweisen aber nur, dass irgend eine protoplasmatische Verbindung zwischen der gereizten Stelle und den 
segmentalen Ganglien der thätigen Muskeln bestehen muss. Wenn man durch Reizung des 3. Ventrikels die Athembewegungen beeinflusst, so folgt daraus nur, dass an der betreffenden Stelle Fasern liegen, welche zu den segmentalen Athemganglien hinziehen. Es ist aber falsch, daraus zu schliessen, dass in 3. Ventrikel Athemganglien oder "Athemcentren" liegen. Die Nichtbeachtung dieser Umstände hat dazu beigetragen, die Ausbildung der Segmentaltheorie zu verhindern. Es sind aber noch andere Umstände hinzugekommen, die in gleichem Sinne gewirkt haben. Erstens der Umstand, dass die vergleichende Gehirnphysiologie und die Embryologie nie gebührend berïcksichtigt worden sind. Da das Gehirn der Wirbelthiere nur in seiner frühesten embryologischen Anlage seinen segmentalen Character verräth, hat wohl nur eine kleine Zahl der bisherigen Gehirnphysiologen ernstlich daran gedacht, dass der segmentale Character des Centralnervensystems den Schlüssel zum Verständniss seiner Functionen liefern muss. Der zweite Umstand ist der Einfluss, den die merkwürdige Shockwirkung nach einer Operation im Centralnervensystem auf den Rest des Gehirns hat. Die Gehirnphysiologie hat sich ja bekanntlich meist der operativen Methode bedient, um zu ermitteln, von welchem Gehirntheil der Ablauf einer thierischen Reaction abhängt: Den Theil, dessen Verletzung diese Function am sichersten stört, hielt man für den betreffenden Hirntheil. Wir hatten ein Beispiel dieses Verfahrens bei der Discussion der Athembewegungen und wir hatten gesehen, wie hier die Nichtberücksichtigung des Shockes dazu führte, die segmentalen Athemganglien ganz zu ïbersehen und den Ursprung der automatischen Athemthätigkeit in den Noeud vital zu legen, bloss weil von hier sich eine intensive Shockwirkung auf die segmentalen Athemganglien erzielen lässt. Der Noeud vital ist aber in aller Wahrscheinlichkeit nichts anderes als ein Punkt, wo sensible Bahnen von rechts und links zu den segmentalen Athemganglien durchpassiren. Die Localisation der Athemganglien erfolgte also zu hoch. Das war ein Characteristicum ungefähr aller Localisationen im Centralnervensystem warmblütiger 'Thiere. Die Erklärung hierfür liegt in einer Eigenthümlichkeit der Shockwirkungen, dass sie sich nämlich ausschliesslich oder hauptsächlich in den caudalwärts gelegenen Theilen des Centralnervensystems fühlbar machen. Wenn man das Brustmark eines Thieres durchschneidet, so zeigen die caudalwärts, d. h. hinter der Schnittstelle gelegenen Körpertheile eine Zeit lang die schwersten Störungen (Lähmung der Sphincteren der Blase und des Mastdarms, vasomotorische Störungen, Verschwärungen der Haut u. s. f.). Diese Störungen verschwinden aber nach einiger Zeit. Der vor der Schnittstelle gelegene Theil des Thieres zeigt dagegen keine derartigen Störungen. Nun hat 
man daraus geschlossen, dass die Ganglien für die Vasomotoren der Hinterbeine, für die Blase etc. vor der Schnittstelle gelegen seien, etwa in der Medulla. Erst Goltz hat durch eine Reihe von Versuchen, auf die wir später näher eingehen, bewiesen, dass die vorübergehenden Störungen der hinter der Schnittstelle gelegenen Körpertheile lediglich Shockwirkungen sind. Wie es aber kommt, dass Shockwirkungen sich leichter cerebrofugal als cerebropetal fortpflanzen, ist nicht bekannt. Es dürtte sich hier vielleicht um das handeln, was Engelmann als irreciproke Leitung bezeichnet, nämlich dass dasselbe Element in einer Richtung besser leitet als in der umgekehrten Richtung.

Wir haben erwähnt, dass bei verschiedenen Thieren die Shockwirkungen verschieden stark entwickelt sind und dass sie beispielsweise bei kaltblütigen Thieren geringer sind als bei Warmblütern. Die Gründe, welche bei sehr shockempfindlichen Thieren und bei Warmblïtern in Besonderen so häufig dazu geführt haben, die nerrösen "Centren" zu hoch, d. h. zwischen den segmentalen Ganglien der betreffenden Metameren und dem Gehirn zu localisiren, existiren demnach bei Kaltblütern resp. weniger empfindlichen Warmblütern nicht. Und in der That fand man dann, dass Vorgänge, welche man bei shockempfindlichen Thieren in die Medulla verlegt hatte, bei Kaltblütern tiefer unten in den zugehörigen Metameren gelegen sind. Anstatt nun hieraus zu vermuthen. dass die scheinharen Abweichungen der Warmblïter von diesem Verhalten auf den bekannten Shockwirkungen beruhen, hat man versucht die falsche Situation durch die Hypothese zu retten, dass die Functionen um so höher nach oben im Centralnerrensystem wandern, je höher das Thier in der Thierreihe steht.

Die segmentale Natur des Centralnervensystems sank zu einem sehr gleichgültigen Umstand herab, angesichts der falschen Annahme, dass Alles hoch oben in der Medulla oder in dem Grosshirn localisirt sei, also ausserhalb der segmentalen Ganglien. Statt dessen aber gerieth die Physiologie ganz in den Bann der metaphysischen Psychologie, die alle Reactionen des Körpers in "Seelenvermögen" abgetheilt hatte. Man befreundete sich mit dem Gedanken, dass die einzelnen Abschnitte des Centralnervensystems gesonderten Seelenrermögen resp. Functionen dienen. Jede „Function" hatte einen gesonderten Sitz im Centralnervensystem, dem "Centrum" der "Function". Das Centralnervensystem ist ein Aggregat von „Centren" für bestimmte ,Functionen“. So riele rerschiedene Reactionen ein Thier zeigt, so viele „Functionen" und so viele "Centren" existiren. Das ganze Problem des Antheils der peripheren Reizbarkeit an der Reaction war damit beseitigt. Das Räthsel der .Function" war ja im „Centrum" enthalten. Das Ziel der Physiologie 
bestand nunmehr ausschliesslieh darin, den Sitz der verschiedenen "Functionen" im Centralnervensystem nachzuweisen, die Centren zu localisiren. Die Physiologie des Centralnervensystems der Wirbelthiere steht heute ziemlich unbestritten auf diesem Standpunkt.

Wir stellen dieser heutigen Centrentheorie des Centralnervensystems die segmentale Theorie gegenüber. Die einzelnen Segmente des Centralnervensystems sind die leitenden Protoplasmaverbindungen zwischen der reizbaren Körperoberfläche und den contractilen Skeletmuskeln, den Blutgefässmuskeln, den Drüsen etc. des zugehörigen Segments. Die peripheren Strukturverhältnisse des Segments sind in erster Linie maassgebend für den Erfolg einer Reizursache. Wenn aber in den segmentalen Ganglien noch weitere specifische Einrichtungen vortianden sind, - und wir werden später vielleicht in der Orientirung der Elemente einen derartigen Umstand erkennen - so sind diese Einrichtungen doch immer so, dass dieselben Elemente des Centralnervensystems bei den verschiedensten Reactionen sich betheiligen. Nach der Centrentheorie existirt für jede bestimmte Reaction auch ein abgegrenzter Theil des Centralnervensystems, der eben nur mit dieser Reaction (Function) zu thun hat, das sog. "Centrum" der betreffenden Function. Der Unterschied beider Standpunkte wird erst dann in seiner ganzen Tragweite deutlich, wenn wir uns über das Niveau der blossen Localisation der Vorgänge erheben und versuchen zu einer Mechanik der thierischen Reactionen zu gelangen. Ein Vergleich mit einem anderen Organ, nämlich der Retina wird den Unterschied klarer machen. Die optische Wahrnehmung der Formen beruht darauf, dass die einzelnen Retinaelemente je nach ihrer Lage auf der Retina verschiedene Raumempfindungen bestimmen. Dasselbe Retinaelement kann also zum Zustandekommen sehr vieler verschiedener Bilder dienen. So stellen wir uns die Rolle des Centralnerrensystems vom segmentalen Standpunkte aus ror, wobei die verschiedenen Elemente resp. Ganglien die Stelle der Retinaelemente bei der Wahrnehmung der Formen einnehmen. Dieselben Elemente resp. Ganglia nehmen an sehr vielen „Functionen“ theil, wobei jedes Element nur nach seiner segmentalen Lage, Orientirung und sonstigen allgemeinen oder besonderen Eigenschaften für den Erfolg maassgebend ist. Versuchen wir uns aber klar zu machen, welche Vorstellung über das Räumlichsehen wir uns nach der Analogie der Centrentheorie des Centralnervensystems bilden müssten, so gelangen wir zu der Monstrosität, dass jedes Retinaelement der Perception eines bestimmten Bildes dient und dass wir so viele verschiedene Bilder sehen können als wir Retinaelemente (z. B. Zapfen) haben. Wir thun mit dieser Parallele der modernen Centrentheorie kein Unrecht: Die consequenten Vertreter 
derselben nehmen in der That an, dass jedes Erinnerungsbild in besonderen Zellen deponirt ist und dass die Zahl der Gehirnzellen die Zahl der möglichen Gedächtnissbilder bestimmt. Auf dem engeren Gebiete der Gehirnphysiologie ist die Centrentheorie sehr energisch von BrownSéquard, Goltz und mir selbst bekämpft worden. Sie ist aber ebenso falsch für das Rückenmark wie für das Gehirn.

\section{Litteratur zu IX.}

1) Goltz. Ueber die Functionen des Lendenmarks des Hundes. Pflüger's Archiv, Bd. 8. 1874.

2) Goltz. Beiträge zur Lehre von den Nerrencentren des Frosches. Berlin 1868. Verlag von Hirschwald.

3) Flourens, P. Recherches expérimentales sur les Propriétés et les Fonctions du Système Nervenx etc. 2. édit. Paris 1842.

4) Schrader, Max E. G. Zur Physiologie des Froschgehirns. Pflüger's Archiv. Bd. 41. 1887.

5) Steiner, J. Die Functionen des Centralnervensystems und ihre Phylogenese. Erste Abtheilung: Untersuchungen über die Physiologie des Froschhirns. Braunschweig 1885.

6) Steiner, J. Die Functionen des Centralnervensystems und ibre Phylogenese. II. Abtheilung, Die Fische. Braunschweig 1888-

7) Goltz, Fr. und Ewald, J. R. Der Hund mit verkürztem Rückenmark. Pflüger's Archiv. Bd. 63. Bonn 1896.

8) Bickel. Beiträge zur Rückenmarksphysiologie des Aales. Pflüger's Archiv. Band 68. 
X.

\section{Halbkreuzungen, associirte Stellungsänderungen der Extremitäten und Zwangsbewegungen.}

Wir erkennen also im Centralnervensystem der Wirbelthiere nur segmentale Ganglien und segmentale Reflexe an. WVir leugnen die Existenz übergeordneter Centren, wie sie etwa in der Annahme eines „Coordinationscentrums" zu Tage treten. Wie wir zeigen konnten, dass die Verhältnisse der Erregbarkeit und Reizleitung ausreichen, um die Coordination der Theile bei Medusen, beim Helzen, bei der Athmung ron Limulus, bei den Gehbewegungen des Regenwurms und den Schwimmbewegungen des Salamanders zu garantiren, so reichen sie auch aus um die übrigen Coordinationserscheinungen bei höheren Thieren zu bestimmen. Wie Schrader es richtig ausdrückt, nur die Art der Verkoppelung bedingt das Zusammenwirken verschiedener Segmente zu einer gemeinsamen Thätigkeit. Nichts zwingt uns, diesen Umstand auf ,übergeordnete Centren" zurückzufïhren. Einige dieser Verkoppelungen zeigen Besonderheiten, welche den Reactionen der Thiere characteristische Eigenschaften verleihen, nämlich die Kreuzungen und Halbkreuzungen ron nerrösen Verbindungsfasern.

Ein bekanntes Beispiel für die Halbkreuzung ist das Verhalten des Sehnerven. Jedes Auge hat seinen besonderen Sehnerven. Aber während die Fasern der lateralen Seite der Retinae ungekreuzt durch das. Chiasma gehen, d. h. auf derselben Seite des Kopfes und Gehirns rerbleiben, erleiden die Fasern, welche von der medialen Seite der Netzhaut kommen, eine Kreuzung. Jenseits des Chiasmas findet man also im linken Tractus opticus die Fasern, welche zur lateralen Seite des linken Auges und zur medialen Seite des rechten Auges gehen. Schneidet man einen, etwa den linken Tractus, durch, so werden die linken Seiten beider Augen blind, und der Patient erkennt nichts mehr in der rechten Hälfte des Gesichtsfeldes. Er ist hemianopisch. Diese Beziehung der Fasern bleibt im Gehirn bestehen. 
Es ist der Mühe Werth, diese Beziehung auch noch von einer anderen Seite zu betrachten. Die Retinaelemente sind normal (rechtwinklig) zur Fläche der Retina angeordnet. Es haben also die Elemente der linken Seite beiler Retinae die gleiche Orientirung, sie sind nämlich nach links und hinten gerichtet, während die Elemente der rechten Hälften beider Retinae nach rechts und hinten gerichtet sind. Das ist die Richtung, die ihre Fasern jenseits des Chiasmas einschlagen. Ob und wie Wachsthumsrichtung und Orientirung ursprünglich zusammenhängen, wäre einer eingehenderen Untersuchung werth. Die Elemente der rechten und linken Retina, welche gleiche Orientirung besitzen, haben auch gleiche Raumwerthe. Es gehen also die Fasern der reclitswerthigen Retinaelemente nach der linken Gehirnhälfte, die Fasern der linkswerthigen Retinaeleniente nach der rechten Gehirnhälfte.

Es bestehen aber auch ähnliche Halbkreuzungen anf motorischem Gebiete.

Wenn wir die Retina eines Auges als ein einheitliches Organ ansehen, obwohl nur die gleich orientirten Elemente beider Retinae zusammen gehören, so dürfen wir auch vielleicht einmal vorübergehend die Muskeln eines jeden Einzelauges als einen einheitlichen Apparat ansehen. In dem Falle finden wir, dass in motorischer Hinsicht dieselbe Halbkreuzung der Augennerven im Gehirn besteht wie in sensibler Beziehung. Bei den Seitwärtsbewegungen unserer Augen functioniren nämlich der Rectus externus des einen und der Rectus internus des andern Auges wie ein einziger Muskel. Nehmen wir einen angeborenen Zusammenhang zwischen den Retinaelementen und den Augenbewegungen an, so müssen der rechte externus und der linke internus von der linken Gehirnhälfte aus innervirt werden. Es verlaufen also die motorischen Nervenfasern der Externi gekreuzt, die der interni ungekreuzt. ') Die Trennung dieser Muskelı und ihrer Nervenfasern in getrennte Bündel lässt die Auffassung dieser Beziehungen als Halbkreuzung weniger naheliegend erscheinen als bei der Retina. Auf pathologischen Gebiet finden wir entsprechend der Hemianopsie die Dériation conjuguée als Ausdruck dieser motorischen Halbkreuzung.

Wir können diese Halbkreuzungen nur da erwarten, wo paarige Extremitäten associirt bewegt werden, d. h. wo, wie bei den Augen, die Linksdrehung des einen Gliedes nicht möglich ist ohne gleichzeitige Linksdrebung des anderen Gliedes. Unsere Extremitäten lönnen sich unabhängig von einander bewegen, dagegen ist das anders bei niederen

1) Natürlich erfolgt die Halbkrenzung hierbei im Gehirn und nicht peripher wie beim Opticus. 
Wirbethieren, wie Fischen. Hier finden wir ähnliche Beziehungen an den Flossen wie bei menschlichen Augen. Ich habe zuerst nachgewiesen, dass man durch Zerstörung eines Ohres oder der Einmündungsstelle des Acusticus in die Medulla associirte Stellungsänderungen der Augen und der Flossen hervorrufen kann. (1) Zerstört man bei einem Haifisch den linken Hömerven oder die linke Seite der Merlulla, wo der Hörnerv eintritt, so blickt das linke Auge des Thieres nach unten, das rechte nach oben. Diese associirte Stellungsänderung beider Augen deutet an, dass in Folge der Operation das Spannungsverhältniss der Heber und Senker beider Augen sich geändert hat. Am linken Aıge überwiegt die Spannung der Senker iiber die der Heber, am rechten die der Heber über die ler Senker. Diese Spamnungsabnahme der Muskeln nach Verletzung des Ohrs gehört wohl in dieselbe Kategorie von Erscheinungen wie die ron Cyon gefundene Spannungsabnahme der Muskeln eines Segments nach Durchschneidung der hinteren Wurzeln desselben. Es sind "Shockwirkungen“, die freilich bis ans Lebensende des Thieres bestehen köunen. Allein auch die Flossen zeigen ebenfalls associirte Stellungsänderungen. Die linke Flosse ist dorsalwärts gehoben, die rechte zu stark ventralwärts flectirt. Während man sagen kann, dass die beiden Augen nach links um die Längsaxe dieses Thieres gerollt sind, sind die Flossen nach rechts um die Längsaxe gerollt. Allein obwohl die Brustflossen die associirten Stellungsänderungen an deutlichsten zeigen, bestehen sie auch in allen übrigen Flossen, nur mit dem Unterschied, dass der Betrag der Stellungsänderung um so geringer ist, je weiter das betreffende Segment von der Operationsstelle entfernt ist. Das ist ja rom Standpunkt der segmentalen Anordnung der Ganglien leicht zu verstehen. Die Stellung eines Flossenpaares hängt ja direct nur rom Zustand seines segmentalen Ganglions ab. Das letztere kann (chemisch) durch Verletzung eines entfernteren segnentalen Ganglions beeinflusst werden. Diese Beeinflussung muss aber um so geringer ausfallen, je weiter das operativ verletzte Ganglion entfernt ist. Die Widerstände für die Fortpflanzung der Veränderung nehmen mit der Entfernung zu.

Diese Beobachtungen erlauben uns nun einen Schluss zu ziehen ïber die Verbindungen der Muskeln mit der rechten und linken Hälfte der betreffenden Ganglien. Wir dürfen aunehmen, dass als dauernde Folge der Zerstörung eines Hirntheils eine Spannungsabnahme del zugehörigen Muskeln eintreten kann, nicht aber eine Zunahme der Spannung. Es sind also diejenigen Muskeln mit der linken Seite der Medulla oblongata in Acusticussegment direct oder indirect verknüpft, welche nach der Zerstörung' dieses Segments eine Spannungsabnahme aufweisen. Demzufolge ist die linke Seite dieses Segments mit den 
Hebern des linken und den Senkern des rechten Auges, sowie mit den Senkern der linken und den Hebern der rechten Brustflossen verbunden. Es ist wieder eine Art Halbkreuzung, wenn wir von der Vorstellung ausgehen, dass alle Muskeln eines Auges resp. einer Flosse ein zusammengehöriges Ganzes bilden. Es sind aber nicht nur die Muskeln der Flossen, welche derartige Spannungsänderungen erleiden, sondern wohl auch die Muskeln der Wirbelsäule.

Wenn die symmetrischen Muskeln der Locomotionsorgane verschiedene Spannung besitzen, so müssen natürlich die gewöhnlichen Reize zur Locomotion anstatt zu symmetrischen Bewegungen zu unsymmetrischen Bewegungen führen. Wenn auf der rechten Brustflosse die Senker überwiegen und auf der linken die Heber, so geräth das Thier bei der Thätigkeit dieser Flossen unter den Einfluss eines Kräftepaars, welches eine Rollbewegung um die Längsaxe seines Körpers nach links herbeiführen muss. So lange das Thier langsam schwimmt, kommt es nicht $\mathrm{zu}$ Rollbewegungen, dieselben werden compensirt. Die Reibung des Fisches im Wasser wird schon ausreichen, um schwache Grade dieser Rollbewegungen zu vernichten. Versucht aber das Thier rasch zu schwimmen oder regt man dasselbe auf, so geräth es ins Rollen. Man bezeichnet diese Rollbewegungen als Zwangsbewegungen, ein allerdings schlecht gewählter Name. Auch bei Hunden und Kaninchen hat man diese Rollbewegungen nach Eingriffen in die Medulla auf einer Seite bemerkt.

Wenn ein Fisch, dessen Progressivbewegıngen durch die Ruderschläge des Schwanzes bestimmt werden, sich nach rechts umdreht, so ist es dazu nöthig, dass der Schwanz mit grösserer Energie nach rechts bewegt wird, als die Energie beträgt, mit der er in seine Indifferenzstellung resp. nach links zurückgeht. Dieser Zustand könnte permanent erzielt werden, wenn es gelänge, die Muskeln auf der linken Seite der Wirbelsäule abzuschwächen. Das geschieht ebenfalls, wenn wir die rechte Seite des Acusticussegmentes der Medulla zerstören. Der Fisch bewegt sich im Kreise nach rechts. Wir erhalten ebenfalls Kreis- oder Reitbahnbewegungen nach rechts, wenn wir den Boden des linken Lobus opticus zerstören. Es müssen also Fasern vom Boden des linken Lobus opticus nach dem rechten Acusticussegment der Medulla ziehen. Nach einer derartigen Operation zeigt sich die Spannungszunahme der Skeletmuskeln einer Seite gelegentlich unmittelbar darin, dass der Fisch permanent im Kreise eingerollt liegt und sich ïberhaupt nicht mehr gerade strecken kann. Ein solcher Fisch kann natürlich auch nicht mehr geradeaus schwimmen. Allein im Allgemeinen ist der Spannungsunterschied der Muskeln auf beiden Seiten des Thieres viel geringer. Die Reitbahn- 
bewegungen treten alsdann ebenfalls nur anfallsweise auf, nämlich wenn das Thier aufgeregt wird.

Einseitige Durchschneidung des Rückenmarks und der Medulla hinter dem Acusticussegment hat keine Zwangsbewegungen zur Folge. (2, 3) Dagegen treten Roll- und Reitbahnbewegungen ein nach Verletzung des Gehirns vor diesem Segment, sobald man nämlich Stellen trifft, welche mit dem Acusticussegment direct oder indirect verbunden sind. Das ist beispielsweise der Fall nach einseitiger Verletzung der Brückenarme sowie selbst nach einseitiger Grosshirnverletzung bei Kaninchen und Hunden. Bei beiden Thieren treten nach Zerstörung einer Hemisphäre des Grosshirns Reitbahnbewegungen auf, bei Kaninchen nach der gesunden Seite, bei Hunden nach der Operationsseite. Alle Thatsachen beweisen, dass die betreffenden Halbkreuzungen in der Gegend des Acusticussegnients und nicht tiefer stattfinden. Bei Menschen sind meines Wissens nie Reitbahnbewegungen beobachtet worden, was wohl zum Theil mit dem aufrechten Gang zusammenhängt. Es wäre interessant, den Versuch zu machen, bei gewissen Erkrankungen (z. B. des innern Ohres) Patienten auf Händen und Füssen gehen zu lassen und zuzusehen, ob eine Kreisbewegung zu Stande kommt.

Es ist, wie wir sahen, eine alte und bekannte Thatsache, dass auch bei Arthropoden durch Zerstörung einer Hälfte des Oberschlundganglions Reitbahnbewegungen eintreten können. Dass sie nicht eintreten müssen, ist von Miss Hyde und ganz besonders durch Bethe (4 u. 5 ) festgestellt worden. Nach den Untersuchungen des letzteren Autors werden diese Kreisbewegungen bei Wirbellosen durch sehr verschiedene Störungen in der Muskelspannung hervorgerufen. Oft handelt es sich nur un Störung der IIuskelspannung der Extremitäten einer Seite, während die andere Seite offenbar normal ist. Es können aber auch gelegentlich bei lirebsen associirte Stellungsänderungen der Extremitäten nach Zerstörung einer Hälfte des Oberschlundganglions auftreten. Bei Cephalopoden hat v. Uexküll Zwangsbewegungen nach Verletzung eines Ohrs beobachtet. Fig. $36^{\circ}$ zeigt das Ueberwiegen der Beuger der Beine über die Strecker auf der linken Seite des Körpers. Dem Thier war die rechte Gelirnhälfte zerstört worlen und es zeigte Reitbahubewegungen nach links.

Eine sonderbare Anwendung hat Steiner von den Zwangsbewegungen gemacht. Er stellt sich vor, dass die Fähigkeit, sich vorwärts zu bervegen, eine specifische „Function" des Gehirns sei, und hat geglaubt, dass es mittelst dieses Kriteriums möglich sei zu entscheiden ob ein Ganglion eines niederen Thieres als Gehirn zu bezeichnen sei oder nicht. Die Thatsachen der rergleichenden Physiologie sprechen 
gegen eine solche Auffassung. Wir kennen nämliclı spontane Progressivbewegungen bei Infusorien, die kein Nervensystem besitzen. ja sogar bei pflanzlichen Organismen, nämlich den Schwärmsporen von Algen. Es

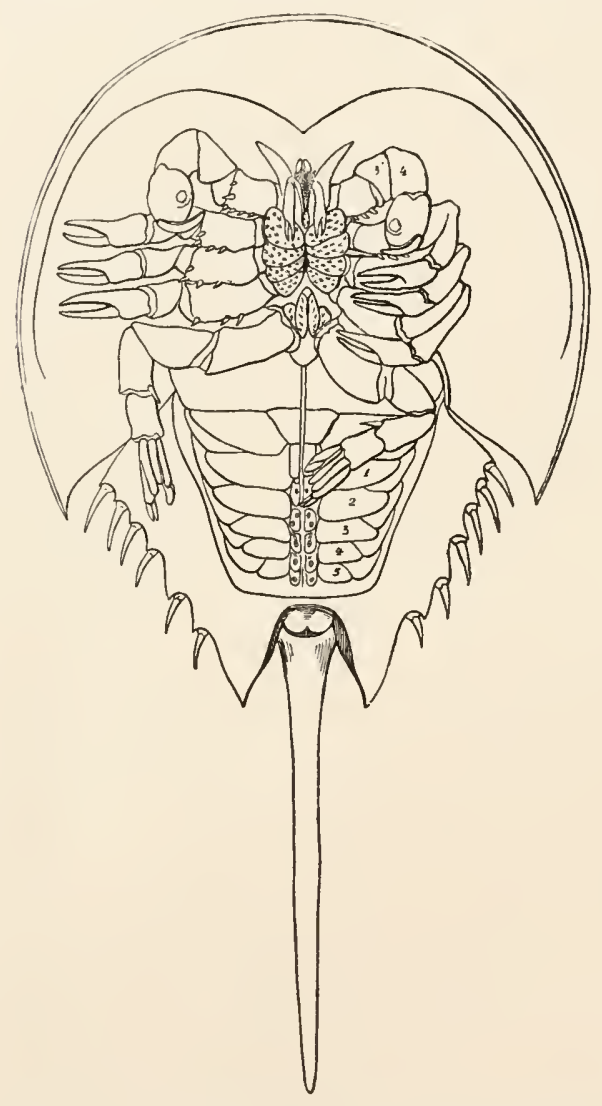

Fig. 36. Stellungsänderungen der Extremitäten eines Limulus nach Exstirpation der rechten Gehirnhälfte. Die Spannung der Flexoren auf der linken Seite überwiegt über die Spannung der Strecker dieser Seite. Das Thier hatte Reitbahnbewegungen nach links. Nach Miss Hyde. ist aber ein wichtiger Grundsatz physiologischen Denkens, dass eine Erscheinung, die allgemein vorkommt, unmöglich die specifische Function eines besonderen Organs sein kann, welches sich nur bei wenigen Formen findet. Steiner fand sehr bald eine Thatsache, die das Irrige seiner Anschauung klar zeigte: nämlich, dass der decapitirte Haifisch noch nunter im Bassin umherschwimmt. Ebenso hatte Schrader nachgewiesen, dass auch der enthirnte Frosch noch spontane Progressivbeweg ungen auszuführen in Stande ist. Weiterhin behauptete Steiner: „Das Gehirn ist definirt durch das allgemeine Bewegungscentrum in Verbindung mit den Leistungen wenigstens eines der höheren Sinnesnerven." "Diese Definition hat neben ihrer grossen Einfachheit noch einen weiteren Vortheil, dass sie nämlich durch einen einzigen Versuch befriedigt wird, insofern als von den beiden Elementen, aus welchen die Definit ${ }^{\text {on }}$ sich zusammensetzt, das eine Element stets anatomisch gegeben ist. Das ist der höhere Sinnesnerv, dessen Anwesenheit auch seine Function verbürgt. Der eine nothwendige Versuch, welcher anzustellen ist, hat den Nachweis zu führen, dass neben dem Sinnesapparat auch noch das allgemeine Bewegungscentrum vorhanden ist. Dieser Nachweis ist dann erbracht worden, wenn die einseitige Abtragung des betreffenden nervösen Central- 
theils die Richtung der Bewegungen der Thiere so ändert, dass aus der geradlinigen eine kreisförmige Bewegung hervorgeht, welche unter der landläufigen Bezeichnung Zwangsbewegung allgemein bekannt ist" (6). Diese Idee ist ebenfalls irrig und lässt sich entsprechend leicht ad absurdum führen. Einseitige Zerstörung des Grosshirns beim Menschen ruft keinerlei Zwangsbewegungen hervor. Nach Steiner sollte also das Grosshirn nicht zum Gehirn gehören. Zweitens müsste aber nach Steiner das Ohr ein Gehirn sein. Einseitige Zerstörung des Ohres ruft mit der grössten Sicherheit bei einer Reihe von Thieren Zwangsbewegungen hervor und ausserdem ist der Gehörnerv ein höherer Sinnesnerv. Ich bin auf diese Dinge hier eingegangen, weil sie ein typisches Beispiel dafür sind, wohin Begriffsspielereien in der Physiologie führen. Es ist nicht unsere Aufgabe, eine Definition für das Wort Gehirn zu finden, sondern eine Einsicht zul gewinnen in die Functionen des Centralnervensystems. Welchen Namen wir den einzelnen Theilen des Centralnervensystems beilegen, ist Nebensache.

Im Anschluss an dieses Kapitel wollen wir noch auf nenere Versuche ron Sherrington sowie von H. E. Hering hinweisen, aus denen zu folgen seheint, dass mit der Innervation eines Muskels zugleich die Erschlaffung seines Antagonisten erfolgt.

\section{Litteratur zn X.}

1) Loeb, J. Ueber Geotropismus bei 'Thieren. Pflüger's Archiv, Bd. 49. 1891.

2) Loeb, J. Ueber den Antheil des Hörnerven an den nach Gehirnverletzung auftretenden Zwangsbewegungen, Zwangslagen und associirten Stellungsänderungen der Bulbi und Extremitäten. Pflïger's Archı, Bd. 50. 1891.

3) Steiner. Die Funclionen des Centralnervensystems und ihre Phylogenese II. Die Fische. Braunschweig 1858.

4) Bethe, A. Vergleichende Untersuchungen über die Functionen des Centralnervensystems der Arthropoden. Pflüger's Archiv, Bd. 68. 1897.

5) Bethe, A. Das Centralnervensystem von Carcinus maenas. II. Mittheil. Arch. f. mikroskop. Anatomie, Bd. 50. 1897.

6) Steiner, J. Die Functionen des Centralnervensystems wirbelloser Thiere. Sitzung der Burliner Akademie der Wissenschaften. 1890 1. S. 39. 


\section{XI.}

\section{Beziehungen \\ zwischen der Orientirung und Function gewisser Elemente der segmentalen Ganglien.}

In einer gemeinsamen Arbeit hatten Garrey und ich festgestellt, dass wenn man einen constanten Strom durch einen Trog schickt, in dem sich Amblystomalarven befinden, eigenthiimliche Aenderungen in der

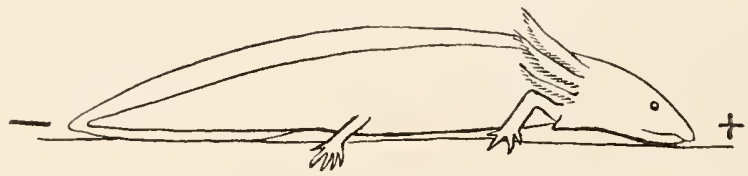

Fig. 37. Amblystomalarve unter dem Einfluss eines absteigenden Stromes.

Haltung des Thieres zu beobachten sind. (1) Geht der Strom in der Längsrichtung durch das Thier und zwar in der Richtung rom Kopf

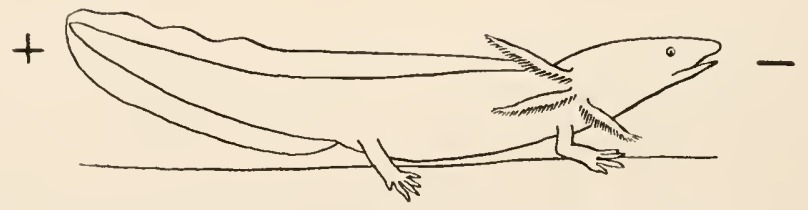

Fig. 38. Amblystomalarve unter dem Einfluss eines aufsteigenden Stromes.

zum Schwanz (Fig. 37), so wird der Rücken des Thieres convex und der Bauch concav. Diese Stellungsänderung wird dadurch zu Stande gebracht, dass die Muskeln an der ventralen Seite (die Beuger der Wirbelsäıle) in Folge der Durchströmung in einen höheren Grad der Spannung gerathen als die dorsalen Muskeln, die Strecker der Wirbelsäule. Geht der Strom dagegen in der Richtung vom Schwanz zum Kopf durch das Thier (Fig. 38), so tritt eine Hebung des Kopfes und Schwanzes ein. Der Körper wird concar auf der Rückenseite und convex auf 
der Bauchseite. Die Strecker der Wirbelsäule gerathen in stärkere Spannung als die Bauchmuskeln. Es besteht ausgesprochener Opisthotonus. Um diese Erscheinungen rein zu erhalten, ist es nöthig, dass man das Thier langsam in den Strom einschleicht. Fährt man mit der Erhöhung der Stromintensität fort, so treten auch Stellungsänderungen in den Beinen ein. Dieselben lassen sich am einfachsten an den Hinterbeinen beschreiben. Geht der Strom vom Kopf zum Schwanze des Thieres, so werden die Hinterbeine mehr nach rückwärts gestemmt (Fig. 37). Die Stellungsänderung ist so, dass dem Thiere die Vorwärtsbewegung zur Anode erleichtert ist. Geht der Strom in der Richtung vom Schwanz zum Kopf durch das Thier, so werden die Hinterbeine nach vorn gestemmt (Fig. 35), wodurch die Rückwärtsbewegung zur Anode erleichtert ist.

Wie haben wir diese Erscheinungen zu erklären? Auf Grund von einer Reihe von Untersuchungen möchte ich folgende Erklärung vorschlagen. Geht der Strom durch das Centralnervensystem, so ist eine Leitung natürlich nur durch Jonen möglich. Es wird an der Grenze ungleicher Electrolyte sowie da, wo sich semipermeable Membranen entgegenstellen, im Allgemeinen zur Ausscheidung von Jonen kommen. Die letzteren werden sich in Atome verwandeln und chemische Wirkungen ausüben. Sind die Elemente des Centralnervensystems, an denen diese Jonenausscheidungen in ausgiebigster Weise stattfindet, so zum Strome orientirt, dass electropositive Jonen an ihnen zur Ausscheidung kommen, so wird hier Alkali gebildet. Wie die Hydroxyljonen hier weiter wirken, ist unbekannt. Möglicher Weise wirken sie direct oxydirend oder oxydationsbeschleunigend (Katelectrotonus). Eine erhöhte Oxydation in den Nervenelementen würde begreiflicher Weise auch die Muskelfasern mit afficiren, die mit den betreffenden motorischen Nervenelementen in Beziehung stehen und zu einer Spannungszunahme dieser Muskelelemente führen. Sind die Nervenelemente aber so orientirt, dass an ihnen die electronegativen Jonen zur Ausscheidung gelangen, so findet hier direct oder indirect Reduction durch die Wasserstoffjonen statt (Anelectrotonus) und eine Abnahme der Spannung derjenigen Muskeln findet Statt, welche mit den betreffenden motorischen Nervenelementen verbunden sind.

Wenn nun bei absteigender Durchströmung (Stromrichtung vom Kopf zum Schwanz) der Amblystomalarven die Spannung der Beuger der Wirbelsäule überwiegt, bei aufsteigender Durchströnung dagegen die Spannung der Strecker der Wirbelsäule, so beweist das, dass die durch die Jonen afficirten nervösen Elemente der Beuger und Strecker im Centralnervensystem entgegengesetzte Orientirung be- 
sitzen. Maxwell und ich haben in unserer Arbeit (2) bestimmtere Vorstellungen über die Orientirung der betreffenden Elemente entwickelt, aber derartige Details sind einstweilen Nebensache. Wir wollen nur so viel über die relative Orientirung dieser Elemente sagen. dass sie in jedem Segment des Rückenmarks die gleiche sein muss. Denn wenn wir bei Amblystomalarven das Rï̈ckenmark durchschneiden oder es in verschiedene segmentale Stïcke zerlegen, so ändern sich die Erscheinungen bei der Durehströmung nicht.

Ich habe nun seitdem gefunden, dass sich Flusskrebse - ich benutze zu diesen Versuchen junge und kleine Exemplare - dem Strom gegenïber ähnlich verhalten wie die Amblystomalarven. Befindet sich die Medianebene des Krebses in der Richtung der Stromlinien (die alle gerade und parallel in diesen Versuchen sind) und ist der Kopf gegen die Anode gerichtet, so contrahiren sich die Beuger des Rumpfes und der Krebs rollt sich bei hinreichender Dichte des Stromes zu einem vollständigen Ringe ein. Der Rücken ist convex, der Bauch concav. Geht aber der Strom in der Richtung von Schwanz zum Kopf, so wird der Rücken völlig gerade, indem die Strecker des Rumpfes sich maximal contrahiren. Concar kann die Rückenseite nicht werden, weil das Exoskelet der Krebse das nicht erlaubt. Es müssen also beim Krebse die vom Strom afficirten motorischen Elemente der Strecker und Beuger dieselbe relative Orientirung im Körper haben wie im Körper der Wirbelthiere. Das gilt nicht nur für die Beuger und Strecker des Rumpfes, sondern, wie wir gleich sehen werden, ganz allgemein.

Wir haben schon erwähnt, dass der constante Strom, wenn er die Anıblystomalarve in der Längsrichtung durchfliesst, nicht nur die Beuger und Strecker des Rumpfes in ihrer Spannung beeinflusst, sondern auch die Muskeln der Extremitäten. Und zwar ist die Spannung, wie wir schon kurz angedeutet haben, in dem Sinne verändert, dass sie dem Thiere die Bewegung zur Anode erleichtert, die Bewegung zur Kathode erschwert. Geht beispielsweise der Strom in der Richtung vom Kopf zum Schwanz durch das Thier, so sind die Hinterbeine nach rückwärts gestemmt und die Stellung der Vorderbeine ist entsprechend verändert, so dass die Vorwärtsbewegung des Thieres erleichtert, die Rückwärtsbewegung erschwert ist. Geht aber der Strom in aufsteigender Richtung d. h. vom Schwanz zum Kopf, so sind die Hinterbeine nach vorwärts gestemmt und die Stellung der Vorderbeine ist entsprechend verändert und das Thier kann leicht rückwärts gehen, aber nur schwer vorwärts. In der That sieht man anch, dass die Thiere, wenn sie sich überhaupt bei der Durchströmung zu einem Ziele hin bewegen, nach der Anode gehen. 
Aus dieser Thatsache folgt, dass auch für den nerrösen Apparat der Progressirbewegungen ron Amblystonı eine enge Beziehung zwischen Orientirung der entscheidenden Elemente der motorischen Nerven und ihrer Function bestehen muss. Und zwar mïssen die nervösen Elemente, welche die Vorwärtsbewegung reranlassen, in Bezug auf die Längsrichtung des Thieres umgekehrt orientirt sein, wie diejenigen Elemente, welche die Rückwärtsbewegung veranlassen. Garrey und ich haben darauf hingewiesen, dass aus den Beobachtungen von Blasius und Schweizer zu entnehmen ist, dass andere Wirbelthiere z. B. junge Aale sich ähnlich verhalten wie Amblystoma. Es ist nun eine merkwürdige Thatsache, dass das Gleiche auch für die Krebse gilt. Diese Behauptung stützt sich auf eine Versuchsreihe von Maxwell und mir, (2) die hauptsächlich an Palaemonetes angestellt ist. Dieser Krebs benutzt das 3., 4. und 5. Beinpaar für seine Locomotion. Das 3. Beinpaar wirkt bei der Vorwärtsbewegung ziehend, das 5. stossend. Das 4. Beinpaar rerhält sich im Allgemeinen wie das 5. und wir können es der Kürze halber hier aus der Discussion lassen. Senden wir nun einen Strom in der Längsrichtung durch das Thier, und zwar in der Richtung vom Kopf gegen den Schwanz, so sehen wir, wenn wir mit der Stromstärke langsam ansteigen, alsbald eine Aenderung in der Stellung der Beìne eintreten: Im 3. Beinpaar überwiegt die Spannung der Beuger, im 5. die Spannung der Strecker. Das Thier kann also leicht mit dem 3. Beinpaar sich durch Zug fortbewegen und mit dem 5. durch Stoss, d. h. der Strom ändert die Spannung der Muskeln in dem Sinne, dass die Vorwärtsbewegung erleichtert, die Rückwärtsbewegung erschwert ist. Es kann also leicht zur Anode gehen und nur schwer oder gar nicht zur Kathode. Senden wir aber einen Strom in der umgekehrten Richtung, nämlich rom Schwanz zum Kopf, durch das Thier, so wird das 3. Beinpaar gestreckt, das 5. gebeugt, d. h. das 3.- Beinpaar kann durch Stoss erhebliche Arbeit leisten und das 5. durch Zug. Das Thier wird also leicht nach rückwärts und nur schwer nach vorwärts gehen. Wir sehen also auch hier, dass die nervösen Elemente des Centralnervensystems, welche die Vorwärtsbewegung besorgen, in Bezug auf die Längsaxe des Thieres umgekehrt orientirt sind wie die nervösen Elemente für die Rückwärtsbewegung. Aber wir können in der Ausführung dieses Gesetzes noch weiter gehen. Palaemonetes kann sich nicht nur gehend fortbewegen, sondern er ist auch ein guter Schwimmer, und zwar kann er sowohl vorwärts wie rückwärts schwimmen. Bei dem Vorwärtsschwimmen schlagen die Schwimmanhänge, zu denen auch die Schwanzflosse gerechnet werden muss ${ }^{1}$ ) kräftig nach rückwärts und schwach

1) Die Schwanzflosse verhält sich dem Strome gegenüber wie die abdomi- 
nach vorwärts, bei dem Rückwärtsschwimmen ist es gerade umgekehrt. Sendet man nun einen Strom in der Richtung vom Kopf zum Schwanze durch den Palaemonetes, so sind die Schwimmanhänge und auch der Schwanz maximal nach hinten resp. dorsalwärts gestreckt. Das beweist, dass die Spannung der Muskeln, die jene Organe rückwärts bewegen, grösser ist als die ihrer Antagonisten. Der Krebs kann also unter dem Einfluss eines solchen Stromes leicht nach vorwärts (zur Anode) schwimmen und nur schwer nach rückwärts. Geht aber der Strom in umgekehrter Richtung (vom Schwanz zum Kopfe) durch das Thier, so sind der Schwanz und die Bauchanhänge mehr nach vorwärts gerichtet. Die Spannung und Energieentwickelung iiberwiegt also jetzt in denjenigen Muskeln, welche die Schwimmanhänge kopfwärts bewegen. Dadurch ist das Thier leicht im Stande, rückwärts zu schwimmen, während es nur schwer oder gar nicht im Stande ist, vorwärts zu schwimmen. Es müssen also auch die nervösen Elemente, welche das Torwärtsschwimmen bestimmen, dieselbe Orientirung in Bezug auf die Längsaxe des Thieres baben, wie diejenigen Elemente, welche das Vorwärtsgehen bestimmen, während die nervösen Elemente für das Rückwärtsschwimmen die umgekehrte Orientirung haben.

Wir haben bisher noch nicht berücksichtigt, dass Palaemonetes, wie viele Krebse, sich auch seitwärtsgehend fortbewegen kann. Diese Bewegung erfolgt so, dass die Beine auf der Seite, nach der hin sich das Thier bewegt, durch Zug (Contraction der Beuger) wirken, während sie auf der anderen Seite durch Stoss (Contraction der Strecker) sich an der Arbeit der Locomotion betheiligen. Senden wir nun einen Strom transversal, etwa von rechts nach links, durch das Thier, so gerathen die Beine auf der rechten Seite in Beugestellung, auf der linken in Streckstellung. Es überwiegt also die Energieentwickelung der Beuger in den Beinen der rechten Seite, der Strecker in den Beinen der linken Seite. Der transversale Strom erleichtert also dem Thiere die Bewegung zur Anode nach rechts und erschwert dem Thiere die Bewegung nach links zur Kathode. Es müssen also die nervösen Elemente, welche Seitwärtsbewegung des Krebses nach rechts bewirken, umgekehrt in Bezug auf die Längsaxe des Thieres orientirt sein, wie die nervösen Elemente, welche die Seitwärtsbewegung nach links bewirken.

Maxwell und ich hatten versucht, ein Bild der Anordnung jener Elemente zu geben, unter der Voraussetzung, dass diese Elemente die

nalen Schwimmanhänge und nicht wie der Rumpf. Das muss bei galvanotropischen Versuchen berïcksichtigt werden. Maxwell und ich haben das in unserer ersten Mittheilung übersehen. 
motorischen Neuronen selbst sind. Es ist aber kein Grund rorhanden, als den Angriffspunkt für die chemische Wirkung der ausgeschiedenen Jonen die Ganglienzellen in toto anzusehen. Es kann irgend ein Element der Ganglienzellen, ja sogar der Faser selbst sein, ja es ist gar nicht einmal nöthig, dass dasselbe histologisch besonders auffällig ist. Es handelt sich ja stets um physiologische und chemische Vorgänge, für welche ganz andere Umstände in Betracht kommen als die histologischen. Was es aber auch sei, es ist sicher, dass die entscheidenden Elemente im Centralnervensystem, deren Thätigkeit Bewegungen des Körpers hervorruft, eine bestimmte Orientirung im Körper haben, die offenbar mit der Richtung der Bewegung, welche durch sie veranlasst wird, in einer einfachen Beziehung steht.

Hiermit eröffnet sich uns vielleicht eine Aussicht zu begreifen, wie es kommt, dass derselbe optische Reiz orler dieselbe Raumvorstellung im Stande ist, unsere Augen nach einem bestimmten Punkt zu richten, unseren Kopf dalin zu drehen, unseren Finger dahin zu führen und unsere Beine in solche Thätigkeit zu setzen, dass unser Körper dahin gelangt. Die Elemente des Centralnervensystems, die hierbei in Thätigkeit gerathen, haben möglicher Weise alle die gleiche Orientirung und das, was wir als Innervation bezeichnen, muss offenbar ein Vorgang sein, bei dem die Orientirung der Elemente eine Rolle spielt. Ein solcher Umstand könnte beispielsweise der electrische Strom sein. Mir ist dieses Problem der Physiologie der geordneten Bewegung, das wir hier berühren, stets als eins der mysteriösesten in der ganzen Physiologie des Centralnervensystems vorgekommen und der Weg zu einer einfachen Lösung, der sich hier bietet, schien mir der Erwähnung werth. Die ganze Auffassung ordnet sich zwanglos der segmentalen Auffassung des Centralnervensystems unter. Augenbewegungen, Kopfbewegungen, Armbewegungen, Beinbewegungen hängen von mindestens ebensovielen verschiedenen segmentalen Ganglien ab. Jedes einzelne dieser Ganglien hat gewisse Züge mit jedem anderen Ganglion gemeinsam, unter anderem die Orientirung und Anordnung seiner Elemente (Neuronen?). Breitet sich nun ein Vorgang durch die Reihe der seymentalen Ganglien aus, der so beschaffen ist, dass er nur Elemente von bestimmter Orientirung in jedem Ganglion erregen kann, so muss er genau die gleiche Bewegungsrichtung bei den afficirten Gliedmassen der verschiedenen Segmente bervorrufen. Damit fällt die Nothwendigkeit fort, künstliche Verbindungen der Neuronen zu ersinnen, welche erlauben, eine solche Reihe ron geordneten Bewegungen der verschiedenen Gliedmassen hervorzurufen. 
114 Beziehungen zwischen d. Orientirung etc. gewisser Elemente d. segm. Ga nglien.

Wenn man aber fragt, wie es kommt, dass eine einfache Bezi ehung besteht zwischen der Orientirung der motorischen Nervenelemente und der durch sie hervorgerufenen Bewegung resp. Progressivbewegung, so müssen wir wieder auf die einfachen segmentalen Verhältnisse der ers ten embryonalen Anlage verweisen, die eben in den Innervationsverhältn issen besser gewahrt bleiben als in den Muskeln.

\section{Litteratur zu XI.}

1) L 00 b, J. und Walter E. Garrey. Zur Theorie des Galvanotropismus, II. Mittheilung. Versuche an Wirbelthieren. Pflüger's Archiv, Bd. 65. 1896.

2) Loeb, J. und S. S. Maxwell. Zur Theorie des Galvanotropismus. Pflüger's Archiv, Bd. 63. 1896. 


\section{XII}

\section{Versuche am Kleinhirn.}

Das Kleinhirn ist (wie das Grosshirn) ein Gebilde, das die Ungleichheit des Wachsthums der verschiedenen Theile des Centralnervensystems klar zum Ausdruck bringt. Beide können als Ausbuchtungen und Anhängsel des segmentalen Nerrensystems angesehen werden. Das Kleinhirn steht durch drei Schenkel mit dem segmentalen System in Zusammenhang, die crura cerebelli ad medullam oblongatam, die crura cerebelli ad pontem, die crura cerebelli ad corpora quadrigemina. Die letzteren verlaufen ziemlich gerade nach vorne, die ersteren ziemlich gerade nach hinten und die Brückenschenkel rechtwinklig zu beiden. Magendie hat nun schon gefunden und Flourens hat es später bestätigt, dass Verletzung dieser Faserzüge, die eine so characteristische Orientirung zu den Hauptaxen des Körpers besitzen, auch "Zwangsmässige" Bewegungen hervorruft, deren Richtung in einer einfachen Beziehung steht zu der Orientirung des durchschnittenen Schenkels. Durchschneidet man die Briickenschenkel auf einer Seite, so rollt das Thier un seine Längsaxe. Durchschneidet man die crura cerebelli, die nach vorn ziehen, so stürzt sich das Thier mit Macht nach vorn; durchschneidet man die crura cerebelli ad medullam oblongatam. so geht das Thier rückwärts oder zeigt eine Tendenz Purzelbäume nach hinten zu schlagen. "La direction des mouvements produits par la section des fibres de l'encéphale est donc toujours déterminée par la direction de ces fibres" (Flourens).

Flourens hat auf die Analogie dieser Erscheinungen mit den von inm nach Verletzung der Halbzirkelkanäle beobachteten aufmerksam gemacht. Diese Analogie besteht jedoch nicht ganz so wie er sie angiebt. Er vergleicht die Wirkung der einseitigen Ponsdurchschneidung mit der Durchschneidung eines horizontalen Kanales. Das ist nicht richtig. Meines Wissens treten bei keinem Thier nach dieser Verletzung Rollbewegungen um die Längsaxe ein. Zerstörung eines ganzen Ohres bringt dagegen wohl im Allgemeinen die Rollbewegungen zul Stande. 
Ferner gicbt Flourens an, dass bei Zerstörung der vorderen Kanäle ein Thier Purzelbäume nach vorn schlägt, bei Zerstörung der hinteren Kanäle Purzelbäume nach hinten. Flourens nimmt nun an, dass die Nerven der drei Kanäle sich in die entsprechenden Kleinhirnschenkel fortsetzen und dass dieser Ursprung der Ampullarnerven die Ursache der Erscheinungen sei, welche man nach Verletzung der einzelnen Halbzirkelkanäle beobachtet (3). Das ist jedoch wohl nicht richtig, da der Hörnerv in der Medulla endigt. Allein es ist wahrscheinlich, dass das Kleinhirn mit denselben motorischen Elementen in der Medulla in Verbindung steht, mit denen auch der Acusticus in Verbindung steht. Das Kleinhirn würde sich also wesentlich als ein Anhang zum Acusticussegment darstellen.

Damit stimmen die Ergebnisse der Reizversuche von Ferrier (1). Ferrier fand, dass Reizung der verschiedenen Stellen des Kleinhirns associative Augenbewegungen veranlasst und dass die Richtung der Bewegung mit der Lage der Electroden wechselt. Auch der Kopf bewegt sich gleichsinnig mit den Augen. Bewegungen der Gliedmassen wurden ebenfalls beobachtet, aber es war nicht zu ersehen, ob sie mit den Kopfbewegungen associirt waren oder nicht. Man darf danach sagen, dass möglicher Weise oder vielleicht wahrscheinlicher Weise die Bewegungen, welche durch Reizung des Kleinhirns ausgelöst werden, denen verwandt sind, welche durch Reizung der Halbzirkelkanäle ausgelöst werden, nur dass die Reizversuche am Kleinhirn nach Ferrier manchmal erfolglos bleiben.

Bei den Durchschneidungs- und Exstirpationsversuchen am Kleinhirn bleiben die sensorischen und psychischen Functionen des Thieres ungestört. Nur im Gebiet der Bewegungen zeigen sich eigenthümliche Störungen, die von verschiedenen Beobachtern verschieden geschildert werden. Vielleicht sind die weit über das Ziel gehenden veitstanzartigen Bewegungen am characteristischsten. Einem Hund, dem das Kleinhirn verletzt ist, muss man in der ersten Zeit nach der Operation beim Fressen den Kopf in der Schüssel fixiren, weil derselbe sonst bei jeder Anstrengung so weit über das Ziel hinausgeschleudert wird, dass er nie in den Napf geräth, so sehr das Thier sich auch bemüht, die Schüssel zu erreichen.

Auch in den Gliedmassen zeigen sich solche Störungen. Das Thier taumelt oft wie ein Betrunkener und findet Schwierigkeiten, sich auf den Beinen zu erhalten. Alle diese Eigenthümlichkeiten weisen in letzter Instanz vielleicht auf eine Abnahme der Spannung der Skeletnuskeln hin. Die gemessenen Bewegungen des normalen Thieres sind nur dadurch möglich, dass die Spannung der Antagonisten zu gross ist, um 
Schleuderbewegungen zu Stande kommen zu lassen. Sind aber, wie das anscheinlich mit Recht für den Hund ohne Kleinhirn behauptet worden ist, die Muskeln der Wirbelsäule erschlafft, so kann leicht jede intendirte Bewegung weit über ihr Maass hinaus ausfallen. Auch nach den zahlreichen Versuchen ron Luciani scheint Schwäche der Muskeln oder Erschlaffung derselben den constantesten Bestandtheil unter den Folgen der Kleinhirnoperationen zu bilden. Die ergriffenen Muskelgruppen scheinen aber mit der Lage der zerstörten Kleinhirnpartie zu variiren, wobei, wie es scheint, als Haupttypen die von Magendie beobachteten Störungen wach Verletzung der drei Kleinhirnschenkel wohl wieder in Betracht kommen. Flourens, der jedem Abschnitt des Gehirns besondere Functionen zuwies, behauptete, dass das Kleinhirn das Coordinationsorgan sei, weil Zerstörungen des Kleinhirns die eben geschilderten Störungen hervorrufen. Luciani (2) hat aber gezeigt, dass Thiere z. B. Hunde ohne Kleinhirn coordinirte Schwimmbewegungen auf dem Wasser ausfübren und auch coordinirte Gangbewegungen machen Nur die Schwäche aller oder bestimmter Muskelgruppen führt zu atactischen Störungen, die aber sehr gering sein können. Die Flourens'sche Theorie, dass das Kleinhirn das Coordinationsorgan sei, ist also verfehlt. $\mathrm{Es}$ ist auch fraglich, ob nicht ein Theil der nach Kleinhirnverletzung beobachteten Störungen im Grunde nur Fernwirkungen auf die Medulla oder die Vierhügel sind.

Diese Auffassung findet eine Stütze in der vergleichenden Physiologie. Bei Fischen und Fröschen, bei denen die Hemmungswirkungen gering sind, kann man das Kleinhirn entfernen, ohne dass irgend eine Störung im Verhalten der Thiere eintritt. (Vulpian, Steiner.) Ich selbst habe an Haifischen, bei denen das Kleinhirn stark entwickelt ist, zahlreiche Durchschneidungsrersuche und partielle wie totale Exstirpationen des Kleinhirns ausgeführt, obne dass die geringste Aenderung im Verhalten der Thiere eingetreten wäre. Es ist unmöglich und unberechtigt, hier von einer bestimmten, „Function" des Kleinhirns zu reden.

Es mag noch im Hinblick auf das Gesagte und auf später zu besprechende Beobachtungen iiber die Folgen von Grosshirnverletzungen an eine Hypothese ron Magendie erinnert werden. Magendie sah Thiere nach Verletzung einer gewissen Stelle der Medulla oblongata dauernd rückwärts gehen resp. rïckwärts fliegen. Er sah ferner, dass Verletzung der Streifenhügel einen Drang nach vorwärts zu laufen, hervorruft. Endlich beobachtete er die Rollbewegungen der Thiere, un ihre Längsaxe nach einseitiger Verletzung der Brücke. Er knüpft daran folgende Bemerkung: „Comme notre esprit a besoin de s'arrêter à certaines images je dirai qu'il existe dans le cerveau quatre impulsions spontanées 
ou quatre forces qui seraient placées aux extrémités de deux lignes, qui se couperaient à angle droit; l'une pousserait en arant, la deuxième en arrière, la troisième de droit à gauche en faisant rouler le corps, la quatrième de gauche à droite en faisant exécuter un mouvement semblable de rotation. Dans les diverses expériences d'où je tire ces conséquences, les animaux deviennent des espèces d'automates montés pour exécuter tels ou tels mouvements et incapables d'en produire aucun autre." Die letztere Behauptung geht zu weit, aber der Grundgedanke Magendie's verdient mehr Beachtung, als die Physiologie ihm geschenkt hat. Die in Kapitel XI erwähnten galvanotropischen Thatsachen zeigen auf das bestimmteste, dass bei Krebsen und Wirbelthieren eine Beziehung besteht zwischen Orientirung und Function gewisser motorischer Elemente und eine derartige Beziehung kommt auch in den Beobachtungen und Schlüssen Magendie's und Flourens' zum Ausdruck.

\section{Litteratur zu XII.}

1) Ferrier. The Functions of the Brain. New York 1886.

2) Luciani, Luigi. Das Kleinhirn. Leipzig 1893. (Enthält eine vollständige Sammlung der Litteratur.)

3) Flourens, P. Fonctions du Système nerveux. Paris 1842. 
XIII.

\section{Zur Theorie der thierischen Instincte.}

1) Die Instincte sind immer stillschweigend der Centrentheorie untergeordnet worden. Für jeden Instinct giebt es nach der Centrentheorie ein oder mehrere bestimmte Centren. Wir wollen nun im Folgenden nachweisen, dass die Theorie segmentaler Ganglien für das Verständniss der Instincte ausreicht.

Unter den Instincten versteht man im Allgemeinen nach einem Ziel gerichtete, unbewusste Handlungen der Thiere. Wenn eine Fliege ihre Eier auf Gegenstände legt, welche der ausschlüpfenden Made als Futter dienen, so ist das ein Instinct. Die periodischen Wanderzüge der Thiere bezeichnen wir als instinctiv. Dass gewisse Thiere sich in Ritzen und Spalten verstecken, wo sie vor Verfolgung sicher sind, dass andere in die Flamme fliegen etc., bezeichnen wir als instinctiv u. s. f. Diese und viele andere instinctive Handlungen haben das Interesse der Biologen und Psychologen lange auf sich gezogen, ohne dass man dem Verständniss dieser Vorgänge erheblich näher gekommen wäre. Ich glaube, dass viele dieser instinctiven Handlungen nichts anderes sind als Specialfälle der thierischen Tropismen. Da diese aber erst in letzter Zeit bekannt geworden sind, so war es nicht wohl möglich, eine Analyse der Instincte mit Erfolg in Angriff zu nehmen.

Wir haben gesehen, dass, wenn gewisse Krebse z. B. Palaemonetes der Wirkung eines galvanischen Stromes ausgesetzt werden, solche Spannungsänderungen in den Muskeln der Extremitäten eintreten, dass diesen Thieren die Bewegung zur Anode erleichtert, zur Kathode dagegen erschwert wird. Die Folge ist, dass bei genügend lange fortgesetzter Durchströmung alle sich am positiven Pol sammeln. Wer diesen Vorgang der Ansammlung beobachten würde, ohne die Wirkung des Stromes genügend zu analysiren, würde vielleicht auch zu der Ansicht kommen, dass diese Krebse den Instinct besitzen, zur Anode zu gehen wie die Motten den Instinct besitzen, in die Flamme zu fliegen. In der That ist das Fliegen der Motte in die Flamme nur die Folge eines Tro- 
pisnus, Heliotropismus, der sich vom Galvanotropismus dadurch unterscheidet, dass die Lichtstrahlen die Stelle der Stromcurven übernehmen.

Denı Leser ist es bekannt, dass gewisse Pflanzen, wenn sie einseitig der Wirkung des Lichtes ausgesetzt werden, z. B. wenn sie am Fenster gezüchtet werden, ihre Spitze so lange gegen das Fenster hin krümmen, bis dieselbe sich in der Richtung der Lichtstrahlen befindet. Alsdann wächst sie in dieser Richtung weiter. Wir bezeichnen diese Abhängigkeit der Orientirung von dem Licht als Heliotropismus und zwar sprechen wir ron positiven Heliotropismus, wenn die Spitze des Organs zur Lichtquelle sich hinkrümmt und von negativem Heliotropismus, wenn die Spitze sich von der Lichtquelle fortkrümmt. Die Mechanik der Reizkrïmmung besteht (analog wie beim Galvanotropismus) darin, dass das Licht chemische Wirkungen hervorruft, welche den Contractionszustand der protoplasmatischen Gebilde beeinflussen. Während eine solche Beeinflussung beim Strom durch die chemische Wirkung der ausgeschiedenen Jonen resp. der durch sie gebildeten chemischen Verbindungen stattfindet. handelt es sich beim Heliotropismus um photochemische Wirkungen in den vom Licht getroffenen Oberflächenelementen des protoplastischen Gebildes. Diese Wirkungen können von zweierlei Art sein. Sie führen entweder zu einer Spannungszunahme des Protoplasmas oder der Muskeln, welche mit dem gereizten Oberflächenelement in Verbindung stehen resp. welche das Thier nach der Lichtseite hin bewegen oder zu einer Spannungsabnahme des Protoplasmas oder dieser Muskeln. Im ersteren Falle wird die Pflanze oder das Thier zur Lichtquelle hingeführt und wir bezeichnen es als positiv heliotropisch; in zweiten Falle wird es von der Lichtquelle fortgeführt und wir bezeichnen es als negativ heliotropisch.

Dabei spielen die Symmetrieverhältnisse der Pflanzen und Thiere eine eigenthümliche Rolle. Nehmen wir an, der Stamm eines Hydroidpolypen, Eudendrium, werde in der Nähe eines Fensters gezüchtet. Er krümmt sich alsdann wie eine am Fenster gezüchtete, positiv heliotropische Pflanze gegen das Fenster. Der Vorgang lässt sich folgendermassen beschreiben.

Fällt das Licht von der Seite auf den Eudendrium-Stamm, so findet auf der Lichtseite desselben eine Contraction des Protoplasmas statt und auf dieser Seite wird also den Längenzuwachs ein grösserer Widerstand geboten als auf der entgegengesetzten Seite. Die Folge ist, dass der Stamm sich krümmt und zwar wird er concar auf der Lichtseite. Sobald aber die Krümmung so weit fortgeschritten ist, dass der Stamm in die Richtung der Lichtstrahlen fällt, werden alle symmetrischen Elemente 
unter gleichem Winkel rom Licht getroffen, und es ist kein Grund mehn rorhanden, dass der Stamm nach rechts oder nach links aus dieser Richtung abweicht. Er wächst demgemäss in der Richtung der Lichtstrahlen weiter. Negativ heliotropische Elemente (z. B. Wurzeln) unterscheiden sich von positiv heliotropischen Elementen dadurch, dass das Licht eine Erschlaffung des Protoplasmas herbeiführt (3). Bei einseitiger Beleuchtung wird also auf der Lichtseite dem Wachsthum weniger Widerstand entgegenstehen als auf der dem Lichte abgewendeten Seite und die Spitze wirl sich von der Lichtquelle fortkriimmen. Sobald die Spitze in die Richtung der Lichtstrahlen fällt und die symmetrischen Punkte alle unter gleichen Winkel ron den lichtstrahlen getroffien werden, fällt jeder Grund fort, der den stamm zwingen könnte, aus der Richtung der Lichtstrahlen abzuweichen und derselbe wächst in derselben Richtung weiter.

Es war nun lange bekannt, dass viele Thiere rom Licht ,angelockt” werden und in die Flamme fliegen. Das war eben ein besonderer Instinct. Man sprach davon, dass diese Thiere „das Licht lieben“, dass "Neugier sie zum Licht treibe", dass hier eine „Anziehung" bestehe etc. Ich habe in einer Reihe von Arbeiten, von denen die erste im Januar 1858 erschien, gezeigt, dass es sich in allen diesen Fällen um nichts anderes handele als $\mathrm{nm}$ diejenigen Erscheinungen, die bei Pflanzen längst als Heliotropismus bekannt waren. Es liess sich zeigen, dass der Heliotropismus der Thiere Punkt für Punkt übereinstimmt mit dem Heliotropismus der Pflanzen. Nehmen wir an, eine Motte werde seitlich rom Lichte getroffen, so besteht die einseitige Wirkung des Lichts darin, dass diejenigen Muskeln, welche den Kopf des Thieres zur Lichtquelle führen, in stärkere 'Thätigkeit gerathen und dass dementsprechend der Kopf des Thieres gegen die Lichtquelle gerichtet wird. Sobald nun der Kopf des Thieres gegen die Lichtquelle gerichtet ist und seine Medianebene (Symmetrieebene) in die Richtıng der Lichtstrablen fällt, werden die symmetrischen Punkte seiner Oberfläche, besonders der Augen, von den Lichtstrahlen unter wleichem Winkel getroffen und es ist kein Grund vorhanden, warum das Thier aus der Richtung der Lichtstrahlen nach rechts oder links abweichen sollte. Es wird so in die Lichtquelle geführt. Handelt es sich um Thiere mit rascher Progressivbewegung (wie bei der Motte), so werden sie in die Flamme gerathen, ehe die Wärme Zeit hat, ihre Progressirbewegung zu hemmen. Handelt es sich um Thiere mit langsamer Progressivbewegung, bei denen die zunehmende Hitze bei der Annäherung an die Flamme in Wirksamkeit treten kann, ehe das Thier bis in die Flamme selbst geräth, so wird das Thier in Folge seines positiven Heliotropismus bis nahe an die Flamme kommen, dann wird in Folge der hohen Temperatur die Progressirbewegung ge- 
hemmt, das Thier entfernt sich von der Flamme, wird wieder orientirt u. s. f. Wie bei den Pflanzen sind auch bei den Thieren die mehr brechbaren Strahlen die wirksameren.

Es handelt sich also bei dem "Instinct", der die Motte in das Licht treibt, um nichts anderes als um eine chemische und indirect mechanische Wirkung des Lichtes, von derselben Art, wie die, welche die Pflanzenstengel am Fenster zwingt, sich zur Lichtquelle zu krümmen oder welche Palaemonetes zwingt, sich an der Anode zu sammeln. Die Motte fliegt nicht aus Neugier zum Licht, sie wird auch nicht vom Licht „angezogen", sie wird nur vom Licht orientirt und zwar so, dass ihre Medianebene in die Richtung der Lichtstrahlen gestellt wird und ihr Kopf \%ur Lichtquelle hin gerichtet wird. In Folge dieser Orientirung müssen ihre Progressivbewegungen sie zur Lichtquelle hinführen.

Wir kommen uun zu der wichtigsten Frage dieses Abschnittes, nämlich zur Beurtheilung der Beziehung des Centralnervensystems zu den Instincten. So lange wir diese anscheinend complexen Dinge wie die Instincte nicht analysiren, sondern als ein Ganzes behandeln, müssen sie uns leicht auf den Gedanken führen, dass ihnen selır geheimnissvolle nervöse Strukturen zu Grunde liegen. Es wäre im Sinne der Centrentheorie bei der Hotte ein besonderes In-die-Flamme-fliegen-Centrum anzunehmen und es wäre die Aufgabe der fehimphysiologie, nach seiner Localisation im Centralnervensystem zu forschen. Allein das In-die Flamme-fliegen der Motte ist nichts anderes als positiver Heliotropismus und der positive Heliotropismus der Thiere ist identisch mit dem positiven Heliotropismus der Pflanzen. Es muss also diese Reaction der Motte auf Umständen beruhen, welche Thieren und Pflanzen gemeinsam sind. Die Pflanzen besitzen aber kein Centralnervensystem und so können auch meiner Ansicht nach die heliotropischen Reactionen der Thiere unmöglich auf specifischen Einrichtungen des Centralnervensystems beruhen. Sie müssen vielmehr in Einrichtungen bestimmt sein, welche Thieren und Pflanzen gemeinsam sind. Es lässt sich sehr leicht aus dem Gesagten ableiten, was diese Eigenschaften sind: Erstens müssen die heliotropischen Thiere wie die heliotropischen Pflanzen an ihrer Oberfläche eine Substanz enthalten, welche durch das Licht chemisch verändert wird und deren Veränderung Spannungsänderungen der contractilen Gewebe hervorrufen kanu. Zweitens müssen beliotropische Thiere wie Pflanzen dieselben Seitlichkeiten und Symmetrieverhältnisse und dem entsprechend die gleiche Vertheilung der Reizbarkeiten besitzen. Durch diese beiden Gruppen von Umständen ist die heliotropische Reaction eindeutig bestimmt. Was aber hat das Centralnervensystem mit diesem Instinct der Motte ins Licht zu fliegen, oder wie wir jetzt 
sagen dürfen, nit dem Heliotropismus derselben zu thun? Meiner Ansicht nach nichts weiter, als dass das Nervensystem eine Reihe segmentaler Ganglien enthält, welche die protoplasmatische Verbindung zwischen Haut und Muskeln herstellt. Zerstören wir das Centralnerrensystem, so hören damit die heliotropischen Reactionen bei vielen Thieren auf, aber lediglich deshalb, weil der Zusammenhang zwischen der durch das Licht afficirten Haut (resp. den Augen) und den Muskeln unterbrochen ist. Es wäre also ebenso verkehrt, ein Centrum für das In-die-Flammefliegen bei der Motte anzunehmen, wie es falsch wäre, ein besonderes nervöses Centrum für das Zur-Anode-gehen der Krebse anzunehmen. Beide Erscheinungen sind vielmehr nur auf Grund der Segmentaltheorie verständlich.

2) Wir wollen einen anderen Instinct auswählen, nämlich die Gewohnheit vieler Thiere, sich in Ritzen und Spalten zu verkriechen. Dieser "Instinct" ist sehr weit im Thierreich rerbreitet. Er ist namentlich auffallend bei Insecten, Würmern u. s. w. Man spricht in diesem Falle von einem Schutzinstinct, wobei man sich vorstellt, dass das Thier sich so seinen Verfolgern und Feinden entziehe. Die Centrentheorie w.ürde ein besonderes Centrum für diesen Instinct voraussetzen. Es handelt sich aber wieder nur um einen einfachen Tropismus. Viele Pflanzen und Thiere sind gezwungen, ihren Körper in bestimmter Weise gegen feste Körper, mit denen sie in Berührung kommen, zu orientiren. Ich bezeichnete diese Art Reizbarkeit als Stereotropismus. Wie es einen positiven und negativen Heliotropismus giebt, so giebt es auch einen positiven und negativen Stereotropismus. Ich habe beispielsweise gefunden, dass wenn man eine Tubularia der Länge nach mit einem festen Körper in Berührung bringt, der Polyp und die wachsende Spitze sich von den festen Körper fortkrümmen, während der Stolon sich an den festen Körper anschmiegt und mit ihm verwächst. Der Polyp ist negativ stereotropisch, der Stolon positiv stereotropisch. Der Stereotropismus spielt auch eine grosse Rolle in den Vorgängen der Fortpflanzung und der Organbildung. Die Neigung vieler Thiere, sich in Ritzen und Spalten zu verkriechen, hat nun nichts mit einem „sich verbergen" zu thun, sondern ist bestimmt durch einen Zwang, den Körper möglichst allseitig in Berührung mit festen Körpern zu bringen. Den Beweis hierfür führte ich beispielsweise bei einer eigenthümlichen Art von Schmetterlingen, Amphipyra, die rasche und flinke Läufer sind. Sobald sie frei sind, laufen sie rastlos umher, bis sie eine Ecke oder Spalte finden, in die sie sich verkriechen. Ich brachte nun diese Thiere in einen langen Kasten, der halb mit einem undurchsichtigen Körper und halb mit einer Glasplatte bedeckt war. Den Boden des Kastens bedeckte ich mit klei- 
nen Glasplättchen, die auf Klötzchen ruhten und die so hoch über dem Boden waren, dass eine Amphipyra gerade unter die Platte schlüpfen konnte. Die Amphipyren sammelten sich nun nicht in der dunkeln Ecke, wo sie dem Auge etwaiger Feinde verborgen waren, sondern unter den Glasplättchen, wo ihre Körper allseitig mit festen Gegenständen in Berührung waren. Sie thaten das auch dann, wenn sie dabei dem rollen Sonnenlicht ausgesetzt waren. Ebenso trat diese Reaction auch ein, wenn der ganze Kasten sich im Dunkeln befand. Hier konnten nur die stereotropischen Reize die Reaction auslösen. Ganz ähnliche Beobachtungen kann man an Würmern, z. B. Nereis, anstellen. Setzt man ebenso viele Glasröhren in eine Schüssel mit Seewasser als Nereis darin enthalten sind, so darf man sicher sein, dass nach einiger Zeit jeder Wurm in einer Röbre sich befindet. Das findet selbst dann statt, wenn diese Röhren dem vollen Sonnenlicht ausgesetzt sind, in dem die Würmer zu Grunde gehen. Auch hier haben wir es mit einer Reaction zu thun, die Pflanzen, Hydroidpolypen und Thieren mit Centralnervensystem gemeinsam ist, und die daher auf Umständen beruhen muss, die direct nichts mit dem Centralnerrensystem zu thun haben. Diese Umstände sind voraussichtlich chemische Wirkungen in der Haut, die der Contact mit festen Körpern in diesen Formen hervorruft. Das Centralnervensystem spielt wiederum nur die Rolle eines protoplasmatischen Reizleiters. Es wäre völlig falsch, etwa nach einem Centrum für den „Verbergereflex" bei diesen Thieren suchen zu wollen. Das bestätigen auch die Versuche an zerstückelten Würmern.

3) Wir wollen uns nummehr der Betrachtung ron einigen complicirteren Instincten zuwenden. Es erschien mir immer als eine der wunderbarsten Einrichtungen in der Natur, dass bei einer Reihe von Species das Weibchen die Eier an solchen Orten ablegt, wo die auskriechenden Larven die für sie passende Art der Nahrung finden. Wer die vergleichende Physiologie hierbei nicht berücksichtigt und statt dessen in der bisher üblichen Weise versucht, diese Reactionen auf zweifelhafte Gehirncentren zurückzuführen, wird schwerlich weit kommen. Vom Standpunkt der vergleichenden Physiologie aber werden wir zu der Einsicht geführt, dass es sich hier um einfache Tropismen handelt, für deren Zustandekommen nur der Vorgang der Reizleitung, aber keinerlei sonstige mysteriöse Einrichtungen im Centralnervensystem erforderlich sind. Die Hausfliege legt ihre Eier auf faulendes Fleisch, Käse oder ähnliches Material und diese Substanzen bilden das Nährmaterial für die jungen Larven. Ich habe oft Stücke Fleisch und Fett rom nämlichen Thier nebeneinander an das Fenster gelegt, aber die Fliege machte nie einen Irrthun, sie legte ihre Eier stets auf das Fleisch und nie auf das Fett. 
Ich machte ferner den Versuch, die Larven auf Fett zu züchten. Wie zu erwarten war, fand auf Fett kein Wachsthum statt und die Larven gingen bald zu Grunde. An den jungen Larven liess sich die Mechanik des eigenthümlichen Instincts ihrer Mutter ermitteln. Die Larven werden durch bestimmte Substanzen, welche von einem Körper ausstrahlen, orientirt und diese Orientirung findet in derselben Weise statt wie die Orientirung heliotropischer Thiere durch das Licht stattfindet. An die Stelle der Lichtquelle tritt in diesen Versuchen das Diffusionscentrum und an die Stelle der Lichtstrahlen die Diffusionslinien, d. h. die geraden Linien, längs welcher die Molecüle vom Diffusionscentrum sich ins umgebende Medium fortbewegen. Die chemischen Effecte der diffundirenden Molecüle auf gewisse Elemente der Haut beeinflussen die Spannung der Muskeln in ähnlicher Weise wie die photochemischen Wirkungen ier Lichtstrahlen in Falle heliotropischer Thiere. Man bezeichnet dic Orientirung eines Organismus durch diffundirende Moleciile als Chemotropismus und wir sprechen von positivem Chemotropismus, wenn das Thier gezwungen ist, seine Symmetrieaxe in die Richtung der Diffusionslinien zu bringen und seinen Kopf gegen das Diffusionscentrum zu richten. Bei einer solchen Orientirung wird jedes Paar von Symmetriepunkten an der Oberfläche des Thieres unter gleichem Winkel von den Diffusionslinien getroffen. Es lässt sich leicht zeigen, dass die Fliegenlarven positiv chemotropisch gegen gewisse chemische Substanzen sind, die in faulendem Fleisch und Käse gebildet werden, die aber beispielsweise nicht im Fett enthalten sind. Die fraglichen Stoffe sind wahrscheinlich flüchtige stickstoffhaltige Verbindungen. Die junge Fliegenlarve wird durch diese Substanzen in derselben Weise zum Diffusionscentrum geführt, wie die Motte in die Flamme. Die weibliche Fliege besitzt denselben positiven Chemotropismus für diese Stoffe wie die Larven und wird demgemäss zum Fleisch geführt. Sobald sie auf dem Fleische sitzt, scheinen chemische Reize reflectorisch die Eiablage auszulösen. Es könnte auch sein, dass zur Zeit, wo das Thier zur Eiablage bereit ist, der positive Chemotropismus für die erwähnten Stoffe besonders stark entwickelt ist. Sicher ist aber, dass weder Erfahrung noch bewusste Wahl eine Rolle bei diesen Vorgängen spielen. Wenn wir nunmehr die Frage aufwerfen, was nöthig ist, um diese Reactionen auszulösen, so lautet die Antwort: Erstens die Gegenwart einer Substanz in der Haut des Thieres, die durch die erwähnten flïchtigen Stoffe, die in faulenden Fleisch enthalten sind, verändert wird, und zweitens die bilaterale Symmetrie des Körpers. Das Centralnervensystem spielt dabei keine andere Rolle, als dass es die protoplasmatische Brücke für die Reizleitung von der Haut zu den Muskeln bildet. In Organis- 
men, wo diese Reizleitung ohne Centralnervensystem möglich ist, bei Pflanzen z. B., finden wir auch dieselben Reactionen (Instincte). Das entspricht der Segmentaltheorie, aber nicht der Centrentheorie.

4) Ein anderes Beispiel eines die Art erhaltenden Instincts finden wir bei den jungen Raupen vieler Schmetterlinge. Die Larven des Goldafters (Porthesia chrysorrhoea) kriechen im Herbst aus dem Ei und überwintern in Colonieen in einem Nest auf Bäumen oder Strāuchern. Die warme Früblingssonne treibt die Larven aus dem Nest und sie kriechen alle an den Zweigen des Baumes in die Höhe bis zur Spitze, wo sie in den jungen Knospen ihr erstes Futter finden. Nachdem sie dieselben gefressen haben, kriechen sie regellos umher, bis sie neue Knospen oder Blätter finden, die inzwischen in grosser Zahl hervorgesprosst sind. Es ist klar, dass der Instinct der Raupen, in die Höhe zu kriechen, sobald sie aus dem Winterschlaf erwachen, ihnen das Leben rettet. Würden sie nicht durch einen solchen Instinct geleitet, so würden diejenigen, welche abwärts kriechen, an Nahrungsmangel sterben. Welche Rolle spielt das Centralnervensystem bei diesem Instinct?

Ich habe gefunden, dass die jungen Raupen von Porthesia, solange sie nüchtern sind, durch das Licht orientirt werden, sie sind positiv heliotropisch. Dieser positive Heliotropismus führt sie zu den Spitzen der Zweige, wo sie ihre Nahrung finden. Während des Winters sind sie starr und unbeweglich. Die höhere Temperatur des Frühlings bringt chemische Aenderungen in ihrem Körper hervor und diese chemischen Vorgänge veranlassen sie, sich zu bewegen. Die Richtung der Bewegung wird vom Licht dictirt. Im Freien, wo das Himmelslicht von allen Seiten auf das Thier fällt, können wir jeden Lichtstrahl in eine horizontale und vertikale Componente zerlegen. Die horizontalen Componenten vernichten einander und nur der Effect der vertikalen Componenten wird übrig bleiben. Die Thiere müssen also in Folge ihres positiven Heliotropismus in die Höhe kriechen, bis sie die Spitze eines Zweiges erreichen. Hier werden sie durch das Licht festgehalten. Die chemischen Reize, welche den Thieren von den jungen Knospen gegeben werden, lösen maschinenmässig die Fressbewegungen aus. Bei diesem Instinct, der für die Erhaltung des Lebens nöthig ist, handelt es sich also um einfachen positiven Heliotropismus und hierbei spielt das Centralnervensystem eben nur die Rolle einer protoplasmatischen Verbindung zwischen Haut und contractilem Gewebe. Diese Verbindung wird in Pflanzen mit demselben Erfolg von undifferenzirtem Protoplasma hergestellt.

Aber wir sahen, dass dieselben Larven, sobald sie gefressen haben, die Spitzen der Zweige verlassen und herunter kriechen. Warum hält 
das Licht sie nicht dauernd am höchsten Punkte der Zweige fest? Meine Versuche ergaben, dass diese Raupen nur so lange positiv heliotropisch sind, als sie nüchtern sind. Sobald sie gefressen haben, verlieren sie ihren Heliotropismus. Das ist nicht die einzige Beobachtung dieser Art. Ich habe eine Reihe von Thatsachen gefunden, welche zeigen, dass chemische Aenderungen im Thiere seine Reizbarkeit gegen Licht beeinflussen. Wir können uns vorstellen, dass die Nahrungsaufnahme zur Zerstörung von lichtempfindlichen Substanzen in der Haut des Thieres führt, von denen der Heliotropismus abhängt, oder dass durch die Nahrungsaufnahme die Wirksamkeit dieser Substanzen indirect vermindert wird. Es handelt sich auch bei diesen Instincten nicht um Functionen bestimunter localisirter "Centren", sondern um Reizbarkeiten peripherer Gebilde und deren Verknüpfung mit Muskeln; das Centralnervensystem dient eben nur als protoplasmatischer Leiter.

5) Wie die Analyse dieser Schutzinstincte zum Errgebniss führt, dass sie nur auf Tropismen beruhen, die auch bei Pflanzen vorkommen, so führt auch die Analyse anderer Instincte, z. B. des Wanderungstriebes, zu demselben Ergebniss. Es wäre natürlich interessanter, an die Wanderungen der Zugvögel anzuknüpfen, aber es ist schwer, über diesen Gegenstand Laboratoriumsversuche anzustellen und ohne Laboratoriumsversuche kommen wir nicht leicht zu sicheren Ergebnissen. Ich habe mich daher an eine andere Klasse von periodischen Wanderungen gewendet, nämlich die periodischen Tiefenwanderungen der Seethiere. Eine grosse Zahl von Seethieren beginnen eine vertikale Aufwärtswanderung zur Oberfläche des Oceans am Abend, während sie am Morgen abwärts wandern. Es ist nun eine merkwürdige Thatsache, dass rliese Formen bei ihren Abwärtswanderungen niemals tiefer als 400 Meter gehen. Der letztere Umstand deutet an, dass das Licht die wesentliche bewegende Kraft in diesen Tiefenbewegungen ist. Wasser absorbirt das Licht und je dicker die Wasserschicht ist, um so mehr Licht wird absorbirt. Man hat gefunden, dass in der Tiefe von 400 Metern eine photographische Platte nicht länger afficirt wird. Die Thiere, welche frei an der Oberfläche des Oceans leben, sind, soweit meine Untersuchungen ergeben haben, alle dauernd oder zeitweilig positiv heliotropisch (und häufig auch negativ geotropisch). Diejenigen unter ihnen, welche die erwähnten täglichen Tiefenwanderungen ausführen, besitzen einige Eigenthümlichkeiten, welche wir nur verstehen können, wenn wir etwas näher auf die Theorie des thierischen Heliotropismus eingehen. Wir haben schon erwähnt, dass es ausser dem positiven, auch noch einen negativen Heliotropismus giebt. Negativ heliotropische Thiere bringen ihre Medianebene ebenfalls in die Richtung der Lichtstrahlen, aber sie richten ihren ab- 
oralen Pol gegen die Lichtquelle. Der Unterschied im Verhalten der positiv und negativ heliotropischen Thiere besteht in Folgendem: Wenn Licht auf eine Seite eines positiv heliotropischen Thieres fällt, so findet eine Zunahme in der Spannung derjenigen Muskeln statt, welche den Kopf zur Lichtquelle drehen, während beim negativ heliotropischen Thier unter dem Einfluss einseitiger Beleuchtung eine Abnahme der Spannung derselben Muskeln eintritt. Die Folge ist, dass die negativ heliotropischen Thiere sich von der Lichtquelle fortbewegen müssen. Vielleicht ist noch ein anderer Unstand hierbei zu berücksichtigen, dass nämlich das Licht, wenn es das vordere Ende positiv heliotropischer Thiere trifft, die Progressivbewegung fördert, während es, wenn es das vordere Ende negativ heliotropischer Thiere trifft, die Progressivbewegung hemmt. Das würde auf eine weitere Analogie des Heliotropisnus und Galvanotropismus hinweisen.

Groom und ich stellten Versuche an den Larven von Balanus perforatus an, von denen es bekannt war, dass sie periodische Tiefenbewegungen ausführen. Eines unserer Versuchsergebnisse bestand darin, dass wir fanden, dass die Thiere bald negativ, bald positiv heliotropisch sind und dass wir im Stande waren, sie nach Belieben positiv und negativ heliotropisch zu machen. Bei schwachem Licht, namentlich bei Gaslicht (das relativ wenig der heliotropisch wirksamen blatuen Strahlen enthält), werden und bleiben sie positiv heliotropisch, während sie in starken Licht sehr bald negativ heliotropisch werden. Dieser Umstand bestimmt die periodischen Tiefenbewegungen dieser Thiere. Wenn sie am Morgen in der Nähe der Oberfläche des Oceans sind, so macht das stärkere Licht sie negativ heliotropisch und zwingt sie vertikal abwärts zu gehen, da in offenen Meere nur die vertikale Componente des Himmelslichtes für die Orientirung in Betracht kommt. Sobald sie sich aber in ihrer Abwärtswanderung der Tiefe von 400 Metern nähern, wird das Licht so schwach, dass sie jetzt positiv. heliotropisch werden. Sie müssen dem entsprechend anfangen, wieder in die Höhe zu wandern, aber sie können nicht bis zur Oberfläche vordringen, da sie ja alsbald während des Tages eine Region von so hoher Lichtstärke erreichen müssen, dass sie wieder negativ heliotropisch werden. So werden sie während des Tages in einer gewissen Tiefe, die aber geringer als 400 Meter ist, in der Schwebe gehalten. Aber sobald es dunkler wird, und die Intensität des Lichtes im Wasser mehr und mehr abnimmt, müssen sie in Folge ihres positiven Heliotropismus in beständig höhere Regionen empor steigen, bis sie, bei der geringen Lichtintensität der Nacht, beständig an der Oberfläche des Wassers festgehalten werden. Gegen Morgen mit Beginn der Dämmerung werden sie dann wieder negativ heliotropisch und sie 
beginnen wieder ihre Abwärtswanderung. Aber die Seethiere zeigen noch eine andere Tiefenbewegung von einer grösseren Periode, welche mehr der Wanderung der Zugvögel entspricht. Im Golf von Neapel bleiben gewisse Formen, wie Chun gefunden hat, im Sommer auch während der Nacht in grössererTiefe, ohne jemals an die Oberfläche zu kommen. Das ist wahrscheinlich durch die höhere Temperatur bedingt, welche das Seewasser während des Sommers an der Oberfläche anninmt. Ich habe nämlich gefunden, dass gewisse Thiere, z. B. die Larven von Polygordius, bei niederer Temperatur positiv heliotropisch sind, während sie bei höherer Temperatur negativ heliotropisch werden.

Ich habe erwähnt, dass auch der Geotropismus bei diesen Tiefenwanderungen mitwirkt. Dieselben Umstände, welche die Thiere negativ heliotropisch machen, machen sie auch positiv geotropisch und vice versa. So konnte ich zeigen, dass bei niedriger Temperatur Polygordiuslarven nicht nur positiv heliotropisch, sondern auch negativ geotropisch sind, während sie bei hoher Temperatur nicht nur negativ heliotropisch, sondern auch positiv geotropisch sind. Vermöge dieses Geotropismus werden sie auch in der Dunkelheit gezwungen, an die Oberfläche zu gehen, wenn die Temperatur des Seewassers gering ist. Es ist auch wahrscheinlich, dass bei manchen Formen innere Umstände, ähnlich ren nyctitropen Erscheinungen bei Pflanzen mit dazu beitragen, dass periodische Tiefenwanderungen stattfinden. Wir finden also, dass der "Wanderungsinstinet", soweit er in den periodischen Tiefenwanderungen der Seethiere zum Ausdruck kommt, bestimmt ist durch die Anwesenheit von lichtempfindlichen Substanzen in der Oberfläche des Thieres, die aber je nach Intensität des Lichtes oder je nach der Temperatur (oder vielleicht auch nach inneren Zuständen) verschiedene Wirkungen hervorbringen. Sie sind ferner bestimmt durch die Symmetrieverhältnisse der Thiere. Das Centralnervensystem hat mit diesen Erscheinungen nichts weiter zu thun, als dass es die Protoplasmaverbindung zwischen Haut und Muskeln liefert. Bei niederen Formen und bei Pflanzen, wo diese Protoplasmaverbindung eine directe ist, kommen daher auch dieselben Wirkungen ohne Centralnervensystem zu Stande. Das steht im Widerspruch mit der Centrentheorie dieser Instincte, es entspricht aber der Segmentaltheorie.

6) Man könnte nun denken, dass alle diese Verhältnisse nur für die Wirbellosen gültig sind. Goltz hat aber eine merkwürdige Entdeckung gemacht, die dafür zu sprechen scheint, dass auch bei höheren Thieren die Dinge nicht wesentlich anders liegen. Eine Hündin, die ein Junges geworfen, beisst die Nabelschnur ab, beleckt das Junge, ist überaus zärtlich gegen dasselbe und erlaubt keinem Fremden es anzurühren. Diese mütterlichen Instincte sind ererbt, und es ist zweifellos, dass mit dem 
Geburtsakt und den darauf folgenden Vorgängen die Veränderungen im Thier vor sich gehen, welche jene Instincte möglich machen. Man könnte in erster Linie hier daran denken, dass das Centralnervensystem durch die Uterusnerven direct erregt wird. Goltz hat nun gefunden, dass diese Instincte auch dann voll entwickelt sind, wenn man das Rückenmark vor der Conception so hoch oben durchschneidet, dass die Reize vonı Uterus her das Gehirn nicht erreichen können (6). Es ist wahrscheinlich, dass gewisse Stoffe, die während der Schwangerschaft, Geburt und Lactation gebildet werden, den Character des Thieres beeinflussen, wie ja auch gewisse Gifte, Alkohol, Tabak, Morphium, die Reactionen eines Menschen beeinflussen. Es bleibt freilich möglich, dass der Sympathicus im Spiele ist.

Mit der Centrentheorie der Instincte fällt auch der Versuch, die Instincte "historisch" zul erklären. Wir haben im ersten Kapitel auf die Behauptung hingewiesen, dass die Instincte ursprünglich bewusste Handlungen gewesen seien, die durch „Uebung“" zur Ausbildung von Reflexcentren geführt hätten. So lange periphere Reizbarkeiten, wie Lichtempfindlichkeit etc., für die Reflexe bestimmend sind, ist es unnöglich anzunehmen, dass es sich bei den Instincten um fixirte Erfahrungen der voraufgehenden Generation handelt. Ich vermag mir nicht vorzustellen, wie ein Thier oder eine Species lichtempfindliche Substanzen in seinen Augen oder auf seiner Haut auf dem Wege der "Erfahrung" oder "Uebung" erwerben könnte. Ich glaube aber, dass der "historische" Weg der Erklärung der Lebenserscheinungen d. h. der Versuch einer phylogenetischen Erklärung derselben erkenntnisstheoretisch ebenso verfehlt ist, wie wenn man etwa darauf bestehen wollte, dass die Dampfmaschine geologisch zu erklären sei. Bei Maschinen interessirt uns die Umwandlung und Dosirung der Energie, die Geschichte unseres Planeten kann uns darin nicht förderlich sein. Lebende Wesen aber sind Maschinen und müssen als solche analysirt werden, sobald wir ein Verständniss ihrer Reactionen erlangen wollen. In den erkenntnisstheoretischen Irrthum "historischer" Erklärungsmethoden ist die Biologie nur dadurch gerathen, dass dem genialen Wiedererwecker des Evolıtionsgedankens, Darwin, die energetischen Naturwissenschaften (Physik, Chemie und Physiologie) weniger nahe lagen. Das schmälert natürlich sein Verdienst ebensowenig, wie es unsere Bewunderung für den Mann verringern darf. Auf der anderen Seite aber ist auch kein Grund vorhanden, dass die erkenntnisstheoretischen Einseitigkeiten des Meisters nunmehr unter den Biologen erblich werden sollten. Selbst das Problem der Entstehung der Arten wird erst danu zu ernsten Resultaten führen, wenn es rom Standpunkt der energetischen Naturwissenschaften d. $h$. von maschinellen Standpunkt aus in Angriff genommen werden kann. 


\section{Litteratur zu XIII.}

1) Loeb. J. Der Heliotropismus der Thiere und seine Uebereinstimmung mit dem Heliotropismus der Pflanzen. Würzburg 1890.

2) Groom und Loeb. Der Heliotropismus der Nauplien von Balanus perforatus und die periodischen Tiefenwanderungen pelagischer Thiere. Biologisches Centralblatt, Bd. X. 1890.

3) Loeb, J. Ueber den Instinct und Willen der Thiere. Pflüger's Archiv, Bd. 47 , p. 407. 1890.

4) Loeb, J. Ueber künstliche Umwandlung positiv heliotropischer Thiere in negativ heliotropische und umgekehrt. Pflüger's Archiv, Bd. 54. 1893.

5) Loeb, J. On Egg Structure and the Heredity of Instincts. The Monist July 1897.

6) Goltz, F. Ueber den Einfluss des Nervensystems auf die Vorgänge während der Schwangerschaft und des Geburtsaktes. Pflüger's Archiv Bd. 9. 1574. 


\section{XIV}

\section{Centralnervensystem und Vererbung.}

1) Die Frage, wie weit das Centralnervensystem für die Vorgänge der Vererbung in Betracht kommt, ist für die Probleme der Erziehung von ausserordentlicher Bedeutung. Wenn wir hoffen dürften, dass in Folge der Thätigkeit einer Generation die Nachkommen derselben mit einer Disposition für diese besondere Thätigkeit geboren werden, so würde sich ja ein fruchtbares Feld für die Verbesserung des Menschengeschlechtes ergeben. Um diese Frage zu entscheiden müssen wir uns zunächst an solche Eigenthümlichkeiten wenden, deren Erblichkeit sicher ist, namentlich die Körperform und die Instincte. Die Analyse der Instincte, die wir im vorigen Kapitel gegeben haben, setzt uns in die Lage, die Frage zu beantworten, wie eine Uebertragung derselben durch das Ei möglich ist. Alle erblichen Eigenschaften der Form und der Instincte und Reflexe müssen durch die Sexualzellen übertragen werden. Die Schwierigkeit, die dabei zu Tage tritt, ist die: Wie können die Sexualzellen, die nur eine flüssige Masse mit festen Einschlüssen darstellen, Träger von anscheinend so complicirten Umständen sein, wie die Formen, die daraus entstehen und ihre Instincte und Reflexe. Zwei Möglichkeiten sind vorhanden. Entweder ist die scheinbare Einfachheit der Struktur des Eis nur eine Täuschung und das Ei besitzt in Wirklichkeit eine unsichtbare complicirte Struktur, die an Complicirtheit der des erwachsenen Thieres nichts nachgiebt; oder die Gesammtheit der Dinge, die wir die Form und die Instincte des erwachsenen Thieres nennen, ist nur die Resultante einfacher Elemente, die sehr wohl durch das Ei übertragen werden könuen, ohne dass das letztere eine complicirte Struktur besitzt. Unsere Discussion ïber die Mechanik der Instincte im vorigen Kapitel zeigt nun, dass das letztere der Fall ist Nehmen wir den Fall derjenigen Instincte, die auf heliotropischen Reactionen beruhen, z. B. das Fliegen der Motte in das Licht. Dieser Instinct ist eindeutig bestimmt 1. durch die Anwesenheit einer licht- 
empfindlichen Substanz in der Oberfäche des Thieres und 2. durch die Symmetrieverhältnisse des Thieres. Für die Uebertragung einer lichtempfindlichen Substanz durch das Ei ist keine complicirte geheimnissvolle Struktur nöthig. Ebenso ist für die Uebertragung der Symmetrieverhältnisse des Thieres durch das Ei keine complicirte Struktur des letztern nöthig.

Für die Vererbung von Formen ist die Lage der Dinge nicht wesentlich anders. Das Ei ist nicht der Träger der Form des erwachsenen Thieres, sondern bestimmter chemischer Stoffe, besonders von Fermenten. Je nach der stereochemischen Configuration der letzteren fallen die Assimilationsproducte und damit das Körpermaterial verschieden aus. Der Vorgang der Entwickelung ist nicht nur eine morphologische, sondern vor allem eine chemische Differenzirung und aus den anfänglichen Rohstoffen werden immer weitere Combinationen von Stoffen gebildet. Mit jeder Differenzirung der Stoffwechselproducte kann und wird auch häufig eine weitere Differenzirung der Form verknüpft sein. Mit dieser Auffassung, die ich im Anschluss an Sachs in einer Reihe von Arbeiten näher entwickelt habe, stehen die Versuchsergebnisse der experimentellen Morphologie in vollem Einklang. Ich erinnere nur an den Versuch, in dem man einem Śeeigel-Ei (Arbacia) die Form einer Doppelkugel giebt und wobei dann jede der Halbkugeln sich in eiven vollständigen Seeigel umwandelt. Dabei macht es keinen Unterschied, ob die Umwandlung des Seeigels in eine Doppelkugel im frisch befruchteten Ei geschieht oder nachdem die Furchung schon bis ins 16. oder 32. Zellenstadium fortgeschritten ist. Diese Thatsachen sind nur verständlich, wenn man im Ei nichts weiter sieht, als den Träger bestimmter chemischer Substanzen und nicht mysteriöser morphologischer Differenzirungen von ähnlicher Complicirtheit wie das erwachsene Thier; und wenn man den morphologischen Entwickelungsvorgang nur als Folge oder Begleiterscheinung entsprechender chemischer Umwandlungen ansieht. Ich darf wohl ferner hier erwähnen, dass die Vorgänge der Heteromorphose, d. h. die Umwandlung resp. der Ersatz eines Organes durch ein morphologisch verschiedenes durch bestinmte äussere Einflüsse zu derselben Auffassung zwingen. Es liessen sich auch noch andere Thatsachen zu Gunsten dieser Auffassung anführen.

2) Tornier hat eine Theorie der Vererbung erworbener Eigenschaften vermittelst des Centralnervensystems aufgestellt. Nach dieser Theorie soll jede Veränderung, die im Körper stattfindet, begleitet sein von einer entsprechenden Veränderung im Centralnervensystem. Die Veränderungen im Centralnervensystem sollen dann eine entsprechende Aenderung im Ei hervorbringen. Nach dieser Theorie müsste also ein ebenss 
inniger Zusammenhang zwischen dem Centralnervensystem und den morphogenetischen Vorgängen bestehen, wie zwischen Centralnervensystem und motorischen und sensorischen Functionen. Es lässt sich aber leicht zeigen, dass diese Annahme Tornier's viel zu weit geht. Wenn die Amblystomalarve sich in ein geschlechtsreifes Thier umwandelt, so verliert sie ein am Kopf befindliches Organ, die Kiemen, und ein an Schwanz befindliches Organ, den Kamm. Beide Organe verschwinden gleichzeitig. Ich durchschnitt bei einer Reihe von Amblystomalarven das Rückenmark in der Nähe des Schultergïrtels. Die vor und hinter der Durchschneidungsstelle gelegenen Theile des Thieres verhielten sich in motorischer wie sensorischer Beziehung wie zwei getrennte Thiere. Wären nun die morphogenetischen Vorgänge ebenso eng mit dem Centralnerrensystem verknüpft, wie die sensorischen und motorischen Functionen - was die Theorie Tornier's verlangt - so hätte man erwarten sollen, dass die Kiemen und der Schwanzkamm nicht länger gleichzeitig sich zurückbilden, sondern zu verschiedenen Zeiten, wie bei zwei verschiedenen Thieren. Ohne Ausnahme trat bei diesen Thieren mit durchschnittenem Rückenmark die Rückbildung der Kopf- und Schwanzorgane gleichzeitig ein (1). Unter den Versuchsthieren befanden sich solche, bei denen die Verwandlung in wenigen Tagen nach der Durchschneidung eintrat, sowie solche, bei denen der Zwischenraum länger war. Es kann also keinem Zweifel unterliegen, dass der Zusammenhang zwischen den morphogenetischen Functionen und dem Centralnerrensystem viel geringer ist, als der zwischen diesem Organ und den sensorischen und motorischen Functionen.

Schaper hat einen neuen Versuch hinzugefügt, der für die Unabhängigkeit der morphogenetischen Entwickelung vom Centralnervensystem spricht. Er schnitt bei $6 \mathrm{~mm}$ langen Froschlarven das Gehirn nnd die Merlulla oblongata heraus. Das Rückenmark schien, als das Thier sieben Tage später getödtet wurde, geschwunden zu sein. Nichtsdestoweniger gingen Wundheilung, Wachsthum und Entwickelung während dieser sieben Tage weiter (2). Wir brauchen uns übrigens angesichts der Thatsache, dass die ersten Entwickelungsvorgänge bei jedem Thier der Bildung des Centralnervensystems vorausgehen, über diese Resultate nicht zu wundern. Sie reichen aber aus, uns zu überzengen, dass die Vorgänge der Entwickelung und Organbildung weniger eng mit dem Centralnervensystem verknüpft sind, als die sensorischen und motorischen Vorgänge. Wir können uns deshalb nicht gut zu der Annahme entschliessen, dass jeder Eindruck auf das Centralnervensystem sich dem Ei mittheilen soll, mit dem es ja übrigens gar nicht direct verbunden ist. 
3) Wie aber sollen wir es mit rlieser Ansicht vereinigen, dass gerade Geisteskrankheiten, bei denen doch das Centralnervensystem afficirt ist, erblich sind? Es ist vielleicht nicht ausgeschlossen, dass diejenigen Geisteskrankheiten, die sich vererben, im Grunde chemische Erkrankungen sind, veranlasst durch Gifte, die im Körper gebildet werden (3). Wie besondere Stoffe, z. B. Alkohol, Haschiscl und andere berauschende Stoffe vorübergehende Geisteskrankheiten erzengen, so dürften auch die Fieberdelirien sowie gewisse andere Geisteskrankheiten Giften ihren Ursprung verdanken, die im Körper gebildet werden. Es ist durchaus möglich, dass es sich um Gifte handelt, die der normale Körper auch bildet. Es ist nur nöthig, dass diese Gifte im Körper des Geisteskranken in etwas grösserer Menge gebildet oder in etwas geringerer Menge zerstört werden, als beim normalen Menschen. Es ist auch ferner gar nicht nöthig, dass diese hypothetischen Gifte, welche den Geisteskrankheiten zu Grunde liegen, im Centralnervensystem gebildet werden. Sie können in irgend einem Organ des Körpers gebildet werden. Es ist nur nöthig, dass sie anf das Centralnervensystem wirken, dass sie mit anderen Worten Nervengifte sind.

Nichts ist geeigneter, diese Anschauung zu verdeutlichen, wie die Folge, welche die Zerstörung der Schilddrüsen auf die geistige und körperliche Entwickelung von Kindern hat. Es ist bekannt, dass bei der Entartung der Schilddrüsen das Wachsthum und die geistige Entwickelung von Kindern stockt. Idiotenthum kann die Folge der Zerstörung der Schilddrüse sein. Man hat gefunden, dass in solchen Fällen durch die innerliche Darreichung von gesunder Schilddrüsensubstanz von Thieren Besserung oder sogar Heilung erzielt wird. Baumann hat gefunden, dass die Schilddrüse ein Element enthält, das sonst in keinem Organ des Körpers sich findet, nämlich Jod. Es ist also durchaus denkbar, dass wir es bei erblichen Geisteskrankheiten mit chemischen Krankheiten zu thun haben. Dabei können sehr wohl auch die Keimzellen durch die im Blute circulirenden Gifte beeinflusst werden.

4) Wenn wir auch so die un mittelbare Beeinflussung des Keimes durch das Centralnervensystem leugnen, und uns durchaus auf den Boden einer chemischen Theorie der Vererbung stellen, so wäre es doch möglich, dass das Centralnervensystem indirect die Vererbung beinflussen könnte, nänlich insofern, als es den Chemisnus des Körpers beeinflussen kann. Als Beispiele einer chemischen Wirkung der Nerven führt man den Umstand an, dass Reizung gewisser Drüsennerven Secretion herrorruft. Mathews hat aber gezeigt, dass wo Reizung des Sympathicus Secretion hervorruft, die Drüsen Muskelfasern enthalten, die sich bei der Reizung contrahiren und so mechanisch Flïssigkeit aus den Ausfüh- 
rungsgängen auspressen (4). Für die Secretion durch Chordareizung liegen die Dinge anders, es ist aber möglich, dass auch hier die Secretion nur eine indirecte Wirkung der Reizung ist. Dagegen giebt es aber anscheinend andere Beispiele für eine chemische Wirkung der Nerven. Die Thatsache, dass die Gürtelrose dem Verlauf von Nerven folgt, legt es nahe, anzunehmen, dass diese Erkrankung durch abnorme chemische Vorgänge veranlasst ist, bei denen die Thätigkeit der Nerven eine Rolle spielt. Goltz hat gefunden, dass nach Durchschneidung des Rückenmarkes Verschwärungen und Eiterungen auf der Haut hinter der Schnittstelle vorkommen, die so symmetrisch sind, dass sie unmöglich allein auf die Rechnung äusserer Insulte gesetzt werden können. Dieselben bestehen nur in den ersten Wochen nach der Operation und verschwinden später (5). Man darf daran denken, dass die Ursache dieser Erscheinungen in abnormen chemischen Vorgängen gesucht werden muss, die vielleicht indirect durch die vasomotorischen Nerven veranlasst sind, insofern, als dadurch Störungen der Sauerstoffversorgung u. s. f. bedingt werden. Diese Störungen können gelegentlich nach der Operation ausbleiben. Auch dem Arzt sind diese Erscheinungen des Decubitus nach Rückenmarksverletzung wohl bekannt. Für die Theorie dieser Vorgänge ist ganz besonders eine Thatsache interessant, welche Goltz und Ewald gefunden haben. Wenn sie Thieren das Rückenmark durchschnitten, so traten diese Erscheinungen der Verschwärung der Haut meist sehr drastisch auf. Operirten sie aber dann später in dem hinter der Schnittstelle gelegenen Stück Rückenmark, so waren die Störungen viel geringer oder blieben ganz aus. Es ist also die Trennung eines Rückenmarkabschnittes rom Gehirn von schwereren Folgen begleitet, als die Trennung eines Abschnittes vom Rückenmark allein (5).

Man darf in dieses Gebiet indirecter chemischer Wirkungen der Nerven auch die Trigeminuskeratitis rechnen. Nach Durchschneidung des Trigeminus tritt eine Entzïndung der Hornhaut derselben Seite ein. Diese Entzündung ist natürlich durch Bacterien veranlasst, aber der Umstand, dass diese Bacterien gerarle auf der Hornhant wirksam werden, deren sensibeler Nerv durchschnitten ist, könnte zweierlei Ursachen haben: Entweder könnte das Thier in Folge der Empfindungslosigkeit der Hornhaut die Fremdkörper nicht beachten, welche auf das Auge fallen, oder es könnten in Folge der Nervendurchschneidung Veränderungen in der Hornhaut eintreten, welche die Entstehung von Entzïndungen erleichtern. Das letztere dürfte der Fall sein, wenn die Angabe von Gaule richtig ist, dass bereits 10 Minuten nach der Durchschneidung des Trigeminus histologische Veränderungen in der Cornea nachweisbar sind (6). Es kann sich alsdann nur darum handeln, dass die Widerstandsfähigkeit 
oder richtiger die chemische Beschaffenheit der Gewebe in Folge der Nervenverletzung verändert ist.

Von trophischen Nerven braucht man deshalb nicht zu reden; wenn es wahr ist, dass der Einfluss jeder Nervenerregung auf die beeinflussten Gewebe ein chemischer ist, so sind in einem gewissen Sinne alle Nerren trophisch und es wäre geradezu falsch zu behaupten, dass besondere Nerven ausschliesslich trophischen Functionen dienten, während andere sensorisch und wieder andere motorisch seien. Es giebt keine specifisch trophischen Nerven, aber es ist möglich, dass manche Nerven so weitgehende chemische Veränderungen indirect (etwa durch Circulationsstörungen und Beschränkung der Sanerstoffversorgung) hervorbringen können, dass morphologische Veränderungen der Gewebe folgen.

Wenn nun das in der That der Fall ist, so ist nicht jede Möglichkeit ausgeschlossen, dass das Centralnervensystem indirect auch die Sexualzellen beeinflusst insofern, als durch Nerventhätigkeit (resp. durch Circulationsstörungen) Substanzen gebildet werden, welche die in den Hoden und Orarien enthaltenen Geschlechtszellen chemisch modificiren. Es wäre so allenfalls denkbar, dass angestrengte Gehirnthätigkeit einer Generation zur Bildung chemischer Substanzen führen könnte, welche die Geschlechtszellen beeinflussen. Aber warum dieser Einfluss gerade so ausfallen sollte, dass diese Geschlechtszellen Nachkommen mit grösserem Intellect hervorbringen, ist schwer einzusehen. Denn der Intellect ist ein Ding, das nicht wie die Muskelarbeit chemischen Umsetzungen proportional ist, sondern bei dem alles auf der richtigen Combination der Ideen beruht. Im Gehirn eines Dummkopfes und eines Genies mögen die gleichen Stoffumsätze vor sich gehen. Der Unterschied zwischen beiden ist jedoch der, dass der Dumnkopf werthvolle Ideenassociationen unbeachtet lässt, während der Kopf des Genies dieselben festhält. Hierbei könnten freilich in letzter Instanz doch chemische Umstände ausschlaggebend sein. Wir kommen also zu dem Schluss, dass eine Uebertragung erblicher Eigenschaften durch das Ei nur in der Form der Uebertragung specifischer chemischer Stoffe möglich ist, und dass das Centralnervensystem die Vererbung nur dann beeinflussen könnte, wenn es die Bildung besonderer Stoffe im Ei (durch Einfluss auf den Stoffwechsel) hervorrufen könnte. Dass das Centralnervensystem überbaupt einen solchen Einfluss hat, wäre freilich erst noch zu beweisen. Es ist deshalb einstweilen unberechtigt, zu behaupten, dass die Thätigkeit einer Generation eine erbliche Erhöhung der Fähigkeiten und Neigungen der folgenden Generation in derselben Richtung hervorbringen könne. Herbert Spencer führt zum Beweise dieser letzteren Möglichkeit den Umstand an, dass die Tastkreise an unserer Zungenspitze 
am kleinsten sind. Das soll nach ihm daher rühren, dass die Menschen seit Urzeiten die Neigung hatten, die Lücken zwischen den Zähnen, mit der Zungenspitze zu untersuchen und abzutasten und das soll eine erbliche Vermehrung der Nervenendorgane in der Zungenspitze veranlasst haben. Spencer übersieht, dass an der Nasenspitze die Tastkreise auch ein relatives Minimum erreichen und es ist sicher, dass dieses Organ zum Abtasten von Zahn- und anderen Lücken seit undenkbaren Zeiten sicherlich nicht gebraucht worden ist. Die relative Zahl der Nervenendorgane oder richtiger die relative Grösse der Tastkreise an der Zungenspitze und der Nasenspitze dürfte vielmehr bedingt sein durch den relativ kleinen Krümmungsradius resp. die relativ kleine Oberflächenentfaltung an der Spitze dieser Organe. ${ }^{\mathbf{1}}$ )

\section{Litteratur zu XIV.}

1) Loeb, J. Hat das Centralnervensystem einen Einfluss auf die Vorgänge der Larvenmetamorphose? Archiv für Entwickelungsmechanik, Bd. 4. 1896.

2) Schaper, A. Experimental Studies on the Influence of the Central Nervous System upon the Developement of the Embryo. Journal of the Boston Soc. of Medical Science. Jan. 1898.

3) Meyer, Adolf. A Few Demonstrations of Pathology of the Brain anil Remarks on the Problems connected with them. Proceedings Am. Psychol. Ass. 95.

4) Mathews. The Physiology of Secretion. Annals N. Y. Academ. of Science. Vol. XI No. 14. 1898.

5) Goltz und Ewald. Der Hund mit verkürztem Rückenmark. Pflüger's Arch. Bd. 63.1896.

6) Gaule, J. Der Einfluss des Trigeminus auf die Hornhaut. Physiologisches Centralblatt, Bd. 5. 1891.

7) Gaub, J. Wie beherrscht der Trigemnus die Ernährung der Hornhaut. Physiologisches Centralblatt. Bd. VI. 1892.

1) Spencer und Weismann haben vor einigen Jahren eine Controverse iiber die Frage der Vererbung erworbener Eigenschatten gehabt. Man möge nun nicht etwa schliessen, dass wir Anhänger aller Ansichten Weismann's seien, weil wir en von Spencer in dieser Angelegenheit benutztes Argument zuruickweisen. - Weismann's Ansichten gründen sich ebenfalls auf irrige Voraussetzungen. Er nimmt an, dass im Ei geheimnissvolle Strukturen existiren von einem ähnlichen Grad der Complication wie der erwachsene Organismus sie besitzt, der aus dem Ei hervorgeht. Weismann ist in diesen Irrthum gefallen, weil er übersieht, dass complicirte Erscheinungen durch die Combination einfacher Elemente hervorgebracht werden können und dass für die Vererbung nur die Uebertragung der letzeren durch das Ei nöthig ist. Nur die physikalischchemische Analyse der Lebenserscheinungen kann uns vor solchen Irrthümern bewahreu. Weder in Spencer's noch in Weismann's Schriften ist diese Analyse consequent unl weit genug durclugefiihrt. 
XV.

\section{Kriterien für die Constatirung von Bewusstsein bei niederen Thieren.}

1) Eine der bedeutungsvollsten Fragen auf dem Gebiete der vergleichenden Physiologie des Centralnervensystems ist die, wie weit in der Thierreihe Bewusstsein, Wille und Empfindung verbreitet sind, und inwieweit Bewusstsein und Empfindung und Wille an das Centralnervensystem oder Theile desselben geknüpft sind. Es wird von einigen Autoren angegeben, dass diese Frage nach der Verbreitung von Bewusstsein einer wissenschaftlichen Discussion unzugänglich sei, weil Bewusstsein nur durch Selbstbeobachtung nachweisbar sei. Die Anhänger dieses Standpunktes übersehen aber, dass Bewusstsein die Function eines ganz bestimmten physiologischen Vorganges ist, nämlich der associativen Gedächtnissthätıgkeit. Sobald die Gedächtnissthätigkeit zur Ruhe kommt, schwindet auch unser Bewusstsein. In der Ohnmacht, im tiefen Schlaf, bei gewissen Vergiftungen schwindet die Gedächtnissthätigkeit und aamit auch das Bewusstsein. Was wir das Ichbewusstsein nennen, ist, wie E. Mach treffend dargelegt hat (1), nichts anderes als der Umstand, dass gewisse Gedächtnissbestandtheile sehr oft, ja fast immer in unseren Empfindungen und Vorstellungen auftreten. Den Complex dieser Gedächtnisselemente bezeichnen wir als das Ich, als unsere Persönlichkeit. Solche Gedächtnissbestandtheile sind beispielsweise das Gesichtsbild unseres Körpers, soweit es ins Gesichtsfeld fällt, gewisse Tastempfindungen z. B. das Tastbild unseres Körpers, das Klangbild unserer Stimme, gewisse Ziele, die wir verfolgen, Interessen und Sorgen, gewisse Gefülılselemente des Behagens oder Unbehagens. Ein Inventar aller Gedächtnissbestandtheile des Ichcomplexes verschiedener Personen würde schon darauf hinweisen, dass das Ichbewusstsein keine bestimmte Einheit ist sondern, wie Mach behauptet, nur eine künstliche Absonderung gewisser Gedächtnissbestandtheile, die in den meisten oder vielen unserer Empfindungen auftreten. Auch in verschiedenen Lebensaltern müssen die Gedächtnissbestandtheile des Ich derselben Person erheblichen Schwank- 
ungen unterliegen. Der Umstand nun, dass das Bewusstsein nur eine Function associativer Gedächtnissthätigkeit ist, erlaubt uns in der That die Frage zu beantworten, wie weit Bewusstsein in der Thierreihe verbreitet ist. Wir können nämlich Bewusstsein nur da erwarten, wo associatives Gedächtniss nachweisbar ist. Wir müssen also zunächst eine bestimmtere Vorstellung geben, wie wir associatives Gedächtniss objectiv nachweisen wollen. ,Wir verstehen unter associativem Gedächtniss diejenige Eigenthümlichkeit, durch welche eine Reizursache nicht nur die ihrer Natur und der specifischen Struktur des reizbaren Gebildes entsprechenden Wirkungen hervorruft, sondern ausserdem noch solche Reizwirkungen anderer Ursachen, welche früher einmal nahezu oder völlig gleichzeitig mit jenem Reiz an dem Organismus angriffen" (2). Der Geruchsreiz einer Blume mag das Gesichtsbild einer Landschaft hervorrufen, in der derselbe Geruchsreiz uns vorher getroffen hatte oder einer Persönlichkeit, deren Bild auf unsere Netzhaut fiel, als wir vorher einmal dieselbe Geruchsempfindung hatten. Unser Gedächtnissorgan muss also die Eigenthümlichkeit besitzen, dass Vorgänge, die gleichzeitig oder nahezu gleichzeitig in demselben vorgehen, Spuren hinterlassen, die zu einer Einheit verschmelzen. Dieser Umstand wird für eine künftige Mechanik der Bewusstseinsvorgänge von der grössten Bedeutung werden. Es ist aber auch ein Beispiel einer solchen Gedächtnissthätigkeit, wenn wir uns auf einen bestimmten Schallreiz, z. B. das Hören unseres Namens, umdrehen. Wir dürfen auf associatives Gedächtniss schliessen, wenn ein Hund auf das Rufen seines Namens in ähnlicher Weise reagirt. Wir dürfen ferner auf associatives Gedächtniss schliessen, wenn ein Thier sich abrichten lässt, auf einen bestimmten Schallreiz zu einem bestimmten Ort zu kommen, um sein Futter zu suchen, orler wenn es überhaupt, sobald es hungrig ist, an einen bestimmten Ort geht, wo man ihm sein Futter gewöhnlich hinstellt. Der optische Reiz des Orts, wo das Futter sich findet und die Hunger- und Sättigungsempfindungen haben nichts Qualitatives gemeinsam, sondern sie waren für das betreffende Thier nur gleichzeitig. Das Verschmelzen oder Verwachsen heterogener aber zufällig gleichzeitiger Vorgänge ist das Kriterium für associative Gedächtnissthätigkeit.

Wir haben immer von associativem Gedächtniss gesprochen, weil das Wort Gedächtniss zuweilen in einem ganz anderen Sinne in der Wissenschaft angewendet wird, nämlich zur Bezeichnung irgend welcher Nachwirkung äusserer Umstände. Man bezeichnet es gelegentlich als Gedächtniss, wenn eine in den Tropen cultivirte Pflanze-niedrige Temperaturen nicht so gut erträgt, wie eine in Norden cultivirte Pflanze 
derselben Species. Hier haben wir es allerdings damit zu thun, dass voraufgegangene Zustände die Reactionsfähigkeit der Pflanze beeinflussen; aber es handelt sich dabei nicht wie beim associativen Gedächtniss darum, dass eine gewisse Reizursache neben ihrer eigenen auch die Wirkungen einer anderen ganz heterogenen Reizursache hervorbringt, bloss weil die letztere in der Vorgeschichte des Individuums zufällig einmal mit jener gleichzeitig eintrat.

Bei der geringeren Widerstandsfähigkeit der im tropischen Klima gezüchteten Pflanze gegen niedere Temperatur dürfte es sich darum handeln, dass die Tropenpflanze chemisch etwas verschieden ist von der im Norden gezüchteten Pflanze derselben Species. In dieselbe Kategorie einer zu weit gehenden Anwendung des Wortes Gedächtniss gehört das Folgende. Viele Motten schlafen am Tag und wachen auf am Abend, wenn es dunkel wird. Hält man sie aber Tage lang ununterbrochen in einem dunkeln Zimmer, so schlafen sie (anfangs wenigstens) deshalb doch nur bei Tage, während sie Abends aufwachen. Dieselben Erfahrungen macht man in den ersten Tagen, wenn man gewisse Pflanzen im Dunkelzimmer cultivirt. Freilich tritt das nur in den ersten Tagen des Aufenthaltes im Dunkelzimmer ein. Man könnte auch hier sagen, dass der Schmetterling oder die Pflanze sich an den Unterschied von Tag und Nacht erinnert. Es handelt sich aber wohl nur darum, dass dem periodischen Wechsel von Tag und Nacht entsprechend innere Veränderungen im Organismus stattfinden, die auch dann noch eine Zeit lang in derselben Periodicität fortdauern, wenn das Thier ununterbrochen im Dunkeln bleibt (2).

Die Frage nach der Terbreitung von Bewusstsein in der Thierreihe wird somit auf ein der objectiven Bestimmung zugängliches Kriterium zurückgeführt, nämlich wie weit associatives Gedächtniss in der Thierreihe verbreitet ist. Wir finden associatives Gedächtniss wohl bei den meisten Säugethieren. Der Hund, der auf das Rufen seines Namens reagirt, der vor der Peitsche davonläuft, der seinen Herrn freudig begrüsst, hat associatives Gedächtniss. Bei Vögeln ist dasselbe ebenfalls vorhanden. Der Papagei, der sprechen lernt, die Taube, die ihren Schlag wiederfindet, haben Gedächtniss. Dasselbe lässt sich aber auch bei niederen Wirbelthieren nachweisen. Laubfrösche, welche sich abrichten lassen, auf ein Geräusch hin an eine bestimmte Stelle zu kommen, um Futter zu empfangen, haben ebenfalls Gedächtniss. Bei anderen Fröschen z. B. Rana esculenta ist einstweilen keine Reaction bekannt, welche mit Sicherheit auf associatives Gedächtniss hinweist. Bei einzelnen Fischen ist anscheinend Gedächtniss vorhanden, bei Haifischen ist die Existenz desselben aber wohl schon zweifelhaft. Den grössten Schwierigkeiten 
sehen wir uns aber bei Wirbellosen gegenüber. Die Angaben von Enthusiasten, welche überall Bewusstsein und Menschenähnlichkeit erblicken, sind mit der grössten Vorsicht aufzunehmen.

2) Bei meinen Versuchen über die Tropismen war es mir klar geworden, wie leicht ein anthropomorph denkender Beobachter die rein maschinenmässigen Wirkungen äusserer Reize auf niedere Thiere für den Ausdruck von Intelligenz ansehen kann. Er braucht nur die Analyse der äusseren Reizursachen zu unterlassen, un überall menschenähnliche Intelligenz bei seinen Thieren zu entdecken; genau so wie der Wilde, der die physikalische Analyse unterlässt, in der Sonne und dem Fener Götter, d. h. menschenähnliche Wesen entdeckt. Ich habe mich in einer Reihe von Arbeiten gegen diese Anthropomorphismen von Romanes, Eimer, Nagel etc. ausgesprochen (3) und darauf hingewiesen, dass nur der Nachweis von associativem Gedächtniss als ein Kriterium für Bewusstsein oder besondere Erscheinungsformen desselben, z. B. Intelligenz, gelten könne. Auch die Anthropomorphismen der Beobachter des Ameisenlebens konnten mich nicht überzeugen, dass dieser Nachweis für die Wirbellosen bisher sicher erbracht sei. Meine Zweifel sind bestärkt worden durch die schönen Untersuchungen von Bethe an Ameisen und Bienen (4). Bethe nimmt ebenfalls das associative Gedächtniss als Kriterium für Bewusstsein an, wie ich das vor ihm gethan hatte; meine Arbeiten über den Gegenstand, sowie über die Tropismen der Thiere sind ihm offenbar unbekannt geblieben.

Das Kriterium lautet bei Bethe folgendermaassen; „Ein Thier, das am ersten Tage seines Daseins schon dasselbe auszuführen im Stande ist, wie an seinem Lebensende, das Nichts lernt, das auf denselben Reiz immer in derselben Weise reagirt, besitzt nachweislich keine Bewusstseinsvorgänge." Diese Definition reicht nicht aus. Es ist möglich, dass ein Thier nach der Geburt oder dem Ausschlüpfen noch nicht völlig entwickelt ist (wie z. B. der Mensch). Es kann dann später Leistungen ausführen, die es am ersten Tage nicht ausführen konnte, ohne dass deshalb diese Leistungen erlernt waren. Ich gebe daher meinem früher dargelegten Kriterium des associativen Gedächtnisses und des Bewusstseins den Vorzug. Es ist eine bekannte Erfahrung, dass eine Ameise, die in ihr eigenes Nest zurückgesetzt wird, nicht angegriffen wird, während eine zu einem anderen Neste gehörige in vielen Fällen angegriffen wird. Man hat hier von Gedächtniss und von Feindschaft und Freundschaft der Ameisen gesprochen. Bethe hat nun folgenden Versuch gemacht: Er nahm eine Ameise und wälzte sie in einer Quetschung von Nestgenossen. Wenn diese Ameise zu ihrem Nest zurückgesetzt wurde, so wurde sie nicht angegriffen. Wälzte er aber eine Ameise in einer 
Quetschung von Angehörigen eines „feindlichen" Nestes, so wurde sie ron' ihren Nestgenossen wie ein Thier des fremden Nestes behandelt und angegriffen und getödtet. Es sind also die chemischen Reize flüchtiger Stoffe, welche je nach ihrer Natur die Ameisen indifferent lassen oder sie erregen. Wir brauchen hierbei nicht mehr Intelligenz anzunehmen, wie im Falle der Tentakel der Aktinien, die ein in Fleischsaft aufgeweichtes Stück Filtrirpapier sofort in der höchsten Erregung ,angriffen" und zum Munde führten, während sie ein in Seewasser aufgeweichtes Stück Papier ignorirten. Bei den Tentakeln der Aktinien kommen wir mit der Annahme maschinenmässiger Reizvorrichtungen aus, Gedächtniss ist für die Reaction nicht nöthig. Es ist nicht anders mit dem Verhalten der Ameise. Dass diese Reactionen der Ameisen nicht etwa durch Erfahrung erlernt sind, sondern angeboren sind, hat Bethe dann noch durch besondere Versuche beweisen können. Das "Kennen" von "Freund und Feind" reducirt sich also bei den Ameisen auf verschiedene reflectorische Reactionen, je nach der Natur des chemischen Reizes. Gedächtniss ist hierbei nicht im Spiele.

Man hat es ferner als einen Akt des Gedächtnisses und des Intellects bezeichnet, dass eine Ameise den Weg zu ihrem Nest zurtïckfindet und dass wenn „Kundschafter" in irgend einer Richtung vom Neste Honig oder Zucker entdeckt haben, die Ameisen des Nestes sich alsbald in grosser Zahl zu den Fundort begeben. Dabei sollte auch Mittheilungsvermögen eine Rolle spielen. Dem gegenüber hat Bethe durch sinnreiche Versuche fesstellen können, dass eine Ameise, die einen neuen Weg beschreitet, auf demselben Weg, den sie gekommen ist, wieder zum Nest zurückkehrt. Es muss also etwas, das dem alten Weg anhaftet, als Wegweiser zurück dienen. Kam ein Thier, das auf einem neuen Wege Nichts gefunden hatte, zum Nest zurück, so betrat nie eine neue Ameise diesen Weg. Hatte es aber Honig oder Zucker zurückgebracht, so folgten immer andere Thiere der Spur, die es gegangen war. Es baftet also auch dem Wege etwas von den Stoffen an, welche ron den Ameisen auf diesem Wege getragen werden. Diese Stoffe müssen stark genug sein, um chemotropisch auf die Ameisen zu wirken. Dass diese Annahme Bethe's gerechtfertigt ist, dass in der That Insecten durch chemische Reize von so geringer Intensität afficirt werden, dass ihr Verhalten für uns ans Wunderbare grenzt, kann ich durch folgende Beobachtung beweisen, die gewiss viele Schmetterlingszïchter vor mir angestellt haben. Ich brachte einen weiblichen Schmetterling einer gewissen Species in eine Cigarrenkiste, die ganz verschlossen wurde. Die Kiste wurde in halber Höhe zwischen Decke und Fussboden eines Zimmers aufgehangen und dann das Fenster des Zimmers geöffnet. Zunächst 
war kein Schmetterling der Species weit und breit sichtbar. Nach weniger als einer halben Stunde zeigte sich ein männlicher Schmetterling derselben Species auf der Strasse. Als er in die Höhe des Fensters kam, hemmte er seine Progressivbewegung und kam allmählich gegen das Fenster. Er flog ins Zimmer, ging aber weder zur Decke noch zum Fussboden, sondern flatterte bald in der Höhe der Cigarrenkiste, erreichte dieselbe und blieb auf ihr sitzen. Im Verlauf des Nachmittags kamen noch zwei weitere Männchen derselben Species auf die Kiste. Es müssen also die Schmetterlinge und gewiss noch viele andere Insecten eine Feinheit der chemischen Reizbarkeit besitzen, welche diejenige des besten Spürhundes womöglich noch übertrifft. Ich bin auch deshalb geneigt, Plateau beizustimmen, wenn er den Blumenbesuch der Insecten mehr auf den Geruch der Blumen und Pflanzen zurückführt, als auf deren Farbe und Zeichnung. Denn der dioptrische Apparat der Insecten steht weit hinter dem des menschlichen Auges zurück, während ihre chemische Reizbarkeit der unserer Riechschleimhaut ausserordentlich ïberlegen ist.

Eins der merkwürdigsten Resultate der Versuche von Bethe ist nun, dass die grossen Heerstrassen der Ameisen zwei Pfade enthalten, einen, der vom Neste fortführt und einen, der zn ihm hinführt. Die Spur, die die rom Nest fortschreitenden Thiere hinterlassen, unterscheidet sich chemisch von der Spur, die ein zum Nest gehen des Thier hinterlässt. Bethe bewies das durch Versuche, welche schon vorher Lubbock unternommen hatte, der jedoch zu keinem bestimmten Resultate gelangt war. Bethe richtete es so ein, dass ein Stück einer breiten Ameisenstrasse über eine drehbare Brücke führte. Wenn er diese Brücke um $180^{\circ}$ drehte, während ein Theil der Ameisen zum Nest, ein anderer rom Nest ging, so war es beiden unmöglich, ihren Weg fortzusetzen. Drehte man aber nach einiger Zeit die Strasse wieder um $180^{\circ}$, so dass die Spuren wieder ihre alte Orientirung hatten, so setzten die Ameisen ihren begonnenen Weg fort. Damit stimmt auch eine Beobachtung von Forel, dass „eine Ameise, die man vom Wege aufhebt und wieder auf die Ameisenstrasse setzt, in welcher Richtung man auch ihren Körper orientirt, fast mit absoluter Sicherheit nach derselben Richtung geht, in der sie vorher ging." Das gilt jedoch nur für eine starke Spur, welche oft begangen ist. Dagegen ist eine schwache Spur, welche in einer Richtung führt, geeignet, auch in umgekehrter Richtung zu leiten, wie daraus hervorgeht, dass ein Thier, welches einen newen Vorrath gefunden hat, denselben Weg zum Nest zurückgeht, den es gekommen ist." Was eine Ameise veranlasst, der einen oder anderen Spur (d. h. von oder zum Neste) zu folgen, ist offenbar die Belastung und der Mangel an 
Belastung. Belastung löst reflectorisch den Gang zum Nest hin, Mangel an Belastung den Gang vom Nest fort aus." In dieser WVeise fülurt Bethe die Reactionen der Ameisen, die stets als psychische Leistungen gegolten haben, auf reflectorische Leistungen, den Tropismen rergleichbar, zurück. - Es war geschlossen worden, dass wenn eine Ameise auf einen neuen Torrath stösst, sie dies dem Neste ,mittheile“, worauf dann viele Kameraden sich zu dem neu entleckten Eldorado begeben. Bethe hat nachweisen liönnen, dass es sich in diesen Fällen nur um ein reflectorisches Terfolgen der Spur handelt, dass nichts zur Annahme eines Mittheilungsrermögens zwingt. Auch andere Fälle aus der Ameisennythologie werden von Bethe zergliedert und auf einfache Fälle von reflectorischen Reactionen zurückgeführt.

Wie das angebliche "Sich kennen" der Anjeisen desselben Nestes so ist auch das "Sich kennen" der Bienen desselben Stockes nur ein Anthropomorphisnus. Gewisse Gerïche z. B. die desselben Stockes, lassen die Biene indifferent, während andere Gerüche z. B. eines fremden Nestes Greifreactionen hervor'ufen. Es handelt sich hierbei ebensowenig um ein Erkennen wie bei der Aktinie. Auch bei den Bienen bestreitet Bethe, dass das Finden ihres Weges, z. B. das Zurückfliegen zum Stocke, auf Gedächtniss beruht; er nimmt an, dass es sich hier um angeborene Reactionen auf einstweilen unbekannte Reize handelt. Es müssen aber doch wohl noch weitere Versuche angestellt werden, ehe wir, mit Bethe, behaupten dürfen, dass Ameisen und Bienen keine Spur von Gedächtniss besitzen.

3) Die Möglichkeit eines associativen Gedächtnisses ist bei Spinnen, gewissen Krebsen und Cephalopoden zuzugeben, bei Coelenteraten und Würmern ist aber wohl sicher kein Gedächtniss rorhanden. Damit glaube ich die Grenze des associativen Gedächtnisses bei Wirbellosen eher zu weit als zu eng gezogen zu haben. Man darf sich nämlich hier nicht durch Wortspielereien irre führen lassen. Wir sahen, dass Aktinien in Seewasser geweichte Papierkügelchen verweigern und Fleisch von Muskeln annehmen, obwohl für unsere Geschmacksorgane kein Unterschied existirt. Romanes wïrde das für einen Ausdruck ron Intelligenz erklärt haben, da das Thier ,unterscheide" und ,eine Wahl ausführe". Danach mïsste auch den chemischen Elementen Bewusstsein und Intelligenz zuerkannt werden, denn sie rerbinden sich auch nicht mit jedem beliebigen Element, sondern nur mit bestimmten Elementen. ITas Romanes als "Unterscheidungsvermögen" bezeichnet, ist nichts weiter als ein unpassend gewählter Ausdluck dafür, dass rerschiedene Ursachen verschiedene Wirkungen haben. Diese Verschiedenheit der Wirkungen kann in gewissen Fällen auf associativem Gedächtniss und damit auf 
Bewusstsein beruhen, aber um diese Fälle herauszufinden, müssen wir erst noch nachweisen, dass bei den betreffenden Formen associatives Gedächtniss rorhanden und im Spiele ist. Bei Aktinien aber fallen alle derartigen Versuche, associatives Gedächtniss nachzuweisen, negativ aus. Ich erwähnte die Versuche an Cerianthus, bei denen es mir gelungen war, einen zweiten Kopf unterhalb des normalen hervorzubringen. Der zweite Kopf besass eine Mundscheibe und Tentakel, aber keine Mundöffnung (Fig. 12 S. 33). So oft ich nun auch dem mundlosen Kopf ein Stück Fleisch anbot, so oft nahm er es, machte die energischsten Anstrengungen, es in den IIund zu presseu, der nicht vorbanden war, um es dann fallen zu lassen. Es war keine Rede davon, dass die Tentakel endlich lernten, dass hier alle Mühe und Hoffnung verloren war. Man findet aber auch gewisse Reactionen, die sich bei niederen Thieren nicht beliebig oft hinter einander anstellen lassen. Man darf aber dann nicht schliessen, dass es sich hier um Bewusstseinsvorgänge bandele, und dass das Thier gelernt habe. Es ist eine alte Erfahrung, dass viele röhrenbewohnende Würmer sich plötzlich in die Röhre zurïckziehen, wenn man einen Schatten auf sie wirft. Ich habe diesen Vorgang zuerst analysirt und gezeigt, dass der Schatten nichts damit zu thun hat, sondern dass es sich hier um eine Reaction gegen negative Schwankungen der Lichtintensität handele, vergleichbar der Oeffnungszuckung eines Iuskels. Der Versuch gelingt nun nicht beliebig oft hinter einander, er versagt ïberhaupt leicht. Daraus schliesst Nagel, dass diese Würmer "Urtheilsfähigkeit" besitzen. "Das Thier erkennt, dass die mehrmalige Beschattung nicht auf dem Nahen eines Feindes oder einer sonstigen Gefahr beruhte, vielmehr unschädlich verlief." (Nagel.) Es handelt sich :indessen bei diesen Reactionen um ererbte Formen der Reizbarkeit, die mit Erfahrungen nichts zu thun haben. Das Versagen der Reaction nach öfterer Wiederholung beruht einfach auf einer Nachwirkung des Reizes, wie wir sie ja in der Physiologie der Thiere und Pflanzen so häufig treffen. Die Aunahme, dass so niedrige Thiere, wie augenlose Würmer und Schnecken, Vorstellungen und noch dazu, wie Nagel ausdrïcklich betont, die Vorstellung ,eines nahenden Feindes oder einer sonstigen drohenden Gefahr" besitzen sollen, ist eine ganz willkürliche Behauptung. So hatte auch Graber behauptet, dass die Thiere, die zum Licht gehen, das deshalb thun, weil sie das Licht lieben und Romanes hat geradezu behauptet, dass die Thiere aus Neugier in die Flamme gehen.

Es handelt sich hier aber nur um dieselben heliotropischen Lichtwirkungen, die bei Pflanzen schon lange bekannt waren. Wenn eine Motte ins Licht fliegt, so ist nicht mehr Neugier im Spiele, wie wenn sich ein am Fenster cultivirter Pflanzenstengel gegen das Fenster hin 
kriummt. Oder sollen wir auch hier annehmen, dass der Pflanzenstengel eine Torstellung davon besitze, dass Leute am Fenster rorbei gehen und dass Teugier ilm veranlasse, zum Fenster hinauszusehen? Es lohnt sich nicht, derartigen Anthropomorphismen in der biologischen Litteratur nachzıgehen. Die Biologie kann dieselben mit ebensoviel Recht ignoriren wie die moderne Physik es ignorirt, wenn der Wilde die Dampfmaschine durch ein darin entlaltenes Pferd erklärt. Dagegen erwächst der Biologie die Aufgabe einer systematischen Untersuchung der verschierlenen Thiere auf die Existenz ron associativem Gedächtniss, und die Gesammtheit der Resultate einer solchen Untersuchung wird das Material zu einer künftigen vergleichenden Psychologie liefern.

4) Unsere Bewusstseinsvorgänge bestehen aus bewusstem Emptinden und bewusstem Wollen. Als bewusstes Wollen bezeichnen wir diejenigen Innervationsvorgänge, bei denen wir eine Vorstellung des Complexes der Endempfindungen haben, bevor die Bewegungen abgelaufen sind. Das bewusste Wollen ist also auch eine Function des associativen Gedächtnisses. Diese Auffassung stösst nur dann auf Schwierigkeiten, wenn wir an der veralteten Vorstellung festhalten, dass „wir" wollen, anstatt uns klar zu sein, dass ,es" in uns will (1). Wenn irgend welche Erregungsvorgänge sich bis in die Muskeln ausbreiten können, so wird die Muskelthätigkeit unseren Körper in eine andere Orientirung zur Aussenwelt bringen und einen neuen Empfindungscomplex hervorrufen. Vermöge des associativen Gedächtnisses wird in Zukunft dieser letztere Empfindungscomplex immer wieder anftauchen, wenn derselbe motorische Erregungsvorgang auftaucht. Dabei aber werden wir das Opfer einer merkwürdigen Unvollkommenheit unserer Selbstbeobachtung. Es finden beim bewussten Willensrorgang drei Processe in unserem Innern statt, ron denen eine die Ursache und zwei die Wirkung sind. Die Ursache ist irgend ein Innervationsvorgang, der entweder unmittelbar durch einen äusseren Reiz bestimmt sein kann oder mittelbar, insofern als del' äussere Reiz eine Reihe innerer Veränderungen nach einander hervorruft. In einer solchen Kette ron Vorgängen ist dann der Innerrationstorgang, von dem wir ausgehen, ein einzelnes Glied. Dieser Innervationsvorgang breitet sich in die Muskeln ans und veranlasst eine Bewegung, die Willenshandlung. Das ist die eine Wirkung: Er reranlasst aber auch das Wiederauftauchen der Empfindungen, die den Erfolg der Willkürhandlung das erste Mal begleiteten, und das ist die zweite Wirkung. Nun trifft es sich, dass die letztere Wirkung rascher eintritt und abläuft als die motorische Wirkung; es trifft sich aber ferner, dass der ursprüngliche Innervationsvorgang, der die beiden Effecte, die Ge- 
dächtnisswirkung und die Muskelwirkung veranlasst, meist ganz übersehen wird. so kommen wir zu der falschen Annahme, dass die Gedäclstnisswirkung die Ursache der motorischen Wirkung sei. ${ }^{1}$ ) Die Gedächtnisswirkung des Innervationsvorganges enthält ferner naturgemäss jenen Complex ron Empfindungselementen, die, wie wir oben sahen, das "Ich" ausmachen und so sind die Psychologen, die sich bloss auf Selbstbeobachtung stiitzen, zu der völlig verfehlten Idee gekommen, dass das „Ich" will oder dass "wir" die treibende hraft der Willensvorgänge sind. Wir werden also auch nur bei solchen Thieren von Willen reden dürfen, bei denen die Existenz von associativem Gedächtniss nachgewiesen ist.

Wir müssen hier aber auch hinzufügen, welchen Sinn es hat, von Verantworthichkeit und Willensfreiheit zu sprechen. Wenn wir keinen metaphysischen Willen anerkennen, so erkennen wir auch keine metaphysische Willensfreiheit an. Aber daraus folgt noch nicht, dass erlaubt ist, was gefällt. Die Thatsache, dass das gebrannte Kind das Feuer scheut, enthält in nuce das ganze Problem der Willensfreiheit. Erfahrung und Erziehung füllen das Gedächtniss des modernen Menschen mit einer genügenden Menge ron Associationen, die hemmend in die motorischen Vorgänge eingreifen können (wo diese Vorgänge dem Codex der sogenannten Ethik zuwiderlaufen). Fehlen bei einem Menschen trotzdem diese Hemmungen, so weist das entweder auf einen organischen Fehler oder auf einen Fehler der Erziehung hin, wofür freilich in den meisten Fällen die Eltern oder richtiger die Gesellschaft verantwortlich ist. ${ }^{2}$ )

Das Strafverfahren ist vielleicht insofern physiologisch gerechtfertigt, als es hemmende Associationen herbeiführt resp. die hemmenden Associationen schwächerer Mitglieder der Gesellschaft zu kräftigen im Stande ist. Allein es ist zu berücksichtigen, dass die wirksamen Hemmungen in der Jugend anerzogen werden müssen und dass in dem Alter, wo

$\left.{ }^{1}\right)$ Ich stehe hiermit im Wesentlichen auf dem Standpunkt, den Münsterberg in diesen Fragen einnimmt.

2) Niemand hat die Absurdität der Hegel'schen Metaphysik, die ihrer Zeit selbst von ernsten Köpfen ernst genommen wurde, erbarmungsloser aufgedeckt als Schopenhauer, und es ist geradezu tragiseh, dass derselbe Antor sich ebenfalls Hals über Kopf in die Metaphysik gestürzt hat, nämlich mit seinem „Willen“ in der Natur. Er sah im Tischrücken de.. Ausdruck jenes „Willens“ und erwartete, dass der Schwindel des Tischrückens seiner Philosophie zur danernden Anerkennung lrelfen werde. In einem Anflug guter Laune schrieb er darüber in einem Briefe:

„Der Wille, der die Welt

Gemacht hat und erhält,

Er kann sie auch regieren.

Die Tische geh'n auf Vieren." 
das Strafgesetzbuch in Wirksamkeit tritt, die Erziehung meist zu spät kommt. Grausamkeit des Strafgesetzbuches und die Tendenz, Strafen nach der strengen Seite zu übertreiben, ist das sichere Zeichen einer niedrigen Civilisation und mehr noch cines unvollkommenen Zustandes des Erziehungswesens in Familic und Schule. - Der völlig metaplıysische Character der Frage nach der „Freiheit des Willens" berlarf keiner weiteren Erläuterung, sobald man sich einmal darüher klar ist, lass nicht ,wir" wollen, sondern dass, „es" in uns will. Das Spiel der Hemmungen der motorischen Associationen hat im Zusammenhang mit den principiell rerfehlten Annahmen über dic Natur des Willens zu dem metaphysischen Problem der Freiheit des Willens gefühırt.

Was die Empfindungen betrifft, so sind sie eben nur so lange in uns vorhanden, als unsere associative Gedächtnissthätigkeit oder Bewusstsein functionirt. In der Chloroformmarcose, in tiefer Ohnmacht, im tiefen Schlaf ist unsere Gedächtnissfähigkeit aufgehoben und wir empfinden auch nichts. Man sagt, dasś im Anfang einer Ohnmacht noch Empfindungen vorhanden sind. Aber das ist nur dann der Fall, wenn am Anfang der Ohnmacht noch nicht alle associative Gedächtnissthätigkeit erloschen ist. Im Traume ist ja ebenfalls eine lückenhafte und geschwächte Gedächtnissthätigkeit vorhanden und entsprechend treten Empfindungen auf. Ich glaube, wir dürfen es als eine sichere Thatsache ansehen, dass nur da und insoweit Empfindungen vorhanden sind, als associatives Gedächtniss vorhanden ist.

5) Unserer Auffassung erwächst eine scheinbare Schwierigkeit darin, dass Reize, welche bei uns Schmerzempfindungen herrorrufen, auch bei niederen gedächtnisslosen Thieren Reactionen auslösen, welche sehr leicht für den Ausdruck von Schmerzempfindungen angesehen werden können Was liegt näher als zu schliessen, dass solche Thiere wirklich Schmerzempfindungen besitzen? Der verletzte Wurm krimmt und windet sich und es ist schwer, sich dem Eindruck zu entziehen, dass diese Bewegungen dem heftigsten Schmerz entspringen. Und doch hat WV. W. Norman nachgewiesen, dass diese Schlussfolgerung gänzlich unberechtigt ist (5). Er beobachtete nämlich, dass wenn man eimen Regenwurm der Quere nach durchschmeidet, nur das hintere Stück diese Windungen und krümmenden Bewegungen macht, während das vordere Stück fortkriecht, als ob nichts passirt sei. Es wäre natürlich absurd anzunehmen, dass nur das hintere Stïck der Schmerzempfinılung fähig sei, während das vordere hirnbegabte Stück keine Schmerzempfindung besitze. Die ganze Schlussfolgerung, dass dieses Winden und Sichkrümmen ein Ausdruck der Schmerzempfindung sei, wird noch hinfälliger durch folgende Beobachtungen. Fährt man nämlich mit den Durchschneidungss- 
versuchen fort und theilt man die hintere Hälfte des Wurms durch einen Schnitt in der Witte, so kriecht das vordere Theilstïck der hinte-ren Hälfte des Wurms ruhig fort, als ob nichts passirt sei, während das hintere Theilstïck wieder die windenden Beregungen zeigt. Ebenso fälıt eine weitere Durchschmeidung der vorderen Hälfte des Thieres aus. Das vordere Theilstïck kriecht weiter, während das hintere Theilstïck anscheinend heftige Schnerzbewegungen zeigt. Wie man also auch den Wurm durchschneidet, stets zeigt das nach vorn von der frischen Schnittstelle gelegene Stück geordnete Kriechbewegungen, während das nach hinten gelegene Stück windende und krïmmende Bewegungen macht. Es handelt sich also darum, dass der Schnittreiz andere Wirkungen anslöst. wenn er sich nach vorn durch das Thier ausbreitet, als wenn er sich nach rückwärts ausbreitet. Breitet er sich nach vorn aus, so velursacht er geordnete Progressirbewegungen. Breitet er sich nach hinten aus, so kommen ungeordnete windende Bewegungen zu Stande. Es ist also röllig unberechtigt, aus solchen Bewegungen zu schliessen, dass das Thier Schmerzempfindungen besitze.

Diese Beobachtung Norman's ist deshalb werthroll, weil sie zeigt, dass da, wo kein Gedächtniss vorhanden ist, auch der Schluss auf Schmerzempfindungen bedenklich ist. Sie unterstïtzt also unsere Schlussfolgerungen ïber dic Verbreitung des Bewusstseins in der Thierreihe in willkommener Weise. Aber es sind noch andere Thatsachen vorhanden, die dasselbe beweisen. Ich hatte schon früher gefunden, dass Planarien, wenn man sie quer durchschneidet, kein Zeichen von Schmerz geben. Das Vorderstück kriecht rorwärts, als ob nichts geschehen sei (2). Im äussersten Falle schwimmt oder kriecht es etwas rascher. Bethe hat beobachtet, dass man einer Biene, während sie Honig saugt, das Abdomen abschneiden kanu, ohne dass das sie in ihrer Beschäftigung stört (6). Ich habe 1888 Aehnliches an kleinen Krebsen Gammarus, während der Copulation beobachtet. Nan kann dem auf dem Rücken des Weibchens sitzenden Männchen das Abdomen abschneiden, ohne dass es das Weibchen loslässt. Ja, wenn mich mein Gedächtniss nicht täuscht, so waren diese des Abdomens beraubten Männchen, wenn man sie rom Weibchen losriss, bereit, ein neues zu umklammern, sobald sie eines solchen habhaft werden konnten. Natürlich lebten diese verwundeten Thicre nicht lange. Wir sehen jedenfalls, dass kein zwingender Grund rorhanden ist, bei Thieren, die kein associatives Gedächtniss besitzen, auf die Existenz von Empfindungen zu schliessen.

Es ist aber bisher eine Seite der Empfindungen unberücksichtigt geblieben, nämlich die rein subjective Seite derselben. Wir können analysiren, welche Umstände eine bestimmte Empfindung hervorrufen, aber 
Kriterien für die Constatirung von Bewusstsein bei niederen Thieren.

wil können einstweilen nicht angeben, wie es komme, dass wir gerade grewisse Kategorien rou Empfindungen besitzen. Die beste Auseinandersetzung iiber die objective und subjectire Seite der Empfindungen findet sich in Mach's Analyse der Empfindungen (1). Ein befreundeter Psychologe hat mir den Einwand erhoben, dass in meiner Auffassung der Bewusstseinsvorgänge als Function der associativen Gerlächtnissthätigkeit die ,pșehologische“ Deutung der Gedächtnissthätigkeit vermisst werde. Ich habe darauf zu erwidern, dass ich den Gedäehtnissvorgang für einen rein physikalisehen Vorgang halte und dass ebensowenig eine psychologisehe Dentung desselben nöthig ist, wie eine psyehologische Deutung des Phonographen nöthig ist.

\section{Litteratur zu $\mathrm{Xr}$}

1) Nach, E. Beiträge zur Analyse der Empfindungen. Jena 1886.

2) Loeb, J. Beiträge zur Gehimphysiologie der Würmer. Pflüger`s Archir,Bd. 56 .

(Diese Abhaudlung enthält, so viel mir bekannt ist, die erste Darlegung, dass die associative Gedächtnissthätigkeit das Kriterium für die Existenz von Bewusstsein in der Thierreihe bilden muss. Denselben Gedanken habe ich dann später in zwei Schriften, Zur Psychologie und Physiologie der Aktinien, Pflüger's Archis, Bd. ă9, 1596, uud „Zur Theorie rer physiologischen Licht- and Schwerkraftwirkungen“, Pflüger's Arehiv, Bd. 66, 1S97, ausführlicher begründet. Ich erwähne das, weil meine Arbeiten von Bethe, der später (189S) einen ähnlichen Standpunkt eingenommen hat, übersehen worden sind.

3) Itoeb, J. Weitere Bemerkungen über den Heliotropismus der Thiere und seine Uebereinstimmung mit dem Heliotropiswus der Pflanzen. Pflüger's Archiv, Bd. 47. Siehe anch Vorlesung: Zur Theorie der thierischen Instincte.

4) Bethe, A. Dürfen wir den Ameisen und den Bienen psychisehe Qualitäten zuschreiben? Pflüger's Archiv, Bd. 70. 1898.

5) Norman, W. W. Dürfen wir aus den Reactionen niederer Thiere auf Schmerzempfindungen derselben schliessen? Pflüger's Archir, Bd. 67. 1897.

6) Bethe. Functionen des Centralnervensystems der Arthropoden. Pflïger's Archw, Bd. 68. $189 \%$.

7) Münsterberg. Die Willenshandluug. Freiburg 1858. 


\section{XVI.}

\section{Gehirn und Bewusstsein.}

1) Die Anschauung, dass Bewusstsein nur eine Function einer bestimmten maschinellen Vorrichtung ist, nämlich des associativen Gedächtnisses, findet eine Stütze in den Erfahrungen an höheren Thieren. Wir finden hier, dass das associative Gedächtniss mit der Entfernung des Grosshirns schwindet und dass nach einer solchen Operation nichts mehr vorhanden ist, was wir als Bewusstseinserscheinung zu deuten in Stande wären.

Entfernt man bei einer Rana esculenta oder temporaria das Grosshirn, so ist der Frosch dasselbe Thier, das er auch vorher gewesen ist. Das ist durclı die Arbeiten von Schrader über jeden Zweifel erboben (1). Ein solcher des Grosshirns beraubter Frosch fängt noch Fliegen, er gräbt sich, wenn die kalte Jahreszeit kommt, in den Schlamm ein, er wechselt mit seinem Aufenthalt auf dem Lande und im 'Wasser' ganz wie ein normaler Frosch. Aber alle die erwähnten Vorgänge sind keine Function des associativen Gedächtnisses, sie beruhen auf ererbten Reactionsfähigkeiten. Der Frosch hat kein associatives Gedächtniss, oder wenn eine Spur davon vorhanden sein sollte, so tritt es jedenfalls so weit zurück, dass der gänzliche Ausfall desselben keinen Unterschied im Verhalten des Frosches zurücklässt. So erklärt es sich, warum der Verlust des Grosshirns, der die Persönlichkeit eines höheren Thieres so gewaltig ändert, einen Frosch intact lässt. Was wir beim Frosch finden, finden wir auch beim Haifisch. Auch hier ist in den Gewohnheiten und Reactionen des normalen Thieres wenig oder nichts von einem associativen Gedächtniss wahrzunehmen. Was an Reactionen existirt, ist im Wesentlichen ererbt. Entsprechend finden wir, dass Entfernung des Grosshirns das Thier ziemlich unverändert lässt. Trotz dem Ausfall des Grosshirns bleiben alle segmentalen Reflexe erhalten und die meisten Reactionen dieser Thiere setzen sich nur aus segmentalen Reflexen zusammen. Das Grosshirn ist gewissermaassen nur ein Anhang an das segnentale Nerkensystem. - Aber auch da, wo kein Gedächtniss vor- 
handen ist, kann das Grosshirn doch modificirend in das spiel der segmentalen Reflexe eingreifen. Bei Nattern sind beispielsweise auch nach Verlust des Grosshirns noch alle segmentalen Reflexe erlalten. Aber doch zeigten solche Thierc, wie Schrader gefunden hat, keine Furcht mehr, es gelang nicht mehr, sie zu erschrecken, obwohl die Opticusreflexe alle noch thätig waren (2). TVir müssen daraus schliessen, lass Erregungen, welehe von dem Opticussegment aus sich in Centralnervensystem verbreiten, andere Wirkungen haben können, solange das Grosshirn existirt, als wenn es entfernt ist. Auch beim Frosch zeigt sich bereits etwas derartiges. Goltz hat gefunden, dass der Frosch ohne Grosshirn besser ist zur Demonstration ron Reflexen, als der Frosch mit Grosshirn. Reibt man einem Frosch die Rïckenhaut, so quakit er manchmal, manchmal aber auch nicht. Goltz zeigte, dass beim entgrosshirnten Frosch dieser Quakreflex nie rersagt (3). Kein normalen Frosch löst die Berührung der Rückenhaut aber noch einen anderen Reflex ans, nämlich die'Tendenz, davon zn springen. Das Thier, welches noch Grosshirn besitzt, ist ein Reflexthier, wie das entgrosshirnte Thier, d. h. alle seine Reactionen sind lediglich segmentale Reflexe. Aber beim Thier mit Grosshirn kann derselbe Reiz mehr als einen einzigen Reflex auslösen und das ist ein Umstand, der zu der grösseren Complicirtheit und Unberechenbarkeit des Thieres mit Grosshirn beiträgt. Andrerseits kann aber auch das Grosshirn beschränkend in das Spiel der segmentalen Reflexe eingreifen. Der Umarmungsreflex des Froschmännchens bei der Begattung ist ein segmentaler Reflex der Armsegmente während der Brunstzeit. Es scheint, dass Sexualstoffe diesen Reflex bestimmen, da er bei Thieren, die ror ler Brunstzeit castrirt werden, nicht nachweisbar ist. Froschmännchen ohne Grosshirn sind nun viel gleichgültiger in der Auswahl des Gegenstandes, den sie während der Brunstzeit umklammern, als Thiere mit Grosshirn.

2) Anders wie bei Fröschen und Haifischen liegen die Dinge bei Vögeln. Eine genane und in mancher Hinsicht classische Untersuchung der Wirkung, welche die Entfernung des Grosshirns bei Vögeln hat, verdanken wir Schrader (4). Die Arbeit dieses Forschers über das Vogelgehirn gehört neben Goltz' Abhandlung ïber den Hund ohne Grosshirn und Goltz' und Ewald's Schrift über den Hund mit verkürztem Rüickenmark zu den besten Abhandkungen auf dem Gebiete der Physiologie des Centralnervensystems. Es war ein Dogma der Physiologie gewesen (und ist es in vielen Lehrbiichern dieser Wissenschaft noch heute), dass Thiere ohne Grosshirn keine spontanen Bewegungen mehr ausführen. Namentlich Flourens ist für diese Angabe rerantwortlich. Nachrlem Schrader diesen Mythus in Bezug auf den Frosch zerstört hatte, gelang 
es ihm auch, die Unrichtigkeit dieser Angabe für Vögel nachzuweisen. „, Keins unserer Beobachtungsthiere (Tauben) zeigte länger als die ersten 3-4 Tage (nach der Entfernung des Grosshims) jenen schlafähnlichen Zustand, wie ilm Rolando und Flourens beschrieben haben, in dem anscheinend auf bestimmte Reize der Hautsensibilität Bewegungen ausgeführt werden, sonst aber das Thier in absoluter Ruhe verharrt. In dieser Zeit entsprechen die Thiere allerdings vollkommen den bekannten Schilderungen. Sie stehen mit gesträubtem Gefieder und angezogenem Kopf, geschlossenen Augen, oft auf einem Bein, wo man sie hinstellt. $\mathrm{Ab}$ und zu schütteln sie sich, putzen das Gefieder mit dem Schnabel, recken sich wie schlaftrunken, nur bei der Kothentleerung werden einige Schritte gemacht. Lässt man die Thiere in Ruhe, so bekommt man nichts weiter zu sehen. Wirft man sie in die Luft, so fliegen sie schräg abwärts, stossen gegen die Wände und sonstige Hindernisse und kommen mehr fallend anf dem Boden an, um alsbald wieder in ihren Stupor zu rersinken. Reizt man jetzt ihre Haut, so machen sie einige Schritte. rennen dabei auch wohl gegen ein Hinderniss an." Solche Thiere hatte Flourens offenbar vor sich, als er die Behauptung aufstellte, dass Vögel ohme Grosshirn alle Spontanëität verlieren und blind, taub u. s. f. werden.

Aber der Unterschied zwischen den Beobachtungen ron Flourens und denen Schrader's war der, dass im Falle von Flourens' Thieren dieses Verhalten dauernd war, während es bei Schrader's Tauben nur wenige Tage dauerte, bis der Effect des Shockes der Operation rerschwunden war. Das könnte daran liegen, dass Schrader nicht das ganze Grosshirn entfernt batte. Aber daron war keine Rede. Die Versuche Schrader's sind Meisterwerke in Bezug auf Tollkommenheit des Operationsverfahrens und sorgfältige Controlle der Operation durch die Obduction. Der Widerspruch in den Angaben der verschiedenen Autoren rührt, wie so häufig auf deni Gebiet der Gehirnphysiologie, daher, dass die Nebenwirkungen der Operation in einem Falle und bei einem Forscher gross, bei dem andern klein waren, oder dass der eine Autor mehr die schwersten Störungen als die ,gelungenen“ Fälle für seine Publication auswählte, der andere dagegen die leichtesten Störungen. Das letztere ist aber in der Gehirnphysiologie das allein Zulässige, weil ja neben den Störungen, die der Ausfall eines Gehirntheils verursacht, auch noch die Shockwirkungen auf den Rest des Centralnervensystems im Symptomenbild auftreten. Sind die Versuche von Schrader meistergültig in Bezug auf Technik, so gilt das Gleiche ron den Versuchen von Flourens keineswegs, worauf ja schon der treffliche Forscher Magendie, wiewohl vergebens, hingewiesen hatte. 
Sind die ersten Tage nach der Operation rorüber, so sieht man die entgrosshinte Taube den grössten Theil des Tages unermüdlich im Zimmer umherwandern. Die Spontanëität kehrt nicht nur zurück, sie ist sogar eher gesteigert. Das Thier ist nicht blind, sondern seine Bewegungen werden durch Ciesichtseindrücke bestimmt. Es geht (wie der Frosch olne Grosshirn) Hindernissen ans dem Wege. „Bestäubte Glasplatten, ganz durchsichtige Glasglocken wurden ebenso sicher rermieden, wie die Tisch- und Stuhlbeine oder die rerschieden gefürbten Brettchen, mit welchen man ihnen den Weg rerbaute." Es zeigt sich also, dass die Fühigkeit des Rüumlichsehens noch fortbesteht, wenn auch das Grosshirn (und damit, wie wir gleich sehen werden, das associative Gedächtniss) spurlos rerschwunden ist. Wenn man nämlich eine solche Taube ohne Grosshirn in eine unbequeme Stellung bringt, so lässt sie sich nicht etwa an der ersten besten andern Stelle nieder, sondern sie hält Umschan nach allen Seiten und fliegt dinn plötzlich und mit richtigem Ausmaass der Bewegung auf den Gegenstand zu, auf dem sie Platz nimmt. Wie weit das geht, illustrirt die folgende Schilderung Schrader's. „Wir setzen unsere Taube auf die mit Zeugstoff überzogene Platte des Stöpsels einer grossen Glasflasche. Die Unterlage ist gross genug, dass das Thier mit beiden Füssen rollkommen unterstiitzt steht. Die Flasche ist so aufgestellt, dass die Taube sich 1-2 Meter über dem Fussboden befindet. Sie steht in der Nitte eines geräumigen, vollkommen leeren Zimmers. Einige Jinuten sitzt die Taube da mit angezogenem Kopf, gestränbtem Gefieder, im Zustande des Schlafes oder der Hemmnng, dann schüttelt sie sich und beginnt sich herum zu drehen, nach allen Seiten Ausschau zu halten, hierauf duckt sie sich und blickt angestrengt nach unten auf den Fussboden, als wollte sie die Tiefe ausmessen. Sie macht Anstalten herabzufliegen, unterbricht sie aber wieder, wendet sich auf's Neue hin und her und richtet wieder ihre Aufmerksamkeit auf den Fussboden. Dieses Spiel geht so verschieden lange fort, endlich aber fliegt sie in seichtem Bogen herab und lässt sich geschickt auf den Fussboden nieder. Stellen wir jetzt 1-2 Jeter ron der Flasche ein gleich bohes Reck auf und setzen die Taube wieder anf ihren erhöhten Sitz zurück, so sehen wir bald, wie dieselbe viel schneller entschlossen dem Reck zufliegt und auf demselben festen Fuss fasst. Stellen wir nun wieder 1 Meter entfernt einen Stuhl auf, mit der Lehne der Taube zugewandt, so danert es nicht lange und unser Versuchsthier sitzt auf der Stulıllehne." Diese Versuche beweisen, dass das Ausmaass der Bewegungen auch bei solchen Tauben noch durch Gesichtscindriicke bestimmt wird, die alle Gedächtnisseindruicke verloren haben und ausser St:nde sind, neue Gedächtnisseindrücke zu erwerben. 
Die Beobachtung ron Schrader ist auch ron Bedeutung für die Entscheidung der Frage, ob Rammempfindungen eine reine Gedächtnissangelegenheit sind, wie u. A. Helmholtz annimmt, oder ob sie durch angeborene Strukturverhältnisse bestimmt sind, wie beispielsweise Hering behauptet. Für die weitere Erforschung der Bewusstseinserscheinungen ist die Frage rou grosser Bedentung, und so mögen wir hier dieselbe beiläufig erwälnen. Man schliesst, dass die Raumempfindungen erworben sind, weil der Neugeborene noch nicht sofort die Zeichen der Orientirung im Raum giebt, die wir beim Erwachsenen finden. Man übersieht aber dabei, dass der Neugeborene unfertig auf die Welt kommt, d. l. dass viele Strukturverhältnisse, über welche er später verfügt, erst in dem ersten Lebensjahr oder später sich entwickeln. Die Empiristen hatten denselben 'Trugschluss in Bezug' auf das Gehen genacht. Sie sagten, das Kind müisse das Gehen ,erlernen“. Dass das Hühnchen im Stancle ist zu gehen, wenn es aus dem Ei schlüpft, lätte ausreichen könuen, den Irrthum der Empiristen zu verhindern, wenn die Physiologen die Bedeutung der vergleichenden Physiologie früher gewürdigt hätten. Der Unterschied zwischen dem Hühnchen und dem menschlichen Säugling besteht eben darin, dass die strukturelle Entwickelung bei jenem weiter vollendet ist im Augenblick des Ausschlïpfens, als bei diesem, wenn er geboren wird. Das Kind erlernt nicht das Gehen, sondern es geht ,von selbst", sobald die Nerren, Muskeln etc. den für diese Leistung nöthigen Entwickelungsgrarl erreicht haben. Genau so ist es auch mit dem Räumlichsehen. Das eben ausgeschlüpfte Hühnchen sieht räumlich, d. h. es pickt nach Punkten, die sich durch Lichtintensität und Farbe von der Umgebung auszeichnen. Es braucht diese Reaction so wenig zu erlernen, wie ein Pflanzenstengel seine hleliotropische Reaction zu erlernen braucht. Aber ebensowenig braucht auch der Säugling die Raumreactionen zu erlernen. Sie sind "von selbst" da, sobald die embryonale Entwickelung des Säuglings weit genug fortgeschritten ist. Diese Auffassung, wozu die vergleichende Physiologie zwingt, wird weiterhin auf das Wirksamste unterstützt durch die Beobachtung Schrader's (u. früherer Autoren z. B. Longet's), dass das Räumlichsehen bei Vögeln erhalten bleibt, auch wenn das Grosshirn exstirpirt ist. Die Möglichkeit, dass das nur für Vögel aber nicht für Säugethiere gelte, wird durch die entgegenstehende Angabe von Christiani am Kaninchen widerlegt. Dass aber die Raumreactionen durch das Gedächtniss modificirt werden können, dass wir z. B. „lernen“ können, uns vor dem Spiegel zu rasiren oder "lernen" können, trotz prismatischer Gläser richtig zu greifen, widerspricht dieser Auffassung nicht mehr wie die angelernten Leistungen des Tänzers der Thatsache widersprechen, dass das 
Gchen und die geordneten Wischbewegungen des decapitirten Frosches keine Gedächtnisssache sind. Die Thatsache, dass auf der Drehscheibe und durch den constanten Strom geordnete Progressivbewegumgen in der Kichtung der Ebene der Drehung resp. der Stromeurren ausgelöst werden, spricht weiter für diese nativistische Auffassung und unser Hinweis auf die Beziehung zwischen der Orientirung der nervösen Elemente und der Richtung der durch sie bestimmten Bewegungen giebt einen Ausgangspunkt, ron dem aus sich wohl weitere Einsichten gewinnen lassen werden.

Wir wollen nach dieser Abschweifung zu den Versuchen Schrader's zurückkehren. Die entgrosshirnte Taube, die sich den Tag über munter im '/immer umher treibt, schläft in der Nacht. Wir wissen, dass der Schlaf mit Bewusstsein und Gedächtniss nichts zu thum hat, er kommt ja auch bei Pflanzen ror. Es ist selbstrerständlich, dass auch das entgrosshirnte Thier den Unterschied zwischen Schlafen und Wachen zeigt. Zur Zeit der Brunst umwirbt der Täuber das Weibchen mit Gurren. Schrader beobachtete zwei entgrosshirnte Täuber, ., welche mit ganz den Allüren des Verbens lebhaft gurrend fast den ganzen Tag sich im Zimmer umhertrieben." Aber zwischen dem normalen Täuberich und dem entgrosshirnten bestand ein grosser Unterschied, der das Fehlen des associatiren Gedächtnisses schlagend demonstrirt: Setzt man ein Weibchen zu dem entgrosshirnten Täuberich, so bleibt es unbeachtet. Und dieses Fehlen allen Gedächtnisses ist der wesentliche Umstand, der das entgrosshirnte Thier vom normalen unterscheidet. „Für dies entgrosshirnte Thier ist jedes Ding nur eine raumerfüllende Masse, es geht einer anderen Taube ebenso aus clem Wege, wie einem Stein, oder versucht über beide hinwegzusteigen. Uebereinstimmend geben alle Autoren an, dass sie niemals bei ihren Thieren einen Unterschied gefunden, ob ein lebloser Körper oder eine Katze, ein Hund, ein Raubrogel dem Thiere im Wege stand, es hat keine Feinde und keine Freunde, in grösster Gesellschaft lebt es als Einsiedler. Das schmachtende Gurren des Männchens ruft ebensowenig einen Eindruck hervor wie das Klappen der Erbsen oder der Lockpfiff, auf den es in gesunden Tagen zum Futterplatz eilte. Ich habe ebensowenig wie die früheren Beobachter geselien. dass eine entgrosshirnte Taube auf das Locken des Täubers reagirt hätte. Wie das Männchen kein Interesse mehr zeigt füi das Weibchen, so dieses für seine Jungen. Die eben flügge gewordenen Jungen verfolgen die Mutter, unaufhörlich nach Futter schreiend, sie könnten ebenso ğut einen Stein um Nahrung bitten. Die entgrosshirnte Taube ist im höchsten Maasse zalım, sie fürchtet den Menschen ebensowenig wie die Katze und den Raubrogel". 
Fassen wir alle Reactionen der entgrosshirnten Taube zusammen, so kommen wir, wie mir scheint, zu dem Resultat, dass der Verlust les Grosshirns den Ausfall der associativen Gedächtnissthätigkeit bedingt. Was in den Reactionen einer Taube angeboren ist, bleibt nach Verlust des Grosshirns erhalten. Was durch Gedächtnissthätigkeit im individuellen Leben erworben ist, geht nach Verlust des Grosshirns unwiederbringlich verloren.

Un diesen Verlust des Gedächtnisses nach Exstirpation des Grosshirns zi characterisiren, wollen wir noch folgende schöne Beobachtung Schrarler's an einem entgrosshirnten Falken mittheilen (2). Der Falke ist bekanntlich ein guter Jäger. Schrader brachte einen entgrosshirnten Falken zusammen mit Mäusen. Jedesmal, wenn eine Maus sich bewegte und ibre Bewegung im Gesichtskreise des Falken stattfand, stürzte der letztere auf sie und erfasste sie mit seinen Klauen. Während nun der normale Falke in solchen Fällen mit der Maus aufräumt, war für den entgrosshimten Falken die Angelegenheit mit dem Ergreifen der Maus zı Ende. Die associative Gedächtnissthätigkeit fehlte und so war die Maus vergessen, sobald sie keine Bewegung mehr machte. Sobald der Falke sich bewegte, wurde die Maus frei, und sobald sie sich wieder bewegte, stïrzte der Falke wieder auf sie, um aber dann ihre Existenz gleich darauf wieder zu vergessen. Er würde natïrlich in der gleichen Weise sich auf irgend einen leblosen, sich bewegenden Gegenstand gestiurzt haben. Die merkwïrdige Gesellschaft blieb beisammen, bis eines Tages die Mäuse den Falken im Rücken bei lebendigem Leibe auffrassen. Das gedächtnisslose Thier war völlig wehrlos.

Bei entgrosshirnten Thieren besteht nun eine Störung, die nicht mit den Gedächtnissstörungen anf eine Stufe zu setzen ist, nämlich die Unfähigkeit, Nahrung selbstständig aufzunehmen. Bei Fröschen, und nach Steiner's Beobachtungen auch bei Fischen (5) besteht die Fähigkeit selbstständig Nahrung aufzunebmen auch nach der Entfernung des Grosshirns noch weiter. Vögel obne Grosshirn verhungern, wenn man sie nicht füttert. Schrader kam zum Schluss, dass es sich hier um eine Störung der motorischen Innervation handele, welche die Thiere am Aufnehmen der Nahrung hindert. Sie sind nämlich auch nicht im Stande, eine vorn in den Schnabel gesteckte Erbse zn verschlncken, die Erbse muss weiter nach hinten in den Schnabel gesteckt werden. Ich glaube, man darf noch einen Schritt weiter gehen als Schrader und schliessen, dass hier die Spannung gewisser Muskelgruppen, welche für die selbstständige Aufnahme von Nahrung ins Spiel kommen, verringert ist. Wir werden eine derartige Abnahme der Spannung gewisser Muskeln nach Grosshirnverletzung noch kennen lernen. Dabei aber handelt es sich 
um secundäre Wirkungen der Operation auf die noch erhaltenen segmentalen Gebiete des Centralnervensystems, also nicht um eigentliche Grosshirnfunctionen. Es ist dabei auch sehr wahrscheinlich, dass man bei Fortsetzung der Schrader'schen Versuche Vögel finden wird, bei denen die Fressstörungen fehlen. Zu dieser Annahme veranlasst uns die Erfahrung an Fröschen, für die man auch angenommen hatte, dass Ausfall des Grosshirns die Unfähigkeit der Nahrungsaufnahme nach sich zöge, bis Schrader bessere Resultate erzielte.

3) Das kübne Wagniss, einem erwachsenen Hunde das gesammte Grosshirn zu entfermen und ihn dann Monate und Jahre am Leben 7. erhalten, hat Groltz unternommen und mit Erfolg ausgeführt (6). Die Ergebnisse seiner Versuche laufen in Kürze darauf hinaus, dass bei einem solchen Hunde alle diejenigen Reactionen dauernd fehlen, bei welchen das associative Gedächtniss eine Rolle spielt, während die einfachen Reactionen, die sich nur auf ererbte Umstände stïtzen, erhalten sind; ganz wie bei Tauben und den übrigen Thieren.

Der entgrosshirnte Hund schläft und wacht. Beim Wachen reckt er sich wie ein gesunder Hund. Er bewegt sich spontan, d. h. ohne nachweisbaren äusseren Reiz; die Spontanëität der Progressivbewegung findet sich ja auch, um es zı wiederholen, bei den Schwärmsporen von Algen. Die einzige Abnormität der Progressivbewegungen des gehirnlosen Hundes war, dass er nur z u unrubig war. Er ging, wenn er nicht schlief, rastlos im Käfig umher und das war vielleicht der Grund einer auffallenden Tendenz zur Abmagerung bei diesen Thieren. Die eigenthümlichen Stellungen, welche ein Hund beim Uriniren und Kothlassen einnimmt, wurden auch noch ron diesen gehirnlosen Hunden eingenommen. Die Reactionen auf Sinnesreize waren zum Theil normal, soweit kein associatives Gedächtniss dabei nöthig war. Fleisch und Milch wurden gierig verschlungen, aber wenn diese Nahrungsstoffe durch Chinin und Coloquinthen bitter gemacht waren, wurden sie ausgespieen. Kniff man einem solchen Hunde die Pfote, so knurrte er und biss nach der Hand. Stellte man seinen Fuss in kaltes Wasser, so entfernte er ihn alsbald. Als er sich eine Pfote verletzt hatte, war er noch im Stande, auf drei Beinen zu gehen. War er im Schlaf, so konnte er durch das Blasen eines Horns im benachbarten Zimmer aufgeweckt werden. War er im Dunkeln, so schloss er seine Augen, wenn man plötzlich ein grelles Licht in dieselben fallen liess. Er schien aufgerveckter und unruhiger, wenn er hungrig war und ruhiger, nachdem er gefütter't wurde. In Bezug auf das Fressen brachte der grosshirnlose Hund es weiter als die Schrader'schen Tauben. Während den letzteren das Futter tief in den Schlund gesteckt werden musste, bevor sie es schluckten, brauclite 
man dem grosshirnlosen Hunde die Fleischischüssel nur an die Nase zu halten. Sobald die Schnauze mit dem Fleisch in Berührung kam, fing der Hund an zu fressen. Allerdings bestanden hierbei motorische Störungen. Diese letzteren, wie der Umstand, dass solche Hunde Hindernissen nicht aus dem Wege gingen, und sich in dieser Hinsicht wie blinde Hunde verhielten, darf man wohl als Nebenwirkungen auf die subcorticalen Opticussegmente ansehen, welche durch die Operation ausgeübt wurden. Der Hund war noch im Stande zu bellen und zu heulen. Aber alles, was associatives Gedächtniss erheischt, war bei diesen Hunden ausgefallen. Der Hund war nicht im Stande, seine Nahrung zu suchen. Er erkannte seinen Herrn nicht melir und ebensowenig seine Spielgenossen. Er hörte, aber Scheltworte machten keinen Eindruck auf ihn, ebensowenig wie Schmeichelworte. Es war ilım unmöglich, sich aus irgend einer unbequemen Lage zu ziehen. Brunst wurde bei diesen Thieren nicht melr beobachtet. Sie entsprechen im Wesentlichen den gehirnlosen Tauben Schrader's, nur mit den Unterschiede, dass die Nebenwirkungen der Operation auf die erlualtenen Theile des Centralnervensystems bei Hunden stärker sind als bei Tauben. Das mag rein technische oder anatomische Gründe haben, es könnte aber auch auf einer grösseren Empfindlichkeit des Centralnervensystems bei Hunden beruhen. Man muss an die letztere Möglichkeit denken, im Hinblick auf die Thatsache, dass Herderkrankungen im menschlichen Grosshirn häufig ron Lähmungen der Extremitäten begleitet sind, während das bei Hunden nie der Fall ist. Dieser Unterschied zwischen Hund und Mensch zeugt von einem Unterschied der Empfindlichkeit der nervösen Organe und diesem Unterschiede dürften möglicher Weise chemische Unterschiede zu Grunde liegen.

Der Verlust der associativen Gedächtnissthätigkeit ist also die wesentliche Störung, die nach Verlust des Grosshirns eintritt. Beide Thatsachen, dass bei Thieren, welche normaler Weise kein Gedächtniss besitzen, Verlust des Grosshirns keine Störung lerbeiführt, während bei Thieren mit Gedächtniss das letztere nach Verlust des Grosshirns verschwindet, beweisen, dass das Grosshirn für die Gedächtnissthätigkeit nöthig ist.

5) Pflüger hat vor vielen Jahren die Anschauung rertreten, dass auch das des Gehirns beraubte Thier Bewusstsein besitze (7). Er schloss das aus den Reactionen decapitirter Thiere. Wenn man den Schwanz eines decapitirten Aales an einer Seite sanft reibt, so schmiegt sich der Schwanz an den Finger, berïhrt man ihn dagegen mit einem brennenden Streichholz, so wendet er sich ab. Aus diesen und ähnlichen, zweifellos richtigen Beobachtungen schloss Pflïger, dass das Rückenmark Bewusstsein besitze. Die Behauptungen Pflüger's erregten 
eine lebhafte Discussion. Die Gegner konnten seine Schlïsse nicht direct widerlegen, aber sie brachten Argumente vor, welche zeigen sollten, dass dem Rückenmark Bewusstsein fehlt. Tor Allem sind hier die geistreichen Versuche von Goltz zu erwälınen. Dieselben laufen darauf hinaus, dass der decapitirte Frosch nicht im Stande ist, sich aus der Verlegenheit zn ziehen. Setzt man einen geblendeten, aber sonst normalen und einen enthirnten Frosch zusammen in einen Trog mit Wasser und beginnt man das Wasser langsam zu erhitzen, so wird, wenn die Temperatur des Wassers steigt, der geblendete Frosch unruhig. springt umber und rersucht trotz seiner Blindheit aus dem Gefäss zu entkommen. Der enthirnte Frosch bleibt dagegen ruhig sitzen und die Wärmestarre überrascht ihn in der Stellung, welche er ursprünglich eingenommen hatte. Das spricht natürlich gegen die Anwesenheit ron Bewusstsein im Rückenmark. Aber da damit die Unrichtigkeit der Schlüsse ron Pflüger nicht direct bewiesen war, so blieben die Meinungen getheilt. Ich glaube, wir sind jetzt in der Lage nachzuweisen, dass die Beobachtungen ron Pflïger eine ganz andere Erklärung nicht nur zulassen, sondern bedingen und dass es unrichtig ist, sie zum Kriterium von Bewusstsein zu machen. Es handelt sich nämlich beim Versuch mit dem Aalschwanz um Tropismen. Der Aal ist positir stereotropisch. Genau so wie Nereis und viele Insecten, wie die Stolonen von Hydroidpolypen und die Wurzeln vieler Pflanzen ist der Aal gezwungen, seinen Körper möglichst allseitig mit festen Körpern in Berührung zu bringen. Er bält sich meist in Spalten auf. Das ist so wenig ein Bewusstseinsrorgang wie das Einbohren der Wurzel in den Sand. Es findet sich in jedem Segment des Aales und wenn man ihn auf einer Seite mit dem Finger berülıt, so treten positiv stereotropische Krümmungen nach dem Finger ein. Der Reiz der Reibung erböht die Spannung der Mruskeln auf der gereizten Seite. Nehmen wir aber einen brennenden Körper, so erhalten wir eine Erschlaffung derjenigen Muskeln, die den Körper nach der gereizten Seite bewegen. Die Temperaturerhöhung bringt vielleicht so starke oder abnorme Stoffumsätze in der gereizten Hautpartie hervor, dass eine Abnahme des Tonus der Hautelemente und der damit verbundenen Protoplasmagebilde (der Nerren und Muskeln) entsteht. Der Körper wird nach der entgegengesetzten Seite bewegt. Auch hier ist das Bewusstsein nicht mehr betheiligt, als wenn wir ein positir heliotropisches Thier durch Temperaturerhöhung negatis heliotropisch machen. Ich habe dieses Beispiel deshalb ausgewählt, weil es auch zugleich zeigt, wie das Thatsachenmaterial der rergleichenden Physiologie und namentlich die Tropismen Schwierigkeiten in der Physiologie der höheren Thiere zu beseitigen im Stande sind. - Es weisen so alle That- 
sichen der Psychologie und Physiologie darauf hin. rlass das Bewusstsein eine Function des associativen Gedächtnisses ist. Das associative (redächtniss setzt bestimmte maschinelle Vorrichtungen voraus, die einstweilen noch unbekannt sind und deren Ermittelung das Hauptproblem der modernen Gehimphysiologie ist. Es ist aber zweifellos, dass diese Vorriclitungen bei Wirbelthieren wahrscheinlich entweder ausschliesslich oder wesentlich im 'Grosshirn sich finden, oder dass das Grosshirn ein nothwendiger Bestandtheil für vas Zustandekommen der Bewusstseinsrnrgänge ist.

5) Es ist nun vielfach die Idee verbreitet, dass Bewusstsein sich in der ganzen Thierreihe und in allen Stadien der embryonalen Entwickelung vorfindet, nur in verschiedenen Graden der Ausbildung, je nach dem ontogenetischen und phylogenetischen Entwickelungsgrad der betreffenden Form. Diese Auffassung muss natïrlich auch den Pflanzen einen niedrigen Bewusstseinsgrad zugestehen. Da die Tropismen bei Thieren die gleichen sind wie hei Pflanzen, so muss Jeder, der annimmt, dass eine heliotropische Reaction bei einem Thiere von einem Bewusstseinsvorgang begleitet ist, auch dasselbe für die Pflanzen gelten lassen. Dann freilich ist aber auch kein Grund mehr vorhanden, der photographischen Platte, die durch Licht afficirt wird, Bewusstsein abzusprechen, denn photochemische Wirkungen bilden ja auch wolıI die Grundlage aller heliotropischen Vorgänge. Damit aber gelangen wir $7 n$ der Annahme, dass Bewusstsein eine Begleiterscheinung aller Veränderungen in der Natur ist. Derartige Anschanungen werden in der That ron einigen Naturforschern vertreten. Die Anhänger dieser Vorstellung können es sich nicht gut denken, dass Bewnsstsein mur bei bestimnten Species von Thieren vorhanden sein soll, bei anderen nicht. Der Darwinismus hat den Gedanken allmählicher Uebergänge so sehr zum Dogma gemacht, dass man nicht mehr den Muth hat, an sprungweise Aenderungen zu glauben, obwohl Mathematik, Chemie und Physili uns auf Schritt und Tritt mit rer letzteren Thatsache vertrant machen. Es mischt sich anch wohl etwas Sentimentalität in diese Annahme der Allbeseeltheit ein. Man denkt sich, dass wie die Zerreissung des Zusammenhangs unseres Körpers uns Schmerz verursacht, so müsse auch rlas Molekül bei seiner Zerreissung Schmerz empfinden. Die vorhin angeführten Erfahrungen an nierleren Thieren zeigen aber, dass wir mit unseren Schlüssen in Bezug auf Schmerzempfindung sehr leicht in die Irre gehen. Mir scheint, dass die Annahme von Schmerzempfindungen bei Infusorien und Pflanzen getrost ins Reich der Mythologie verwiesen werden darf. ron den Schmerzempfindungen der Moleküle gar nicht erst zu reden. 
IIan braucht aber die Annahme allmählicher Entwickelung gar nieht in Abrede zu stellen, um doch zu der Einsicht zu komnen, dass mit einem bestimmten Grade der Entwickelung plötzlich ein qualitatir verschiedenes Gebilde auftritt. Allnähliche Aenderung führt ron der Ellipse zum Kreis, nichtsdestoweniger ist der Kreis ein Gebilde, das bestimmt von rler Ellipse verschieden ist. Stetige Druckerhöhung führt bei hinreichend niedriger Temperatur schliesslich zur Verflüssigung eines Gases, aber die Flüssigkeit hat Eigenschaften, die in rem Gase nicht einmal rudimentäl enthalten sind. Wo chemische Reactionen stattfinden, entstehen neue Combinationen von Figenschatten, die in den einzelnen Bestandtheilen rorher nicht rorhanden waren. Nicht anders hat man sich die Thatsache vorzustellen, dass trotz der Stetigkeit der embryonalen Entwickelung das associative Gedächtniss und damit das Bewusstsein nur von einem bestimmten Entwickelungsstadium an rorhanden sind; die stetige Entwickelung muss erst bis zu einem bestimmten Grade volschreiten, ehe die physikalischen und chemischen Bedingungen gegeben sind, die für das associative Gedächtniss nöthig sind. Was für die ontogenetische Entwickelung gilt, gilt anch für die phylogenetische Entwickelung und so brauchen wir uns nicht zu wundern, dass weder alle Thiere noch alle Thiere mit Grosshirn mit associativem Gedächtniss ausgestattet sind. Der Denkfehler, den wir hier rügen, kann vermierlen werden, wenn wir den 7usammenhang mit rer Physik und Chemie zu wahren suchen. Die Biologie kann keinen sicheren Fortschritt machen, ohne das 'Thatsachengebiet der Physik und Chemie als Grundlage zu benutzen. Wenn wir an dem Gerlanken einer Continuität in der Entwickelung der Lebewesen festhalten, wie die Darwinisten, wenn wir aber zugleich die Errungenschaften der Physik und Chemie im Ange behalten, so ist keine Teranlassung fiir uns vorhanden, in die Mythologie der Allbeseeltheit der Organismen oder gar aller Materie zu gerathen.

Selbstverständlich geben wir zu, dass bei den Thieren, bei denen associatives Gedächtniss rorhanden ist, Unterschiede in der Ausbildung: desselben bestehen. Diese Unterschierle sind der Hauptsache nach Unterschiede der Capacität und Resonanzfähigkeit. Unter Verschiedenheit der Capacität verstche ich den Umstand, dass die Zahl der Gedächtnisselemente, welche das Gehirn, oder besonders das Grosshirn zu fassen uncl zu reproduciren im Stande ist, bei rerschierlenen Formen verschieden ist. Unter Unterschieden der Resonanzfähigkeit verstehe ich sowohl den Umstand, dass beim Entstehen eines grossen Empfindungscomplexes die Gedächtnissbilder, welche Bestandtheilen jenes Complexes entsprechen, leicht auftauchen, als auch den Umstand, dass bein Entstehen einer sehr elementaren Empfindung grösserc Gedächtnissbilıler 
leicht auftanchen, welche jene elementare Empfindung als Bestandtheile enthalten. Was wir als Intelligenz bezeichnen, ist bestimmt durch die Zahl der möglichen Gedäehtnissbilder (die Capacität) und durch die Resonanzfähigkeit. Der letztere Unstand ist vielleicht der wesentlichere, solange die Capacität nicht unter den Durchschnitt sinkt. Der gescheite Kopf unterscheidet sich rom dummen Menschen u. a. durch die Leichtigkeit der Analyse resp. Synthese der auftauchenden Empfindungscomplexe mittelst des associativen Gedächtnisses; d.h. beim langsamen oder dummen Menschen werden nur solche Gedächtnissbilder associativ hervorgerufen, die mit dem erregenden Complex eine sehr weit gehende Uebereinstimnung zeigen; während beim raschen Denker auch solche Gedächtnisscomplexe associativ herrorgerufen werden, die mit dem erregenden Complexe nur in einzelnen Elementen übereinstimmen.

6) Es ist nach den Gesagten klar, dass die absolute Masse des Gehirns nicht der wesentlichste Umstand für die Bestinmmung der Intelligenz scin kamn. Wir finden auch in der That, dass beispielsweise bei verschiedenen Hunderassen die Gehirnmasse ebenso variirt wie das Körpergewicht. Hunde kleiner Rasse aber künnen intelligenter sein als Hunde grosser Rasse. Es folgt auch gleichzeitig hieraus, dass Geistesthätigkeit in einem ganz anderen Abhängigkeitsrerhältniss rom Stoffwechsel des Centralnervensystems steht, wie etwa die Muskelarbeit vom Stoffwechsel des Muskels. Die Leistungsfähigkeit der Muskeln ist proportional ihrer Masse und ähnlich dürfte es sich bei Drüsen verhalten. Die Gehirnwägungen bei Menschen haben collauf bestätigt, dass die Gehirnmasse sobald sie nicht unter ein gewisses Maass sinkt, keine Beziehung zum Grade der Intelligenz erkennen lässt.

Speck, der auf diesen Unterschied zwischen Muskeln und Gehirn zuerst lingewiesen hat (8), hat auch eine andere wichtige Entdeckung gemacht, nämlich dass bei Sauerstoffmangel die associative Gedächtnissthätigkeit zuerst schwindet und dass entsprechend Bewusstsein aufhört. Er athmete sauerstoffarme Luft ans einem Behälter und war genöthigt bei seinen Versuchen zu zählen. Sobald der Partialdruck des Sauerstoffs der Einathmungsluft unter $8 \%$ einer Atmosphäre fiel, vergass er das Zählen und rerlor er alsbald das Bewusstsein, obwohl die übrigen Funetionen seines Körpers keine Aenderung zeigten. Speck schliesst darans, dass das Grosshirn am empfindlichsten gegen Sauerstoffnangel ist. Es ist nicht absolut nöthig, daraus zul schliessen, dass das Grosshirn relativ den grössten Stoffwechsel unter allen Organen hat. Es wäre anch möglich, dass im Grosshirn oder in anderen Organen besonders ungeeignete Stoffwechselproducte entstehen, die durch den Sanerstoff, wenn er in genügender Menge vorhanden ist, unschädlich gemacht 
werden, die aber, wenn der Sauerstoff fehlt, im Kirper circuliren und im Grosshirn giftige Wirkungen ausïben. Dabei braucht das, was wir ats "giftige" Wirkung bezeichnen, nicht gerade eine chemische, sondern kann auch eine physikalische besonders molekularphysikalische Wirkung sein.

Man findet bei Psychiatern gelegentlich die Meinung verbreitet, dass, wenn das Gehirn recht viel Blut erhält, der Körper ein besonderes Glücksgefühl empfinde. Ich entsinne mich eines populären Vortrages eines hervorragenden Psychiaters, in dem derselbe behauptet, dass wenn das Grosshirn sehr viel Blut erhalte, der Besitzer dieses Gehirnes das volle Glïck (?) eines Champagnerrausches geniesse. Der betreffende Psychiater stellt sich offenbar vor, dass, je lebhafter die Blutversorgung, um so besser die Ernährung des Gehirns und mit steigender Ernährung des Gehirns, so wird angenommen, soll auch das Glücksgefühl zunehmen. Unter den Nahrungsmitteln, welche dem Gehirn bei der Erweiterung der Arterien in grösserem Maasse geboten werden, nimmt der Sauerstoff die erste Stelle ein. Früher nahm man an, dass die Menge des Sauerstoffs den Stoffwechsel bestimme, wir wissen aber jetzt mit roller Bestimmtheit, dass innere Vorgänge in den Geweben den Sanerstoffrerbranch bestimmen, vermuthlich Fermentationsrorgänge. Ist genug Sauerstoff im Gehirn vorhanden, um alle reducirenden Substanzen zu oxydiren, so ist der überschüssige Sanerstoff bedentungslos. Dasselbe gilt für alle anderen Nahrungsbestandtheile. Unter normalen Bedingungen ist ohnedies die Sauerstoffversorgung bei der durchschnittlichen Blutsrersorgung des Gehirns ausreichend. Es grehört zu den elementarsten Thatsachen der Physiologie, dass Hebung der Saúerstoffzufuhr über das nothwendige Maass den Stoffwech sel nicht vermehrt. Es stimmt mit dem Gesagten ïbcrein, dass geistige Thätigkeit, wie Speck durch höchst sorgfältige Versuche festgestellt hat, die Oxydationsvorgänge nicht beeinflusst, sowie dass sich überhaupt bis jetzt kein bestimmter Einfluss der geistigen Thätigkeit auf den Stoffwechsel lat nachweisen lassen. Daraus aber darf man nicht etwa schliessen, dass die Gehirnthätigkeit überhaupt olıne stoffliche Aenderungen rerläuft, sondern nur, dass die stofflichen Aenderungen, welche durch geistige Thätigkeit bedingt werden, zu gering sind, um im Gesammtstoffwechsel erkennbar zu sein. Die Bebauptung, dass Erweiterung der Gehirngefässe ein Glïcksgefühl hervorrufe, beruht auf keiner wissenschaftlich begründeten Thatsache. Da wir die Ohnmachten bei Sauerstoffmangel erwälnt haben, so soll hier nur kurz erwähnt werden, dass die Anhänger der Theorie der Allbeseeltheit oder eines „Subbewusstseins“" im Ei die ohnmachtsähnlichen Anfälle zur. Stüitze ihrer Anschauung verwenden. Sie berufen sich darauf, dass im Beginn 
einer Ohnmacht noch dunkele Bewusstseinsvorgänge wie im Traum ablaufen. Wo das der Fall ist, im Traum oder in der Ohnmacht, ist eben die Thätigkeit des Grosshirns noch nicht vollständig unterbrochen, sonder'n nur erschwert oder gehemmt. Ein grosser Theil der Gedächtnissbilder kann nicht auftauchen, der Umfang des Bewusstseins ist rerringert. Die maschinelle Vorrichtung für die associative Gedächtnissthätigkeit geht ja im Schlafe und in der Ohmmacht nicht etwa zu Grunde. sie ist nur in ihrer Thätigkeit theilweise oder rollständig gehemmt. Dieser Zustand ist aber keineswegs vergleichhar dem Zustande des Emhryo, in dem die maschinelle Vorrichtung für das associative Gedächtniss ïberhaupt noch nicht existirt.

Diese Anffassung würde sich gut mit der Ansicht Duval's (9) vertragen, dass im Schlaf wie bei der Anwendung von Chloroform die Protoplasmafortsätze der Ganglienzellen sich zusammenziehen und dass daher rielfach eine Unterbrechung der Continnität und Leitung der Erregung im Centralnervensystem stattfindet. Das Erhaltenbleiben einzelner Associationen im Schlaf und im Traum würde darauf beruhen, dass nicht alle Fortsätze gleichmässig contrahirt sind. Das Zusammenhangslose und Unlogische der Träume würde so seine Erklärung finden. Ich halte es aber für möglich, dass die Erklärung dieser Erscheinungen auf einer chemischen und physikalischen Grundlage und nicht anf einer histologischen Basis erfolgen wirl. Wir finden nämlich auch die Erscheinungen des Schlafes bei Pflanzen in Form der sogenannten nyctitropen Berregungen und hier ist eine Erklärung des Torgangs im Sinne ron Dural wohl unmöglich.

Wir wollen noch einmal einen Umstand besonders betonen: Alle Versuche weisen darauf hin, das das Grosshirn bei Wirbelthieren unumgänglich nöthig ist für die Vorgänge des associativen Gedächtnisses und des Bewusstseins. Aber ich fürchte, dass wir über das Erlaubte hinausgehen, wenn wir sagen, das Grosshirn sei „rlas Organ“ des Bewusstseins. Organ des Bewusstseins könnte sehr wohl das ganze Gehim oder Centralnervenșstem sein, so lange es mit dem Grosshirn rerbunden ist, und das Grosshirn könnte nur ein absolut nothwendiger Theil des Ganzen für die eine Thätigkeit der Gedächtnissassociation sein. Nichtbeachtung dieses Umstandes könnte möglicher Weise für die weitere Entwickelung der Gehirnphysiologie gefährlich werden. 


\section{Litteratur zu XVI.}

1) Sehrader, Max E. G. Zur Physiologie des Froschhims. Pflïger's Arehir, Bi. 11. 1887.

2) Sehrader. Jit Stellung des Grosshirns in Reflexmechanismus. Archiv tür experiment. Pathologie und Pharmakologie. Bd. 29. 189\%.

3) Goltz, F. Beiträge zur Lehre ron den Nervencentren des Frosches. Berlin $181 j$.

4) Schrader, Max E. G. Zur Physiologie des Vogelgehirns. Pflinger's Arehir, Bd. 44. 1889.

5) Steiner, J. Die Functionen des Centralnervensystens und ihre Phylogenest. II. Abth.: Die Fische. Bramschreig 1855.

6) Goltz, F. Der Hund ohne Grosshirn. Ptlüger's Archiv, Bd. 51. 1592.

7) Pfl üger, E. Die sensorischen Functionen des Rï̈ckenmarks. Berlin 15.3.

S) Speck. Physiologie des menschlichen Athmens. Leipzig 1892.

9) Dural, M. Théorie histolugique du summeil. r. R. Soc. de Biol. 1595. 
XVII.

\section{Centrentheorie (Functionslocalisation) und Segmentaltheorie im Grosshirn.}

1) Wir haben uns bemüht darzulegen, dass die vergleichende Physiologie uns zu der Anschauung zwingt, dass das Centralnerrensystem nicht aus einer Reihe von Centren für die verschiedenen Functionen besteht, sondern ans einer Reihe segmentaler Ganglien. Diese Ganglien sind indifferent und nur die verschiedenen Reizbarkeiten der peripheren Segmentalorgane und die Anordnung der Muskeln bedingen die Verschiedenheiten der Reflexe in den verschiedenen Segmenten. Nur die Wachsthumsverschiedenheiten und -verschiebungen modificiren die Monotonie dieses Schemas.

Wir haben nunmehr auseinanderzusetzen, wie sich die sogenannte Functionslocalisation im Grosshirn zur Segmentaltheorie verhält. Das Grosshirn wie das Kleinhirn ist ein Anhängsel an das segmentale Centralnervensystem. Jedes der segmentalen Ganglien ist aber durch besondere Nervenfasern mit dem Grosshirn verbunden. Was man heute als Centren der Grosshirnrinde bezeichnet, sind wohl nur die Einmündungsbezirke der Fasern, welche das Grosshirn mit den verschiedenen segmentalen Ganglien verbinden. Das sogenannte Vorderbeincentrum in der Grosshirnrinde D Fig. 39 ist beispielsweise die Stelle, wo die Fasern von den Ganglien der Brachialsegmente in das Grosshirn einmünden, und wenn Reizung dieses Vorderbeincentrums Zuckungen des Vorderbeins hervorruft, so handelt es sich nur um eine indirecte Erregung der segmentalen Brachialganglien. Es ist aber nicht einmal nöthig, dass die Verbindung zwischen den segmentalen Rückenmarksganglien und dem Grosshirn eine ununterbrochene ist. Es mögen anch Ganglien zwischen beiden Endstationen eingeschoben sein.

Wir wollen nun kurz eine historische Uebersicht über den Ursprung der jetzigen Centrentheorie des Grosshirns geben und dann zur Begründung der segmentalen Theorie übergehen. 
Die moderne Functionslocalisation im Grosshirn ist historisch die directe Eortsetzung der Gatl'schen Phrenologie. Gall, der bekanntlich allen möglichen und unmöglichen "Seelenrermögen“ cinen besonderen Sitz im Grosshirn anwies, unterschied u. a. einen Wortsinn (Wortgedächtniss) und Sprachsinn (philologisches Talent) (1). Er rerlegte diese "Vermögen" in die Stimlappen hinter und über ler Orbita. In den .,Phrenological Transactions" Vol. IIr veröffentlichte Thomas Hood den ersten durch Autopsie illustrirten, genauer beschriebenen Fall von Aphasie aus dem Jahre 182.2. Es fand sich eine Erkrankung des linken Stirnlappens. Der Nächste, der sich eingehend mit der Localisation des "Sprachorgans" im Gehirn beschäftigte, war ein Schüler Gall's, Bouillaud. Nach ihm waren die Stirnlappen, ,principe legislateur de la parole". Er kämpfte für diese Idee vor der Pariser Akademie und in dieser Körperschaft fand er heftigen Widerspruch. Den Zusammenhang mit Gall beweist schon der Titel seiner Hauptarbeit: Recherches cliniques propres ì démontrer que la perte de la parole correspond à la lésion des lobules antérieurs du cerreau, et à coufirmer l'opinion de Mr. Gall sur le siège de l’or-

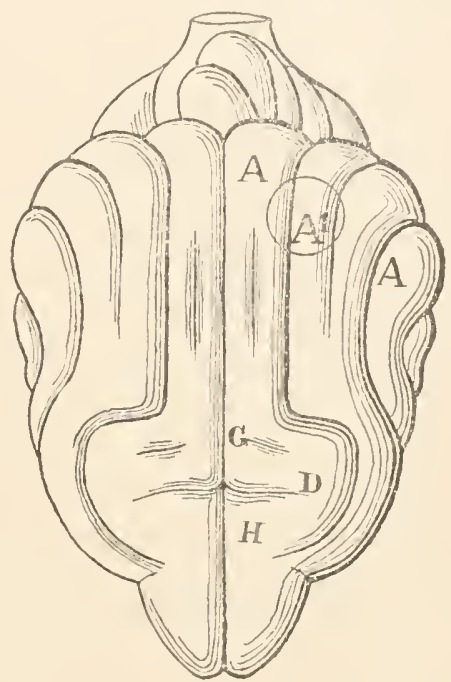

Fig. 39. Grosshirnrinde des Hunles. A 1 A Sehsphäre, G Hinterbeinregion, D Vorderbeinregion, $\mathrm{H}$ Nackenregion. Nach Junk. gane du language articulée. Arch. de Méd. 1825. Dax wies 1836 daranf hin, dass er seit 1800 in allen Fällen von Hemiplegie mit Beeinträchtigung der sprache die Lähmung stets rechts und die Hirnsläsion links gefunden. Sein Sohn brachte 1863 dieselbe These vor die Pariser Akademie, erreste aber den Widerspruch des Berichterstatters, der alle Versuche, die Sprache zu localisiren, schlechthin für Phrenologie erklärte, die er als pseudoscience bezeichnete. Bouilland trat dabei für Dax ein. Man sieht, dass dic erste Localisation des Sprachcentrums eine rein phrenologische Angelegenheit im Sinne Gall's war und ron Freund und Feind auch in diesem Sinne aufgefasst wurde.

Unter den Gegnern Bonilland's in diesen Controversen hatte sich Broca befunden. Es erregte deshalb kein geringes Aufsehen, als dieser Autor 1861 mit einer Arbeit auftrat, in der er die Gall-Bouillaud'sche 
Hypothese alloptirte und noch ferner präcisirte ,es sei die Unrersehrtheit der 3. linken Stirnwindung, und vielleicht der 2. unerlässlich für die Ausbildung des articulirten Sprachrermögens." Es kamen danı die Beobachtungen hinzu, welche im Sinne ron Dax zeigten, dass die linke 3. Stirnwindung ron grösserer Bedentung sei, als die rechte. Broca stellte nummehr eine Hypothese zur Erklärung dieses Torranges der linken Hemisphäre auf, die an die Rechtshändigkeit der meisten Menschen anknüpfte und erklïrte daraus die Fïlle, wo bei angeborenem Mangel der linken 3. Stirnwindung doch die Sprache erlernt wurde. Ein solcher ron Moreau beobachteter Fall wurde ron ihm selbst mitgetheilt. Eine von frühester Kindheit an epileptische 47jährige Person hatte sprechen, lesen und mit der linken Hand näben gelernt, ubwohl ihr die ganze 1. linke Urwindung, welche die Fossa Silvii umgiebt, fehlte. Diese Person war genöthigt, die rechte Grosshirn-Hemisphüre auf das Nähen und Sprechen einzuïben, weil die linke in Folge des Defects der 1. Urwindung dazu nicht befähigt war. - Die Fähigkeit sprechen zu lernen ist somit nach Broca an die Unrersehrtheit mindestens einer 3. Stirnwindung gebunden. Die meisten Menschen ïben nur die linke 3. Stirnwindung darauf ein." (Kussmaul.)

Wir können hier schon zeigen, inwiefern Broca zu weit in seinen Schlüssen ging. Er behauptet, dass diejenige Stelle des Gehirns, deren Zerstörung motorische Aphasie hervorbringt, auch das Organ der Sprachinnervation sei: während die Segmentaltheorie auf eine andere Möglichkeit hinweist, dass nämlich an der betreffenden Stelle die Nervenfasern, wclche das Grosshirn mit den segmentalen Ganglien der Mund- und Kehlkopfnerven in der Medulla oblongata verbinden, in die Rinde einmïnden. Damit Innervationen vom Grosshirn aus diese segmentalen Ganglien und die Sprachnuskeln erreichen, muss die Terbindung des Grosshirns mit diesen letzteren Organen offen stehen.

Es kommt noch ein weiterer Umstand hinzu, welcher oft übersehen worden ist, nämlich die Shockwirkungen, die durch eine Terletzung oder eine Operation im Grosshirn, in dem übrigen Centralnerrensystem entstehen, soweit es mit der rerletzten Stelle durch Fasern verbunden ist Auf Shockwirkungen dürfte es beruhen, das ein Kind, das durch einseitige Erkrankung der betreffenden Grosshirnpartieen ron motorischer Aphasie befallen wird, nicht mehr sprechen lernt, trotzdem es doch noch die andere Hemisphäre besitzt und nummehr doch im Stande sein sollte rlas andere Sprachcentrum der Phrenologen einzü̈ben.

Nachdem Broca seine Unterwerfung unter die Phrenologie angekündigt hatte, ging man in hellen Haufen in's Lager der Centrentheorie ïber. Und dabei beging man, wie immer in derartigen Fïllen, pine 
bittere Ungerechtigkeit. Anstatt Gall, der der Vater dor Localisation des Spracheentrums war, die Ehre zu geben, gab man sie Broca, der in diesem Falle doch nur ein Nachgünger ron Gall und Bouillaud war. Man latte Gall und Bonillaud so lange bekïmpft, dass man 11 n, nachdem man ihre Fchlschlïsse adoptirte, nicht mehr den Muth hatte, das einzugestehen, und diese Ungerechtigkeit haben die Functionslocalisatoren bis auf den hentigen Tag fortgesetzt. Aber jede wissenschaftliche Ungerechtigkeit ist anch gleichzeitig eine sachliche Schädigung der Forschung und hemmt die letztere. Wenn man sich allgemein klar darüher wäre, dass die heutige Functionslocalisation nichts ist, als eine directe Fortsetzung der Gall'schen Phrenologie, so würden Physiologen und Psychologen viel eher bereit sein, die Centrentheorie des Grosshirns mit der nöthigen kritischen Zurückhaltung zu behandeln.

2) Es stellte sich in der Folge mehr und mohr heraus, dass auch bei den apoplectischen Lälımungen der Arme und Beine bestimmte Stellen des Grosshirns mit Vorliebe der Sitz der Erkrankung waren. Namentlich die blutigen Kriege zwischen 1860 und 1870 lieferten ein umfangreiches Material, das die topographische Diagnostik der Herderkrankungen im Grosshirn zu einer sicheren Disciplin erhob. Das Gefïhl der Sicherheit und Berechtigung der Localisation der Herderkrankungen wurde aber ganz besonders erhöht, als es Hitzig und Fritsch gelang, den Nachweis zu führen, dass es bestimmte Stellen im Grosshirn giebt, deren Reizung mit einem relatiren Stromminimum die Bewegun $m$ bestimmter Muskelgruppen hervorruft (2). Sie nannten diese Stellen „Centren“ für die betreffende Muskelgruppe. Derartige Centron für die Bewegung der Vorder- und Hinterbeine, der Nackenmuskeln, fanden sich hauptsächlich in der vorderen Hälfte des Grosshirns, während die hintere sich anscheinend unerreghar erwies. Dieses Resultat von Hitzig und Fritsch erregte noch höheres Aufsehen dadurch, dass die damalige Schulphysiologie behauptet hatte, dass das Grosshirn anf electrische und sonstige Misshandlung nie Bewegungen auslöse. Diese Marotte der damaligen Schulphysiologie war natiirlich rlurch die Versuche von Hitzig and Fritsch widerlegt, und dieser Umstand trug mit clazu bei, den Einfluss ihrer Arbeit zu rermehren. Fritsch und Hitzig machten ihre Reizversuche durch folgende Probe auf die Richtiglieit derselben rollständig: Sie exstirpirten bei zwei Hunden diejenige Stelle der Rinde, deren Reizung Bewegung der rorderen Extremität ergeben hatte, also das Torderbeincentrum (D Fig. 39): Man musste in dem Falle störungen der Extremität heobachten. Das war in der That der Fall. Das linke Torderheincentrum war exstirpirt worden und die rechte Vorderpfote zeigte folgende Störungen: „Beim Laufen setzten die Thiere die rechte Vorder- 
pfote unzweckmässig auf, bald mehr nach innen, bald mehr nach aussen als die andere, und rutschten mit dieser Pfote (nie mit der anderen) leicht nach aussen davon, so dass sie zur Erde fielen. Keine Bewegung fiel ganz aus, indessen wurde das rechte Bein etwas schwächer angezogen. Beim Stehen ganz ähnliche Erscheinungen. Ausserdem kommt es vor, dass die Vorderpfote mit dem Dorsum statt mit der Solle aufgesetzt wird, ohne dass der Hund etwas daron merkt. Man komnte dem Hunde, wenn el rulig dastand, leicht die Pfote in abnorme Stellungen bringen. Aus diesen Beobachtungen ziehen die Autoren folgenden Schluss: Die Thiere, hatten offenbar nur ein mangellaftes Bewusstsein von den Zuständen diesez Gliedes, die Fähigkeit, sich vollkommene Vorstellungen über dasselbe zu bilden, war ihnen abhanden gekommen." Aus der Gesammtsumme aller ihrer Versuche ziehen aber diese Autoren folgenden Schluss: „Es geht ferner aus der Summe aller unserer Versuche herror, dass keineswegs, wie Flourens und die Meisten nach ihm meinten, die Seele eine Art Gesammtfunction der Gesammtheit des Grosshirns ist, deren Ausulruck man wohl im Ganzen, aber nicht in seiuen einzelnen Theilen durch mechanische Mittel aufzuheben vermag, sondern class vielmehr sicher einzelne seelische Functionen, wahrseheiulich alle, zu ihrem Eintritt in die Materie oder zur Entstehung aus derselben auf circumskripte Centra der Grosshirnrinde angewiesen sind." Die Vorstellung, dass "seelische Functionen in die Materie eintreten" oder ,aus ihr entstehen", ist übrigens so ungeheuerlich, dass sie sich der wissenschaftlichen Discussion entzieht.

3) Gegen die Deutung, welche Hitzig seinen Versuchen gegeben hatte, dass ein Centrum der Sitz der Theilseele für das betrefiende Organ sei, führte alsbald Goltz die gewiehtigsten Thatsachen an (:')). Er zeigte, dass in den ersten Tagen oder Wochen nach der Durchschneidung des Rückenmarks in dem unterhalb des Schnittes gelegenen Theile des Thieres keine der segmentalen Reflexe mehr ablaufen. Soll man nun daraus schliessen, dass die segmentalen Reflexe höher oben im Rückenmark localisirt seien? Aber er fand ferner, dass die Reflexe sich einige Wochen nach der Operation wieder einstellen. Soll man zu der metaphysischen Annahme greifen, dass sich im hinteren Rückenmarksstück nach der Operation neue ,Centren" gebildet haben? Ich glaube, es liegt näher mit Goltz zu schliessen, dass die segmentalen Reflexe im hinteren Rückenmarksstïck nur vorübergehend durch die jedem Chirurgen geläufige Shockwirkung der Operation gehemmt waren. Die gleichen Bedenken gelten aber auch für. die Schlüsse von Hitzig, denn die Störungen nach Verletzung eines Vorderbeincentrums sind ebenfalls nur vorübergehend. Wiu citiren, um das Gesagte klarer zu 
machen, einige Stellen aus der Arbeit von Goltz nnd Ewald ,Ueber ren Hund mit rerkürztem Rückenmark:" Sie beschreiben das Verhalten des hinteren Theiles eines Hundes mmittelbar nach. Durchschueidung des Rückenmarkes. „Druck auf die Hinterfüsse löst keine Reaction aus. Bei den männlichen Thier kann keine Erection reflectorisch angeregt werden. Der Harn sammelt sich in der erschlafften Blase an. Der After klafft, kurz der ganze Hinterkörper scheint regungslos gelähmt. Schon wenige Tage darauf kann sich das gewissermaassen scheintodt gewesene Rückenmark fast vollständig erholt haben. Das Hinterthier bietet dann eine ganze Fülle von Reflexerscheinungen dar." (S. 397.) „Niemand wird annehmen, dass das rom Hirn abgetrennte Rückenmarkstück in kürzester Zeit völlig neue ihm bis dahin fremde Fähigkeiten als reflectorisclıes Centralorgan erwirbt, sondern wir müssen schliessen, dass diese Fähigkeiten nur vorübergehend durch die Verletzung des Rückenmarks unterdrückt oder gehemmt wurden." Ebenso verhält es sich mit den Vasomotoren. Durchschneidung des Rüchenmarks setzt den Tonus der Blutgefässe der hinteren Extremitäten herab. Nach einiger Zeit erholen sich die Blutgefässe und werden wieder normal. Ausrottung des in Folge der ersten Durchschneidung rom Gehirn getrennten Rückenmarkstïckes ruft ron Nenem vorübergehend Lähmung der Vasomotoren herror, (wälırend Zerstörung des oberhalb der ersten Durchschneidungsstelle gelegenen Rückenmarks keinen Einfluss auf die Vasomotoren hat). Durchschneidet man nun bei demselben Thiere wieder den Hüftnerren, und zwar an inmer mehr peripher gelegenen Stellen, so tritt jedesmal wieder vorübergehende Lähmung der Vasomotoren ein. Das berveist, dass die bei der ersten Rückenmarksdurchschneidung in den Hinterbeinen aufgetretenen vasomotorischen Lähmungen eine Fernwirkung des Schnittes auf die Gefässmuskeln selber waren. Diese Annahme einer Fernwirkung einer Operation ist übrigens besser gestïtzt als irgend ein anderer Schluss der Nervenphysiologie. Wir erinnern an den Versuch von Cyon ïber die Folge der Durchschneidung der hinteren Wurzeln der Rückenmarksnerven auf die Spannung der Muskeln, welche ron der entsprechenden rorderen Wurzel ihre motorischen Fasern erhalten (4) Die Spannung dieser Muskeln nimmt nach der Durchschneidung der entsprechenden hinteren Wurzel des Rückenmirks ab. Es liegen zwei Möglichkeiten der Erklärung ror: Entweder fliessen ron der Hautoberfläche beständig Erregungsimpulse zu dem Rückenmark und von da zu den Muskeln, welche die Spannung der ietzteren beständig auf einem holien Erregungsgrad erhalten; die Durchschneidung der hinteren IVurzeln verhindert alsdann den weiteren Zufluss dieser Erregungen und daher die Abnahme der Muskelspannung. - Oder die Operation bringt 
eine chemische Veränderung in dem rerletzten Neuron hervor, die sich bis auf den Muskel fortpflanzt und eine Herabsetzung seines Tonus reranlasst. Das Letztere muss der Fall sein, wo es sich um forübergehende Störungen handelt, es kann aber auch der Fall sein, wo die Störung dauernd ist. Eine gute Illustration des Gesagten bieten auch die Beobachtungen ïber Verletzung des inneren Ohres oder über Durchschneidung des Hörnerren. Bei einseitiger Durchschneidung des Hörnerren nimmt die spannung gewisser Muskelgruppen so weit ab, dass alle Glieder in abnorme Stellungen, in Zwangsstellung gerathen. Bei ren Versuchen am Ohr ergiebt sich nun eine Thatsache, die für die Kritik der Functionslocalisation von der allergrössten Bedeutung ist. Die Spannnngsabnahme der Muskeln wird um so geringer, je weiter ihr segmentales Ganglion von den segmentalen Ganglien des Hörnerren entfernt ist. So sind beim Haifisch, dem man ein Ohr exstirpirt hat, die Brustflossen stark um die Längsaxe des Körpers gedreht, während bei den übrigen Flossen diese Drehung um so geringer wird, je weiter sie nach binten gelegen sind. Ganz dasselbe beobachtet man bei Fröschen und Krokodilen: Die Abuahme der Spannung gewisser Muskelgruppen und der Betrag der Zwangsstellung der Extremitäten (welche ja der Ausdruck des Unterschiedes der Spannung der geschwächten Muskeln und ibrer Antagonisten ist) ist am grössten bei den Nackenmuskeln, dann folgen die vorderen Extrenitäten, während sie bei den hinteren Extremitäten noch geringer ist. Der Grund ist leicht einznsehen. Es handelt sich um Widerstände für die Fortpflanzung der Shockwirkung. Mit der Zunahme der Zahl der segmentalen Ganglien, welche der Reiz zu passiren hat, nimmt der Widerstand zu und die Wirkung ab. Die Berechtigung der Uebertragung dieser Daten auf die Beurtheilung der Centrentheorie des Grosshirms sehen wir darin, dass anch die Störungen, welche Hitzig nach Exstirpation der Centren beobachtet hat, nur voriibergehender Natur sind. Das stimmt sehr wohl mit der Segmentaltheorie, aber nicht mit der Centrentheorie des Grosshims. Wir wollen nun im Einzelnen nachweisen, dass die Auffassung ron Goltz resp. die Segmentaltheorie richtig und die Centrentheorie falsch ist, d. h. wir wollen zeigen, dass die sogenannten Centren eben nur die Stellen sind, wo die Fasern von den rerschiedenen segmentalen Ganglien in das Grosshirn einmünden, und dass die Störungen, die nach Verletzung dieser Stellen zm Beobachtung gelangen, im Wesentlichen nur Shockvirkungen sind.

1) Wir beginuen mit den sogenannten Centren der Extremitäten. Sach Hitzig bewirkt die Entfernung des linken Vorderbeincentrums (D Fig. 39) beim Hunde "Terlust des Muskelbewusstseins" der rechten 
Torderpfote. Wir wollen den Unstand, dass wir kein Bewusstein unserer inneren Organe, also auch kein Muskelbewusstsein besitzen, unberïcksichtigt lassen, unıl nur darauf hinweisen, dass die Störungen des angeblichen, ,Huskelbewusstseins" in Wirklichkeit in der Spannungsänderung bestimmter Muskelgruppen und Abnahme der Sensibilität rler. Fxtremität bestehen.

Nach Entfernung des sogenannten Vorderbeineentrums ron Hitrig tritt eine Spannungsabnahme der Strecker der volderen Extremität (und vielleicht auch anderer Muskelgruppen) ein. Die Folge ist, dass rlas Bein leicht ausrutscht und leicht im Fussgelenk einknickt, so rlass das Thier gelegentlich mit rlem Rïcken statt mit rler Sohle des Fusses auftritt. Diese Spannungsabnahme bewirkt auch, dass es leicht gelingt, das Bein zu verschieben, ohne dass der Hund es merkt: Da die Mruskelwirlerstände gegen die Verschiebung geringer sind, so ist ein geringerer Druck auf die Pfote ausreichend, um eine Verschiebung herbeizufüluren. Ausserdem ist aber auch die Sensibilität der Pfote in der betreffenden Pfote verringert. Es berlarf eines stärkeren Druckes, um eine Reaction auszulösen. Der Hund merkt es auch beispielsweise nicht, wenn man ihm die betreffende Pfote in kaltes Wasser stellt. Es handelt sich also hier darum, lass die Exstirpation des "Centrums des Vorderbeins" in der Grosshirnrinde nicht etwa einen Verlust des ,.Muskelbewusstseins" hervorruft, wie Hitzig will, sondern eine Erschlaffung der Strecker des Vorderbeins (und gewisser anderer Muskelgruppen), sowie eine Abnahme der Hautsensibilität. Bis zu einem gewissen Grade ähnliche Wirkungen können durch Durchschneidung ter hinteren Wurzeln der Armnerven hervorgerufen werden. Es wird aber Niemand einfallen, darauf hin zu hehaupten, dass das "Centrum" der Armbewegungen in den hinteren Wurzeln localisirt sei. Dass es sich in der That bei diesen Störungen, die Hitzig beschreibt (und die ich aus eigener Anschaumng kenne), um Abnalme der Spannung der Strecker handelt, wird ferner durch eine Thatsache der vergleichenden Physiologie unterstützt, die ich aber diesmal einem höheron Thier entnehme, nämlich dem Menschen. In Falle der Lähmung eines Armes nach einer Herderkrankung im Grosshirn tritt, nachrem die Lähmung eine Zeit lang bestanden hat, eine Contraction des Armes in Bengestellung ein. Das heweist, lass dieser Arm in Folge der Herderkrankung im Grosshirn nicht gänzlich gelähmt ist, sondern dass nur die Spannung der Strecker abgenommen hat und dass in Folge dessen der Spannungszustand der Benger allein die Stellung des Arnı bestimmt. Das ist aber dasselbe wie beim Hunde, bei lem ja auch noch nach Verletzung des ,Vorderbeincentrums" die Spannung rer Strecker im Ellbogengelenk abnimmt. 
Welche Anhaltspunkte haben wir nun dafüs, dass diese Wirkungen ler Exstirpation der Beincentren nur Shockwirkungen auf die segmentalen Ganglien sind? Zunächst haben wir zu betonen, dass die ron Hitzig beobachteten Wirkungen nur gauz rorübergehender Natur sind. Zweitens aber können wir einen mehr positiren Nachreis führen, dass es sich bei Störungen nach Verletzung der Grosslirncentren nur um indirecte Shockwirkungen auf die segmentalen Rückenmarksganglien handelt. Die Störungen der Vorderbeine, deren segmentale Ganglien in dell Brachialsegmenten des Rückenmarks liegen, sind nämlich nach Grosshirnverlust viel stärker als die Störungen der Hinterbeine, deren segmentale Ganglien so viel weiter mach hinten im Rïckenmark liegen. Ich zeigte das durch folgenden Versuch. Ein Hund wurde gelehrt, sich auf die Hinterbeine zu erheben und auf diesen zu gehen, wenn er Futter wollte. Dann wurden ihm beide Hinterbeincentren entfernt (G Fig. 39). Der Hund war trotzdem in Stande, weiter auf den Hinterbeinen zu gehen. Dagegen bestanden leichte aber dentliche Aenderungen der Haltung der vorderen Extremitäten, hervorgebracht durch die erwähnten Aenderungen der Muskelspannungen. Die sogenannten Centren der Vorderbeine in der Grosshimrinde liegen nämlich in der Nähe der corticalen "Hinterbeincentren" (Fig. 39). Die leichte Reizung der ersteren bei der Exstirpation der Hinterbeincentren ist gentigend, eine stärkere Wirkung auf den Tomus der Muskeln der Vorderbeine auszuïben, als die Exstirpation der Hinterbeincentren auf die Muskeln der letzteren auszuüben im Stande ist, einfach aus dem Grunde, weil die segmentalen Ganglien der Hinterbeine in Lendenmark liegen und deshalb rom Operationsfeld erheblich weiter entfernt sind, als die segmentalen Ganglien der Vorderbeine. Die Shockwirkungen der Operation sind also stärker im Torderbein, als im Hinterbein.

Ich zeigte diesen Hund auf der Naturforscherversammlung in Berlin 1886. Am nächsten Tage zeigte ich das Gebirn des inzwischen getödteten Thieres und wies nach, dass die "Hinterbeincentren" rollständig entfernt und die "Vorderbeincentren" erhalten waren. Auch beim Menschen dürfte es sich wohl darthun lassen, dass die Lähmungen der Beine nach Apoplexieen rascher rerschwinden, als die Lähmungen der Arme.

Aber man kann nicht nur ein Centrum fortnehmen, sondern man kann eine ganze Hemisphäre fortnehmen und dennoch bleiben in einer Reihe von Fällen die Armbewegungen erhalten. Man kann beispielsweise einen Hund abrichten, sein Futter mit einer, etwa der rechten Vorderpfote aus einem Haufen Kies herauszugraben. Das „Centrum" der rechten Pfote liegt bekanntlich in der linken Hemisphäre. Goltz zeigte auf dem Physiologencongress in Basel (1859) einen Hund, dem 
cr die ganze linke Hemisphäre entfernt hatte und der im Angesiclit der Versammlung sein Fleiseh mit der rechten Vorderpfote aus dem Kieshaufen herausscharrte. Wäre das Vorderbeincentrum, wie die morlerne Localisationstheorie das lehrt, ein nothwendiges Organ für alle Leistungen des Yorderbeins, so hätte der Hund nicht mehr im Stande sein dürfen, sein Fleisch aus dem Kieshaufen mit der ihres "Centrums" beraubten Pfote zu graben. Aber das "Forderbeineentrum" ist nichts weiter, als die Stelle der Rinde, von der aus Fasern zu den eigentlichen Ursprungsnerven der Armuerren im Rückenmark entweder direct oder indirect verlaufen. Verletzung oder Ausfall des „Vorderbeineentrums" bringt eine chemische Aenderung in allen nit ihm verbundenen Fasern und Ganglien und sehliesslich auch in den mit ihnen verbundenen Muskeln hervor, die in einer Abnahme der Spannung der letzteren resultirt. Ton diesem Standpunkt aus begreifen wir die Versuche Hitzig's sowohl wie die ron Goltz und meine eigenen Versuche. Danit harmonirt es auch ferner, dass dieselbe Operation manchmal mit sehweren Spannungsänderungen der betreffenden Muskeln verläuft, und manchmal mit geringen, je nach dem Individuum und sonstigen einstweilen unberechenbaren, weil unbekannten Umstänrlen. Auch beim Menschen bringt Ausfall des Armeentrums durch eine Herderkrankung bald eine Lähmung des Arnes hervor, bald geht sie unbemerkt oder mit so geringen Symptomen rorïber, dass der pathologische Anatom überrascht ist, bei der Obduction eine Herderkrankung zu finden. Wäre das Armcentrum ein nothwendiges Organ für die Armbewegungen, so müsste derselbe Symptomencomplex jedesmal eintreten. Handelt es sich aber bei der Zerstörung dieses Centrums nur um Nebenwirkungen, Slrockwirkungen auf die segmentalen Ganglien in Rückenmark und die Armmuskeln, so begreifen wir, dass dieselbe Herderkrankung manchmal mit schweren und manchmal mit leichten Symptomen verläuft. Leider verhindern die gegenwärtig herrschenden localisatorischen Vortirtheile die Aerzte sehr oft. Obductionsbefunde von Herderkrankungen im Grosshirn, die ohne Symptome verliefen, zu publiciren; gerade wie ror Broea den Aerzten der Muth fehlte, solche Fälle z.1 veröffentlichen, die Gall im Sinne der Phrenologie hiitte verwerthen können. Es ist aber klar, dass die Kenntniss beider Klassen ron Erfahrungen von Bedeutung ist: Die Fälle von Herderkrankungen mit positiven Symptomen, weil sie die topographische Diagnostik und die Gehirnanatomie fördern, die Fälle von Herderkrankungen ohne Symptome, weil sie für die Auffassung der "Centren" von fundamentaler Wichtigkeit sind.

Die angeführten Beispiele über die Wirkungen von Exstirpation der Hinterbein- und Vorderbeincentren könnten aus den Mittheilungen 
von Goltz und meinen eigenen Erfahrungen vermehrt und auch auf die übrigen motorischen Centren in der Grosshirninde übertragen werden. Für die Feststellung der Principien dürfte aber das hier Gesagte genügen. Wir werden also an der Ansicht festhalten dürfen, dass die „Beincentren“ nichts anderes sind als diejenigen Stellen, wo Fasern von den segmentalen Beinganglien in die Grosshirnrinde einmünden. Die Störungen, welche nach Verletzung dieser "Centren" beobachtet werden, sind lediglich Shockwirkungen auf die segmentalen Rückenmarksganglien der Extremitäten.

5) Wie verhält es sich mit der Functionslocalisation der Sinnesorgane? Wir wissen, dass Verletzung bestimmter Theile der Hinterhauptslappen Sehstörungen verursacht. Man bezeichnet die betreffenden Stellen als Sehcentren oder Sehsphären (Fig. 39). Was ist die Bedeutung dieser Sehsphären? Sind sie, wie H. Munk annimmt, die unmittelbaren Opticusendigungen oder sind sie die Stelle, wo die Fasern von den segmentalen Opticusganglien (Thalamus etc.) in die Hirmrinde einstrahlen? Es lässt sich leicht nachweisen, dass die letztere Annahme die wahrscheinlichere ist.

Nach der Ansicht von Hermann Munk (5), der das Verdienst besitzt, zuerst die Eintrittsstelle der segmentalen Opticus- und Acusticusfasern in die Hinterhaupt- resp. Schläfenlappen des Grosshirns experimentell genauer bestinmt zu haben, giebt es auf dem Hinterhauptslappen des Hundes innerhalb der Sehsphäre eine bestimmte Region (A ${ }^{1}$ Fig. 39), deren Exstirpation den Verlust aller optischen Erinnerungsbilder für das gegenüberliegende Auge bedingen soll. Der Hund, dem diese Stelle entfernt ist, wird damit ,seelenblind". Er sieht, er verneidet z. B. Hindernisse, aber erkennt nicht mehr, was er sieht. Dieser letztere Zustand war schon von den früheren französischen Hirnphysiologen richtig elkannt und gedentet worden, und auch Goltz hatte ihn schon vor Munk in all seinen Einzelheiten beschrieben und als Hirnsehschwäche bezeichnet. Nun beobachtete Munk weiter, dass die Seelenblindheit oder Hirnsehschwäche nach Exstirpation der betreffenden Rindenstelle (A') nicht dauernd ist, sondern dass nach einiger Zeit der Hund anch wieder erkennt, was er sieht. Er schloss darans, dass der Hund wieder neue optische Erinnerungsbilder gesammelt habe. Munk stellt sich vor, dass der Hund nach der Operation wieder lerne, und dass er so mit der Bedeutung dessen, was er sieht, wieder bekannt werde. Die so erworbenen neuen Erinnerungsbilder sollen in der Umgebung der exstirpirten Stelle $A^{1}$ deponirt werden. Die Umgebung dieser Stelle (A Fig. 39) ist eine Art Reservemagazin für optische Erinnerungsbilder. Und zum Beweis der Richtigkeit seiner Ansicht führt MIunk an, dass 
wenn man bei einem solchen Hunde, der sich von seiner Seclenblindheit erholt hat, die Hirninde in der Ungebung der Stelle $A^{\mathbf{1}}$ abträgt, die Scelenblindheit wieder auftritt. So lange noch ein sitick der Sehsphäre intact ist, kamn sich aber der Hund von seiner Scelenblindheit erholen, indem er neue optische Erinnerungsbilder in der erhaltenen Partie der Sehsphäre deponirt. Ist aber die ganze Schsphäre auf einer Seite entfernt, so ist der Hund dauernd seelenblind. Sind die Thatsachen, auf die Munk seine Schlüsse basirt, richtig und sind seine Schlüsse berechtigt? Ich habe eine grosse Zahl ron Versuchen angestellt in der Absicht, die Vorstellungen Munk's zu prïfen, und habe rlic Ergebnisse dieser Versuche in meiner Erstlingsarbeit veröffentlicht (6). Ich fand, dass Entfernung der Stelle $A^{1}$ die Folge haben kann, welche Munk beschreibt, dass aber in der Mehrzahl der Fälle ein so operirter Hund schon unmittelbar nach rer Erholung aus der Chloroformnarkose oder doch am nächsten Tage alles erkennt was er sieht. Ich habe meine Beobachtungen noch dadurch sicher gestellt, dass ich eine Zahl einäugiger Hunde verwendete und denselben die Stelle $\mathrm{A}^{\mathbf{1}}$ auf der dem erhaltenen Auge gegenüberliegenden Hemisphäre des Grosshirns entfernte. Ein Theil dieser Hunde erkannte am Tage nach der Operation alle Gegenstände, (z. B. seinen Herm aus der Ferne, er zeigte Furcht vor der erhobenen Peitsche, lief auf rlie Futterschüssel zu etc.). Diese Versuche beweisen, dass die Seelenblindheit keine nothwendige Folge des Verlustes der Stelle $A^{\mathbf{1}}$ ist. Sie legen den Gedanken nahe, ob nicht in den Fällen, in welchen eine solche Störung nach Exstirpation der Stelle $A^{1}$ beobachtet wurde, eine vorübergehende Nebenwirkung der Operation auf tiefer gelegene Theile vorlag. Wenn das so wäre, so wäre die Rückkehr des vollen Sehvermögens bei dem Thiere bedingt durch das Aufhören der Hemmungs- oder Shockwirkung der Operation und würde nicht davon abhängen, dass das Thier allmählich wieder nene Erinnerungsbilder erwirbt. Ich prüfte diese Ansicht, indem ich Thiere, welche unmittelbar nach der Exstirpation der Stelle $A^{1}$ volle Seelenblindheit zeigten, 6 Wochen lang isolirt in einem dunkeln Kasten hielt in dem sie keine Gelegenheit hatten, neue optische Erinnerungsbilder zu sammeln (6 Wochen war ungefähr die Zeit, die ein Thier mit schwerer Seelenblindlieit brauchte, um zur Norm zurückzukehren). Als diese Thiere ihr Dunkelgemach verliessen, waren sie völlig normal! Das Verschwinden der Seelenblindheit beruht also nicht auf der Neuerwerbung optischer Erinnerungsbilder, wie Munk schloss, sondern darauf, dass eine Neben- oder Shockwirkung der Operation (und vielleicht auch des IVundheilungsvorganges) auf tiefergelegene Theile, nämlich die segmentalen Opticusganglien allmählich sich verliert; und die Seelenblindheit selbst 
ist nur bedingt durch diese Neben- oder Shockwirkung der Operation. Nun behauptete Munk, dass ein Thier, das sich von der Seelenblindbeit erholt habe, wieder seelenblind wird, wenn man ihm Substanz in der unmittelbaren Umgebung der Stelle $\mathrm{A}^{1}$ wegnimmt. Er schloss daraus, dass bei der zweiten Operation die neuerworbenen Erinnerungsbilder wieder exstirpirt worden seien. Meiner Ansicht nach handelt es sich bei der zweiten Seelenblindheit auch wieder nur um eine Shockwirkung der Operation. Ich konnte nämlich genau dieselbe Seelenblindheit wieder hervorbringen, indem ich die Narbe der alten Operationsstelle mechanisch reizte (kratzte), ohne neue Substanz zu entfernen. In diesem Falle war nichts als eine Shockwirkung erzielt worden und doch folgte eine Seelenblindheit oder Hirnsehschwäche auf dem gegenüberliegenden Auge.

Wenn es sich aber nicht um Verkust der Erinnerungsbilder bei der Seelenblindheit nach der Verletzung der Sehsphäre handelt - die Stelle $\mathrm{A}^{1}$ spielt dabei keine privilegirte Rolle - sondern nur um eine vorïbergehende Shockwirkung der Operation, so bleibt uns die Aufgabe, die Natur der Sehstörung genauer zu bestimmen. Dem Leser ist es bekannt, dass Erkrankung eines Hinterhauptlappens beim Menschen häufig Hemianopsie, d. h. Erblindung der mit der verletzten Hemisphäre gleichnamigen Retinaseiten hervorbringt. Munk fand ebenfalls, dass ein solcher Zusammenhang zwischen Hinterhauptlappen und Retinae existirt und er nahm an, dass eine Projection der beiden Retinahälften auf die fleichnamige Sehsphäre stattfinde, der Art, dass die einzelnen Stellen der Selısphäre bestimmten Zellen der Retinae entsprechen. Zerstörung einer Stelle der Sehsphäre soll aber zur dauernden Blindheit der entsprechenden identischen Punkte beider Retinae führen. Ich habe viele Versuche gemacht, die Ansicht Munk's zu bestïtigen, aber mit durchaus negativem Resultat. Ich halte aber eine solche projective Anordnung der Opticusenden im Gehirn keineswegs für ausgeschlossen, nur entspricht sie nicht den Angaben Munk's, falls sie existirt. Auch in einem zweiten Punkt kann ich Munk nicht beistimmen. Er giebt an, dass Abtragung der Rinde einer Sehsphäre Hemianopsie bedinge, wie beim Menschen. Was ich finde, ist Folgendes. Nach Abtragung irgend eines kleineren oder grösseren Bezirkes einer Sehsphäre tritt häufig eine Störung ein, dic ich als Hemiamblyopie bezeichnet habe und die darin besteht, dass die Erregbarkeit in don der verletzten Sehsphäre gheichseitigen Retinahälften herabgesetzt ist. Entfernt man einem Hunde ein Stück der linken Sehsphäre, so tritt Hemiamblyopie für seine rechte Gesichtsfeldluälfte ein. Stellt man sich vor einen solchen Hund und hält man ihm symmetrisch rechts und links gleichzeitig zwei Fleischstiicke ror, so wählt der Hund ausnahmslos das linke. Das sieht fast 
so aus, als ob er das rechte nicht sïhe. Nun ist es bekannt, dass ein bewegter Gegenstand als ein stïrkerer optischer Reiz wirkt als ein ruhender. Hält man jetzt dem Hunde wieder die zwei Fleischstücke in der angegebenen Weise vor, nur mit dem Unterschied, dass man das in der rechten Gesichtsfeldhälfte gelegrene leicht bewegt, so springt der Hund nach dem letzteren (7). Das beweist, dass bei dem Hund eine Erhöhung der Reizschwelle für optische Reize auf der rechten Gesichtsfeldhälfte besteht. Der Hund benimmt sich, nach Korányi's Ausdruck, als ob seine Aufmerksamkeit nach rechts rerringert wäre. Aus dieser Herabsetzung der Reizschwelle für optische Eindrücke leite ich das Entstehen der Seelenblindheit ab. Sind beide Hinterhauptlappen in nicht zu starker Ausdehnung rerletzt, so erhält man eine Amblyopie, bei der der Hund genug sieht, um Hindernissen aus dem Wege zu gehen, aber nicht genug, um die Gegenstände in ihrem Detail zu erkennen. Sobald die Wirkungen der Operation geringer werden, d. h. mit der Zeit wird auch im Allgemeinen sein Sehvermögen wieder besser. Es handelt sich also um eine Wirkung der Operation, die der Wirkung, welche die Exstirpation eines motorischen Centrums hat, analog sind: In beiden Fällen haben wir es mit einer Herabsetzung des physiologischen Tonus zu thun, der beim Muskel in einer Spannumgsabnahme zum Ausdruck kommt, beim Sinnesorgan in einer geringeren Erregbarkeit. Der Zusammenhang mit der Grosshirnoperation ist in beiden Fällen derselbe: Die Nerrenfasern, welche an bestimmten Stellen der Grosshirmrinde eintreten, werden durch eine Zerstörung ihrer Ganglienzellen in einen chemisch verschicdenen Zustand versetzt und diese Zustandsänderung pflanzt sich über die ganze Länge dieser Fasern bis zı den segmentalen Ganglien und ihren peripheren Endungen (Muskeln und Simmesorganen) fort und bewirkt in diesen eine Thätigkeitsabnahme. Die letztere ist um so gelinger, je weiter das betreffende Element rom Herde der Operation entfernt ist oder je mehr Neuronen zwischen den beiden Stationen liegen. Wie es kommt, dass man beim Menschen nur Hemianopsie, aber nie Heniamblyopie beobachtet, vermag ich nicht zu erklären. Aber wir beobachten ja beim Menschen sehr häufig Lähmung des Armes nach Herderkrankungen im Grosshirn, während beim Hunde niemals eine Lähmung in solchen Fïllen eintritt. Vielleicht liegt der Grund dieses verschiedenen Verhaltens in Strukturunterschieden beider Klassen, die vielleicht mit dem aufrechten Gang beim Menschen und dem Gang auf Tieren bei Hunden in einer Correlation stehen. Es könnte sich aber auch darum handeln, dass die Shockirirkungen beim Menschen stärker sind als bei Hunden. Die letztere Möglichkeit lässt sich nicht abweisen im Hinblick auf die Thatsache, dass bei Fröschen und Haifischen die 
Shockwirkungen gering sind und dass sie bei manchen Wirbellosen anscheinend ganz fehlen.

Die Behauptung IIunk's, dass beiderseitige Abtragung der Rindenoberfläche, welche er als Sehsphäre bezeichnet, bei Hunden nothwendig und dauernd Blindheit bedinge, kann ich nicht zugeben. Dagegen trat Blindheit in allen bisher beobachteten Fällen ron totaler Exstirpation des Grosshirns oder der gesammten hinteren Hälften desselben bei einer Thierklasse, nämlich bei Hunden, ein. Es ist aber sehr wohl möglich, rlass bei Fortsetzung dieser Versuche Hunde zur Beobachtung kommen, welche auch nach Verlust des Grosshirns noch auf Lichtreize, ähnlich wie Schraders Tauben, reagiren.

Fassen wir alle diese Thatsachen zusammen, so sehen wir, dass die Centrentheorie in der Grosshirnrinde ein Beispiel der zu holien Localisation ist, auf die wir schon in einer früheren Torlesung aufnerksam gemacht haben. Alle die, Functionen", welche rliese Theorie in die verschiedenen Theile der Grosshirnrinde legt, sind segmentale Functionen und die sogenannten Grosshirncentren sind nur die Einmündungsstellen für Faserzïge, welche von den verschiedenen segmentalen Ganglien in das Grosshirn einstrahlen. Dass diese Einmündungsstellen im Grosshirn nicht der Anordnung der segmentalen Ganglien im Rückenmark, der Medulla und dem Mittelhirn entsprechen, beruht auf den Raumverhältnissen, Wachsthumsbedingungen und -verschiebumgen während der embryonalen Periode. Die Störungen, welche nach Verletzung eines Centrums folgen, sind nur Wirkungen der Terletzung auf die segmentalen Ganglien.

Wenn wir so die Centrentheorie des Grosshirns durch die segmentale Theorie ersetzen, so ist das nicht so zu verstehen, als ob wir die topographische Diagnostik der Hirnerkrankungen bekämpfen. Die topographische Diagnostik der Hirnerkrankungen ist ein Triumph der Wissenschaft und die Centrentheorie hat der topographischen Diagnostik der Hirnerkrankungen sicherlich grosse Dienste geleistet, da durch die Centrentheorie zuerst die Einmündungsstellen der verschiedenen segmentalen Faserzüge in die Grosshirmrinde ermittelt worden sind. Irrig wird die Centrentheorie nur dadurch, dass sie über die Thatsache der anatomischen Localisation hinausgeht und Schlüsse über die physiologische Bedeutung der Localisation zieht, welche mit den Thatsachen in directem Widerspruch stehen. Gegen diese Fehlschlüsse kämpfen wir, weil sie nothwendig die weitere Entwickelung einer Mechanik der Hirnthätigkeit hemmen müssen. Sie ist aber auch ein Hinderniss für eine umfassende topographische Diagnostik, weil sie zu dem Glauben verleitet, dass jede Erkrankung der Rincle zu einer Störung der segmentalen 
Organe führen müsse. Dic Thierversuche sowohl wie die Befunde am Obductionstisch zeigen, dass Verletzung von "Centren" symptomlos rerlaufen kann. Der Ersatz der Centrentheorie durch die Segmentaltheorie lässt die topographische Diagnostik der Hirnerkrankungen unversehr't, vermeidet aber die Fehlschlüsse der Centrentheorie. Endlich haben meine Versuche auch zu dem Ergebniss geführt, dass wenn auch ein und dieselbe Stelle rorwiegend mit einem bestimmten segmentalen Cianglion in Terbindung steht, das doch nicht ausschliesslich der Fall zu sein braucht. Ich beobachtete beispielsweise auch Hemiamblyopie nach Verletzungen ausserhalb der Sehsphären (6 ı. 7).

\section{Litteratul zu XriI.}

1) Kussmaul, A. Die Störungen der Sprache. Leipzig 1881. (In der Darstellung der historischen Entwickelung der Localisation des Sprachcentrums folge ich kussmaul.)

2) Hitzig, E. Untersuchungen über das Gehiru. Berlin 1874, und Reichert's und Du Bois-Reymond's Archiv 1570.

3) Goltz, F. Ueber die Verrichtungen des Grosshirns.

I. Abhandlung Pflïger's Arehiv, Bd. 13. 1876.

\begin{tabular}{|c|c|c|c|}
\hline " & ," & " & " \\
\hline " & , & ," & „, \\
\hline •, & ", & ", & $"$ \\
\hline ", & , & . & .. \\
\hline
\end{tabular}

4) v. Cyon, E. Gesammelte Physiologische Arbeiten. Berlin 1SsS. S. 197 u. $f$

5) Munk, H. Ueber die Functionen der Grosshirnrinde. Berlin 1851 .

6) Loeb, J. Die Sehstörungen nach Terletzungen der Grosshirnrinde. Pfliger's Archir, Bd. 34. 1SSt.

Ђ) Loeb, J. Beitrïgre zur Physiologie des Grosshirns. Pflüger's Archiv, Bd.39. 1851j. 


\section{XVIII.}

\section{Theilseelentheorie und Localisation einzelner Erinnerungsbilder.}

1) Viele Anhänger der Centrentheorie stellen sich ror, dass die Einmüindungsstelle der Fasern eines segmentalen Ganglions in die Grosshirnrinde, das sogenannte Rindencentrum, die Theilseele für die Organe des betreffenden Segmentes enthalte, oder m. a. W., dass sich ausschliesslich in dem "Centrum" eines Organes alle die Bewusstseinsvorgänge abspielen, bei welchen das betreffende Organ mitwirkt. So ist die "Sehsphäre" der Grosshirnrinde nach diesen Autoren das Theilseelenorgan für alle optischen Vorgänge, das Armcentrum das Theilseelenorgan für alle bewussten Bewegungen des Armes etc. Eine solche Vorstellung wäre an sich mit der Segmentaltheorie durchaus vereinbar. Es giebt aber, wie Goltz gezeigt hat, andere Thatsachen, die gegen eine solche Annahme sprechen. Es ist bekannt, dass Personen, die von Kindheit an taubstumm und blind gewesen sind, nicht nur eine normale, sondern eine relativ hohe Intelligenz besassen. Wäre die Theilseelentheorie richtig, so müsste die beiderseitige Entfernung der Sehsphäre und der Hörsphäre im Grosshirn nicht mehr Einfluss auf die Intelligenz haben wie Blindbeit und Taubheit. Goltz hat aber nachgewiesen, dass ein Hund, der beide Hinterhauptsschläfenlappen verloren hat, hoffnungslos blödsinnig ist (1). Im Gehirn eines solchen Hundes rommt es entweder ïberhaupt nicht mehr zu Associationsvorgängen oder sie laufen in einer unvollständigen oder veränderten Form ab. Aus dieser Thatsache folgt, dass die Theilseelentheorie entweder falsch oder unvollständig ist.

Es fragt sich nun, ob und welche Thatsache wir besitzen, um die Lücken auszufüllen resp. richtige Anschauungen zu gewinnen. Es scheint mir, dass hier vor Allem eine Entdeckung von Goltz berücksichtigt werden muss, die zu den merkwürdigsten Thatsachen der Gehirnphysiologie gehört. Er hat gefunden, dass wenn man einem Hunde eine Hemisphäre des Grosshirns entfernt, die Persönlichkeit des Thieres, d. h. sein Gedächtnissinhalt und sein Intellect unverändert bleiben (1). Ein solches Thier erkennt seinen Herrn, hat dieselben Freunde und Feinde wie vor 
der Operation. Entfernt man aber etwa denselben Betrag an Grosshimmasse nur mit dem Unterschiede, dass man die Vorderlälften beider Hemisphären oder die hinteren Hälften derselben exstirpirt, so ist der Hund danernd verdummt (1). Was die negative Bedeutung dieser Thatsachen betrifft, so sind sie mit der Theilseelentheorie ohme die gewaltsamsten Hülfshypothesen nicht zu vereinigen. Nach Zerstörung einer Hemisphäre müssten ja die Theilseelen für eine Reihe von Gliedern verschwinden. Was aber die positiven Folgen der Operation anbetrifft, so ist es schwer einstweilen aus diesen Thatsachen diejenigen Schlüsse zu ziehen, welche für die weitere Entwickelung unserer Einsicht in die Mechanik der Hirnthätigkeit fruchtbar werden können. Bei der Bedeutung des Gegenstandes möge man es entschuldigen, wenn ich eine Termuthung äussere, die einstweilen sehr wenig bestimmt und berveisbar ist. Ich meine, dass hier die Symmetrieverhältnisse und Polaritäten des Körpers resp. die Orientirungsverhältnisse der nervösen Elemente ron Bedeutung sind. Die rechte und linke Körperhälfte sind wenig ron einander verschieden. Entfernt man die ganze linke Hemisphäre, so können alle Vorgänge noch angenähert in derselben Form stattfinden, wie wenn beide Hemisphären noch vorhanden wären. Entfernt man aber die beiden vorderen Hälften der Hemisphären, so fällt ein Theil fort, der von dem noch vorhandenen in Bezug auf die Orientirung der Elemente erheblich verschieden ist. Das könnte bedingen, dass in dem noch übrigen Grosshirn die Vorgänge nicht mehr in derselben Form ablaufen können, wie in dem normalen Gehirn und daher die Verblödung und Verdummung des Thieres. Einige Autoren haben behauptet, dass die Stirnlappen der Sitz der Intelligenz seien. Dem gegenüber betont Goltz mit Recht, dass ein Thier, das die beiden hinteren Hälften der Hemisphäre verloren hat, entschieden ebenso blödsinnig ist, wie ein Thicr, das sie bei den vorderen Hälften beider Hemisphären eingebüsst hat. Ich habe ferner direct nachgewiesen, dass nach Verlust der Stirnlappen allein die Intelligenz eines Hundes nicht verändert wird (2). Es ist schwer verständlich, wie die irrige Angabe, dass die Stirnlappen "Sitz" der Intelligenz seien, immer wieder auftauchen und Glauben finclen kann.

Was mich dazu gefühturt hat, daran zu denken, ob nicht der Unterschied der Orientirung der Elemente eine Bedeutung für die Verschiedenheit der Folgen eines Eingriffes in Grosshirn besitzt, ist folgender Umstand. Goltz hat betont, dass ein Thier, dem man beide hinteren Hälften der Hemisphäre entfernt, schwer dazu zu bringen ist, sich fortzubewegen (1). Das Thier ist übertrieben ruhig und erinnert an stuporöse Patienten. Goltz entdeckte noch eine andere Eigenthümlichlieit an diesen 
Thieren: Sie sind schwer oder gar nicht dazu zu bewegen, treppah zu gehen, während man sie viel leichter dazu bringt, sich treppauf zu bewegen. Auch die Haltung der Thiere ist eigenthümlich: Sie stehen steifbeinig, d. h. die Beine, namentlich die Yorderbeine, sind abnorm gestreckt. Ganz das entgegengesetzte Terhalten zeigen diejenigen Hunde, denen die beiden rorderen Hälften beider Hemisphären entfernt sind. Die Thiere bewegen sich übermässig leicht vorwärts, sie haben oft einen förmlichen Laufdrang, wobei sie gegen Hindernisse anrennen, obwohl sie keineswegs blind sind. Sie lanfen oder kollern unbedenklich treppab und die Haltung ihres Körpers ist gerade umgekehrt wie bei den beiderseits hinten operirten Hunden: Die Spannung der Beuger im Elloogen der Vorderbeine überwiegt über die der Strecker, so dass diese Thiere leicht mit den Torderpfoten einknicken. Hitzig hat bemerkt, dass sie gelegentlich mit der dorsalen Seite des Fusses auf den Boden treten, statt mit der Plantarseite. Das rührt, wie schon erwähnt, wohl eben claher, dass die Spannung der Beuger des Fussgelenkes abnorm über die der Strecker überwiegt. Mir scheint nun, dass diese Gegensätze im Terhalten beider Thiere eine Analogie zeigen mit dem früher erwähnten Terhalten der Amblystomen, die in der Längsrichtung ron einem constanten Strom durchflossen werden. Der Hund, der die beiden rorderen Hälften des Grosshirns verloren hat, gleicht dem in absteigender Richtung durchströmten Amblystoma insofern, als bei beiden derartige Aenderungen in der Spannung der Muskeln der Beine (und des Körpers) erfolgen, dass die Vorwärtsbewegung erleichtert und die Rückwärtsbervegung erschwert ist. Der Hund dagegen, der die beiden hinteren Hälften der Hemisphäre verloren hat, gleicht einem Amblystoma, das in aufsteigender Richtung durchströmt wird. Die Spamnung der Muskeln ist so verändert, dass die Vormärtsbewegung erschwert ist. Zur wirklichen Rückwärtsbewegung kommt es nun nicht bei einem derartigen Hunde, aber die Torwärtsbewegung ist fast ummöglich. Auch die fast unüberwindliche Abneigung eines solchen Hundes, treppab zu gehen, rülırt meines Erachtens daher. Wie aber ist es möglich, dass Zerstörung. rler vorderen oder hinteren Particen des Grosshirns Erscheinungen hervorruft, die cine Analogie zeigen mit dem Verhalten von Thieren, die in der Längsrichtung ron einem galvanischen Strom durchflossen werden?

Bei unseren Versuchen über Galvanotropismus sind wir zu dem Resultate gedrängt worden, dass eine einfache Beziehung bestehen muss zwischen der Orientirung der motorischen Elemente in Centralnerrensystem und der durch sie bestimmten Bewegungsrichtung. Die Versuche au den crura cerebelli weisen auf eine solche Beriehung mit solcher 
Deutlichkeit hin, dass Flourens sie ausdrücklich betont. Beim Grosshim begegnen wir derselben Bezichung wieder. Die Elemente der vorderen Hälften des Grosshirns sind umgekchrt in Bezug auf die dorsorentrale Axe des Körpers orientirt, als die Elemente der hinteren Hälften. Es ist möglich, dass die rorderen und hinteren Partieen des Grosshims mit jenen motorischen Elementen der Medulla oblongata verknüpft sind, nit denen auch die entsprechenden crura cerebelli und die entsprechenden Halbzirkelkanäle rerbunden sind. Es stimmt ferner mit unserer Auffassung, dass Zerstörung einer Hemisphäre, z. B. der linken Grosshirnhemisphäre, bei cinem Hunde wie allbekannt Reitbahnbewegungen nach links herrorruft. Man erhält diese Reitbahnbewegungen auch rorübergehend, wenn man kleinere Bezirke einer Hemisphäre zerstört, gleichriel ob das zerstörte Stück in der sogenannten motorischen oder sensorischen Region (d. h. nach hinten) gelegen ist, wenn man nur eine genügende Zahl von Stabkranzfasem oder Ganglienzellen einer Seite rernichtet. Der Zusammenhang ist auch hier wohl wieder so zu denken. dass Zerstörung der linken Hemisphäre die Spannung und Energieentwickelung derjenigen Muskeln herabsetzt, welche den Kopf und Kïrper nach rechts bewegen. In Folge dessen ist die Linkschehung für das Thier erleichtert, die Rechtsdrehung erschwert. Ob es sich hierbei nur um eine Shockwirliung auf motorische Elemente der Medulla oder der segmentalen Rückenmarksganglien handelt, mag dahingestellt bleiben. Jedenfalls besteht eine unverkenubare Analogie in der Wirkung de1 Entfernung der vorderen Hälften der Grosshiruhemisphären und der nach rorn rerlaufenden crura cerebelli ad corpora quadrigemina einerseits und der Entfernung der hinteren Hälften der Grosshirnhemisphären und der crura cerebelli ad medullam. Es geht ferner aus den galranotropischen Versuchen an Krebsen und niederen Wirbelthieren herror. dass eine einfache Beziehung zwischen Orientirung der Elemente und der durch sie bestimmten Bewegungsrichtung sehr weit in ler Thierreihe verbreitet ist.

Es folgt aus dem Gesagten, dass überall, wo man das Gehim eines Thieres so theilt, dass man alle die Hinterhauptselemente, welche eine Torwärtsbewegung bestimmen, entfernt, während die Torderhauptselemente, welche die Progressivbewegung hemmen, erlalten bleiben, Verminderung oder Verlust der Progressirbewegung entstehen muss; class aber weiterhin nach Entfernung der die Progressirbewegung hemmenden Elemente die Progressivbewegung wieder möglich ist. Ein Hund, der nur die binteren Partieen des Grosshirns verloren hat, macht wenig Progressirbewegungen und gleicht darin einem Stuporösen. Entfernt man ihm aber dann noch die vorderen Partieen des Grosshirns, 
so tritt die freie Vorwärtsbewegung wieder ein. Ich glaube, hierhin gehört auch die Beobachtung von Steiner, dass ein Haifisch, dem man die vordere Partie der Medulla entfernt, keine Progressivbewegung mehr macht, während wenn man etwas mehr von der Medulla (und dem Rückenmark?) entfernt die Progressivbewegungen wieder eintreten (1). Ebenso gehören wohl dahin die Beobachtung von Schrader, dass ein Frosch nach Entfernung der Grosshirnhemisphären und des Thalamus opticus keine Progressirbewegungen mehr macht, dass er aber nach Verlust des Restes des Gehirns inclusive der pars commissuralis der Medulla oblongata ununterbrochen Progressirbewegungen ausführt und in seiner abnormen Ruhelosigkeit den Hunden vergleichbar wird, welche die vorderen Hälften beider Hemisphären des Grosshirns verloren haben.

Bringt man alle diese Thatsachen in Erwägung, so ist die Möglichkeit nicht von der Hand zu weisen, dass Hunde, welche die vorderen oder hinteren Hälften beider Hemisphären verloren haben, deshalb verdummen, weil in den Empfindungscomplexen und der Associationsthätigkeit dieser Thiere wesentliche Homente ansfallen, während die Thiere, die noch eine ganze Hemisphäre besitzen, trotz des Verlustes der anderen Hemisphäre ihre Persönlichkeit nicht ändern, weil sie noch alle Empfindungselemente und Associationselemente in nahezu ungeänderter Form hervorbringen können. Wie es möglich ist, dass Ausfall einer Klasse von Rindenelementen mit bestimmter Orientirung die Gehirnvorgänge verändert, kam man natürlich einstweilen nur durch ein Bild erläutern. Wie der Character der Vocale verwischt wird wenn gewisse Töne (die Determinanten) ausfallen, so könnten auch die Processe im Gehirn bis zur Wirkungslosigkeit verstïmmelt werden, wenn alle Elemente von gewisser Orientirung ausfallen.

Wenn wir versuchen, die Consequenz dieser Vorstellung zu ziehen, so würde das Grosshirn als einheitliches Organ etwa im Sinne der Retina anzusehen sein, wo jeder Zapfen je nach seiner Orientirung gegen die Fläche der Retina einen anderen Raumwerth besitzt. Dagegen würde es nicht als einheitliches Organ im Sinne einer Drüse angesehen werden können, wo alle klemente durchaus gleichwerthig sind. Wie nun die Empfindung der Lage und Form eines Schdings bestimmt ist durch die Lage und Anordnung der durch das Netzhautbild bedeckten Zapfen, so könnte auch wohl im Grosshirn eine Empfindung oder gewisse Bestandtheile derselben bestimmt sein durch die Lage und Anordnung der erregten Elemente. Dasselbe Rindenelement könnte nach einander zu der Entstehung aller müglichen Empfindungen und Vorstellungen beitragen, wie dasselbe Retinaelement nach einander zur Entstehung unzähliger Retinabilder beiträgt. Die consequenten Anhänger der Centren- und Theilseelen- 
theorie haben eine andere, weniger dynamische und mehr corpusculäre Theorie des Empfindungsrorganges und des Erinnerungsbildes oder der Vorstellung entwickelt. IDie Mechanik des Gedächtnisses besteht für sie darin, dass je ein Erinnerungsbild in einer besonderen Zelle oder Zellgruppe „niedergelegt" wird, gerade wie wenn das „Erinnerungsbild" etwas Körperliches wäre. Ein Anhänger dieser Theorie hat auch aus der Zahl der Ganglienzellen ausgerechnet, wie riele Erinnerungsbilder unser Kopf zu fassen im Stande sei. Dieser Hypothese würde in der physiologischen Optik die monströse Annalıme entsprechen, dass für das Sehen eines jeden rerschiedenen Gegenstandes ein rerschiedenes Retinaelement benutzt würde. Der Autor, der aus der Zahl der Ganglienzellen in unserer Rinde ausrechnete, wie viele Erinnerungsbilder in unserem Gehirn Platz haben, hätte wohl mit ebensoviel Recht aus der Zahl unserer Retinaelemente berechnen können, wie viele Dinge wir im Laufe unseres Lebens zu sehen im Stande sind.

2) Historisch sind diese corpusculären „Theorieen" der associatiren Gedächtnissthätigkeit wohl im Hinblick anf gewisse Thatsachen der Aphasie entstanden. Es sind Fälle bekannt, in denen einzelne Buchstaben des Alphabetes oder einzelne Zahlwörter etc. dem Gedïchtniss entfallen, während andere erhalten bleiben. Da die Histologie den Aerzten näher liegt, als die Physik, und da es dem Nichtphysiker einfacher erscheint, alles substanziell anstatt dynamisch zu erklären, so war es nicht zu verwundern, dass die Kliniker auf die Idee kamen, dass jeder Buchstabe und jeder Zahlbegriff und endlich überhaupt jedes Erinnerungsbild in einer besonderen Ganglienzelle „enthalten" sei. Die erwähnten Eälle der Aphasie fanclen ihre "einfache" Erklärung in der Annahme, dass die Zellen für die fehlenden Buchstaben zerstört seien, und ich entsinne mich, dass ein Kliniker allen Ernstes die Behauptung anfstellte, dass beim Lesen des Wortes Haus nach einander die H-Zelle die a-Zelle, die u-Zelle und s-Zelle in unserer "Sehsphäre" in Thätigkeit gerathen! Wenn man ihm gesagt hätte, dass seine "Theorie" des Lesens auf dem Niveau der bekannten Erklärung der Locomotive durch ein darin enthaltenes Pferd stehe, so würde er das wohl sehr ungläubig aufgenommen haben.

Die Untersuchung eines derartigen Falles von Aphasie durch Konrad Rieger hat aber, wie mir scheint, ergeben, dass in der That die Symptome dieses Krankheitsbildes keineswegs eine corpusculäre Theorie der Erinnerungsbilder, sondern eine dynamische erfordern (3). Unter den vielen Thatsachen des von Rieger glänzend analysirten Beobachtungsmateriales will ich nur die folgende hier erwähnen. Der Patient war nicht im Stande, irgend welche Zahlen mit Ausnahme ron 1,2 und 3 
zu erkennen. Die corpusculäre Theorie der Erinnerungsbilder nimmt an, dass alle Zahlwörter, welche der Patient ursprünglich besessen hatte, jedes einzeln in einer besonderen Zelle localisirt gewesen sei, und dass diese Zellen alle zu Grunde gegangen seien, mit Ansnahme der gerade die drei ersten Zahlen beherbergenden Zellen. Das erscheint von vornberein seltsam und wird noch seltsamer durch die folgende Beobachtung. Es dauerte jedesmal eine geraume Zeit, bis der Patient im Stande war, eine vorgehaltene 1 als solche zu benennen. Die Reactionszeit für das Benennen einer 2 war erheblich länger und die Reactionszeit für das Benennen der 3 war noch viẹl länger. Er war auch noch im Stande, alle Rechenoperationen mit diesen drei Zahlen auszuführen, aber wenn eine 3 in der Operation vorkam, so dauerte die Ausführung entsprechend länger, als wenn nur eine 2 vorkam. Diese Reactionszeitbestimnungen lieferten den Schlïssel für das Verständniss der Thatsache, dass alle Zalılen über 3 fehlten. Es stellte sich nämlich bei allen Versuchen Rieger's an diesem Patienten heraus, dass wenn es ihm nicht gelang; in einer bestimmten Zeit (ca. 18 Secunden) nach dem Erblicken eines Gegenstandes den Namen desselben zu finden, er überhaupt ausser Stande war, den Gegenstand zu benemnen. Nun brauchte er zum Benennen der 3 eine Zeit, welche nahe der Grenze des für ihn Möglichen lag, und in der That versagte auch das Erkennen dieses Zahlwortes bei ihm schon gelegentlich. Es sind aber gerade die ersten drei Zahlwörter diejenigen, welche ein Kind zuerst lernt und die auch im Leben öfter genannt werden als alle anderen. Es ist auch eine bekannte Erfahrung, dass unserm Gedächtniss diejenigen Worte am leichtesten entschwinden, die wir am seltensten gebranchen (z. B. Eigennamen, fremde Sprachen, die wir nicht iiben etc.), während Worte, die häufig gebraucht werden, auch relativ stärker haften, namentlich solche, die in unserer Kindheit schon eine Rolle spielten. Es handelte sich also bei den Rieger'schen Patienten darum, dass eine Erschwerung resp. Verstümmelung gewisser Vorgänge im Gehirn stattfand, bei der die häufigst gebranchten Zahlworte noch ïber die Schwelle treten konnten, während das bei den seltneren und schwereren Zahlworten nicht mehr möglich war. Diese Auffassung wird weiterhin noch dadurch bestätigt, dass er im Stande war, ein 10 und 50 Pfennigstïck noch in Folge ihres verschiedenen Randes mit dem Tastsinn zu unterscheiden, obwohl im Uebrigen die Zahlwörter 10 und 50 ilım entschwunden waren und die auf diesen Geldstïcken stehenden Zahlen 10 und 50 nur die Bedeutung von Hieroglyphen für ihn hatten. Wäre die corpusculäre Theorie richtig, so hätte der Patient nicht den Begriff des 50 Pfennigstiickes besitzen dürfen, da ja der Behälter für den Begriff 5 zerstört war. Der Geldbegriff des 
10 und 50 Pfennigstückes haftete zäher in Gedächtniss dicses Mannos, der als Steinmetze um sein Dasein zu kïmpfen hatte, als die abstracten Begriffe 10 und 50, die in seinem Gedächtniss mehr als scholastischer Luxus existirt hatten. Will man sich also ein Bild rom Wesen rer Erkrankung dieses Mannes machen, so muss es ein dynamisches sein, welches darauf hinausläuft, dass im verletzten Gohirn dieses Patienten gewisse Vorgänge mit geringerer Intensität oder nur unvollständig ahzulaufen im Stande waren. Dadurch können solche Wortinnervationen, deren Schwellenwerth ein relatives Minimum ist, oder die einen Bestandtheil von relativ vielen oder bedeutungsvollen Associationen bilden, noch zı Stande kommen, während andere Innervationen unmöglich werden. ${ }^{1}$ ) Es wäre dagegen ebenso falsch, anzunehmen, dass dic einzelnen Begrifle oder Buchstaben alle besonders in einzelnen Zellen localisirt sind unit dass die betreffenden Zellen bei diesen Patienten zu Grunde gegangen wären, wie es falsch sein würde, in einem Falle von Interferenz von Tönen zu schliessen, dass die Schallquelle beseitigt sei. Wie in der Theorie des Lichtes die corpusculären Vorstellungen durch eine Wellentheorie ersetzt werden mussten, so muss auch, wie mir scheint, die Gehirnphysiologie ihre histologisch-corpusculären Vorstellungen durch dynamische Vorstellungen ersetzen.

Munk hatte behauptet, dass es bei cinem Hunde gelinge, direct nachzuweisen, dass die einzelnen Erinnerungsbilder des Gesichtssinnes in isolirten Zellen resp. Zellgruppen jener Stelle $A^{\mathbf{1}}$ localisirt seien. Er führt zum Beweise zwei Versuche an, ,bei welchen nach Exstirpation der Stelle $A^{1}$ unter Verlust aller anderen Erinnerungsbilder der Gesichtsempfindungen ein einzelnes solches Erinnerungsbild unversehrt erhalten gefunden wurde; in dem einen Falle das Bild des Eimers, aus welchem der Hund zu trinken gewohnt war, in dem anderen Falle das der Handbewegung, auf welche die Pfote zu reichen der Hund vor der Operation eingeübt worden war." Diese Angabe Munk's war die Ursache, welche mich als Student zu Hirnversuchen führte. Ich glaubte an , die Richtigkeit seiner Angaben und hoffte, dass nun ein Weg zu einer exacten Psychologie gefunden sei. Ich begann meine Versuche im Laboratorium von Goltz als überzeugter Anhänger von IIunk. Je mehr Versuche ich anstellte, um so mehr stellte es sich heraus, dass viele der Behauptungen Munk's unrichtig waren, ganz besonders aber seine allerdings spärlichen Angaben über die angebliche Localisation ein-

3) Man kam ähuliche Zustände, wie sie bei diesem Patienten rorhanden waren. künstlich hervorrufen durch die Dynamometerversuche, welche wir im nächsten Kapitel schildern werden. 
zelner Erinnerungsbilder. Es handelt sich bei Munk's Hunden, wie in der voraufgehenden Torlesung gezeigt worden ist, überhaupt nicht um Verlust ron Erinnerungsbildern, sondern um Hemiamblyopie.

\section{Litteratur zu XVIII.}

1) Goltz, Ueber die Verrichtungen des Grosshirns. 5. Mittheilung. Pflüger's Archir, Bd. 34. 1884.

2) Loeb. Beiträge zur Physiologie des Grosshirns. Pflüger's Archiv, Bd. 39. $18 \$ 6$.

3) Rieger, K. Beschreibung einer Intelligenzstörung in Folge einer Hirnverletzung etc. Verhandl. der Würzburger Physikalisch-MredicinischenGesellschaft. Bd. 22 und 23. 1889 und 1890. 
XIX.

\section{Ueber einige Angriffspunkte für eine künftige Mechanik der Gehirnthätigkeit.}

1) Wir haben gesehen, dass der Segmentaltheorie nirgends ein Hinderniss im Wege steht. Wir müssen nunmehr die Consequenz dieser Theorie für eine Mechanik der Hirnthätigkeit höherer Thiere ziehen. Wir hatten gefunden, dass bei den Reactionen eines Thieres das segmentale Ganglion nur die Rolle eines protoplasmatischen Leiters spielt, dass die Reactionen aber in Wirklichkeit bestimmt sind durch die Reizbarkeiten (resp. Sinnesorgane) der peripheren Gebilde und die Anordnung der Muskeln. Nur solclie Umstände wie die Anordnung und Orientirung der nervösen Elemente, (möglicher Weise die geotropische Reizbarkeit derselben), sowie die associative Gedächtnissthätigkeit kommen als specifische Eigenschaften des Centralnervensystems in Betracht. Es ist klar, dass ein grosser Theil von dem, was wir heute als Gehirnfunctionen bezeichnen, nur Functionen der peripheren Gebilde sind.

Damit gewinnen wir die Zuversicht, dass eine Analyse der Reizbarkeiten der Sinnesorgane und der Emptindungen die Basis für das Verständniss der sogenannten Hirnfunctionen bilden muss.

Helmholtz hat betont, dass unsere Sinne uns nur Symbole der Aussenwelt liefern. Jeder physikalische Vorgang, der ein Sinnesorgan trifft, ruft hier Veränderungen hervor, welche durch die periphere Struktur oder wie die Physiologie das seit Joh. Müller nennt, durch die specifische „Energie" des Sinnesorgans bestimmt ist. Ob ein Schlag, ein elektrischer Strom oder Aetherschwingungen von rund 0.000S-0.0004 mm. Wellenlänge die Netzhaut erregen: die Empfindung ist stets eine specifische, nämlich Licht, während Schlag und elektrischer Strom im Ohr Schallempfindungen hervorrufen. Dieses sogenannte Gesetz der specifischen Energie der Sinnesorgane ist nicht nur den Sinnesorganen eigenthümlich, es passt, wie Sachs hervorgehoben hat, auf alle lebende Substanz, ja es gilt für jede Maschine. Es ist eben nur ein anderer Aus- 
druck für die Thatsache, dass Auge, Ohr und überhaupt jedes Sinnesorgan und lebende Gebilde nur in bestimmter Form Energie umzusetzen im Stande sind, d. h. dass sie besondere Maschinen bilden. Die Feststellung dieser Form würde die nähere Bestimmung dessen sein, was wir uns eigentlich unter der specifischen Energie der Sinne rorzustellen haben. Die Physiologie giebt uns auf die letztere Frage keine Antwort. Man hat den Begriff der specifischen Energie stets als das letzte in der Sinnesphysiologie angesehen, bis zu dem die Forschung vordringen könne. Um so höher ist das Terdienst von Mach und Hering anzuschlagen, die mit ihrer chemischen Theorie der Farbenempfindungen jene Grenze zuerst überschritten haben. Mach hat weiter neuerdings mit aller Bestimmtheit den Gedanken ausgesprochen, dass chemische Umstände den Empfindungen zu Grunde liegen (1). Es ist klar, dass, wenn wir die Natur der Torgänge kennen, welche durch die äusseren Einwirkungen in unseren Sinnesorganen hervorgerufen werden, wir in der Lage sind zu bestimmen, in welcher Form die Erregungen unserem Centralnervensystem ron den Sinnesorganen zufliessen.

Für das Auge dürfen wir es allerdings als wahrscheinlich ansehen, dass das Licht chemische Wirkungen hervorruft. Es werden verschiedene Substanzen in der Retina gebildet und zersetzt und die chemischen Vorgänge der Bildung und Zersetzung dieser Substanzen bestimmen die Licht- und Farbenempfindungen. Die Aetherschwingungen bestimmter Wellenlängen beeinflussen diese Zersetzungen in bestimmtem Sinne. Die elektromagnetische Theorie des Lichts wird hier wohl noch zu reichen Einsichten fülıren. Durch den elektrischen Strom werden ebenfalls derartige Umsetzungen hervorgerufen. Der Strom selbst kann nur durch Elektrolyse die Retina durchsetzen und es könnte sein, dass die durch die freiwerdenden Jonen gebildeten secundären Zersetzungsproducte erst die Sehsubstanzen angreifen. Es ist aber auch nicht ausgeschlossen, dass die sogenannten Sehsubstanzen selbst Elektrolyte sind. Wir können es also leicht verstehen, dass auch der elektrische Strom im Auge Lichtempfindungen auslöst. Dass auch Druck und Stoss auf das Auge solche Wirkungen hat, kann nicht befremden. Carey Lea hat gefunden, dass in gewissen Verbindungen, z. B. auf photographischen Platten, Druck den chemischen Umsatz rermehrt resp. hervorruft.

Die specifische Energie des Auges wäre danach nichts weiter, als der Umstand, dass ganz bestimmte Verbindungen und zwar jedes Mal in derselben Weise in der Retina Umsetzungen erleiden, gleichviel ob die Umsetznngen durch Aetherschwingungen, durch den elektrischen Strom oder durch Druck, Zug oder Stoss veranlasst sind. Die Erregungen; welche dem Gehirn rom Auge aus zufliessen, werden also genau die Mannig- 
faltigkeit und Eigenthümlichkeiten aufweisen, welche der Mannigfaltigkeit und dem Verlauf der chemischen Vorgänge in der Retina entsprechen.

Für die Erregungen, welche dem Gehirn ron den Geschmacksorganen und der Nase zufliessen, gilt das Gleiche. Die chemische Natur der die Empfindung auslösenden Umstände liegt hier zu sehr auf der Hand, um noch eines Nachweises zu bedürfen. Es ist klar, dass auch hier zum Theil Jonenwirkungen im Spiele sind.

Schwieriger liegen die Dinge für die Hautsinnesorgane. Aber dennoch wäre es wenigstens denkbar, dass auch hier die Möglichkeit einer chemischen Grundlage der Sinnesthätigkeit besteht. Ich stütze mich dabei auf einen Gedankengang, mit dem ich den merkwürdigen Einfluss der Schwerkraft auf die Orientirung von Thieren und Pflanzen und auf deren Organbildung klar zu machen suchte (2). In diesen Fällen ist es zweifellos, dass Aenderung der Orientirung der betreffenden Organe eine Aenderung des chemischen Umsatzes herbeiführt, da ja sonst nicht zu verstehen wäre, wie die Spannungsänderungen der MIuskeln und die Aenderung der Organbildung und des Wachsthums zu Stande kommen könnten. Bestehen die chemischen Vorgänge in den betreffenden Fällen beispielsweise in hydrolytischen Spaltungen, so muss der Betrag des chemischen Umsatzes in der Zeiteinheit ceteris paribus eine Function der Reactionsfläche oder der Zahl der in Berührung kommenden Fermentmoleküle und der spaltbaren Moleküle sein. Nehmen wir an, dass beide in verschiedenen Formbestandtheilen der lebenden Zellen vorhanden sind, dass beispielsweise das Ferment in festen Bestandtheilen, die spaltbare Substanz in flüssigen Bestandtheilen der Zelle vorhanden ist, so ist es klar, dass eine Umlagerung der Zelle, wenn das ein Fliessen der flïssigen Bestandtheile reranlasst, die Folge haben kann, dass neue Moleküle der spaltbaren Substanz mit den Fermenten in Berührung kommen und dass so der Stoffumsatz vermehrt wird. Das kann eine chemische Weiterleitung des vergrösserten Umsatzes durch die Nerven, und damit eine chemische Fernwirkung zur Folge haben. Es ist einstweilen nicht möglich, aber auch nicht nöthig; über die Andeutung ron Möglichkeiten einer chemischen Auslösung der geotropischen Reactionen in besonders orientirten Zellen, wahrscheinlich in gewissen Gehirntheilen, hinauszugehen. In demselben Sinne könnte der Druck auf die Tastnerven der Haut eine Vergrösserung der Reactionsfläche zwischen Ferment und spaltbarer Substanz und entsprechend eine Zunahme des Stoffumsatzes bedingen. Am gezwungensten, wenn nicht unmöglich, erscheint dagegen die Uebertragung dieser Anschauungen auf die Schneckenorgane des Ohres. Wir könnten uns hier vorstellen, dass die Vibrationen der MCembrana basilaris in den entsprechenden Hörnervenendigungen Erschütte- 
rungen hervorruft, wobei ebenfalls für die Dauer der Vibrationen die Zahl der in Berührung kommenden reactionsfähigen Moleküle vermehrt wird. Mit einer solchen Theorie würde aber eine Schwierigkeit geschaffen, von der ich einstweilen nicht sehe, wie sie zu umgehen ist, nämlich: die Mannigfaltigkeit unserer Empfindungen und die Unterschiede ihrer Form sind zu gross, als dass alle auf Vorgänge ein und derselben Art, nämlich chemische Umsetzungen, zurückgeführt werden könnten. Es wird deshalb besser sein, einstweilen eine chemische Theorie für die Thätigkeit aller Sinnesorgane nur als Möglichkeit im Auge zu behalten.

Ich glaube, dass die wesentliclısten Thatsachen der Gehirnphysiologie, soweit sie auf vivisectorischem Wege zu gewinnen sind, feststehen. Die weiteren Einsichten knüpfen sich an eine tiefere Analyse der Empfindungen resp. der Reizbarkeiten. Wir müssen vor allem die Lücken unseres Wissens, die wir bisher mit dem Hinweis auf die specifische Energie der Sinnesorgane ausgefüllt haben, durch bestimmtere Einsichten ausfüllen.

2) Ein weiterer Angriffspunkt für eine künftige Mechanik der Hirnthätigkeit liegt im Problem der associativen Gedächtnissthätigkeit. Wie kommt es, dass zwei nahezu gleichzeitig stattfindende Vorgänge soweit verschmelzen, dass später das Eintreten des einen Vorganges auch den zweiten wieder zum Vorschein bringt? Verschmelzen gleichzeitig stattfindende Vorgänge im Gehirn?

Wenn wir mit einer Hand rasch ein Rad drehen, ohne uns weiter um die Art und Geschwindigkeit der Drehungen zu kümmern, und gleichzeitig in Gedanken ein Gedicht declamiren, ohne die Lippen dabei zu bewegen, so steht die Zahl der Drehungen in einem einfachen Verhältniss zu der Zahl der Intensitätsschwankungen bei der Innervation für das Declamiren des Gedichts. Im Deutschen, wo die Arsen mit grösserem Nachdruck gesprochen werden, als die Thesen, ist die Zahl der Drehungen im Allgemeinen gleich der Zahl der Arsen. Brücke hat zuerst auf eine derartige Beziehung hingewiesen und ich habe vor 12 Jahren viele (noch nicht veröffentlichte) Versuche über diesen Gegenstand angestellt, die dasselbe ergaben. Ich fand aber weiter, dass wenn man mit Absicht sehr rasch dreht und langsam declamirt, die Zahl der Drehungen ein einfaches Multiplum der Arsen ist. Man macht 2, 3 oder mehr Drehungen im Intervall einer Arse. Declamirt man sehr rasch und dreht man mit Absicht sehr langsam, so wird die Zahl der Arsen ein einfaches Multiplum der Zahl der Drehungen. Am bäufigsten ist in letzterem Falle die Zahl der Drehungen der Zahl der Verse gleich. Nehmen wir an, dass bei dem Denken wie bei dem Aussprechen des 
Gedichtes die Innervationen, welche den Rhythmus zum Ausdruck bringen, sich als harmonische Curven darstellen lassen, und dass dasselbe für die Innervationen gilt, welche für das Drehen des Rades verantwortlich sind, so folgt aus diesen Thatsachen, dass gleichzeitig stattfindende harmonische Innervationsrorgänge sich so beeinflussen, dass die Perioden beider Torgänge entweder gleich werlen oder doch in Verhältniss einfacher ganzer Zahlen stchen. Es gehört Absicht und grosse Entschlossenheit dazu, gegen jenes Gesetz zu verstossen. Ich bin nicht einmal ganz sicher, ob nicht, wo das gelingt, die Abweichung vom Gesetz nur scheinbar ist. In Wirklichkeit dürfte es sich so verhalten, dass wir einen der beiden Vorgänge vorübergehend zum Stillstand bringen. Darüber sind noch weitere Beobachtungen anzustellen. Die Thatsachen reichen aber jetzt schon aus, um festzustellen, dass natürlicher Weise zwei gleichzeitig stattfindende harmonische Innervationsvorgänge verschiedener Innervationsgebiete sich gegenseitig beeinflussen und am leichtesten Vorgänge gleicher Periode bilden. Diese Thatsachen sprechen nicht dafür, dass der Innervationsvorgang des sprachlichen Denkens bloss auf das motorische Sprachcentrum der Grosshirmrinde und die Innervationen des Armes auf das "Armcentrum" beschränkt sind. Es folgt vielmehr aus diesen Beobachtungen, dass, wenn wir sprachlich denken, der Innerrationsvorgang sich dem Rest des Grosshims (und event. auch weiteren Theilen) mittheilt und dasselbe gilt auch für die motorischen Innervationen des Armes.

Das Gleiche gilt ferner nicht nur für gleichzeitige Innervationsvorgänge, sondern auch für gleichzeitige Sinneserregungen und Innervationen. Beim Tanz haben wir denselben Fall vor uns, nur dass der Rhythmus der Musik die Periode der Innervationen bestimmt.

Handelt es sich um aperiodische Vorgänge, so muss dasselbe Princip, das bei harmonischen Vorgängen fördernd eingreift, sich oft als Störung bemerklich machen. So erkläre ich die bekannte Erfahrung, dass wir nicht gut zwei Dinge auf einmal thun können. Allgemein gültig ist das nicht, bei harmonischen Innervationsvorgängen fanden wir ja gerade das Gegentheil. Aber es gilt für viele aperiodische Vorgänge. Wenn wir über einen breiten Graben springen, so können wir nicht gut gleichzeitig eine Gleichung lösen. Fechner fasste das so auf, als ob dem Gehirn nur eine bestimmte Menge Energie auf einmal zu Gebote stehe. Beim Sprung über den Graben solle nun alle Energie den Muskeln zufliessen und nichts mehr für den Denkprocess übrig bleiben. Ich babe schon vor zwölf Jahren gezeigt, dass Fechner's Auffassung falsch ist. Die Hemmung eines Denkprocesses durch gleichzeitige Muskelthätigkeit 
ist nämlich die gleiche, wenn wir einen Arm in maximale Thätigkeit setzen oder beide Arme oder alle Muskeln unseres Körpers. Sie ist eher noch grösser, wenn wir nur einen Arm in Thätigkeit setzen, als wenn wir beide gleichzeitig innerviren. Nach Fechner müsste aber um so mehr Energie im Gehirn aufgebraucht werden, je mehr If uskelgruppen innervirt werden. In diesen Versuchen bediente ich mich einer messenden Methode, welche darin bestand, dass ich die Grösse des maximalen Druckes ermittelte, welchen die Beuger unserer Hand auf ein Dynamometer auszuïben im Stande sind. Dieser Druck nimmt nicht nur nicht $a b$, wenn man gleichzeitig die andere Hand oder alle Muskeln innervirt, sondern sogar zu. Versucht man dagegen gleichzeitig zu rechnen, so erreicht der Dynamometerdruck nicht das Maximum, das er ohme gleichzeitige Geistesthätigkeit erreichen würde (3). Die weitere Anwendung dieser Methode ergab denn auch die Erklärung der Ausgangsthatsache, dass wir nicht gut gleichzeitig geistig und körperlich thätig sein können.

Beginnen wir mit dem Lösen einer nicht gerade leichten Aufgabe im Kopfrechnen und rersuchen wir, wenn wir mitten in der Aufgabe begriffen sind, mit der Hand den höchsten dynamometrischen Druck zu erreichen, so bleibt der Druck etwa 20-30\% unter dem Maximum, das wir sonst erreichen, wenn wir alle Aufmerksamkeit dem Drucke allein zuwenden (4). Hanchmal aber erreicht man auch beim Rechnen den maximalen Druck, den man in der Ruhe beobachtet. Allein in dem Falle hat die Versuchsperson das Rechnen wälırend des Drückens sicher unterbrochen, was sich darin zeigt, dass sie entweder mit einem sinnlos falschen Resultat endigt, oder die Aufgabe, die ihr gestellt war, gänzlich vergisst und erstamt fragt, worin die Aufgabe bestanden habe. Es gehört zu den grössten Ausnahmen, dass die Versuchsperson beim Rechnen den maximalen Druck erreicht und dennoch die Aufgabe richtig löst. Ganz anders aber fallen die Versuche aus, wenn die Versuchsperson zuerst mit dem Drucke beginnt und ilır die Rechenaufgabe erst gestellt wird, wenn sie den maximalen Druck schon erreicht hat und sie nur nöthig hat, den Druck aufrecht zu erhalten. In dem Falle habe ich in meinen Versuchen keinen oder einen sehr geringen Einfluss beider Thätigkeiten bemerkt: Die Person konnte richtig rechnen und der Abfall der Curve während des Rechnens war gar nicht oder nur wenig steiler als ohne gleichzeitiges Kopfrechnen.

Wir sehen also, dass eine gleichzeitige statische Innervation, sie mag noch so stark sein, das Kopfrechnen nicht verhindert, dass dagegen eine rasch zunehmende Innervation, eine steile positive Innervationsschivankung den Rechenprocess empfindlich stört. Ich habe versucht, ob auch ein steiler Innervationsfall, d. h. ein plötzliches Erschlaffen der 
Innerration den Rechenprocess stört. Das war aber nicht der Fall. Der Vorgang des Kopfrechnens besteht aus einer Reihe dynamischer Vorgänge (den Theiloperationen, in die die Aufgabe zerlegt wird) und aus statischen Processen, die in dem Behalten der Resultate der einzelnen Theilrechnungen bis zum Feststellen des Gesammtresultats bestehen. Handelt es sich nun um ein plötzliches Aufgeben des dynamometrischen Druckes während der Rechnung, so erfolgt das meist, wenn eine Theilrechnung gerade vollendet ist, d. h. der Abfall der Handinnervation fällt zusammen mit dem Abfallen des Innervationsrorganges beim Abschluss eines Theiles der Rechnung. Es hat so keinen Einfluss auf die Rechenoperation. Ich bin aber nicht sicher, dass es mehr Einfluss besitzt, wenn die Versuchsperson während des Rechnens plötzlich aufgefordert wird, das Drnamometer loszulassen, anstatt dass die Wahl des Zeitpunktes des Loslassens ihr selbst überlassen bleibt.

Was auch die Erklärung dieser Erscheinungen sein möge, wir sehen, dass zwei gleichzeitige maximale aperiodische, mit Anstrengung verknüpfte Innervationsvorgänge, die verschiedene Organe betreffen, sich gegenseitig stören. Sind sie dagegen nicht ron maximaler Intensität, so können sie ruhig gleichzeitig ablaufen. Ich fand, dass leichte Rechenaufgaben oder das Reproduciren von Gedächtnissmaterial das Druckmaximum nicht herabsetzen.

In dieselbe Kategorie ron Erscheinungen gehören auch vielleicht die bekannten Hemmungen ron Reflexen. Wir haben erwähnt, dass ein Hund mit durchschnittenem Rï̈ckenmark pendelnde Bewegungen der Hinterbeine zeigt, wenn dieselben frei herabhängen. Kneift man aber die Haut am Hinterkörper des Thieres, so hören die pendelnden Bewegungen sofort auf (Goltz).

Die Rolle, welche die Intensität bei dem gleichzeitigen Ablauf von zwei Innervationsrorgängen spielt, erinnert an die Zusammensetzung ron Wellenbewegungen, bei denen ja auch eine Superposition nur dann möglich ist, so lange die Amplitude nicht zu gross wird. Es wäre denkbar, dass zwei Vorgänge nur dann in unserem Gehirn gleichzeitig umgestört ablaufen können, wenn ihre Intensität gering genug ist, um eine superposition zu gestatten.

Es ist vielleicht erlaubt, die Aussichten, welche diese Analogie der Gehirnvorgänge mit Wellenbewegungen und deren Zusammensetzung bietet, einen Schritt weiter zu verfolgen und zu sehen, wie sich die Associationsvorgänge diesem Bilde einfügen. Ein Vorgang bleibt mit denjenigen Vorgängen in unserem Gehirn associirt, welche röllig oder nahezu gleichzeitig mit ihm ablaufen, so dass wenigstens der letzte Theil des einen Vorganges und der Anfangstheil des anderen zusammenfallen. 
Wir stellen uns nun vor, dass jeder Vorgang in unserem Centralnervensystem eine bestimmte Form besitzt insofern, als sich sein Verlauf in einer Curre darstellen lässt. Finden nun zwei Vorgänge gleichzeitig statt und ist ihre Intensität nicht zu stark, so superponiren sie sich. Die Spuren, welche dieser Vorgang in unserem Centralnervensystem zurücklässt, entsprechen der Curve, welche durch die Zusammensetzung beider Vorgänge bestimmt ist. Findet später der eine Vorgang statt, so erklingt auch der früler associirte Vorgang mit. Umgekehrt bringt ein sehr complicirter Vorgang einfachere Vorgänge zur Resonanz, welche als Theilbestandtheile in ihm enthalten sind und die früher in einfacher Form schon einmal abliefen. Die Lehre von den Tonempfindungen giebt uns Analogieen dafür, wie einfache Töne sich zu einem Klang zusammensetzen und wie wir umgekehrt in einem Klangbild die elementaren Bestandtheile heraus zu bören im Stande sind. In unseren Gehirnvorgängen wirkt das, was wir in der psychologischen Terminologie als das Gedächtnissbild eines Vorganges bezeiclnen, wie der Helmholtz'sche Resonator heim Heraushören eines Theiltons aus einem zusammengesetzten Klang. Ich glaube, dass zum grossen Theil auf der Ausbildung der Resonanzfähigkeit in beiden Richtungen - des associativen Herausklingens der Theilbestandtheile aus einem complicirten Vorgange und der Erregung complicirter Vorgänge durch einen in ihnen enthaltenen elementaren Vorgang - das beruht, was wir als Intelligenz bezeichnen. Das kann natïrlich nichts mit dem Gewicht des Gehirns zu thun haben. Der zweite Umstand, der neben dieser Resonanzfähigkeit für die geistige Leitungsfähigkeit in Betracht kommt, ist, wie schon oben erwähnt, die Capacität, die Zahl der im Gehirn bleibenden Gedächtnissbilder.

IIan versucht heute alle Erscheinungen der Gehirnthätigkeit rein auf Grundlage anatomischer Nervenverbindungen zu erklären, ohne zu berücksichtigen, dass dynamische Theorieen ganz andere Möglichkeiten zulassen. Wenn gewisse Töne einen Hund zum Heulen bringen, gewisse Laute ein Kind zum Sprechen, gewisse Gerüche einen männlichen Hund sexuell erregen, das Reiben der Rückenhaut einen Frosch zum Quaken veranlasst, so ist für Viele die Sache damit abgethan, wenn sie sagen, es führe eine Bahn von dem Acusticuscentrum zu den Stimmmuskeln etc. Dabei aber wird übersehen, dass nur bestimmte Töne den Hund zum Heulen veranlassen, nur bestimmte Gerïche ihn erotisch beeinflussen, andere Gerüche dagegen nicht u. s. w. Es ist also nicht ausschliesslich die nervöse Verbindung, sondern ein Umstand, den wir als die Form des Erregungsvorganges bezeichnen, welcher für den Erfolg entscheidend ist. Wollten wir die Parallele der Gehirnvorgänge mit Wellenbewegungen noch weiter führen, so hätten wir anzunebmen, 
dass vielleicht auch die Centralendigungen verschiedener Organe als Resonatoren anzusehen sind, die auf ganz bestimmte und begrenzte Erregungsvorgänge abgestimmt sind.

Ich glaube aber, dass eine derartige Theorie einstweilen so gehalten werden muss, dass sie dem Einflusse chemischer Vorgänge den grössten Spielraum lässt. Die correlativen Aenderungen, welche wir bei rielen Thieren zur Brunstzeit beobachten, müssen ja wohl durch Stoffe bedingt sein, die während dieser Zeit im Blute circuliren (innere Secretion) und die in den Stoffwechsel gerade derjenigen Organe eingreifen, welche während dieser Zeit Aenderungen des Aussehens oder der Reizbarkeit aufweisen.

Ich will diese hypothetischen Betrachtungen hier nicht weiterführen. Nur darauf wollte ich hinweisen, dass die histologisch-corpusculären Vorstellungen der Anhänger der Centrentheorie nicht zu einer Mechanik der Gehirnthätigkeit führen, sondern dass eine dynamische Theorie der Associationsvorgänge nöthig ist.

3) Eine gesonderte Stellung in der Mechanik der Hirnthätigkeit nehmen die Raumempfindungen ein. Wie kommt es, dass unsere Raumempfindungen eine Mannigfaltigkeit von drei Dimensionen sind, und wie kommt es, dass die Erfassung von geometrischen Beziehungen gewisser Art uns so leicht fällt? Jach hat auf die Bedeutung unserer Körperform und unserer Innervationsverhältnisse für die Erfassung der Symmetrie aufmerksam gemacht (5) und seine Ausführungen gehören zu dem Geistvollsten, das die physiologische Litteratur besitzt. Unsere Versuche über Galvanotropismus weisen darauf hin, dass eine einfache Beziehung bestehen muss zwischen der Orientirung gewisser Elemente des Centralnerrensystems und der durch sie bestimmten Richtung der Bewegung. Unsere Erfahrungen ïber Augenbervegungen - insbesondere das Heringsche Innervationsgesetz - die Erfahrungen über das Verhalten der vorn und hinten im Grosshirn operirten Hunde etc. lassen daran denken, ob jene Elemente des Centralnervensystems nicht etwa parallel den drei Hauptaxen unseres Körpers orientirt sind. In dem Falle wäre es möglich, dass die drei Urcoordinaten unserer Raumempfindungen bestimmt sind durch den Umstand, dass die für die Raumempfindungen wesentlichen Elemente des Centralnervensystems von dreierlei Art sind, die sich ron einander durch ibre Orientirung gegen die drei Hauptaxen unterscheiden. Wir haben in Vorlesung XI darauf hingewiesen, dass der Vorgang, den wir als willkürliche Innervation bezeichnen, vielleicht ein Vorgang ist, bei dem die Richtung, in der er abläuft, von besonderer Bedeutung ist, ähnlich wie bei galvanischen Vorgängen. In dem Falle können wir es verstehen, wie es beispielsweise kommt, dass, 
202 Ueber einige Angriffspunkte für eine künftige Mechanik der Gehirnthätigkeit.

wie Mach betont hat, der Wille Blickbewegungen auszuführen, mit der Raumempfindung identisch ist. Da ich hier keine Theorie der Raum. empfindungen geben, sondern nur zeigen will, welche Stellung dieselben in einer künftigen Nechanik der Hirnthätigkeit einnehmen dürften, so mögen diese Andeutungen genügen. Ich hoffe, dass meine weiteren Untersuchungen mir eine Gelegenbeit bieten werden, die Thatsachen dieses Kapitels weiter zu entwickeln.

\section{Litteratur zu XIX.}

1) Mach, E, Die Principien der Wärmelehre. Leipzig 1896. S. 360.

2) Loeb, J. Zur Theorie der physiologischen Licht- und Schwerkraft-II irkungen. Pftüger's Archiv, Bd. 66. 1897.

3) Loeb, J. Muskelthätigkeit als Maass psychischer Thätigkeit. Pflïger's Archiv, Bd. 39. 1886.

4) Welch, J. C. On the Measurement of Mental Activity through MIuscular Activity etc. The American Journal of Physiology, Vol. I, 98.

5) Mach, E. Beiträge zur Analyse der Empfindungen. Jena $18 S 5$. 


\section{Register.}

Aal 94. 100. 111. 160.

Acalephen 11. 12 12. ff.

Actinien 30 u. ff. 145.

Amblystoma 108-110. 131.

Ameisen 14:-145.

Amphipyra 123.

Anneliden $56 \mathrm{u}$. ft.

Apáthy 29.91.

Aphasie 169-171. 189-191.

Arnold 25.

Arthropoden 68 u.ff.

Ascidien 2:- u. ff.

Ascidienherz 15. 16.

Associative Gedächtnissthätigkeit, nothwendig für Bewusstsein 7. S. 140.149.16\%.

- - Verbreitung 141. 145-147.

- - , abhängig vom Grosshirn 152-160.

- - beeinflusst durch Innervationen $196-201$.

- -, corpusculäre Theorie derselben 9. 1SS. 189. 191. 192.

— - dywanische Theorie derselben 9. 1SS. 190. 191. 196-201.

Astacus siehe Flusskrebs.

Asterina gibbosa 45 .

Asterina temispina 46 .

Athemzentren bei Arthropoden 71. 72. 73.

- bei Wirbelthieren 73. 74. 97.

Aurelia aurita 11. 12.

Automatische -Vorgänge 6. 10. 16. 17. 1S.

Balanus perforatus 128. 129.

Baumann 135.

Bell 90.

Beseeltheit der Pflanzen und aller Materie

7. 162. Siehe anch Bewusstsein.

Bethe 28. 29. 75. 77-S1. 83. 8t. 87. 105. $142-145.150 .151$.

Bewegungsdrang enthirnter Würmer 62 u.ff.

- bei Krebsen 77. 7S.

- Mollusken 87.

- " Fröschen 93.

- "Hunden 117. 156. 187.
Bewusstsein. Kriterium und Verbreitung 7. 8. 139-151. 162.

- abhängig von Grosshirn 153 u. ff.

- Entwickelung desselben 162-163.

- Unterschiede des Umfanges 163-164.

- abhängig von Sauerstoff 161-165.

Siehe auch Localisation.

Bienen. Gehiruphysiologie 81.

- Intelligenz $145^{\circ}$.

- Schmerzempfindungen 150.

Bickel 100.

Blasius 111.

Blutgefässe 27. 28. 183.

Bouillaud 169. 171.

Broca 169. 170. 171. 177.

Brown-Séquard 25. 74. 100.

Brïcke 196.

Budge 25.

Cajal 29.

Carcinus maenas 28. 79 .

Centren im Grosshirn 16S-183.

- im Rï̈ckenmark 89-100. Siehe auch Localisation.

Cephalopoden 86.

Cerianthus 32. 33.34 u. ff. 146.

Characteränderungen nach Gehirnverletzung bei Würmeru $62-67$.

— - - bei Krebsen 77-7S.

- - n Mollusken 87.

- - " F'röschen 92-93.

- - " Hundeu 117. 186 и. ff.

Chemische Reizbarkeit bei Actinien 30 u. ff.

- - bei Krebsen 78.

- - Siehe auch Chemotropismus.

Chemische Theorie der Empfindungen 194 bis 196. 201 .

- - der Vererbung 133-138.

- _ . Geisteskrankheiteu 135.

- - " Triebe und Instinkte 96. 119 bis 130 .

- - des Electrotonus 109.

- - der Shockwirkungen 174. 181. Siehe auch Chemotropismus. 
Chemotropismus 4. 60. 61. 124. 125. 143. Christiani 156.

Chun 129.

Ciona 3. 22 u. ff.

Compensatorische Bewegungen 95.

Siehe auch Hörnerv und Geotropismus.

Contaktreizbarkeit bei Actinien 34. 37.

- bei Seesternen 41.

- Siehe auch Stereotropismus.

Coordination der Athmung 72. 73.

Coordination der Bewegung5.6.13-16.113.

— - - beim Regenwurm 58. 59.

- _ - " Hunde 59. 117.

— - " Froseh 93. 94.

_ - Kleinhirn und - 117. Siehe auch Orientirnng und Function motorischer Elemente.

Coordination der Herzthätigkeit 13-15.

Cucumaria 43 u. ff.

Cyon, v., E. 90. 103. 173. 1 S3.

Darwin 130.

Dax 169. 170.

Deviation conjuguée 102.

Dohrn 89.

Dural 166. 167.

Duyue, van 55.67.

Dynamometerversuche 197-2C0.

Dytiscus 69.

Echinodermen 39 u. ff.

Eimer 21.

Electrische Reizung 96. 10S-114. 116. 171. 193. 194.

Electrotonus 109 น. ff.

Eledone 86.

Empfindungen 149-151. 162. 194-196. 201. 202.

Engelmann 6. 21. 91.

Entrickelung des Bewusstseins 8. 9. 162 bis 163 .

Frinnerungsbild. Siehe associative Gedächtnissthätigkeit u. Localisation.

Eudendrium 120.

Ewald 25-29. 96. 100. 136. 13S. 153. 173.

Faivre 69. 70, 71. 75. 83.

Falken ohne Grosshirn $15 \mathrm{~S}$.

Fechner 197. 198.

Ferrier 116. 118.

Fische 96. 103. 104. 117.

Fliege 124.

Fliegenlarve 125.

Flourens 70. 73. 74. 77. 92. 93. 100. 115. 116-118. 153. 172. 187.

Flusskrebs $75-80$. $110 u$. ff.

Forel 144.

Fressstörungen 90. 158, 159, 160.

Friedländer, B. 58. 59. 60. 6\%。

Fritsch 171.

Frosch. Nervensystem 91 .
Frosch. Rückenmark 92-36.

- Grosshirn 152.

- Localisirungsreflex 20.

Froschlarve 134 .

Funetionslocalisation $97-100 . \quad 168-183$. 184-192. $197-202$.

Gall 169. 171. 177.

Galvanotropismus 5. 119. 123.

-, Theorie eles 109 и. ff.

- bei Amblystoma 108-111.

- beim Flusskrebs 110.

- bei Palaemonetes 111.

Gammarus 150.

Ganglien, Bedeutung für anatomische Thätigkeit 5. 6. 16. 18 .

-, Bedeutung für Reflexe 2-5. 22-29.

-, " Coordination 5, 12-16.

Ganglienzelle, tropische Function derselben 90. 91.

-, unnöthig für den Reflex 28. 29.

Garley 108. 111. 114.

Gaskell 6.

Gaule 136. 138.

Gefässreflexe 27. 28. 173.

Gehirn der Planarien 48 и. tf.

- $\quad$ Mollusken 85 u. ff.

- "Wirbelthiere 89 u. ff. Siehe auch Grosshirn und Oberschlundganglion. Gehirn und Bewusstsein 152 u. ft.

Gehirnmasse ohne Berleutung für Intelligenz 164 .

Geisteskrankheiten, chemische Theorie derselben 135 .

Geotropismus bei Actinien 34 u. ff.

- bei Seestermen 41. 42. 45.

- "Insecten 43.

- "Cucumaria 43.

- "Krebsen 79 und Tiefenwanderungen der Seethiere 1:9.

Geppert 7?.

Golgi 91.

Goltz 25. 29. 59. 64. 74.91. 94. 96. 9S. 100. 129. 130. 131. 136. 138. 153. 159.161. 167. 172. 173. 174. 176. 17S. 183. 184. 185. 191. 19:. 199.

Gonionemus 10. 11. 14. 15.

Graber 67. 146.

Grillen S1.

Groom 12S. 131.

Grosshirn, Exstirpation des, bei Fröscinen 152. 153.

- - - bei Haifischen 152.

— - - Vögeln 153-159.

- - ${ }^{\prime}$ Hunden 159-160.

- - Kaninchen 156. Siehe auch electrisch" Reizung und Localisation.

Grosshirn, Segmentaltheorie desseiben $168 \mathrm{ff}$. Grosshirn und Reflexe 152-153.

Haifisch 103. 104. 153. 153.

Halbkreuzung 101-103. 
Halbzirkelkanäle 115. 116. Siehe auch Hörnerv.

Hargitt 14. 15.

Hegel 148.

Heliotropismus 2. 4.

- ber Asterina 46.

- „Eudendrium 120.

- Motten 121.

- "Raupen 126.

- . Seethieren 127-129.

- Umwandlung des Sinnes des H. 128. 129.

Helmholtz 193. 200.

Hemiamblyopie 180, 181.

Hemianopsie 180. 181.

Hemmung der Reflexe 153. 196-201.

- der Progressivbewegung 92-93. 106 bis 107. 115. 185-188.

- Iurch electrischen Strom 110-114. Siehe auch Shockwirkung.

Hering 107. 156. 194. 201.

Hertwig, 0. und R. 21.

Heteromorphose 32. 133.

Heuschrecken 81.

Hintere Wurzeln, Einfluss auf Musheltonus 90. 103. 173. 174.

Hinterhauptsiappen 178-182. 185-188.

Hitzig 171. 172. 174-177, 183, 186.

Hood, Thomas 169.

Hörnerv, Folgen der Verletzung 103. 104. 107. 115. 116. 174. 187.

Hummer 76.

Hund, Rückenmarksreflexe 59. 91.

-, Rückenmarksentfermung 25-28.

- ohne Grosshirn 159. 160.

-, Grosshirnlocalisation 171-183.

-, Grosshirn und Intelligenz 185.

- Erinnerungsbilder 191.

Hunter 26.

Hyde, Ida 69. 70. \$3. 105. 106.

Hydromedusen 10. 11.

Hydrophilus 82.

Hydrotropismus 45.

Ichbewusstsein 139. 140.

Innervationsvorgang, Natur des 113.

-, Analogie mit Wellenbewegungen 196 bis 201.

- und Raumempfindungen 113, 201. 202.

Instinkte 4. 96.

-, Theorie der 119-131.

Intelligenz bei Seesternen 42.

- Vererbung von 137.

- und Tropismen 142.

—, Unterschiede der 163.

-, Localisation der, im Stirnlappen 185.

-, Störung der, nach Gehirnverletzung 184. 185. 188. 189.

- und associatives Gedächtniss 200.

Jonen, siehe chemische Theorie.

Iris 24.25 .
Kettenreflex $₫ 6$.

Kleinhirn 115. 118.

Korányi 181.

Krebs, siehe Arthropoden.

Kussmaul 170. 183.

Langendorff 74. 83.

Lea 194.

Le Gallois 73.

Limulus $68-75.106$.

Iingle 16.

Localisation, Kritik und Fehlerquellen derselben 73. 74. 96-100. 172. 173. 174. 176. 177-183. 184-192. 197.

Localisation von Reflexen im Rückenmark $89-100$.

- - - im Grosshirn 168-122.

- - Erinnerungsbildern 17S-181. 188 bis 192 .

Localisirungsreflex 18-20.

Locomotionscentrum, allgemeines 93. 106. 107.

Locy 89.

Loeb 9. 29. 35. 47. 67. 107. 114. 131. 138. 151. 183. 192. 202.

Longet 156 .

Lubbock 144.

Luciani 117. 118.

Lumbricus 61.

Mach 139. 151. 194. 201. 202

Magendie 115. 117. 118. 154.

Mathews 135. 135 .

Maxwell 60.62. 65. 66. 67. 87. 93. 110. 111. 112. 114.

Macaskill 65 .

Mechanik der Gehirnthätigkeit 193 ฉ.ff.

Medulla oblongata, Functionen 73. 92. 93. 95. 97. 98. 103-105. 115-118.

Medusen, Nervensystem $10 \mathrm{u} . \mathrm{ff}$.

Meyer, Adolf 138.

Mollusken 85 u. ff.

Horeau 170 .

Motorische Zone des Grosshirns 168-178. $184-188$.

Motte 119. 121. 122.

Mïller, Joh. 193.

Munk 178-180. 182. 183. 191. 192.

Münsterberg 148. 151.

Mushelbewusstsein 174.175.

Muskelthätigkeit als Maass physischer Thätigkeit 197 11. ff.

Nagel 38. 142. 146 .

Nahrungsaufuahme, nach Exstirpation des Grosshirns 158-160.

Nereis 57. 62-66. 124.

Noeud vital. Siehe Athemzentrum.

Neuronentheorie 28. 29.

Norman 42. 149-151. 
Oberschlundganglion bei Anneliden 57-66. - bei Limulus 71.

- "Astacus 77-79.

- "Squilla 80.

- "Bienen 81.

- " Hydrophilus 82.

Ohr." Siehe Hörnerv.

Ophiuriden 42.

Orientirung und Function motorischer Elemente 108-114. 115. 118. 185-189. 200. 201.

Oxydation. Siehe Sauerstoff.

Palaemonetes 111. 112. 119.

Parker 32.

Patten 70.

Pflüger 160. 161. 167.

Pfropfversuche an Medusen 14.

Phrenologie 169-171.

Planaria torva 52-56.

Plateau 144.

Pollock 38 .

Polygordius 129.

Porthesia chrysorrhoea 126. 127.

Preyer 42. 46. 47.

Progressivbewegung. Siehe Locomotionscentrum, Coordination, Spontaneität, Hemmung.

Psychische Erscheinungen. Siehe Bewusstsein.

Pterotrachea S5.

Quakreflex 153.

Quincke 17.

Raumempfindungen 113. 156. 201. 202.

Reflexe, allgemeines $1-4$. 22-29. Specielles, siehe die verschiedenen Thierklassen.

-,- , geordneter Character derselben 5. 113.

- , -, ohne Ganglien 3. 23-29.

,,-- zweckmässiger Character derselben 2. 4. 9 .

Regenwurm 57 ı. ff. 149.

Reitbalmbewegungen. Siehe Zwangsbewegungen.

Reizschwelle nach Exstirpation von Ganglien $25 \mathrm{u}$. ff.

Rheotropismus 45.

Rhythmische Vorgänge 6.

- - Ursache derselben 14. 17. 18.

- - bei Medusen 12. 13. 15.

- - im Herzen 12-16.

Rieger 189-192.

Rolando 154 .

Rollbewegungen. Siehe Zwangsbewegungen.

Romanes 10 u. ff. 41. 142. 145.146.

Rosenthal 17.
Rückenmark, Function des 25-28. 59. 73. 74. $59-100$. 133. 13ิ4. 136. $160-162$. 172-174. 176.

Rückenmarksbewusstsein 160. 161.

Sachs 133, 193 .

Salamander 94. 108 u. ff. 134.

Sauerstoff und Gebirnthätigkeit 164. 165.

Schaper 26. 29. 134. 138.

Sehilddriise 185.

Schildkröte 1S. 20.

Schlaf.

- Dural's Theorie des 166.

Schmerzempfindungen bei Thieren 149 . 150.162 .

Schmetterlinge 121. 1:3. 143. 144.

Schopenhauer 148.

Schrader 92-95. 100. 106. 152-160. 166. 167. 182. 188 .

Schweizer 111.

Seelenblindheit 178-181.

Seesterne $39 \mathrm{u} . \mathrm{ft}$.

Segmentaler Character der Reflexe bei Würmern 56 u. ff.

- $-\ldots$ - bei Krebsen 83.

- _ - _ Fröschen 93.

_ - - $-"$ bei Hunden 91.

Segmentaltheorie, allgemeine 56. 57. 66. 68. $83.96-99$.

- - bei Wirbelthieren $S 9 \mathrm{u}$. ff.

- - " Würmern $56 \mathrm{u}$. ff.

- - " bei Arthropoden $68 \mathrm{u}$. ff.

- _ Grosshirn 168-183.

Sehsphäre 178-183.

Sherrington 107.

Shockwirkungen als Fehlerquelle bei Localisation 73. 74. 96-98. 172-174. 176 . 177. $179-181$.

-, Erklärung der. Siehe chemische Theorie. Spannungsänderung der Muskeln nach Gehirnverletzung bei Würmern 67.

— _ _ - bei Arthropoden 77. 105.

- - - Grosshirn verletzung 175. 176. 181. 186.

- - - D Durchschneidung der binteren Wurzeln 90. 103. 173.

Specifische Energie der Sinnesorgane 193 bis 196.

Speck 16i. 165. 167.

Spencer 137. 138.

Sphincterreflex 25. 26.

Spontaneität 5 . 6 .

- bei Planarien 49 u. ff.

-, enthirnten Anneliden $61 \mathrm{u}$. ff.

- "Krebsen 77.

- "Fröschen 92.

- und Grosshirn 152-160. 185̃-1S8.

-, unabhängig von Ganglien 6. 105-107.

Squilla 80.

Stechreflex bei Bienen 81 .

Steinach. 2529. 
Steiner 85. S7. 8S. 93. 100. 106. 107. 117. 158. 167

Stellungsänderung der Extremitäten. Siehe Spannungsänderung.

Stereotropismus bei Actinien $3 S$.

- bei Seesternen 42.

- .. Thysanozoon 50.

- .. Regenwrim 61.

- "Nereis 64

- . Krebsen 79.

- " Amphipyra 123.

- Aal 161.

Stirnlappen 18ว-187.

Tastkreise $13 \mathrm{~S}$.

Tauben ohne Grosshirn 153-159.

Theilseelentheorie 148-192.

Thysanozoon 4S-52.

Tiaropsis 19.

Tiefenvertheilung der Seethiere 45. 46. $127-129$.

Tornier 133. 134.

Trigeminuskeratitis 136 .

Trophische Nerven 137.

Tropismen, Identität der thierischen und pflanzlichen 2. 4. 5. 120-122.

-, Bedleutung fïr Instinkte 4. 121-131.

- , " Psychologie 7. 146. 161.

—. Mechanik del" 109. 120. 121. 125. 126. 128.

Tubularia 123.

Uexküll, v. 87. 88. 105.

Umarmungsreflex 153.
Unterscheidungsvermögen bei Actinien 31 ff.

Unterschiedsempfindlichkeit bei Planarien 52. 53 .

- bei Würmern 60. 61. 62. 65. 146.

Unterschlundganglien bei Anneliden 65 .

- bei Limulus 71 .

- r Astacus 79.

- " Mollusken 85.

Vasomotoren. Siehe Blutgefässe.

Vererbung 131-138. 156

Vulpian 75. 83. 117.

Ward 77.

Weismann 138.

Welch, J. C. 202.

Wellenschema der Innervationsvorgänge 196-201.

Wendung der Seesterne 39.

Wille 147. 148.

Willensfreiheit 148. 149.

Würmer $4 \mathrm{~S}$ u. ff. 146. 149.

\section{Yersin 81.}

Zuntz 72.

Zwangsbewegungen 101-107. 115. 117. 11s. 187.

Zweiköpfige Planarien 55. 56.

- Actinien 55

Zweckmässigkeit, Kriterium für Bewusstsein 7. 8 . 


\section{Druckfehlerverzeichniss.}

S. 10. Zeile 5 von oben lies "concaven" statt convexen.

S. 166. Zeile 27 von oben lies "dass" statt das.

S. 170. Zeile S von unten lies ,dass" statt das.

S. 181. Zeile 9 von oben lies „Erhöhung“" statt Herabsetzung.

S. 181. Zeile 18 von oben lies, ,ist" statt sind.

S. 1S5̄. Zeile 13 ron unten lies, ,die beiden" statt sie bei den. 


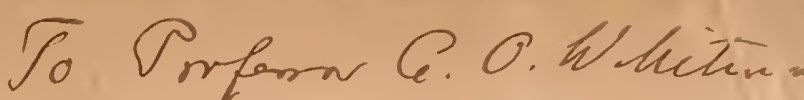 sith Re author's teid kegens?}

\section{EINLETTUNG}

IN DIE

\section{VERGLEICHENDE GEHIRNPHYSIOLOGIE}

UND

\section{VERGLEICHENDE PSYCHOLOGIE}

MIT BESONDERER BERÜCKSICHTIGUNG

DER WIRBELLOSEN THIERE.

VON

\section{D疋 JACQUES LOEB,}

DIRECTOR DES PHYSIOLOGISCHEN INSTITUTS AN DER UNIVERSITÄT CHICAGO.

MIT 39 ABBILDUNGEN.
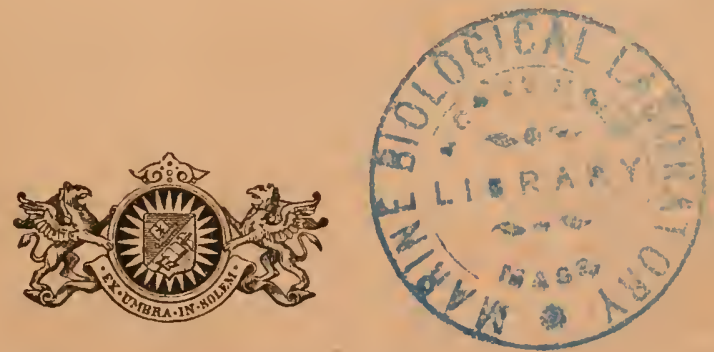

L EIP ZIG,

VERLAG VON JOHANN AMBROSIUS BARTH. 1899. 


\section{Verlag von Johann Ambrosius Barth in Leipzig.}

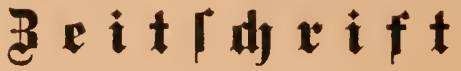 \\ iiir

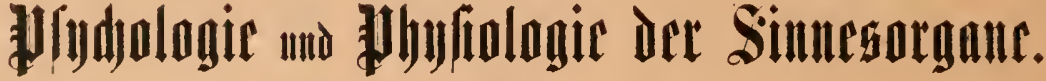

In Gemeinschaft mit

S. Exner, E. Hering, J. v. Kries, Th. Lipps, G. E. Müller, C. Pelman, C. Stumpf herausgegeben von

\section{Herm. Ebbinghans und Arthır König.}

Jährlich erscheinen 2-3 Bände, jeder zu 6 Heften. Preis des Bandes 15 Mark. Im Jahre 1899 erscheint der 19.-21. Band. Käufer der ganzen Serie erhalton einen ermässigten Preis eingeräumt und macht die Verlagsbuchhandlung gern Offerten.

CAJAL, Prof. Dr. S. RAMON, Beitrag zum Studium der Medulla oblongata, des Kleinhirns und des Ursprungs der Gehinnerven. Deutsch von Dr. Joh annes Bresler. Mit einem Torwort von Prof. Dr. E. Mendel. VIII, 139 S. gr. $8^{0}$ mit 40 Abb. 1896. M. 6.-, geb. M. 7.-

Die hochinteressanten Hirnuntersuchungen des berühmten spanischen Gelehrten werden nicht nur bei Anatomen, sondern auch bei jedem Psychiater, Psychologen, Irren- und Nervenarzt lebhaftester Anteilnahme sicher sein.

DELBRÜCK, Direktor Dr. A., Gerichtliche Psychopathologie. Ein kurzes Lehrbuch fiir Stu-

dierende, Aerzte und Juristen. VIII, 224 S. $1897 . \quad$ M. 5.60, geb. M. 6.60

In seinen Vorlesungen über "Gerichtliche Psychopathologie“ sah sich Verfasser vielfach genötigt, von der in den gebräuchlichen Lehrbiichern üblichen Darstellung nicht unerheblich abzuweichen, um den durch die modernen Forschungen gewonnenen Anschauungen des Strafrechts und der criminellen Anthropologie gerecht zu werden. Dies veranlasste ihn, seine Vorlesungen in einem kurzen Lehrbuch zusammenzustellen. Er hat sich dabei bemüht, das jetzt allgemein Gültige und allgemein Diskutierte, wenn auch mit besonderer Berücksichtigung der neueren Anschauungen, in Kürze möglichst abjektiv wiederzugeben.

GOLDSChEIDER, Prof. Dr. A., Gesammelte Ahandlungen.

1. Band: Ueber die Physiologie der Hautsinnesnerven. X, 432 S. mit Abbild. u. 3 Tafelu. 1898.

II. 12.-

2. Band: Ueber die Physiologie des Muskelsinnes. VI, 32\% S. m. Abb. 1898. II. 8.-

Zeitschr. f. Nervenheilkunde: Die Untersuchungen Goldscheider's nehmen unter den sinnesphysiologischen Arbeiten der letzten Jahre einen allgemein anerkannten hervorragenden Platz ein. Für den Neurologen sind dieselben von noch besonderem Interesse, weil sie vielfach an pathologische Verhäitnisse anknüpfen, und vielfach mit Rücksicht auf gewisse pathologische Erscheinungen unternommen sind.

Deutsche medizin. Wochenschrift: Möge das Buch in keinem physiologischen und experimentell-psychologischen Laboratorium fehlen!

GOLDSCHEIDER, Prof. Dr. A., Die Bedeutung der Reize für Pathologie und Therapie im Lichte

der Neuronlehre. IV, 88 S. 1898.

Das vorliegende Buch wird jedem eine Quelle der Anregung bieten und ihm den WVeg zeigen, wie eine grosse Reihe sowohl von täglich beobachteten und deshalb als „selbstverständlich" angesehenen Dingen als auch von Symptomen seltener und scheinbar widersimniger oder gar scheinbar vorgetäuschter Art ihre Erklärung finden können.

HANSLICK, Prof. Dr. ED., Vom Musikalisch-Schönen. Ein Beitrag zur Revision der Aestlietik

der Tonkunst. 9. Anfl. XII, 221 S. $1896 . \quad$ geeb. MI. 3.-

Die berühmte Schrift, die unbekümmert un alle Vorurtheile und Angriffe den Begriff des MlusikalischSchönen zuerst aus nebelhafter Dämmerung herausgearbeitet hat, bleibt neu und behält ihren bestimmten Werth für alle wahrhaft Gebildeten.

UENNIG, Prof. C. R., Aesthetik der Tonkunst. VIII, 232 S. 1896.

M. 4.-, geb. M. 4.75

Die vorliegende Arbeit geht davon aus, dass der menschliche Geist die Fähigkeit, ,reinen Anschauens" als eine Hauptkategorie seines Wesens besitzt; sie erläutert Pegriffe wie die der Idee, des Ideals, der Phantasie, der Intuition u. s. w. und stellt auf dieser Grundlage die Natur des Kunstschaffens und des Kunstgeniessens fest. Ueberall werden die Beziehungen zwischen der "Aesthetik" und der "Psychologie" aufgesucht und verwerthet, so entsteht ein System der Aesthetik, welches sich an keines der vorhandenen ästhetisch-philosophischen Systeme anlehnt.

HIRSCH, Dr. M., Suggestion und Hypnose. Ein kurzes Lehrbuch für Aerzte. 1893. VI, $210 \mathrm{~S}$

geb. M. 3.75

Dr. Hirsch in Berlin hat sich der Aufgabe nit grossem Geschick entledigt. Grosse Klarheit bei kuapper Kiirze und gleichwohl eine Besprechung aller wissenswerten Fragen mit specieller Beriicksichtigung der Bediurfnisse des prakt. Arztes zeichnen das lileine Buch aus. 


\section{Verlag von Johann Ambrosius Barth in Leipzig.}

KRAFFT-EBING, Prof. Dr. R., Arbeiten aus dem Gesamtgebiete der Psychiatrie und Neuropathologie 4 Hefte. $1897-1899$.

zusammen greheftet M. 18.in einem Band gel). M. 20.-

Die Hefte sind auch einzeln zu haben. Preis je M. 4.50, geb. II. 5.50.

Inhalt: r. Heft: r. Ueber transitorisches Irresein auf neurasthenischer Grundlage. 2. Beziehnnges zwischen Neuralgie und transitorischer Psychose. 3. Ueber Hemicranie und deren Beziehungen zur Epilepsie und Hysterie. 4. Ueber transitorische Geistesstörung bei Henicranie. 5. Zur Intermittens larvata.

2. Heft: Die Aetiologie der progressiven Paralye. 2. Ueber Vortäuschung organ. Erkrankungen des Nervensystems durch Hysterie. 3. Zur Athetotis bilateralis. 4. Varia.

3. Heft: Enthaltend zehu liangere und kürzere Aufsätze iber Paraly'se, Ilämmer- und Traumzustände, Delirien, epileptische Psychosen etc.

4. Heft: Zur Aetiologie der multiplen Sklerose. Zur Lehre von den Zwangsvorstellungen. Zur Psycho und Neuropathia sexualis.

KRAEPELIN, Prof. Dr. EMIL, Psychiatrie. Ein Lehrbuch für Studierende und Aerzte. Sechste. vollständig umgearbeitete Auflage. 2 Bänrle. 1899.

I. Band: Aligemeine Psychiatrie. XIII, 362 S. M. 9.-, geb. II. 10.-

II. Band: Klinische Psychiatrie. XIV, 607 S. mit Abbildumgen und 9 Tafeln. M. 15.geb. II. 16.50 .

Das Werk wird von einem grossen Teil der Fachpresse für das beste deutsche Lehrbuch der Psychiatrie angesehen; es ist daher erklärlich, dass bereits 2 Jahre nach dem Erscheinen der 5. Auflage sich eine neue Auflage nothwendig macht.

KRIES, Prof. Dr. J. VON, Abhandlungen zur Physiologie der Gesichtsemplindungen. 1. Heft. VIII, 198 S. n. 1 farb. Tafel. 1897.

Inhalt: Ueber die Fnnktion der Netzhautstäbchen. Ueber den Einfluss von Lichtstärke und Adaption auf das Sehen des Dichromaten (Grïnblinden). Ueber die Wirkung kurzdauernder Lichtreize auf das Sehorgall. Ueber Farbensy'steme. Ueber den Einfluss des Makulapigments auf Farbengleichungen.

IPPS, Prof. Dr. TH., Zur Psychologie der Suggestion. Vortrag mit angeschlossener Disknssion. 45 S. 1897.

M. 1.20

ACH, Prof. Dr. E., Populär-wissenschaftliche Vorlesungen. VIII, 336 Seiten mit 46 Abbildungen. 2. Aufl. 1897.

M. 5.-, geb. MI. 5.

A us dem Inhalt: Ueber die Cortischen Fasern des Ohres, Die Erklärung der Harmonie. Zur Geschichte der Akustik. Wozu hat der Mensch zwei Augen. Die Symmetrie. Bemerkungen zur Lehre vom räumlichen Sehen

Kölnische Zeitung: Der Verfasser dieses Buches ist einer der geistvollsten Physiker der Gegenwart, ein Forscher, der nicht allein als Experimentator, sondern anch als philosophischer Denker unter den Ersten glänzt. Dass er anch Meister in der Kunst des populären Vortrags ist, beweist das vorliegende Werk.

Naturwissenschaftliche Wochenschrift: Die geistreichen Vorträge des trefflichen Gelehrten gehören zu dem Gediegensten, was die Litteratur in diesem Genre besitzt. Sie stehen auf derselben Stufe, wie etwa Helmholtz' Vorträge.

IARTIN, L. u. Prof. Dr. G. E. MÜLLER, Zur Analyse der Unterschiedsempfindlichkeit. VIII, 233 1899.

In dem vorliegenden Buche wird der Standpunkt vertreten, dass nicht die Gewvinnung äusserlicher Maassgrössen, sondern die Ermittelıng der psychologischen Faktoren, welche die Urtheile bestimmen, und die Feststellung der Abhängigkeit, in welcher diese Faktoren zu den verschiedenen Versuchsbedingungen und individuellen Dispositionen stehen, die erste Aufgabe der Untersuchung auf diesem Gebiete ist.

ÖBIUS, Dr. P. J., Neurologische Beiträge. 5े Hefte. 1894-1898.

II. $18 .-$

Inhalt: r. Heft: Ueber den Begriff der Hysterie und andere Vorwürfe vorwiegend psychologischer Art. VI, 2xo S. I894. $\mathrm{V}, \mathrm{I} 37 \mathrm{~S} .1894$

3. Heft: Zur Lehre von der Tabes. IV, 154 S. I895.

M. 3.-

Ueber verschiedene tugeumuskelstorthat $216 \mathrm{~S} . \quad 1895$.

1895.

5, Heft: Ueber die Eintheilung der Krankheiten. Ueber die Behandlung der Nervenkranken und die Frrichtung von Nervenheilstätten. Zur Bekämpfung der Nervosität. Ueber die Ursachen der Krankheiten Ueber den Kampf gegen den Alkoholismus, gegen die Tnberkulose und die venerischen Krankheiten. Ueber das Rauchen. Ueber die Veredelung des menschlichen Geschlechts etc. etc. IV, I76 S. I898.

NI. + -

MÖBIUS, Dr. P. J., Ueber das Pathologische bei Goethe. 208 S. 1898. M. 2.40, geb. M. 3.-

In seinem Buche über Goethe hat der Verfasser zweierlei gethan: Einmal hat er alles zusammengestellt, was Goethe iiber krankhafte Geisteszustände gedacht hat, insbesondere die lange Reihe pathologischer Gestalten in Goethe's Dichtungen geschildert und besprochen. Sodann aber hat er Goethe's Person vom ärztlichen Stand. punkte aus betrachtet und hat gezeigt, class auch für Goethe der Satz gilt: le génie est une névrose.

Es werden also Goethe's Werke und Person von einem durchaus neuen Standpunkte aus betrachtet, und man gewinnt nach beiden Richtungen hin eine Fülle neuer Einsichten. 
$M^{0}$

ÖBIUS, Dr. P. S., Nervenkrankheiten. Ein kurzes Lehrlunch. VIII, 188 S. 1893. geb M. 4.50

Deutsche Medizinal-Zeitung: Das gediegene kleine Buch wird sich schnell überall einhürgern. Es enthält bei aller Kürze das WVissenswerteste aus dem Gebiete der Nervenkrankheiten und zwar in so ansprechender origineller Form, dass es das Interesse des Lesers stets fesselt.

$M^{0}$

ỎBIUS, Dr. P. J., Ueber Schopenhauer. 264 S. mit 12 Porträts. 1899. MI. 4.50. geeb. II. 5.50

M. hat hier die Person und die Lehre des Philosophen besprochen. Im x. Theil wird gezeigt, dass Sch. eine ,patholog. Mehrwertigkeit" war; ei: Anhang enthält eine Abhandlung iber die Sch.-Bilcler. Der 2. Theil enthält eine Kritik der Philosophie Schopenhauers.

PARISH, EDMUND, Zur Kritik des telepathischen Beweismaterials. Vortrag. 1897. $48 \mathrm{~S}$.

PIERSON-SPERLING, Elektrotherapie. 6. Auflage bearb. von Dr. A. Sperling. XII, $420 \mathrm{~S}$. mit $88 \mathrm{Abb} .1893$.

gel). M. 6.75

Münchener ärztliches Intelligenzblatt: Nicht sowohl für den Specialisten, als vielmehr für den praktischen Arat geschrieben, der nicht Zeit hat, dickleibige Specialwerke zu studieren, aber doch Kenntnis von den Fortschritten eines der hervorragendsten Teile der modernen Therapie haben muss, behandelt das IVerkchen in prägnanter Kïrze und dabei in anregender, leicht verständlicher Weise die ganze Lehre der Elektrotherapie.

CHRENCK - NOTZING, Dr. VON, prakt. Arzt, Ueber Suggestion und Erinnerungsfälschung im Berchtold-Process. 110 S. 1897.

II. $3 .-$

Gerade der Fall Berchtold liefert eine Fülle von Belegen für die praktische Wichtigkeit der Suggestionslehre und die forensische Bedeutung der rïckwirkenden Erinnerungsfälschungen.

Schriften der Gesellschaft für psycholog. Forschung.

Erschienen sind bis jetzt: Heft 1. v. Schrenck-Notzing, Die Bedeutung narkotischer Vittel für den Hypnotismus mit besonderer Berücksichtigung des englischen Hanfes. Forel, Ein Gutachten ïber einen Fall von spontanem Somuambulismns mit angeblicher Wahrsagerei und Hellseherei. M. 3.-. - Heft 2. Münsterberg, Ueber Aufgaben und Methorlen der Psychologie. M. 6.-. - Heft 3/4. Moll, Der Rapport in der Hypnose. Untersuchungen itber den thierischen Magnetismns. M. 8.-. - Heft 5. v. Koeber, Jean Paul's Seelenlehre. Ein Beitrag zm Geschichte der Psychologie. Offner, Die Psychologie Charles lionnet's. Eine Studie zur Geschichte der Psychologie. M. 7.-. - Heft 6. v. Bentivegni, Anthropologische Formeln für das Verbrecherthum. II. 1.20. - Heft 7/8. Parish, Ueber die Trugwahrnchmung (Hallucination und Illusion). Mit besonderer Beriichsichtignng der internationalen Enquête iiber Wachhallucination bei Gesunden. 11. 7.-. - Heft 9:10. Lipps, Rammästhetik und optische Täuschungeщ. (1897). M. 12.- - - Heft 11. Wreschner, Methodologische Beiträge zu psycho-physisclıen Messungen (1898) M. 7.-.

STUMPF, Prof. Dr. CARL, Beiträge zur Akustik und Musikwissenschaft.

1. Heft: Stumpf, Konsonanz und Dissonanz. VIII, 108 Seiten.

II. 360

2. Heft: Versch. Aufsätze ron C. Stumpf und M. M e yer. IV, 170 S. 1888. M. 5.-

An Stelle der noch rückständigen zwei Bände śseiner Tonpsychologie hat Verfasser sich entschlossen seine Untersuchungen zur Nusiktheorie künftig in diesen Beiträgen zu veröffentlichen, die sich ihrem Inhalte nach sowohl an die psychologischen Fachgenossen wie an die Musikgelehrten wenden werden. Das I. Heft beleuchtet Helmholtz' und Anderer Theorien für Konsonanz kritisch und versucht eine neue Theori: aufzustellen, - Ein 3. Heft ist in Vorbereitung.

VOGT, Dr. 0., Die directe psychologische Experimentalmethode in hypnotischen Bewusstseinszuständen. $64 \mathrm{~S}$. 1897.

Der Verfasser beabsichtigt, die Stellung der Psychologen zu den Hypnotisten zu klären und weist darauf hin, welche Vorteile die Psychologie a, d. Hypnot. ziehen kann, wenn die richtigen Methoden angewandt werden.

ENTSCHER, Dr. MAX, Ueber physische und psychische Kausalität und das Prinzip des psychophysischen Parallelismus. X, 122 S. 1896.

II. 4.-

Eine sehr interessante Studie aus der Schule Stumpfs. Verf. bekennt sich zu Lotze's philosophischen Gruudsätzen. Er verwirft den Parallelismus und stıcht auf besondere Weise die Annahme einer Wechselwirkung zu ermóglichen.

WOLFF, Dr. GUSTAV, Ueber krankhafte Dissoziation der Vorstellungen. IV, 70 S. 1897. M. 2.-

Zeitschrift für Hypnotismus, Psychotherapie sowie andere psychopatholog. und psychophysiolog. Forschungen. Unter besonlerer Förderung ron Prof. Dr. A. Forel herausgegeben von Dr. O. Vog t. pro Band II. 12.-

Die Zeitschrift stellt sich jetzt als strengwissenschaftliches Fachorgan dar, das dem Psychiater, Psychologen und dem prakt. Nervenarzte kaum noch entbehrlich sein dürfte. Jährlich erscheinen $1-2$ Bände, im Jahre 1899 Band 8 und 9.

Lippert \& Co. (G. Pätz'sche Buchdr.), Naumburg a. S. 
$\sqrt{2}$

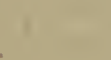




